\title{
Transient Performance of Fan Engine With Water Ingestion
}

S.N.B. Murthy and A. Mullican

Purdue University

West Lafayette, Indiana

April 1993

Prepared for

Lewis Research Center

Under Grant NASG-481
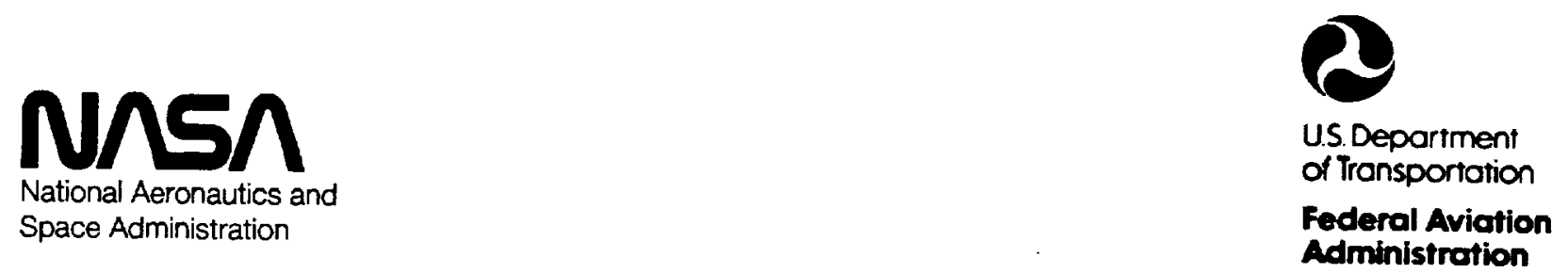
TRANSIENT PERFORMANCE OF FAN ENGINE WITH WATER INGESTION

\author{
S.N.B. Murthy and A. Mullican \\ Purdue University \\ West LaFayette, Indiana 47907
}

Executive Summary

In a continuing investigation on developing and applying codes for prediction of performance of a turbine jet engine and its components with water ingestion during flight operation, including power settings, and flight altitudes and speed changes, an attempt has been made to establish the effects of water ingestion through simulation of a generic high bypass ratio engine with a generic control. In view of the large effects arising in the air compression system and the prediffuser-combustor unit during water ingestion, attention has been focused on those effects and the resulting changes in engine performance.

Under all conditions of operation, whether ingestion is steady or not, it has become evident that water ingestion causes a fan-compressor unit to operate in a time-dependent fashion with periodic features, particularly with respect to the state of water in the span and the film in the casing clearance space, at the exit of the machine. On the other hand, the aerodynamic performance of the unit may be considered as quasi-steady once the distribution of water has attained an equilibrium state with respect to its distribution and motion. For purposes of engine simulation, the performance maps for the generic fan-compressor unit have been generated based on the attainment of a quasi-steady state (meaning steady except for long-period variations in performance) during ingestion and operation over a wide enough range of rotational speeds.

The prediffuser-combustor performance, with air-water mixture flows of the type encountered at core compressor exit during water ingestion into an engine, is being studied under a different (industry-supported) project. In the current investigation preliminary results from tests and predictions have been utilized in parametric form in engine simulation.

In carrying out predictions, water ingestion has been specified in terms of (a) temperature, (b) mean velocity relative to air, (c) mass fraction, (d) droplet size, (e) saturation with respect to humidity and ( $f$ distribution of water across span and in clearance space. Regarding (d) and (e), it has been assumed at entry that the mean volumetric diameter is 600 microns and the air is saturated.

The main observations from predictions of performance for the multi-stage compressors with various types of ingestions are as follows: (1) Compressor performance deteriorates as the mass fraction of water increases; at mass fraction values above 8.0 per cent the core compressor of the generic engine could not deliver any useful output in a stable fashion for periods larger than a duration of a few times the residence time of air-water mixture in the machine. (2) The main effects of nonuniformities (and scoop factor) at entry. are on water distribution and the resulting changes in aerodynamic performance. (3) A combination of values of mass fraction of water, number density, and relative velocity between water and air can, under certain operating conditions, lead to a complete conversion of water to vapor at an intermediate stage of a multistage machine. (4) Changes in amount of water ingested are accommodated in relatively short periods of time, except when a change consists of a large excursion in the amount of water ingested and the compressor operation becomes unstable. (5) A film of water entering a unit along with ingested water has no appreciable effect on performance.

The main observations from predictions on the generic engine with the generic control are as follows: (1) The compressor and the combustor both have a determining influence on engine performance at all values of ingestion parameters. (2) As water mass fraction increases, the compressor attains critical conditions. (3) The main combustor performance parameter, namely exit temperature, if reduced, affects the low pressure turbine performance and therefore, the supercharger performance. (4) High rates of change of power demand, flight speed and altitude affect engine performance more than low rates. This is particularly so in power demand changes from cruise to flight idle. And, (5) there is considerable nonlinearity in engine performance changes with respect to changes in water ingestion and power demand. 


\section{TABLE OF CONTENTS}

Executive Summary

1. Introduction 1

1.1. Outline 5

2. Parameters of Interest during Water Ingestion 6

2.1. Engine Related Parameters 7

2.1.1. Some complexities in engines 12

2.2 Atmospheric and Rain Conditions 13

2.2.1. Air-water mixture entering the engine 14

2.3. Engine Operating Conditions 16

2.3.1. Compressor operational conditions 16

2.3.2. Combustor operational conditions 17

2.3.3. Engine operational conditions 17

$\begin{array}{ll}\text { 2.4. Pilot Interaction } & 18\end{array}$

3. Compressor Unit Performance with Water Ingestion:

Results and Discussion $\quad 18$

3.1. Overall Performance $\quad 21$

3.2 Transient Performance with Steady, Uniform Ingestion 22

3.2.1 Steady, uniform ingestion without film at entry 23

3.2.2 Steady, uniform ingestion with film at entry 24

3.3 Transient Performance with Specified Differences in

Temperature and Velocity of Air and Water 25

3.4 Transient Performance with Changes in Mass Fraction of Water Ingested 27

3.5 Transient Performance with Non-Uniformity in Ingestion 30

4. Bypass Engine Performance with Water Ingestion:

$\begin{array}{ll}\text { Results and Discussion } & 30\end{array}$

4.1 Transient Performance with Fixed Ambient Conditions 31

4.1.1 Cases 1 and 2

4.1.2 Cases $3-7$

4.2 Transient Performance under Varying Ambient Conditions 34

4.2.1 Groups 1 and 2 of Predicted Cases 34

4.2.2 Groups 3 and 4 of Predicted Cases 34 
5. Conclusions

References

Table I

Predicted Cases For High Pressure Compressor

38

Table II

Predicted Cases of Transient Performance of Engines

Under Fixed Ambient Conditions

41

Table III Predicted Cases of Transient Performance of Engines Under Varying Ambient Conditions

45

46 


\section{LIST OF FIGURES}

1.1 .

2.1 .

2.2 .

2.3 .

2.4 .

2.5 .

2.6 .

2.7 .

3.1 .

3.2 .

3.3. and 3.4 .

3.5. and 3.6.

3.7. and 3.8.

3.9. - 3.32 .

3.33. - 3.46 .

3.9, 3.21., 3.26., 3.28., 3.33., 3.38., and 3.47. - 3.59. Performance of the high pressure compressor unti with respect to streamtube 5 under conditons of film flow at entry.

3.60. - 3.68 .

3.69. - 3.88 .

4.1.

4.2.

4.3. - 4.5.

4.6.

4.7 .

Schematic representation of a generic bypass fan engine.

Flowfield in a typical combustor.

Illustration of a rain storm (I).

Illustration of a rain storm (II).

Relation between water content and intensity of rainfall.

Rain drop size distributin.

Schematic of flow pattem in inlet and bypass streams.

Two typical definitions of scoop factor: (i) and (ii).

Heat and mass transfer factor, $\zeta$.

Streamline designation in a fan-compressor unit.

Performance of the fan unit with respect to streamtube 2.

Performance of the fan - low pressure compressor unit with respect to streamtube 5 .

Performance of the high pressure compressor unit with respect to streamtube 5 .

Performance of the high pressure compressor unit with respect to streamtube 5 under conditional of uniform ingestion of water at entry, and 100 per cent design speed. Performance of the high pressure compressor unit with respect to streamtube 5 under conditions of uniform ingestion of water at entry, and 65 per cent design speed.

Performance of the high pressure compressor unit with respect to streamtube 5 under conditons of uniform ingestion of water at entry, and 100 percent design speed, with $\zeta$ given given and various values of $\xi$.

Performance of the high pressure compressor unit with respect to streamtube 5 under conditons of uniform, and timedependent ingestin of water at entry.

Transient performance of the generic engine under fixed ambient conditons, cruise power setting and various amounts of water ingestion at entry.

Transient performance of the generic engine under fixed ambient conditons, flight-idle power setting, and 4.0 per cent of water ingestion with air.

Transient performance of the generic engine under fixed 
4.8 .

4.9. - 4.12. Transient performance of the generic engine under fixed ambient conditons, and with varying amount of ingestion of water and varying power setting.

4.13. - 4.28. Transient performance of the generic engine under varying ambient conditons, varying amounts of ingestion of water, and varying power settings. 


\section{CHAPTER 1}

\section{INTRODUCTION}

Water ingestion into aircraft engines can arise in a number of contexts and forms: (i) presence of high humidity in air and reduction in ambient temperature leading to condensation in engine inlets; (ii) take-off from runways with puddles of water when tire-generated spray may enter the engine inlet depending on its installation relative to landing wheels; (iii) flight through a rain storm causing entry of water from the atmosphere directly or from water flows formed on aircraft surfaces, for example a fuselage when the engine inlet is fuselagemounted; and (iv) flight through snowing or hail forming conditions. The interest in the current research program is entirely in item (iii) of the foregoing and in establishing the changes in engine performance due to water ingestion in liquid form. Many of the results also apply to item (i), namely ingestion of condensed water; the greater interest in that case is in the thermodynamics and mechanics of the condensation process itself in given inlet geometry and environment.

The investigation of the effects of water ingestion into flight engines has been conducted at Purdue University over a number of years (references 1-7). In the past several years, the Aerospace Industries Association of America (AIA) has revived interest in the subject. Reference 8 provides a summary introduction to some aspects of the current status of assessment and recommendations by the AIA.

At the outset, it is worth pointing out that water ingestion has been recognized to lead to a number of deficiencies in engine performance and operation during flight, including the following. 

i) Vibrations;
ii) power reduction;
iii) engine control problems;
iv) flight and engine handling problems;
v) instrumentation errors;
vi) surging;
vii) flame-out; and
viii) mechanical problems of rubbing and welding between component parts.

The aforementioned problems (listed in increasing order of concern in aircraft operations) become variously compounded in certain circumstances, and therefore become complex in understanding, prediction and mitigation. Also, during flight operations, the combination of aerodynamic, aerothermodynamic and mechanical interactions must be accounted for. In particular, one may mention two sets of flight conditions where such interaction can have severe effects: (i) change of altitude and speed during aircraft descent and deceleration; and (ii) landing and take-off operations with strong ground winds and gusts, and the presence of wind shear.

Water ingestion is invariably accompanied by at least saturation levels of humidity in the air. Furthermore, the processes occurring in the engine, everywhere along the gas path (except the inlet where condensation may arise under certain conditions of temperature), lead to evaporation of water. Thus one is concerned with the effects of the presence of air-water vapor-water mixture in problems of water ingestion. The two-phase flow processes in the engine thus involve heat and mass transfer processes as a major feature. 
Water ingested into engines along with air is predominantly in droplet form, although under various circumstances water may also be found to enter the engine in film form over the inlet surface. In the air compression machinery of the engine, water is found in film form in the casing clearance and over blade surfaces and also, in droplet form in the blade passages. In view of rotation of fans and compressors, water becomes subjected to centrifugal action and therefore, undergoes radial displacement. Such motion is also caused by the rotation of the spinner. Centrifugal displacement is thus another important feature in water ingestion into engines. It leads to redistribution of water everywhere in turbomachinery.

It is also of importance to note here that while engines are occasionally tested under simulated water ingestion conditions during flight, the majority of certification and development testing on engines is conducted on ground. In all cases, simulation of rain and ingestion characteristics becomes a major issue. Two additional difficulties in testing are as follows:

i) Instrumentation: Water ingestion involves a two-phase fluid flow through various parts of the engine with a nearly continuous phase change. While in the inlet there may arise condensation, in the rest of the engine vaporization of liquid water is the common process. Instrumentation for obtaining accurate and reliable measurements of pressure, temperature, vapor mass fraction, and reaction products in a combustor are, in general, not available. The difficulties in obtaining reliable estimates of pressure in a two-phase fluid and distinguishing between pressure of the gas phase and that of the two-phase mixture are discussed in reference 9. It has also been pointed out (reference 3) that flooding of a temperature probe by water, whose measurement is an input to the engine control system, can lead to serious problems in engine performance control, including surging and large variations in engine response times. 
ii) Scalability of engine performance: The response of different engines or of a given engine under different operating conditions to a given type of water ingestion, is, in general, not wholly comparable or scaleable. Neither, in fact, is the response of a given engine scaleable with respect to different types, magnitudes and durations of rain water ingestion. These problems have been discussed in reference 6 . They arise mainly because the performance of a gas turbine, as well as the effects of water ingestion, vary nonlinearly with respect to operational and ingestion parameters. In consequence, the amount of testing that needs to be done becomes large, both in time and expense, and results in each case become very largely specific to that case.

Finally, it is of interest to note some of the options available for reducing the effects of water ingestion in engines, namely the following.

i) Introducing modest changes in design of engine components, primarily to modify air-water mixture flow paths;

ii) introducing changes in engine instrumentation, through changes in probe location and shielding;

iii) modifying the control system, especially in multi-spool engines through changes in fuel supply schedules and turbomachinery rotational speed relations, with respect to power demand and performance deteriorations;

iv) improving engine testing procedures on ground and in flight; and

v) establishing operational procedures in flight.

It is clear that the foregoing may be accomplished only through a hybrid analytical-computational- experimental approach to the problem. The current research program is undertaken as a contribution to the analysis and the development of computational procedures for assessing the nature and magnitude of changes in engine performance with water ingestion. 


\subsection{Outline}

The engine selected for illustrative purposes in the current study is a twospool, bypass gas turbine engine with supercharger unit, consisting of a fan and a low pressure axial-flow compressor, driven by a low pressure turbine. The engine is assumed to incorporate an engine control system. The generic engine is illustrated in figure 1.1. The engine performance and its changes are analyzed in isolation, under test cell conditions. No account is taken of an aircraft in which it may be installed. Both rain water ingestion conditions and engine operating conditions (with respect to power demand and flight speed and altitude) are considered as variables. By specifying engine input conditions at the fan face, no account is taken of the processes in any inlet that is utilized to provide intake to the engine.

In order to calculate the engine performance changes with water ingestion, it is necessary to establish changes in various components of the engine and then to take such changes into account in an engine simulation and matching procedure. In the current investigation, the main emphasis in regard to components has been on the fan-compressor unit. The performance changes of the fan-compressor unit with water ingestion have been established in substantial detail utilizing a computational procedure, the so-called WINCOF-I code; this is a transient performance code evolved from the WINCOF code developed earlier at Purdue University (references 7 and 10). The other component that can be expected to be affected directly by water ingestion is the prediffuser-combustor unit. This is dealt with by specifying performance changes with water ingestion parametrically. No detailed prediction method has been developed for that component. The performance changes in the two components, namely 
the fan-compressor unit and the prediffuser-combustor unit are then incorporated into a transient performance code for the engine as a single unit.

In the following, the principal parameters of interest during water ingestion are discussed in Chapter 2. Various illustrative cases of water ingestion, all of them pertaining to the fan-compressor unit of the generic engine, are presented in that Chapter 3. Also, a number of illustrative cases, all of them pertaining to the generic engine, are included in that Chapter 4 for various ingestion and operating conditions. A discussion of accomplishments, and conclusions on the methodology developed and the results obtained therefrom.

\section{CHAPTER 2}

\section{PARAMETERS OF INTEREST DURING WATER INGESTION}

The main parameters of interest in studying the problem of rain water ingestion into engines are the following.

i) Engine installation;

ii) inlet, engine and nozzle geometry;

iii) engine performance (design and off-design) with air in the absence of water ingestion;

iv) engine and flight control performance;

v) atmospheric and rainfall conditions;

vi) operating conditions of the engine and the aircraft during flight through rain fall; and

vii.) pilot response and action. 
The foregoing fall broadly into four categories: (a) engine-related parameters, (b) atmospheric conditions, (c) operational conditions and (d) operator-in-theloop. Each of the sets of parameters is discussed in the following.

\subsection{Engine-Related Parameters}

In the current research program, no account is taken of engine installation or inlet geometry. The thrust nozzle is included with the engine. The engine is considered in itself, entirely uncoupled from the aircraft, flight operation and flight performance. Ambient conditions with respect to flight altitude and speed, which, in most cases, are realizable in ground test facilities, are considered variables. However, flight operations and control are also left out of consideration. On the other hand, a control system is assumed to be incorporated in the engine. It is expected to be entirely unaffected by water ingestion into the engine. The only exception to that assumption is with respect to engine performance input to the control system. This consists of data generated by various sensors located in the engine and, as stated earlier, the presence of water may affect directly, through deposition, flooding or mechanical damage, the sensor outputs. It may also be pointed out that water ingestion may affect the inertial delays (particularly, the thermal and the combustion delays) in the engine system, and these in turn may affect the operation of the control system. However, these are again left out of account in the current project.

Engine performance obviously depends upon the performance of individual components and their matching at the design point and under various other operational conditions, subject to constraints such as maximum cycle temperature, surge margin and so on. In general, engines are designed for operation with air over a range of ambient temperature and humidity values. They may, however, 
incorporate in some cases adaptive features in order to be able to operate under other conditions of operation including rain water ingestion.

Engine performance also is a function of several length scales connected with the geometry of the engine. In case of water ingestion, both the aerodynamic performance and the state of water in the fan-compressor unit of an engine become a function of rotor and blade geometry including, especially, casing clearance. In general, it is not possible to scale the performance parameters during water ingestion with respect to engine geometry or power output in view of the highly nonlinear nature of ingestion effects.

It may often be necessary to establish the characteristics of transient performance of engines, for example in developing a control system for the engine. It then becomes necessary to start with establishing the transient performance of components and to undertake a time-dependent engine matching procedure. In general, such a procedure involves great expense in time and money with currently available computational resources. In practice, one then proceeds to establish transient performance of engines starting with steady state performance of components and various inertial-type time delays. However, when the operational conditions are such that certain components operate only in a time-dependent manner, it becomes essential to take account of such timedependence. It tums out, as will become evident in Chapter 3, that under conditions of water ingestion at least the fan-compressor unit of a bypass engine demonstrates a strongly time-dependent character in the short time and a periodic behavior in the long time. The behavior of other components, such as the prediffuser-combustor, is not known in sufficient detail at this time. In any case, then, the performance calculations for an engine with water ingestion must take into account the transient performance of whatever components display timedependent behavior. 
A further complication in water ingestion is that the ambient conditions, including the mass fraction of water, are themselves subject to changes with time. Such changes may arise as the aircraft moves to other locations in time at fixed altitude or with changes in altitude.

In summary, in performing estimates of engine performance changes with water ingestion, it becomes necessary to proceed as follows.

i.) Establishing time-dependent changes in performance of various components of the engine with water ingestion accounting for (a) two-phase flow processes occurring in the components with air-water mixture flow and (b) the associated length and time scales.

ii.) Establishing changes in the performance of various components of the engine with water ingestion up to the attainment of time-wise quasi-steady state. And,

iii.) incorporating the quasi-steady performance of components into a transient performance code for the engine.

The foregoing three tasks, related to analytical-computational methodology and application to turbomachinery and the selected generic engine, have been discussed in references 7 and 10. Meanwhile, a brief discussion is presented here on some important aspects of operation of engine components and of the engine.

The main components of a bypass ratio engine are (i) the fan-compressor unit, (ii) the prediffuser-combustor unit, (iii) the high and low pressure turbines and (iv) the nozzles. Of these, there is a high probability of components (i), (ii), and (iv) operating with water, noting that the bypass flow nozzle may also operate with an air-water mixture. When the bypass stream is assumed to mix with the core exhaust in the chosen generic engine, the mixed nozzle flow carries water. On the other hand, the turbines may be expected to operate predominantly with water vapor in a typical fan engine. It may, however, be noted that in the 
case of small engines with rather short residence times of air-water mixture in the unit, there may be water present even in the turbine, especially when the combustor exit temperature is low (reference 3).

Other factors that are significant in regard to components are the following.

(i) The fan-compressor unit is the first component in the engine, following the inlet, to be exposed to the air-water mixture. The inlet may be short in length in many cases. A compressor is also prone to severe losses in performance with change of operating conditions and the occurrence of stalling and surging with rather small margins for operation with respect to the critical limits. Finally a compressor presents the most severe problems in engine matching in view of the sensitivity of its performance to changes in mass flow and rotational speed.

(ii) The prediffuser-combustor section follows the core compressor and therefore, receives the air-water mixture equal to the compressor discharge. The compressor discharge consists in general of water moving in film form in the casing clearance passage and of air-water mixture across the span. The latter may consist entirely of air-water vapor mixture if the heat and mass transfer processes are severe enough between the gas and the liquid phases in the compressor unit for conversion of water in its entirety to vapor form.

The prediffuser-combustor geometry and flow are in general complex and various types of air-water mixtures may be present in different parts of the unit. The prediffuser geometry may cause separation of film over the wall and of the air-water mixture flow. This in turn leads to local changes in composition of airwater mixture flow. Also, because of the complex geometry of the prediffusercombustor section, there may be appreciable differences in the quality of airwater mixture flow in the different streams in various parts of the unit. 
Referring to figure 2.1 , there are four streams of interest in a prediffusercombustor: (a) the stream entering the inner combustion chamber through injector cups, (b) the coolant stream in the outer part of the chamber, (c) the primary jet streams and (d) the dilution jet streams. In figure $2.1, \mathrm{~W} 3, \mathrm{~W}(1)$, $W(2)$, and $W(3)$ refer to the mass fluxes at entry to the prediffuser of the combustor, at entry to the opening in the dome, in the outer part of the secondary stream, and in the inner part of the secondary stream, respectively. They may be expected to differ from one another in composition and velocity.

Lastly, a combustor is prone to large reductions in efficiency and cleanliness of combustion as well as to flameout (local and global flame quenching) due to (a) reduction in temperature and (b) substantial vitiation with water and water vapor. There are few sets of experimental data that are comprehensive and conclusive based on which the prediffuser-combustor can be modeled in detail with respect to either flow or combustion processes during water ingestion.

A companion research project at Purdue University (reference 11) is devoted to addressing the problems of air-water mixture flow in prediffusercombustor units.

In view of the foregoing considerations, the following approach has been adopted in the current investigation in regard to the various components of the engine.

(i) The fan-compressor unit is analyzed in substantial detail.

(ii) The prediffuser-combustor unit is treated parametrically accounting for various processes occurring therein. And

(iii) the performance estimation in the turbine and the nozzle is based simply on assuming the presence of air-water vapor mixture flow therein, and 
correcting for changes in molecular weight and ratio of specific heats of the gasses involved.

\subsubsection{Some Complexities in Engines}

The complexities in engines that affect performance substantially during water ingestion are the following.

(i) Turbomachinery must have clearances at the casing. In some engines, there may be clearance control in order to reduce loss of performance with increased clearance. During water ingestion, it can be expected that the clearance obtained differs from the clearance that would be present under similar conditions of engine operation with air. A rigorous estimation of the clearance with water ingestion for a cooled multi-stage compressor is a problem that has not been attempted before; this subject is referred to in Chapter 5 . The clearance changes are significant not only because of their impact on changes in efficiency, but also because of the resulting changes in film formation and flow and thus, in the overall distribution of water along a multistage compressor. And,

(ii) a two-spool, bypass engine with a supercharger invariably includes a goose-neck section connecting the low pressure compressor with the high pressure compressor. Most of the engines also include several bleed and bypass valves, some of which may also be located in the goose-neck. Figure 1.1 illustrates these schematically for the case of the selected generic engine. Very little test data or analyses are available for droplet-laden flow in such ducts and valves.

In the current investigation, the following approaches have been taken regarding these complexities. (i) Casing clearance is assumed to be fixed and not changing with water ingestion. And, (ii) ducting of the type of goose-necks is assumed to homogenize the mixture across its cross-section. Bleed and bypass 
valves are assumed to remove air-water mixture as a single, homogeneous fluid of composition equal to that of the mean mixture value obtained locally.

\subsection{Atmospheric and Rain Conditions}

Meteorological data (Reference 12) indicate the following relative to rain.

(i) Rain ordinarily arises most frequently in the altitude range of 5,000 $-15,000 \mathrm{ft}$.

(ii) Figures $2.2-2.3$ illustrate some of the complexities in rain storms.

(iii) A typical estimate of water content in relation to intensity of rainfall is illustrated in figure 2.4. And,

(iv) rain drop sizes may vary from orders of microns to orders of millimeters as shown in figure 2.5 . It has been common practice to refer to drops of diameter approximately 20 microns and less as small and all others as large. It may be pointed out that the diameter utilized in such classification is the volumetric mean diameter; various interphase, and droplet breakup and coagulation processes require other diameters to be specified.

The parameters pertaining to rain water ingestion are the following.

i. Mass fraction of water;

ii. humidity of air;

iii. air speed relative to engine;

iv. droplet size distribution;

v. water temperature; and

vi. difference between velocities of air and large water droplets.

Along with ambient air temperature and pressure, the foregoing are considered adequate for defining the air-water mixture at fan face and at entry to individual stages of a multi-stage compressor. 


\subsubsection{Air-Water Mixture Entering the Engine}

The air-water mixture actually entering the engine may differ from the ambient air-water mixture in rain due to a number of reasons, some of the main ones being the following.

(i) Air velocity in the atmosphere;

(ii) suction by the engine under the given engine-operating conditions; this determines the capture volume and streamtube;

(iii) effect of spinner;

(iv) local changes in drop size distribution in the capture streamtubes;

(v) difference between velocity of air and that of large droplets;

(vi) differences in trajectories of small and large droplets, and

(vii) presence of a film over the inlet wall length which merges with the fan casing.

Air velocity in the local atmosphere in the vicinity of an aircraft in flight can be expected to affect (a) temperature and density of air and (b) rain water condensation and motion. They in turn affect the type of mixture entering the engine. However, in the current investigation, no separate account is taken of the influence of air velocity in specifying the entry conditions at the fan face.

Items (ii) and (iii) may be considered together, along with the geometry of the fan and the location of the splitter plate, in determining (a) the total amount of water entering the engine and (b) the split between the bypass and the core streams; figure 2.6 shows schematically the relevant geometry and flow pattern. During operation of a bypass engine with water ingestion, the total amount of water entering the engine becomes larger than the amount of water in the capture streamtube in an area of cross-section equal to the physical annulus area of the fan blading. This is due to two factors: (a) velocities of small and large droplets 
are different with small droplets moving with air and large droplets moving in arbitrary directions relative to air; and (b) the entire flow in the capture streamtube must enter the engine and thus the part of water in the streamtube in front of the spinner must be added to that entering the fan blading area. Furthermore, the spinner presents a rotating, physical surface to the air-water mixture flow. This fact causes part of the water impacting the spinner to be in film form over it. The rest, on the other hand, is rebounded into the flowstream but in directions that may affect the split in water between the upper and the lower parts of the fan. This then leads to a change in split in water flow between the bypass and the core streams; it becomes weighted in relation to the split corresponding to the ratio of areas of cross-section of the bypass and the core streams as determined by the radial location of the splitter plate. It may be pointed out that the axial location of the splitter, in relation to the trailing edge of the fan blade under consideration, also affects the split of water since the diversion of water from the spinner is affected also by this parameter.

It may be stated here that the problem of determining the flowfield of airwater mixture in a bypass engine, accounting fully for the problems caused by engine suction, the complex geometry at entry to the engine (including inlet, spinner, fan and splitter plate) and spillage of flow has not been addressed in detail to date. This subject is discussed further in Chapter 5.

In practice, one proceeds as follows: (a) the mass flow of water in the airwater mixture entering a bypass engine is established in terms of a so-called scoop factor; and (b) the split of air and water mass flows between the bypass and the core streams is assumed to be unaffected by the spinner. In other words, the split of air-water mixture is assumed to be the same as that specified for operation with air at design and off-design conditions; the composition of the air- 
water mixture is determined in each stream with reference to the calculation streamtube under consideration therein.

The scoop factor is essentially a means of accounting for the geometry at the front of the fan. It is defined as shown in figure 2.7. The resulting nonuniformity in the distribution of water at the fan face can be expressed as a function of the scoop factor and the air-water mixture conditions in the atmosphere.

\subsection{Engine Operational Conditions}

Considering the vast possibilities in operational conditions in flight, attention is focused on a few cases that are considered as being significant in time. These pertain to (a) fan-compressor unit, (b) combustor and (c) engine as a total system.

\subsubsection{Compressor Operational Conditions}

The fan-compressor unit has been considered in three parts: (i) the fan, (ii) the multi-stage core compressor and (iii) the complete fan-compressor unit. In each case the unit is supposed to be (a) driven by an independent drive with appropriate rotational speed capability and (b) operated in the desired environment of air-water mixture conditions.

Regarding operational conditions of the fan-compressor unit for input into the engine simulation code, attention is confined to variations in (i) operational speed, (ii) flow coefficient and (iii) mass fraction of water ingested. A set of basic performance maps is generated for each of the three component units of the fan-compressor unit over sufficiently wide ranges of operational conditions. These are then incorporated into the engine simulation code in the form required. 
In the current investigation, the performance of the fan and the multi-stage compressor units have been examined in great detail with reference to the aforementioned operating parameters in various cases of interest during water ingestion into engines. Several such selected cases of operation pertain to the following.

(i) Occurrence of scoop factors that result in appreciable nonuniformity in water mass fraction at the fan face.

(ii) Entry into and exit from rain ingestion conditions.

(iii) Changes with time of water mass fraction ingested.

(iv) Changes in thickness of film present in the casing clearance at fan face.

(v) Changes in initial relative velocity between air and water droplet. And

(vi) changes in air entry temperature.

\subsubsection{Combustor Operational Conditions}

No performance calculations have been made for the combustor as a unit operated with air-water-vapor-mixture. In engine performance calculations, a few trials have been made utilizing the reduction in combustor exit temperature as a parameter during water ingestion. This is equivalent to assuming a reduction in the efficiency of a combustor due to the presence of water and vapor.

\subsubsection{Engine Operational Conditions}

The main emphasis in the case of the engine has been on the following.

i.) Ambient air temperature changes under sea level static conditions; and,

ii.) change of flight speed and altitude of engine operation and engine power demand, individually and in combination. 
It may be pointed out that, since the engine is considered in isolation under test cell conditions, the flight speed and altitude conditions are assumed to be reproduced in front of the engine. Power demand is generally specified in terms of idle, flight idle, take-off, cruise and maximum power conditions. Changes in power demand are specified in terms of a time-rate of change of power level angle (PLA).

\subsection{Pilot Interaction}

In essence, the parameters associated with pilot action pertain to altitude and power demand changes, in type, magnitude, and time-rate. These changes may be demanded under various circumstances in relation to rain water ingestion: (a) an encounter with rain, (b) during ingestion and (c) during changes in rainfall. These possibilities form the basis for the selection of various cases of interest for prediction of performance.

\section{CHAPTER 3 \\ COMPRESSOR UNIT PERFORMANCE WTTH WATER INGESTION: RESULTS AND DISCUSSION}

The unit chosen for detailed analysis of the effects of water ingestion is the high pressure (core) compressor of the fan-compressor unit of the generic bypass engine shown in figure 1.1. Details concerning the unit have been presented in reference 2 . In the calculation of performance changes with water ingestion, casing clearance is an important parameter. The WINCOF-I code utilized for predictions has been discussed in references 7 and 10. As stated therein the heat and mass transfer subroutine in WINCOF-I incorporates a correction to the 
transfer coefficients for the effects of mutual blockage of droplets on the transfer processes. The variation of blockage coefficient, which is referred to as heat and mass transfer factor, is shown in figure 3.1 as a function of mass fraction of water assuming that the droplets have a mean volumetric diameter of 600 microns. In figure 3.1, $\mathrm{X}_{\mathrm{W}}$ refers to mass fraction of water, and other symbols are as indicated therein.

The performance of the high pressure compressor has been determined under various conditions of operation and water ingestion as given in Table I. In Table I, N/N*, $\phi, X_{W}$, and $H / H_{c}(I)$ refer to the ratio of compressor operating speed to design speed, the flow coefficient (being the ratio of flow axial velocity to the rotational speed of the compressor), mass fraction of water, and the ratio of clearance height filled up with water to the total clearance height at the exit plane of the inlet (or equivalently, entry plane of the compressor), respectively. Also, to represent duration of time, given in terms of number of calculation sweeps. Finally, ES and IS represent exit stage and an intermediate stage of the compressor, respectively. Other details on various cases are included in the following subsections under discussion of individual groups of cases.

The entry conditions to the compressor unit consist of the following: (i) pressure of air-water mixture, (ii) air and water temperatures, (iii) humidity of air, and (iv) mass fraction of water. In a few cases, two types of changes in the entry conditions have been examined, namely (i) nonuniformity in spanwise distribution of mass fraction of water ingested, and (ii) occurrence of instantaneous changes in the mass fraction of water ingested at specific times following the beginning of ingestion. Finally, the following parameters have been varied to determine the influence of their changes: (i) relative velocity between air and water at entry, (ii) heat and mass transfer parameters and (iii) thickness of film present in casing clearance space at entry. It may be noted here 
that in all cases investigated the air at entry to the compressor is assumed to be fully saturated with respect to water vapor.

The aerodynamic performance of the unit predicted in all cases pertains to streamtube 5 illustrated in figure 3.2. At the same time the formation and motion of film in the casing clearance space is obtained for each group of entry and exit conditions. The performance of the unit is presented at the end of the last stage, and in several cases, an intermediate stage, generally with respect to the number of sweeps of (calculation) times elapsed since the start of ingestion or a calculation. It may be recalled that the sweep time for a stage is the length of time required for the entry fluid to pass through the stage at the value of axialflow velocity under consideration; and, the sweep time for a multistage machine is the sum of the sweep times for the individual stages. As an example, a $4 \mathrm{ft}$ long unit with a mean axial velocity of $600 \mathrm{ft} / \mathrm{sec}$ has a sweep time of about 6 msecs., and about 80 sweeps correspond to 0.5 sec. clock running time.

An estimate of overall performance of the three parts of the fancompressor unit, namely the fan, the low pressure compressor and the high pressure compressor, with various magnitudes of steady, uniform ingestion of water into each, is presented in section 3,1. This estimate may serve as a reference description of performance of the three parts.

The transient performance of the multistage (high pressure) core compressor is predicted under a variety of conditions and the results are presented as follows.

(i) transient performance with steady, uniform ingestion in section 3.2;

(ii) transient performance with steady, nonuniform ingestion in section 3.3

(iii) transient performance with changes in mass fraction of water ingested at specified times in section 3.4 ; and 
(iv) transient performance with specified differences in temperature and velocity of air and water in section 3.5 .

It may be pointed out here that in all cases, it is assumed that water droplets belong to the so-called large droplet class with a mean volumetric diameter of 600 microns. Furthermore, except in group (iv) above, air and water droplets at entry have the same velocity and a small difference in temperature of about $10 \mathrm{~F}$. In case (iv), the effects of differences in velocity and temperature between air and water droplets are examined as parameters that influence heat and mass transfer processes. Details are provided in section 3.5.

The parameters predicted in the foregoing cases (i) to (iii) consist of the following:

1) mass fraction of water, $X_{W}$;

2) extent of clearance height filled by water film, $\mathrm{H}$, as a fraction of local clearance, $\mathrm{H}_{\mathrm{C}}$;

3) stagnation pressure;

4) stagnation temperature; and

5) adiabatic efficiency, $\eta$.

In case (iv) predictions have been obtained for the manner in which the mass fraction of water varies in the span from stage to stage, along the compressor, for different combinations of 1) droplet size, 2) heat and mass transfer factor, and 3 ) relative velocity factor.

\subsection{Overall Performance}

The overall performance of a fan or compressor is usually presented in the form of maps of pressure ratio and adiabatic efficiency as a function of corrected mass flow at entry to the unit, utilizing corrected (angular) rotational speed as a 
parameter. In case of water ingestion, the mass fraction of water in the air-water mixture entering the unit also becomes a parameter of interest. Assuming that water ingested belongs to the large droplet class, a series of performance calculations have been performed for the unit, the results of which are presented in the following figures.

Figures 3.3 and 3.4: Fan unit with respect to streamtube 2.

Figures 3.5 and 3.6: Fan-low pressure compressor unit with respect to streamtube 5.

Figures 3.7 and 3.8: High pressure compressor unit with respect to streamtube 5 .

In each set, the first and the second figures present pressure ratio and adiabatic efficiency, respectively.

It may be pointed out that the performance maps presented apply at the end of one sweep through the unit starting with the instant of time when ingestion begins. Smooth curves have been drawn through a series of individual points representing performance at chosen values of corrected mass flow and water mass fraction in ingested mixture. The maps present trends in performance changes at the end of nearly equal time at different rotational speeds and over varying ranges of corrected mass flow. Accordingly, they may not be treated as steady state maps, although with no ingestion, for operation with air, the maps do provide steady state maps. Also, the effects of a progressive change in mass fraction of water, e.g. from 4.0 to 8.0 and back to 4.0 , may not be assessed from these maps, since such changes obviously cause time-dependent changes in performance. 


\subsection{Transient Performance with Steady, Uniform Ingestion}

The transient performance of a multistage compressor has been determined under various operating conditions and with different amounts of water ingestion. The example utilized is the high pressure compressor of the generic engine.

\subsubsection{Steady, Uniform Ingestion without Film at Entry}

With reference to Table I, in cases 1-6 the predictions of performance have been obtained with steady, uniform ingestion of water with no film at the casing wall at entry.

In case 1, the performance has been determined at the design speed $\left(\mathrm{N} / \mathbb{N}^{*}\right.$ $=100$ per cent) at a value of water ingestion $\mathrm{X}_{\mathrm{W}}=4.0$ per cent over a range of flow coefficient, $\phi$, equal to $0.440-0.460$. In figures $3.9-3.13$, the performance parameters have been given at the exit stage of the compressor as a function of time. It is possible to observe the manner in which the performance is time-dependent even though ingestion as well as operation parameters are steady.

The time-dependence is further confirmed by examining the performance obtained under the same conditions at an intermediate stage, given in figures 3.14 - 3.15 for the mass fraction of water in the span of the compressor and the height of casing clearance filled in with water.

The performance of the compressor has next been presented, for the same ingestion and operation conditions as in the preceding, over a long period of time (about 2.5 secs.) at the exit of the compressor, in figures $3.16-3.20$. It is observed in those figures that the performance of the compressor displays a periodic character over the long time. Thus it is clear that the performance is not only unsteady but, in fact, does not tend towards an asymptotic steady state, particularly in regard to water form and distribution. Meanwhile, the 
aerodynamic performance parameters, namely the overall pressure ratio, the overall temperature ratio, and the efficiency, can be taken to tend to a nearly steady state at the end of the first period of unsteadiness.

In cases 2 and 3 , figures $3.21-3.27$ and $3.28-3.32$, the performance of the compressor has been determined at values of $\mathrm{XW}_{\mathrm{W}}$ equal to 16.0 and 18.0 per cent, respectively, again at the design speed. It is clear that with such large amounts of ingestion, the range flow coefficient becomes reduced in magnitude as well as restricted in range. It is also found that at $\mathrm{XW}_{\mathrm{W}}$ equal to 16.0 per cent, the compressor operates only for a short period of time before the compressor performance becomes so far reduced that the machine is unable to operate further. Finally, figures 3.26 - 3.27 again indicate the time-dependent nature of performance at the selected intermediate stage, that is different from that obtained at the exit plane of the compressor, figures 3.21-3.22. Thus, the timedependent nature of compressor performance with water ingestion becomes clearly established. These comments also aply to figures 3.28 - 3.32.

In cases 4,5 and 6 , the operating speed has been reduced to a low value, namely 65 per cent of design. The range of flow coefficient that can be utilized at that speed is small. The predicted results presented in figures $3.33-3.46$ are similar to those obtained earlier in the case of operation at design speed in various respects.

\subsubsection{Steady, Uniform Ingestion with Film at Entry}

In cases 7 and 8 , account is taken of the possible presence of a film of water at entry to the compressor. It is assumed that in addition to the amount of water ingested (which is specified by $\mathrm{XW}_{\mathrm{W}}$ ) there is a film at entry equal to the height of casing clearance in the first stage, denoted by $\mathrm{H}_{C}(1)$. 
It is clear that, when such a film is present, all of the water centrifuged in the first stage becomes splashed back into the local span of the blading. As a consequence, the entry conditions to the second and subsequent stages become modified compared to what they would have been under identical conditions but without the film at entry. It is, therefore, of interest to establish the manner in which the transient performance of the compressor becomes affected by the presence of a film at entry.

In cases 7 and 8 , the performance of the compressor is determined under conditions of steady ingestion and steady film flow at entry to the compressor. In case 7 , the operating speed is equal to design speed, while in case 8 , it is 65 per cent of design speed. In both cases, a variety of ingestion mass fractions have been utilized at (typically) feasible values of flow coefficient. The predictions presented in figures listed in Table I for those cases may be compared with those obtained in cases $1-6$. The differences are essentially quantitative, while qualitatively, the effects of ingestion remains the same in all cases.

\subsection{Transient Performance with Specified Differences in Temperature and}

Velocity of Air and Water

As stated earlier, the WINCOF-I code incorporates a subroutine for calculation of heat and mass transfer processes which includes a correction for mutual blockage of droplets to transfer processes. The correction is provided in figure 3.1 in terms of a so-called heat and mass transfer factor, $\zeta$. The heat and mass transfer processes also depend upon the relative velocity between air and water droplets, which is specified in terms of a relative velocity factor, $\xi$, with values between zero and unity. Finally, heat and mass transfer are affected by the difference in temperature of air and water droplets. It may be recalled here that 
the water film in the clearance space is not subject to transfer processes, by assumption.

Case 9 deals with the problem of including the factors $\xi$ and $\zeta$. In figures $3.60-3.68$, the manner in which $\mathrm{X}_{\mathrm{W}}$ changes from stage to stage along the compressor is presented for various ingestion and operation conditions utilizing different values of $\xi$ (varying from 1.0 to 0.1 ) and values of $\zeta$ taken from figure 3.1

As stated earlier, it is assumed that the droplets ingested are large. Along the compressor the large droplets become converted in part into small droplets due to local equilibrium requirements, mechanically and thermodynamically, taking account of heat and mass transfer processes. Thus, in the earlier stages there arises a mixture of large and small droplets, with a reduction in the proportion of large droplets and an increase in that of small droplets. Beginning with some stage along the compressor, there may exist only small droplets. The mass fraction of small droplets must tend to decrease beyond that location in the compressor due to heat and mass transfer processes in various subsequent stages of the machine. The rate of change of droplet size and phase along the compressor is thus a complex function of various processes and factors involved in the compressor flow. The determination of the influence of such processes and factors on the stage of fluid at the compressor exit is the main interest in case 9.

It may be pointed out here that the exit conditions from the core compressor are the entry conditions to the prediffuser-combustor unit in a bypass engine. Among various parameters of interest in the mixture state at that location, it is particularly important to establish 1) the total amount of water in the air-water mixture and 2) the proportions of the total amount of water in vapor, droplet and film form. In all cases, some of the water is likely to be present in film form in the casing clearance at the last stage of the core 
compressor, and, therefore, also in the entry to the diffuser which is contiguous with the compressor casing. On the other hand, in the span section of the compressor and, therefore, also, in the body of the diffuser flow, water may be in part or wholly in vapor form, depending upon the effect of centrifuging and heat and mass transfer processes. Thus, in the current example calculations, illustrated in figures $3.60-3.68$, there are several cases and situations in which there is no liquid water in the span of the compressor in the last one or two stages.

The parameters that influence the process of conversion of liquid water into vapor are the following: 1) the mechanical and transport processes that give rise to reduction in the size of droplets, for example from the class of large droplets to the class of small droplets; 2) the absolute values of and the differences in velocity and temperature of air and water, initially and along the compressor; and 3) the number density of droplets in the mixture, which gives rise to blockage of droplets, and thus a non-zero value of the heat and mass transfer factor, $\zeta$. Figures $3.60-3.68$, in fact, illustrate the influence of these factors on the state of air-water mixture at the exit of the compressor or, equivalently, the entry to the diffuser.

\subsection{Transient Performance with Changes in Mass Fraction of Water Ingested}

During an aircraft flight in rain storms, it is possible to visualize several types of non-steady ingestion conditions, namely 1) entry and exit from rain, and 2) changes in the mass fraction of water ingested, for example due to changes in intensity of rain fall, velocity differences between air and water and also, changes in rain drop size and its distribution. Such events are complex in nature and in the details of effects they may produce on compressor performance. In all cases, it is of interest 0 establish the extent to which the transient performance of a 
compressor becomes affected. The effects of unsteadiness in ingestion couple with the time-dependent effects that arise even with steady ingestion, and it is the overall effect that is of interest.

An effort has been made in cases $10-12$ to investigate one aspect of the foregoing class of problems, namely the effects produced due to a change in the mass fraction of water, $\mathrm{X}_{\mathrm{W}}$, being ingested into the engine, for example during an operation involving a change in $X_{W}$ from value zero to a value to $X_{W 1}$ at the end of a certain length of time of steady operation and then, to another value $\mathrm{X}_{\mathrm{W} 2}$ at the end of another length of time of steady operation with the (ingestion) mass fraction of $\mathrm{X}_{\mathrm{W} 1}$. In practice, this case corresponds to an engine in a flight vehicle entering rain and ingesting water, and a short period of time later suffering increased ingestion due to greater rainfall. The results of predictions are presented in figures $3.69-3.88$. In all of the cases $10-12$, ingestion is assumed to be uniform across the compressor face, with no film at the casing clearance at entry.

Cases 10 and 11 deal with operation at design speed with different values of flow coefficient and different types of changes in $\mathrm{XW}_{\mathrm{W}}$. In case 12, the speed of operation is reduced to 65 per cent of design speed with a lower value, as feasible, of flow coefficient.

In case 10, two problems have been considered as follows: 1) $\mathrm{XW}_{\mathrm{W}}$ changing from 4.0 to 2.0 per cent, figures $3.69-3.71$, and 2) $\mathrm{XW}_{\mathrm{W}}$ increasing from 2.0 to 8.0 per cent, figures $3.73-3.76$. In figures $3.69-3.71$ and figures 3.73 - 3.75, the nonsteady performance parameters are given both for the cases of steady ingestion with the initial and the final values of $X_{W}$ in a given change as well as for the case involving the actual change in $\mathrm{XW}_{\mathrm{W}}$. It is observed in regard to aerodynamic performance parameters that 1 ) the change in $\mathrm{X}_{\mathrm{W}}$ does not seem to cause appreciable additional unsteadiness in the immediate interval of time 
around the instant of change, and 2) the compressor displays a performance following the change that is very nearly equal to that obtained under conditions of steady ingestion with the final value of $\mathrm{XW}_{\mathrm{W}}$.

Considering, however, the composition of air-water mixture, it is found that there can arise some unsteadiness, for example, in the thickness of the film in the casing clearance (denoted by the parameter $\mathrm{H} / \mathrm{H}_{\mathrm{C}}$ ), in the immediate interval of time and joining the instant of change. This is in agreement with the result stated earlier, namely that, while aerodynamic performance attains a quasi-steady character during ingestion, the distribution of water displays a more noticeable time-dependence.

In case 11 , the amount of water ingested is changed from a low value of $\mathrm{X}_{\mathrm{W}}=2.0$ per cent to large values such as 16.0 and 18.0 per cent. Under such high values of $\mathrm{XW}_{\mathrm{W}}$, it is possible to operate the compressor within limited ranges of $\phi$. From figures $3.77-3.84$, it is clear that 1) there is additional unsteadiness due to the change of $X_{W}$ from 2.0 to 16.0 or 18.0 per cent and 2) the compressor may only be operated for a shorter period of time than even the period over which it may be operated with steady ingestion of 16.0 or 18.0 per cent; the latter is itself quite small, as can be seen from the figures.

Finally, in case 12, the compressor performance has been determined at the lower speed of operation, namely 65 per cent design speed.

It may be pointed out that in all of the cases 10-12, there do not appear to be any (undesirable) time-dependent features associated with the onset of changes.

It may be reemphasized that ingestion is assumed to be uniform in all cases. Hence, it can be concluded that while water ingestion leads to time-dependent performance of the compressor, and a drastic fall in performance as the mass fraction of water ingested exceeds a certain limit (about 8.0 per cent in the current compressor of the generic engine), the performance shows no additional 
changes due to changes in ingestion so long as the ingestion is uniform across the compressor face. From other performance predictions, discussed in the next section, for the case of nonuniform ingestion, it may be surmised that nonuniformity plays a much more significant role than changes in ingestion or, equivalently, that a compressor is more susceptible to deterioration due to nonuniformities or distortions than changes in stage properties under conditions of uniform flow.

\subsection{Transient Performance with Non-Uniformity in Ingestion}

It may be recalled, for completeness, that results of investigations conducted on the transient effects of nonuniformity in mass fraction of water ingested into a compressor have been reported in reference 7 .

\section{CHAPTER 4}

BYPASS ENGINE PERFORMANCE WITH WATER INGESTION:

\section{RESULTS AND DISCUSSION}

The bypass engine chosen for illustration of the transient effects of water ingestion is the generic bypass engine shown in figure 1.1 Details concerning the engine have been given in reference 2 . The numerical code utilized for obtaining the transient performance of the engine has also been described in reference 2 .

The two main components of the engine that are assumed to be affected by water ingestion are (i) the fan-compressor unit and (ii) the prediffuser-combustor unit. The transient performance of the fan-compressor unit is input into the engine simulation code, as described in reference 10 , in the form of parameterized performance maps as shown in figure 4.1 The change in prediffuser-combustor performance is input into the engine simulation code in 
the form of combustion efficiency, expressed as a reduction in the value of combustor exit temperature. The water that enters the prediffuser-combustor unit is assumed to undergo complete evaporation in the combustor. Thus, the turbines are expected to operate with air-water vapor mixture.

The performance of the engine is expressed in terms of four parameters, each as a function of time, namely the following: 1) speed of low pressure compressor or the supercharger, 2) speed of the high pressure compressor or the core engine, 3) output of gross thrust and 4) thrust specific fuel consumption.

All the cases for which predictions have been obtained are summarized in Tables II and III, which also include the numbers of figures showing the results of predictions for each case. In Table II, CRP, FIP, and MXP refer to power settings at cruise, flight idle, and maximum power settings, respectively. In Table II the cases discussed assume fixed ambient conditions. In Table III, the engine operating conditions are assumed to correspond to those occurring during operations over two flight paths as follows shown in figure 4.2: 1) 1-2 and 2-1 with flight Mach number change while the altitude number is held constant and 2) 1-3 and 3-1 with changes in both altitude and flight Mach number.

It might be recalled that a particular engine is being considered in the examples, namely the generic bypass fan engine, with a given control system.

\subsection{Transient Performance with Fixed Ambient Conditions}

Cases 1 to 7 given in Table II pertain to constant ambient conditions, namely standard atmospheric conditions. It is assumed, as stated earlier, that the air is fully saturated with water vapor whenever there is water ingestion.

\subsubsection{Cases 1 and 2}


In case 1, the transient performance of the engine is predicted for engine operation under cruise power (CRP) conditions while the mass fraction of water ingested is held constant at values $0,2.0$ and 8.0 per cent. The performance predictions are presented in figures $4.3-4.5$. It is found that the engine performance changes smoothly from initial to final conditions. The loss of thrust is largest with ingestion of 8.0 per cent of water.

In case 2, the engine performance is examined while the engine operates with a constant mass fraction of water, namely 4.0 per cent, in one case at flight idle power (FIP) condition and in the other at maximum power (MXP) condition. In the case of operation at FIP condition, it is found, as shown in figure 4.6, that at the end of a certain length of time, there arises some form of instability and the engine does not seem to be able to operate further in time. In the case of operation at MXP condition, the engine does not seem to be able to operate at all.

\subsubsection{Cases 3-7}

Next, in cases 3-7, engine operation is examined with changes in engine power setting, or mass fraction of water ingested, or both, specified as occurring over different lengths of time. It may be noted that the mass fraction of water, when changed, is supposed to change from one value to another at the specified time and not gradually as a function of time.

In case 3, the engine power setting is considered to be changed from FIP to MXP in an interval of time of 60 secs while the mass fraction of water ingested is assumed to be held constant at 4.0 per cent in one case and 8.0 per cent in the other. As shown in figures 4.7 and 4.8 , the engine performance indicates an instability and termination before the 60 seconds, both for the cases $X_{W}=4.0$ and $\mathrm{XW}_{\mathrm{W}}=8.0$ per cent. 
It is interesting to observe in figure 4.8 that in the case $\mathrm{XW}_{\mathrm{W}}=8.0$ per cent, the engine seems to be able to "recover" after the first signs of instability and operate for a total period that is a little larger than the total period for which the engine is able to operate with $\mathrm{X}_{\mathrm{W}}=4.0$ per cent (fig. 4.7). This kind of performance is a clear indication of the inherently nonlinear nature of the engine system and the complex manner in which instability is likely to set in and change.

In case 4 , the engine power setting is held constant at FIP and $t=0$ to $t=$ 30 secs, and then changed to MXP during $t=30$ secs. to $t=40$ secs. Meanwhile the mass fraction of water is assumed to change from 0 to 4.0 per cent at the end of $t=10$ secs, and then to 8.0 per cent at the end of $t=60$ secs. However, the engine displays as may be observed in figure 4.9 , the same unstable performance as in case 3 when $\mathrm{XW}_{\mathrm{W}}=4.0$ per cent at the end of about 39 secs. Thus the engine performance predictions show that the engine has ceased to continue to operate before the increase in $\mathrm{X}_{\mathrm{W}}$ to 8.0 per cent has occurred.

In case 5 , both the engine power setting as well as the mass fraction of water ingested are changed with time. The engine power setting is changed from MXP to CRP between $t=0$ and $t=10$ secs while $X_{W}=0$. Then the engine power setting is changed from CRP to FIP in 60 secs, while the mass fraction of water is changed to 4.0 per cent beginning with $t=10$ secs. It is found that the engine performance, as shown in figure 4.10, changes smoothly from the CRP condition to the FIP condition. This is in contrast to the result obtained in case 2 and also, in cases 3 and 4. It appears that changes from CRP setting are stable with water ingestion of 4.0 per cent, and the difficulty in the generic engine is with water ingestion at the MXP setting.

The foregoing conclusion becomes further supported by examining the results obtained in cases 6 and 7, figures 4.11 and 4.12, respectively. There is again the occurrance of instability and termination of operation of the engine in 
case 6 wherein the engine power setting is changed from FIP to MXP and back again to FIP. On the other hand, in case 7, the engine power setting is changed from FIP to CRP and back again to FIP, and the engine performs, according to prediction, without any problems. It will be observed in Table $I I$ that in both cases 6 and 7, the water mass fraction is considered to undergo identical changes with respect to time.

\subsection{Transient Performance under Varying Ambient Conditions}

The cases for which performance predictions have been obtained with varying ambient conditions are those illustrated in figure 4.2 and listed in Table III.

In Table III, a case is given a designation $\mathrm{XYZ}$ where $\mathrm{X}$ indicates the value of $\mathrm{XW}_{\mathrm{W}}$, the mass fraction of water in percent value, and $\mathrm{Y}$ and $\mathrm{Z}$ indicate the initial and the final points, respectively, of the flight path shown in figure 4.2. Thus, case 231 indicates operation of the engine with $\mathrm{X}_{\mathrm{W}}=2.0$ per cent while the ambient conditions change from those corresponding to point 3 to those corresponding to point 1 along the flight path 31 in figure 4.2. In each case the water mass fraction ingested is held constant at a particular value while the flight conditions are varied.

As previously, the predicted engine performance is presented in each case in terms of four parameters, namely 1) $\mathrm{N}_{1}$, the supercharger speed, 2) $\mathrm{N}_{2}$, the core engine speed, 3) overall thrust output, and 4) thrust specific fuel consumption.

\subsubsection{Groups 1 and 2 of Predicted Cases}

Groups 1 and 2 of the predicted cases pertain to the same flight path but in opposite directions, 12 and 21 , with various values of $\mathrm{X}_{\mathrm{W}}$. 
It can be observed from figures $4.13-4.16$ (Group 1) and also, figures 4.17 - 4.20 (Group 2) that no problems seem to arise in engine performance, except for some observable excursions in thrust output and specific fuel consumption when $\mathrm{X}_{\mathrm{W}}=8.0$ per cent, figure 4.16.

\subsubsection{Groups 3 and 4 of Predicted Cases}

Groups 3 and 4 of the predicted cases pertain to the same flight path but in opposite directions, 13 and 31, with various values of $\mathrm{X}_{\mathrm{W}}$.

It is found from figures $4.21-4.24$ that some problems arise in engine performance in following the flight path 13 under the chosen conditions. There are excursions in thrust output and specific fuel consumption even in the absence of water ingestion, case 013 , and they become further accentuated when the amount of water ingestion becomes appreciably large.

On the other hand, referring to Group 4 cases, the engine performance does not indicate any problems in figures $4.25-4.28$. Even with a high value of $\mathrm{X}_{\mathrm{W}}=8.0$ per cent, both the thrust output and the specific fuel consumption are shown to change without noticeable excursions or instabilities.

\section{CHAPTER 5 \\ CONCLUSIONS}

A brief summary of accomplishments and results obtained is summarized in the following.

1) the WINCOF-I code provides a practical and versatile tool for establishing the transient performance of a fan-compressor unit operating with a variety of air-water vapor-water film and droplet mixtures at entry to the unit.

2) The WINCOF-I code can be utilized to establish transient performance 
changes in any stage of a fan-compressor unit or in the total unit under conditions of a) nonuniformities in entry conditions and b) time-dependence in entry conditions; the latter is of particular interest during entry and exit relative to flight through rain and also, during changes in intensity of rainfall and hence in mass fraction of water ingested along a flight trajectory.

3) An engine-simulation code for obtaining the transient performance of an engine can be combined effectively with the output from the WINCOF-I code.

4) The WINCOF-I code output for the core compressor of a bypass engine is the input to the prediffuser-combustor unit. Thus, the time-dependent output for the core compressor generated with the WINCOF-I code for given ingestion conditions into the engine becomes of great interest in testing and analyzing a prediffuser-combustor unit and the core engine as a whole; the latter is of considerable importance in evolving engine performance assessment and engine acceptance tests.

5) Engine simulation has been demonstrated with various types of water ingestion conditions while accounting for a) fan-compressor unit performance changes obtained by utilizing the WINCOF-I code, and b) prediffuser-combustor performance changes on a parametric basis; the latter has significant effects on engine performance changes even when included by itself.

6) The methods of undertaking and assessing engine performance prediction with changes in flight conditions, altitude and Mach number, have been demonstrated successfully. The three main parameters that influence engine performance during such changes are the following: 1) rate of change of power setting; 2) rate of changes of flight path changes; and 3) the design of the engine control system, in particular the acceleration and the deceleration schedules for fuel flow relative to engine speeds in a bypass engine. 


\section{* References}

1. Leonardo, M. Tsuchiya, T., and Murthy, S.N.B., PURDUE-WINCOF- A Computer Code for Establishing the Performance of a Fan-Compressor Unit with Water Ingestion, NASA CR-168005, 1982.

2. Haykin, T. and Murthy, S.N.B., Dynamic Performance of a High Bypass Ratio Engine with Water Ingestion, Interim Report No. DOT/FAA/CT-TN 86/14, October, 1986.

3. Haykin, T. and Murthy, S.N.B., Jet Engine Simulation with Water Ingestion Through Compressor, NASA Contractor Report 179549 and DOT/FAA/CT-TN87/1, January, 1987.

4. Haykin, J. and Murthy, S.N.B., Transient Engine Performance with Water Ingestion, Joumal of Propulsion and Power, July-August, 1987.

5. Murthy, S.N.B., and Mullican, A., Transient Performance of Fan Engine with Water Ingestion, AIAA 91-1897, 1991.

6. Murthy, S.N.B., Ehresman, C.M., and Haykin, T., Direct and System Effects of Water Ingestion into Jet Engine Compressors, ASME FED-Vol.

7. Mullican, A. and Murthy, S.N.B., WINCOF-I Code for Prediction of Fan Compressor Unit with Water Ingestion, NASA Contractor Report No. 185157, DOT/FAA/CT-TN89/63, M/NAFA/89-1, December, 1990.

8. Devine, K., Inclement Weather Induced Aircraft Engine Power Loss, AIAA 90-2169, July 1990.

9. Leonardo, M., Ehresman, C.M., and Murthy, S.N.B., A Stagnation Pressure Probe for Droplet-Laden Air Flow, Journal of Propulsion and Power. May-June 1986.

10. Murthy, S.N.B. and Mullican, A., WINCOF-I Code: Detailed Description, Report No. DOT/FAA/CT-TN 92-10, December 1991.

11. Minster, T., and Murthy, S.N.B., Prediffuser-Combustor Model Studies under Conditions of Water Ingestion in Engines, Report No. M/GE-WI/91F, September 1991. 
12. Chalon, J.P., Characterization of Meteorological Phenomena Influencing Aircraft Operations, Lecture Series 1987-03, Von Karman Institute, Rhode Saint Genese, Belgium, 1987. 
Table I

PREDICTED CASES FOR HIGH PRESSURE COMPRESSOR

\begin{tabular}{|c|c|c|c|c|c|c|}
\hline $\begin{array}{l}\text { Case } \\
\text { No. }\end{array}$ & $\begin{array}{l}\mathrm{N} / \mathrm{N}^{*} \\
\text { per cent }\end{array}$ & $\phi$ & $\begin{array}{c}X_{W} \\
\text { per cent }\end{array}$ & $\mathrm{H} / \mathrm{H}_{\mathrm{c}}(1)$ & $\begin{array}{l}\text { Fig. } \\
\text { No. }\end{array}$ & Notes \\
\hline 1 & 100 & $\begin{array}{r}0.440 \\
-0.460\end{array}$ & 4.0 & 0 & $\begin{array}{l}3.9 \\
3.10 \\
3.11 \\
3.12 \\
3.13 \\
3.14 \\
3.15 \\
3.16 \\
3.17 \\
3.18 \\
3.19 \\
3.20\end{array}$ & 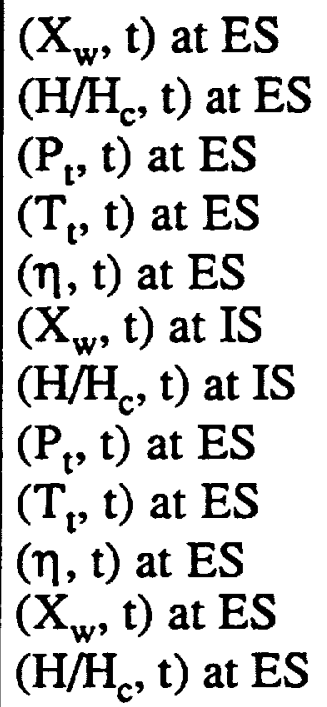 \\
\hline 2 & 100 & 0.412 & 16.0 & 0 & $\begin{array}{l}3.21 \\
3.22 \\
3.23 \\
3.24 \\
3.25 \\
3.26 \\
3.27\end{array}$ & $\begin{array}{l}\left(X_{w}, t\right) \text { at } E S \\
\left(H / H_{c}, t\right) \text { at } E S \\
\left(P_{t}, t\right) \text { at } E S \\
\left(T_{t}, t\right) \text { at } E S \\
(\eta, t) \text { at } E S \\
\left(X_{w}, t\right) \text { at } I S \\
\left(H / H_{c}, t\right) \text { at IS }\end{array}$ \\
\hline 3 & 100 & 0.384 & 18.0 & 0 & $\begin{array}{l}3.28 \\
3.29 \\
3.30 \\
3.31 \\
3.32\end{array}$ & $\begin{array}{l}\left(X_{w}, t\right) \text { at } E S \\
\left(H / H_{c}, t\right) \text { at } E S \\
\left(P_{t}, t\right) \text { at } E S \\
\left(T_{v}, t\right) \text { at } E S \\
(\eta, t) \text { at } E S\end{array}$ \\
\hline
\end{tabular}

- continued 
Table I (continued)

PREDICTED CASES FOR HIGH PRESSURE COMPRESSOR

\begin{tabular}{|c|c|c|c|c|c|c|}
\hline $\begin{array}{l}\text { Case } \\
\text { No. }\end{array}$ & $\begin{array}{c}\mathrm{N} / \mathrm{N}^{*} \\
\text { per cent }\end{array}$ & $\phi$ & $\begin{array}{c}\mathrm{X}_{\mathrm{W}} \\
\text { per cent }\end{array}$ & $\mathrm{H} / \mathrm{H}_{\mathrm{c}}(1)$ & $\begin{array}{l}\text { Fig. } \\
\text { No. }\end{array}$ & Notes \\
\hline 4 & 65 & $\begin{array}{r}0.210 \\
-0.213\end{array}$ & 4.0 & $\overline{0}$ & $\begin{array}{l}3.33 \\
3.34 \\
3.35 \\
3.36 \\
3.37 \\
3.38 \\
3.39\end{array}$ & $\begin{array}{l}\left(\mathrm{X}_{w}, t\right) \text { at } E S \\
\left(H / H_{c}, t\right) \text { at } E S \\
\left(P_{t}, t\right) \text { at } E S \\
\left(T_{t}, t\right) \text { at } E S \\
(\eta, t) \text { at } E S \\
\left(X_{w}, t\right) \text { at } I S \\
\left(H / H_{c}, t\right) \text { at } I S\end{array}$ \\
\hline 5 & 65 & 0.190 & 16.0 & 0 & $\begin{array}{l}3.40 \\
3.41 \\
3.42 \\
3.43\end{array}$ & $\begin{array}{l}\left(X_{w}, t\right) \text { at } E S \\
\left(H / H_{c}, t\right) \text { at } E S \\
\left(X_{w}, t\right) \text { at IS } \\
\left(H / H_{c}, t\right) \text { at IS }\end{array}$ \\
\hline 6 & 65 & 0.182 & 18.0 & 0 & $\begin{array}{l}3.44 \\
3.45 \\
3.46\end{array}$ & $\begin{array}{l}\left(X_{w}, t\right) \text { at } E S \\
\left(H / H_{c}, t\right) \text { at } E S \\
\left(H / H_{c}, t\right) \text { at } I S\end{array}$ \\
\hline 7 & 100 & $\begin{array}{l}0.450 \\
0.412\end{array}$ & 18.0 & 1.0 & $\begin{array}{l}3.9 \\
3.47 \\
3.48 \\
3.21 \\
3.49 \\
3.26 \\
3.50 \\
3.28 \\
3.51 \\
3.52 \\
3.53\end{array}$ & $\begin{array}{l}\left(X_{w}, t\right) \text { at } E S \\
\left(H / H_{c}, t\right) \text { at } E S \\
\left(H / H_{c}, t\right) \text { at IS } \\
\left(X_{w}, t\right) \text { at ES } \\
\left(H / H_{c}, t\right) \text { at } E S \\
\left(X_{w}, t\right) \text { at IS } \\
\left(H / H_{c}, t\right) \text { at IS } \\
\left(X_{w}, t\right) \text { at ES } \\
\left(H / H_{c}, t\right) \text { at } E S \\
\left(X_{w}, t\right) \text { at IS } \\
\left(H / H_{c}, t\right) \text { at IS }\end{array}$ \\
\hline
\end{tabular}

- continued 
Table I (continued)

PREDICTED CASES FOR HIGH PRESSURE COMPRESSOR

\begin{tabular}{|c|c|c|c|c|c|c|}
\hline $\begin{array}{l}\text { Case } \\
\text { No. }\end{array}$ & $\begin{array}{c}\mathrm{N} / \mathrm{N}^{*} \\
\text { per cent }\end{array}$ & $\phi$ & $\begin{array}{c}X_{W} \\
\text { per cent }\end{array}$ & $\mathrm{H} / \mathrm{H}_{\mathrm{c}}(1)$ & \begin{tabular}{|l} 
Fig. \\
No. \\
\end{tabular} & Notes \\
\hline 8 & 65 & $\begin{array}{l}0.190 \\
0.182\end{array}$ & $\begin{array}{l}16.0 \\
18.0\end{array}$ & $\begin{array}{l}1.0 \\
1.0\end{array}$ & $\begin{array}{l}3.33 \\
3.54 \\
3.38 \\
3.55 \\
3.56 \\
3.57 \\
3.58 \\
3.59\end{array}$ & $\begin{array}{l}\left(\mathrm{X}_{\mathrm{w}}, \mathrm{t}\right) \text { at } \mathrm{ES} \\
\left(\mathrm{H} / \mathrm{H}_{\mathrm{c}}, \mathrm{t}\right) \text { at } \mathrm{ES} \\
\left(\mathrm{X}_{\mathrm{w}}, \mathrm{t}\right) \text { at } \mathrm{IS} \\
\left(\mathrm{H} / \mathrm{H}_{\mathrm{c}}, \mathrm{t}\right) \text { at } \mathrm{IS} \\
\left(\mathrm{H} / \mathrm{H}_{\mathrm{c}}, \mathrm{t}\right) \text { at } \mathrm{ES} \\
\left(\mathrm{H} / \mathrm{H}_{\mathrm{c}}, \mathrm{t}\right) \text { at IS } \\
\left(\mathrm{H} / \mathrm{H}_{\mathrm{c}}, \mathrm{t}\right) \text { at } \mathrm{ES} \\
\left(\mathrm{H} / \mathrm{H}_{\mathrm{c}}, \mathrm{t}\right) \text { at IS }\end{array}$ \\
\hline 9 & 100 & $\begin{array}{l}0.450 \\
0.412 \\
0.384\end{array}$ & $\begin{array}{r}4.0 \\
16.0 \\
18.0\end{array}$ & 0 & $\begin{array}{l}3.60 \\
3.61 \\
3.62 \\
3.63 \\
3.64 \\
3.65 \\
3.66 \\
3.67 \\
3.68\end{array}$ & $\begin{array}{l}\xi=1.0 ; \zeta \text { given } \\
\xi=0.55 ; \zeta \text { given } \\
\xi=0.10 ; \zeta \text { given } \\
\xi=1.0 ; \zeta \text { given } \\
\xi=0.55 ; \zeta \text { given } \\
\xi=0.10 ; \zeta \text { given } \\
\xi=1.0 ; \zeta \text { given } \\
\xi=0.55 ; \zeta \text { given } \\
\xi=0.10 ; \zeta \text { given }\end{array}$ \\
\hline 10 & 100 & 0.450 & $\begin{array}{c}0 \text { to } 4.0 \\
\text { to } 2.0 \\
0 \text { to } 2.0 \\
\text { to } 8.0\end{array}$ & 0 & $\begin{array}{l}3.69 \\
3.70 \\
3.71 \\
3.72 \\
3.73 \\
3.74 \\
3.75 \\
3.76\end{array}$ & $\begin{array}{l}\left(\mathrm{P}_{\mathrm{t}}, \mathrm{t}\right) \text { at } \mathrm{ES} \\
\left(\mathrm{T}_{\mathrm{t}}, \mathrm{t}\right) \text { at } \mathrm{ES} \\
(\eta, \mathrm{t}) \text { at } E S \\
\left(\mathrm{H} / \mathrm{H}_{\mathrm{c}}, \mathrm{t}\right) \text { at } E S \\
\left(\mathrm{P}_{\mathrm{t}}, \mathrm{t}\right) \text { at } E S \\
\left(\mathrm{~T}_{\mathrm{t}}, \mathrm{t}\right) \text { at } \mathrm{ES} \\
(\eta, \mathrm{t}) \text { at } \mathrm{ES} \\
\left(\mathrm{H} / \mathrm{H}_{\mathrm{c}}, \mathrm{t}\right) \text { at } E S\end{array}$ \\
\hline
\end{tabular}




\section{Table I (continued)}

PREDICTED CASES FOR HIGH PRESSURE COMPRESSOR

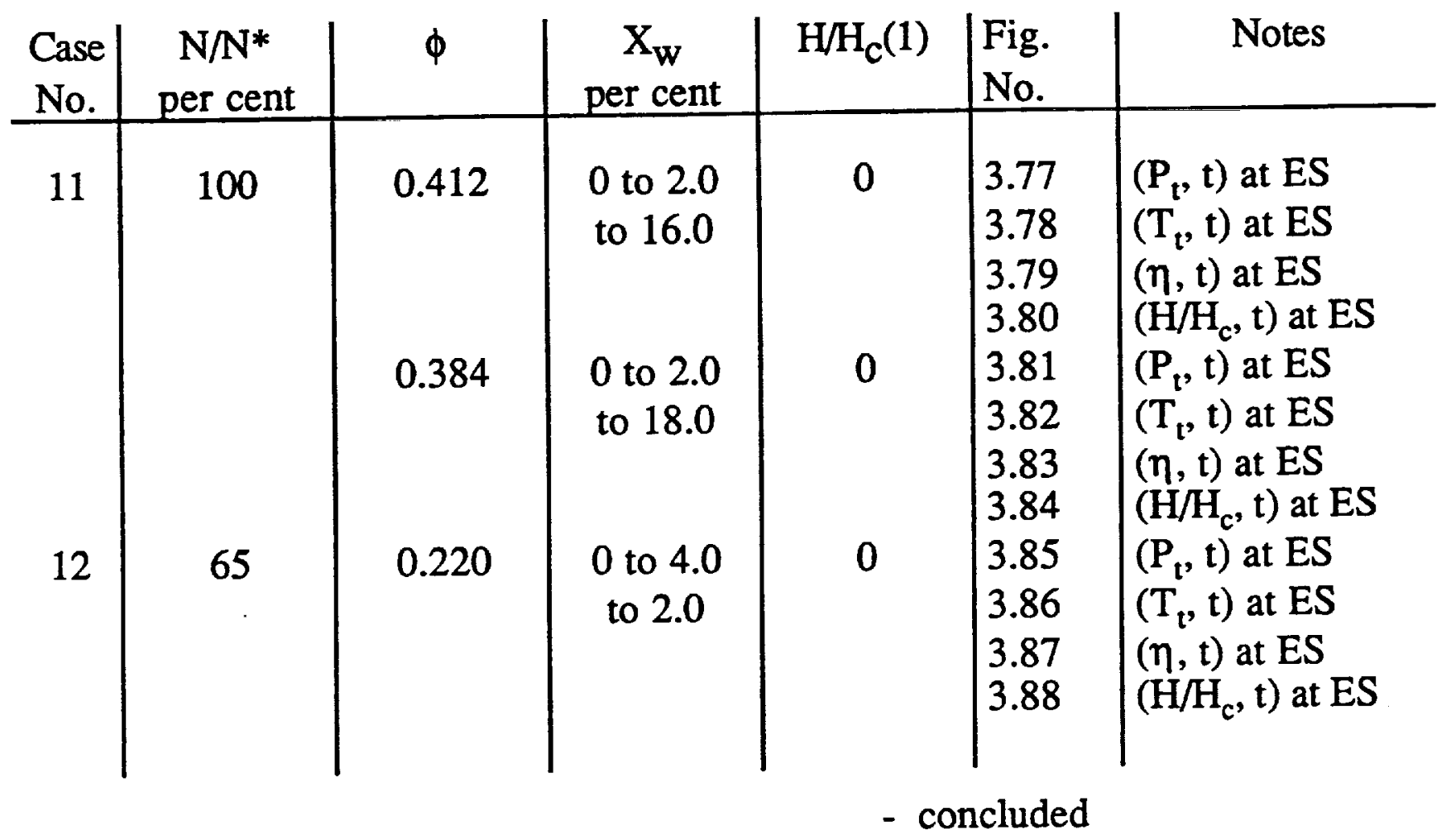

\section{Notation in Table I}

$\mathrm{N} / \mathrm{N}^{*}=$ operating rotational speed/design rotational speed, per cent.

$\phi \quad=\quad$ flow coefficient

$\mathrm{X}_{\mathrm{W}} \quad=\quad$ mass fraction of water

$\mathrm{H} / \mathrm{H}_{\mathrm{C}}(\mathrm{I})=$ height of film of water at entry to compressor/height of tip clearance of first stage rotor.

Es $\quad=$ exit stage

Is $\quad=$ intermediate stage 
Table II

PREDICTED CASES OF TRANSIENT PERFORMANCE OF THE GENERIC ENGINE UNDER FIXED AMBIENT CONDITIONS

\begin{tabular}{|c|c|c|c|}
\hline Case No. & Engine Setting & $\mathrm{XW}_{W}$ per cent & Fig. No. \\
\hline 1 & CRP & $\begin{array}{l}0 \\
2.0 \\
8.0\end{array}$ & $\begin{array}{l}4.3 \\
4.4 \\
4.5\end{array}$ \\
\hline 2 & $\begin{array}{l}\text { i) FIP } \\
\text { ii) MXPP }\end{array}$ & $\begin{array}{l}4.0 \\
4.0\end{array}$ & $\begin{array}{l}4.6 \\
-\end{array}$ \\
\hline 3 & $\begin{array}{l}\text { i) FIP to MXP } \\
\text { in } 60 \text { secs }\end{array}$ & 4.0 & 4.7 \\
\hline & $\begin{array}{l}\text { ii) FIP to MXP } \\
\text { in } 60 \text { secs }\end{array}$ & 8.0 & 4.8 \\
\hline 4 & $\begin{array}{l}\text { FIP } 0 \text { to } 30 \text { secs; } \\
\text { FIP to MXP in } 10 \text { secs. }\end{array}$ & $\begin{array}{l}0 \text { to } 4.0 \text { in } 10 \text { secs; } \\
4.0 \text { to } 8.0 \text { in } 50 \text { secs. }\end{array}$ & 4.9 \\
\hline 5 & $\begin{array}{l}\text { MXP to CRP in } 10 \text { secs; } \\
\text { CRP to FIP in } 60 \text { secs. }\end{array}$ & $\begin{array}{l}0 \text { up to } 10 \text { secs: } \\
4.0 \text { after } 10 \text { secs. }\end{array}$ & 4.10 \\
\hline 6 & $\begin{array}{l}\text { FIP } 0 \text { to } 10 \text { secs; } \\
\text { FIP to MXP in } 10 \text { secs; } \\
\text { MXP for } 30 \text { secs; } \\
\text { MXP to FIP in } 30 \text { secs. }\end{array}$ & $\begin{array}{l}0 \text { to } 8.0 \text { in } 0.1 \mathrm{sec} \\
4.0 \text { after } 30 \text { secs. }\end{array}$ & 4.11 \\
\hline 7 & $\begin{array}{l}\text { FIP } 0 \text { to } 10 \text { secs; } \\
\text { FIP to CRP in } 10 \text { secs; } \\
\text { CRP for } 30 \text { secs; } \\
\text { CRP to FIP in } 10 \text { secs. }\end{array}$ & $\begin{array}{l}0 \text { to } 8.0 \text { in } 0.1 \text { secs; } \\
4.0 \text { after } 30 \text { secs. }\end{array}$ & 4.12 \\
\hline
\end{tabular}

Notation for Table II

$\mathrm{CRP}=$ cruise power setting

$\mathrm{FIP}=$ flight-idle power setting

MXP $=$ maximum power setting 
Table III

PREDICTED CASES OF TRANSIENT PERFORMANCE OF ENGINES

UNDER VARYING AMBIENT CONDITIONS

Group 1: Cases 012, 212, 412, 812; figures 4.13 - 4.16

time, secs

engine setting

altitude, $\mathrm{kft}$

flight Mach number $\begin{array}{rrrrrr}0 & 10 & 30 & 40 & 90 & 120 \\ \text { FIP } & \text { MXP } & \text { MXP } & \text { FIP } & \text { FIP } & \text { FIP }\end{array}$ $\begin{array}{llllll}15.0 & 15.0 & 15.0 & \rightarrow & 8.0 & 8.0\end{array}$ $\begin{array}{llllll}0.6 & 0.6 & 0.6 & 0.6 & 0.6 & 0.6\end{array}$

Group 2: Cases 021, 221, 421, 821; figures 4.17-4.20

time, secs.

engine setting

altitude, kft

flight Mach number

\begin{tabular}{cccrrr}
0 & 10 & 30 & 60 & 90 & 120 \\
FIP & MXP & MXP & \multicolumn{1}{c}{ MXP } & MXP & MXP \\
8.0 & $\vec{a}$ & $\overrightarrow{4}$ & 15.0 & 15.0 & 15.0 \\
0.6 & 0.6 & 0.6 & 0.6 & 0.6 & 0.6
\end{tabular}

Group 3: Cases 013, 213,413,813; figures 4.21-4.24

time, secs.

engine setting

altitude, $\mathrm{kft}$

flight Mach number

\begin{tabular}{rrrrrr}
0 & \multicolumn{1}{c}{10} & 30 & 40 & 90 & 120 \\
FIP & MXP & \multicolumn{1}{c}{ MXP } & FIP & FIP & \multicolumn{1}{c}{ FIP } \\
15.0 & 15.0 & 15.0 & $\rightarrow$ & 8.0 & 8.0 \\
0.6 & 0.6 & 0.6 & $\rightarrow$ & 0.3 & 0.3
\end{tabular}

Group 4: Cases 031, 231, 431, 831; figures 4.25-4.28

time, secs.

engine setting

altitude, $\mathrm{kft}$

flight Mach number

\begin{tabular}{crrrrr}
0 & 10 & 30 & 60 & 90 & \multicolumn{1}{c}{120} \\
FIP & MXP & MXP & MXP & MXP & MXP \\
8.0 & $\rightarrow$ & $\rightarrow$ & 15.0 & 15.0 & 15.0 \\
0.3 & $\rightarrow$ & $\rightarrow$ & 0.6 & 0.6 & 0.6
\end{tabular}


Delibuately blauk 


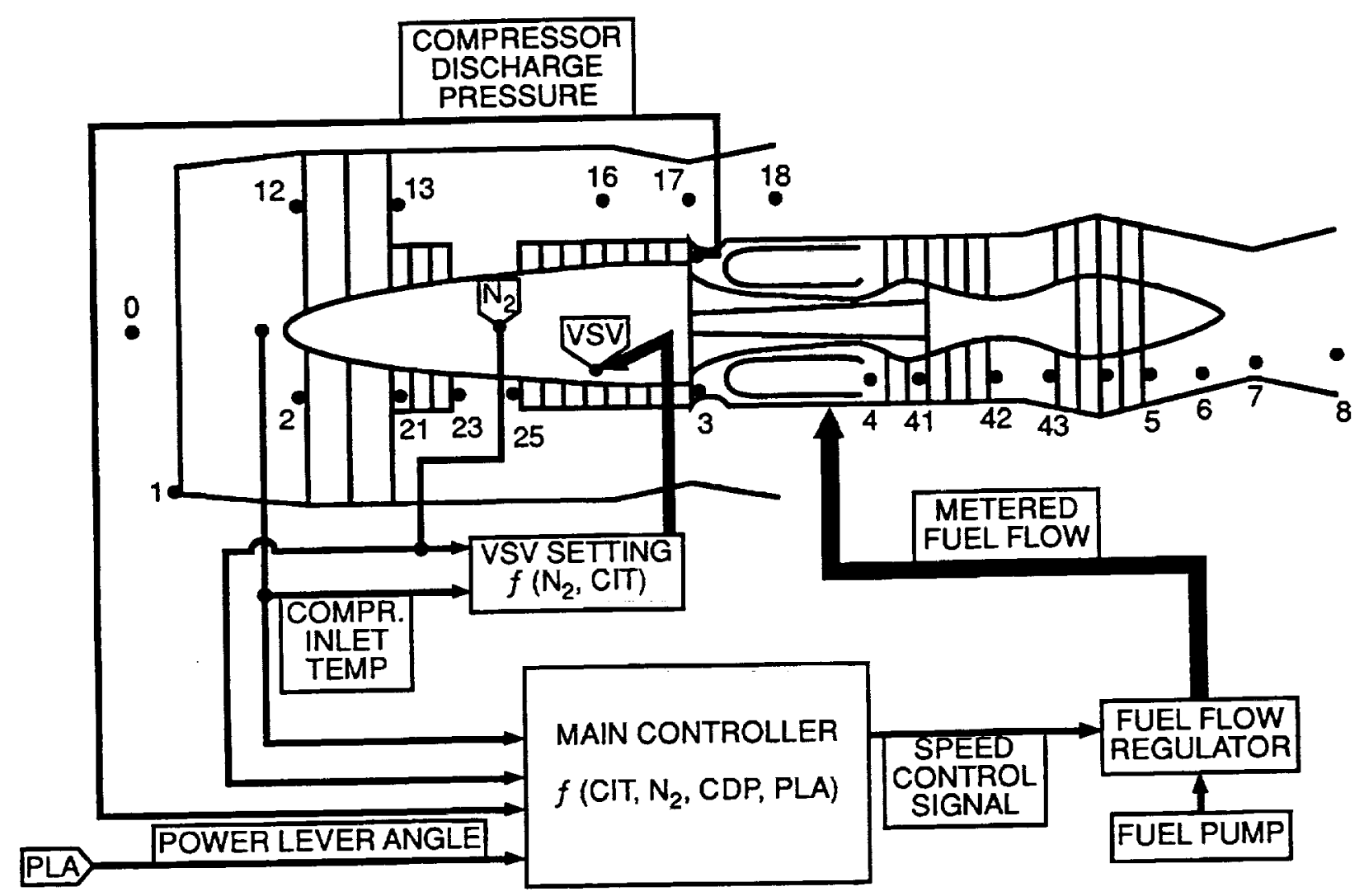

\section{PRIMARY GAS STREAM}

STATION DESCRIPTION

AMBIENT

INLET/ENGINE INTERFACE

FAN FRONT FACE

FAN DISCHARGE AT HUB

BOOSTER DISCHARGE (STATOR EXIT)

HIGH PRESSURE COMPRESSOR INLET

HIGH PRESSURE COMPRESSOR DISCHARGE

BURNER DISCHARGE

HIGHE PRESSURE TURBINE ROTOR INLET

HIGH PRESSURE TURBINE EXIT

LOW PRESSURE TURBINE ROTOR INLET

TUTBINE DISCHARGE

EXHAUST NOZZLE/ENGINE INTERFACE

EXHAUST NOZZLE THROAT

EXHAUST NOZZLE DISCHARGE

\section{PRIMARY GAS STREAM}

STATION DESCRIPTION

12 FAN INLET AT TIP

13 FAN DISCHARGE

16 DUCT EXHAUST NOZZLE

ENGINE INTERFACE

17 DUCT EXHAUST NOZZLE

THROAT

18 DUCT EXHAUST NOZZLE EXIT

Figure 1.1. Schematic Representation of a Generic Bypass Fan Engine. 


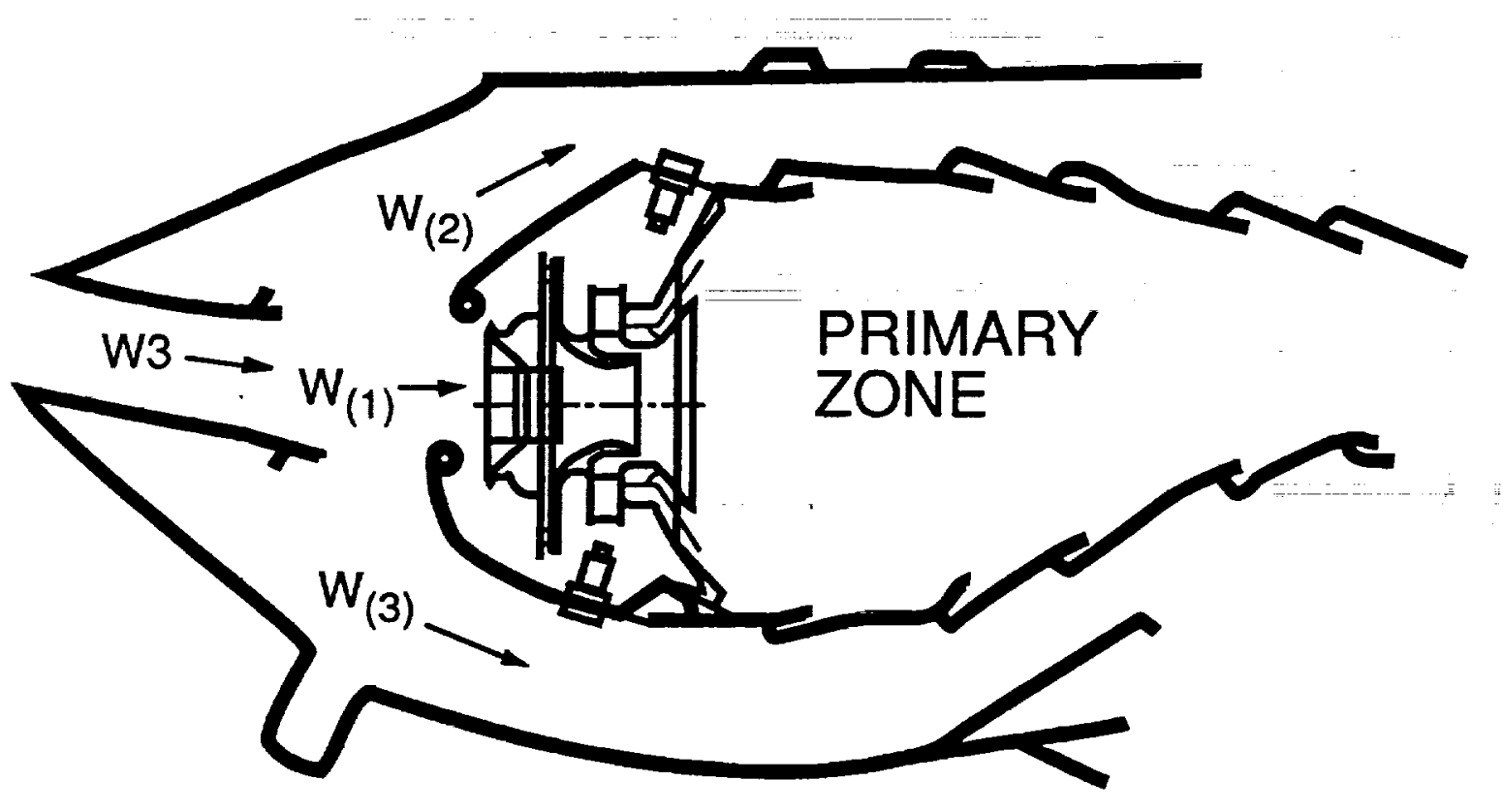

Figure 2.1. Flowfield in a Typical Combustor. 


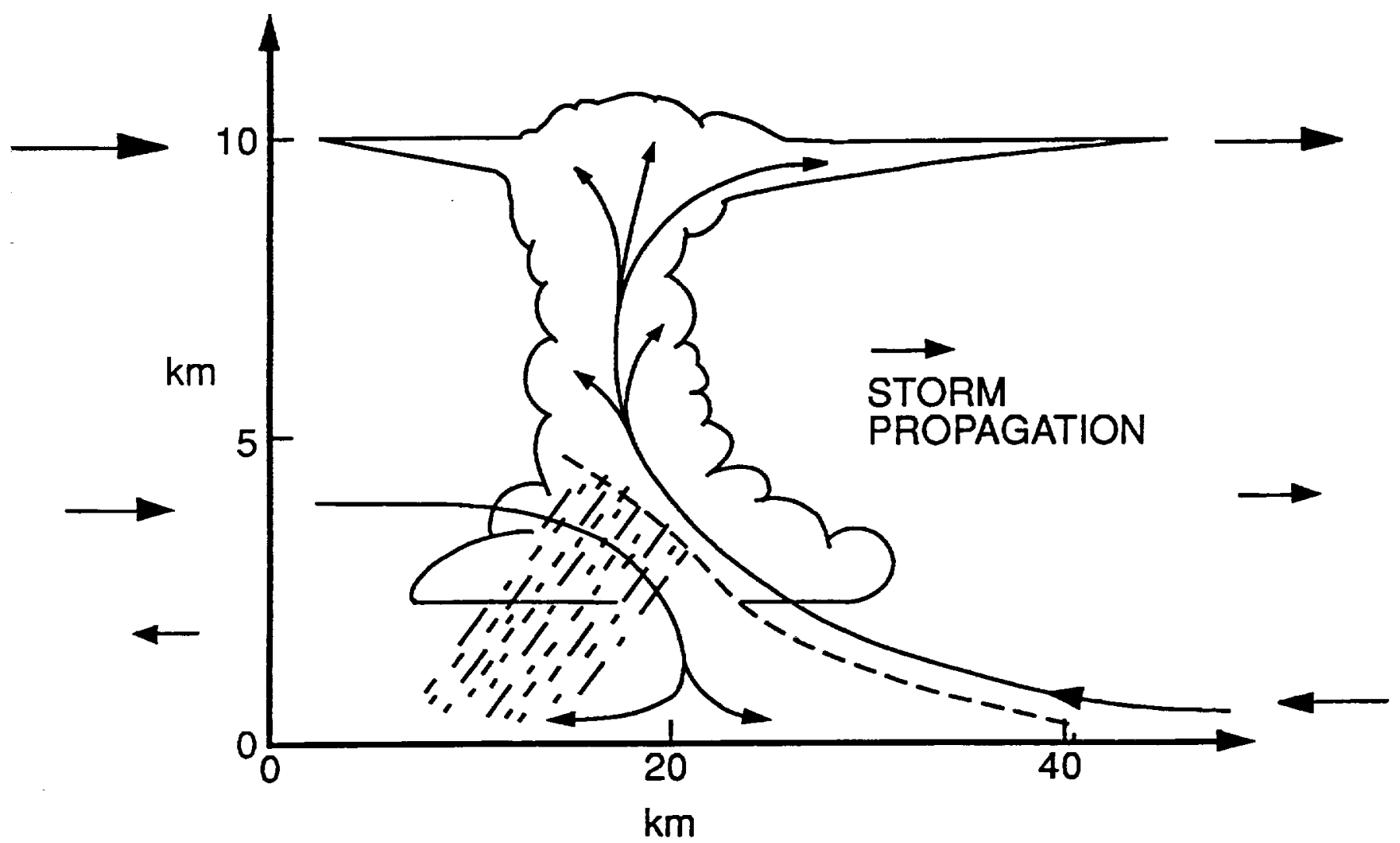

Figure 2.2. Illustration of a Rain Storm (I). 


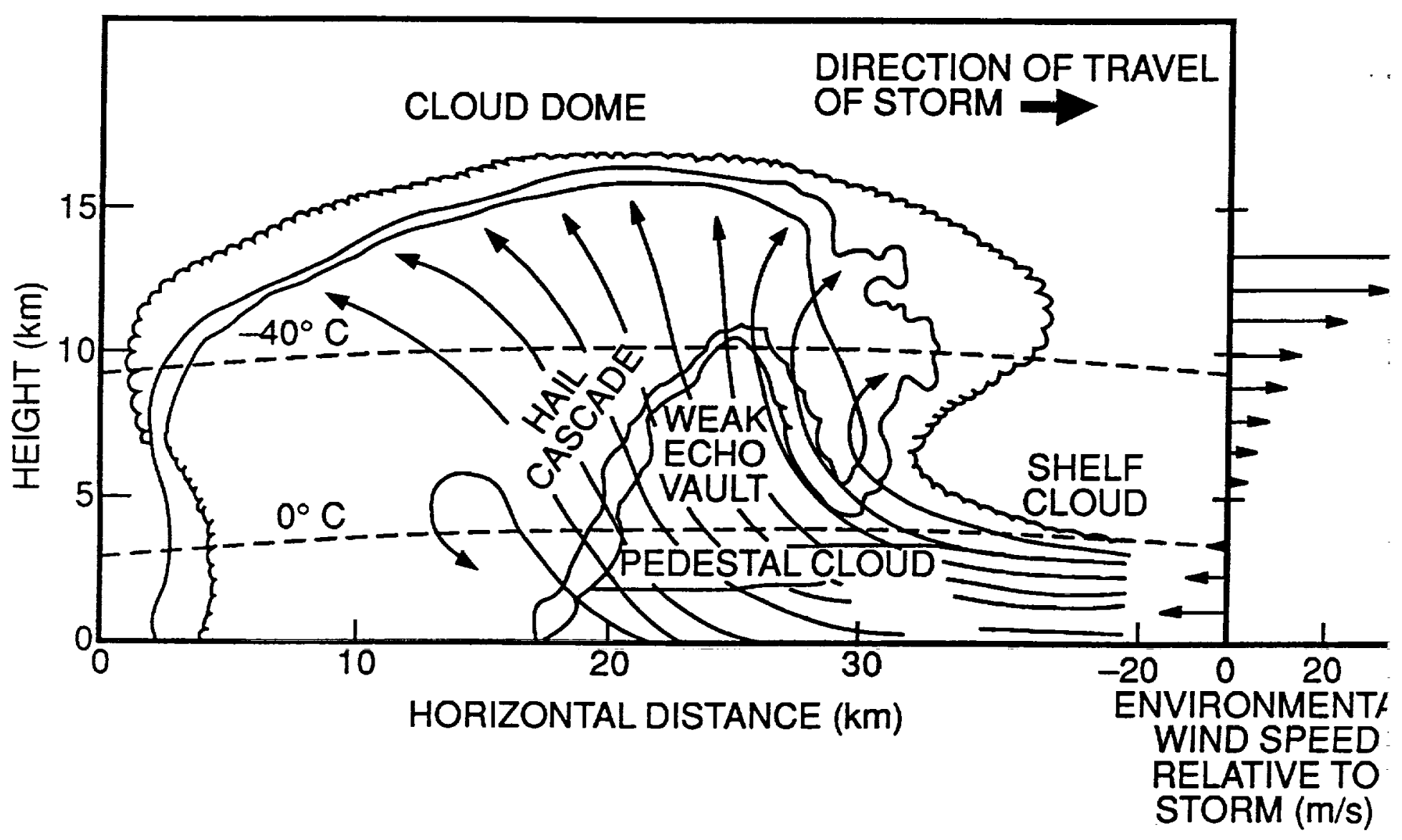

Figure 2.3. Illustration of a Rain Storm (II). 


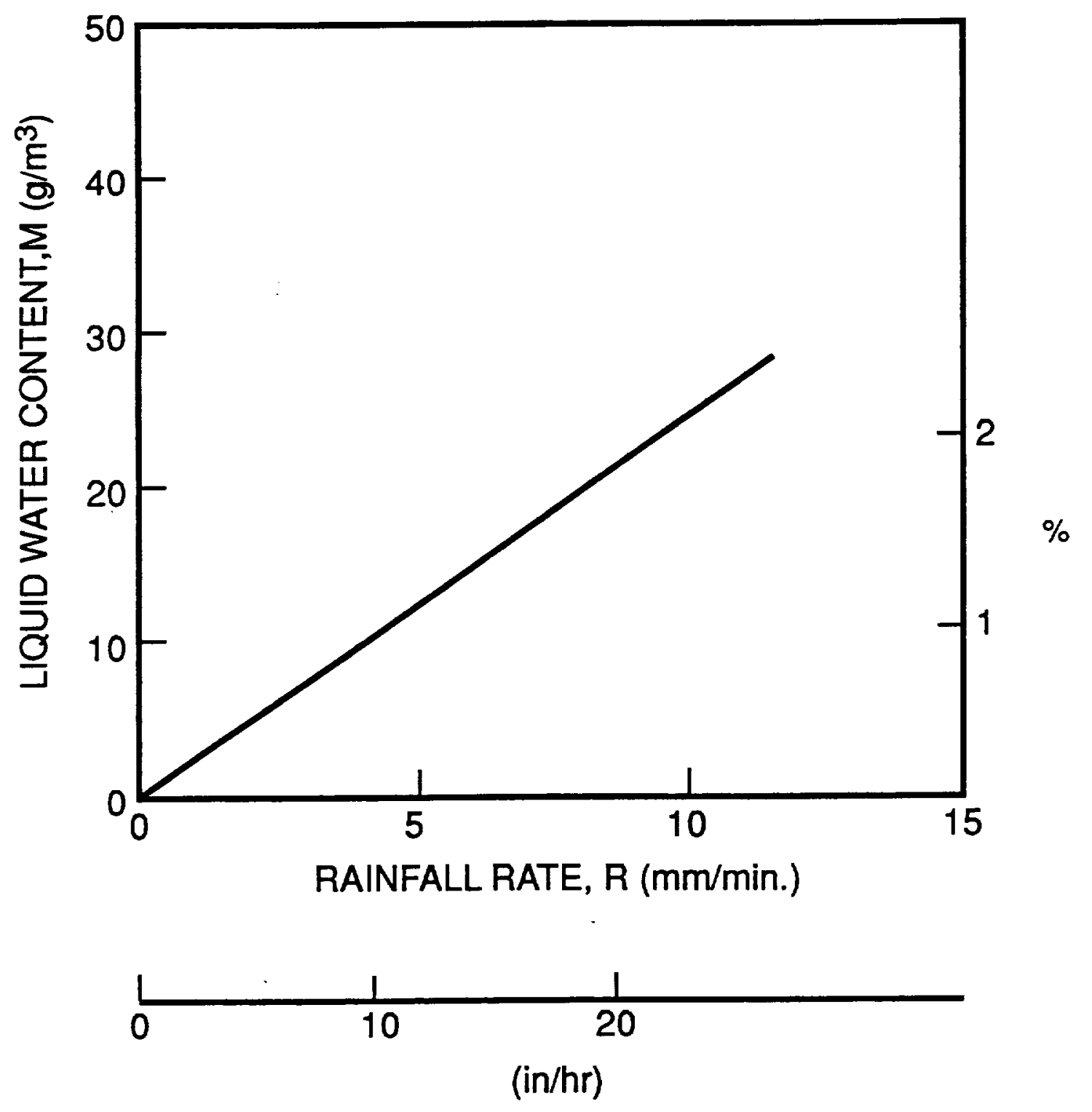

Figure 2.4. Relation between Water Content and Intensity of Rain Fall. 


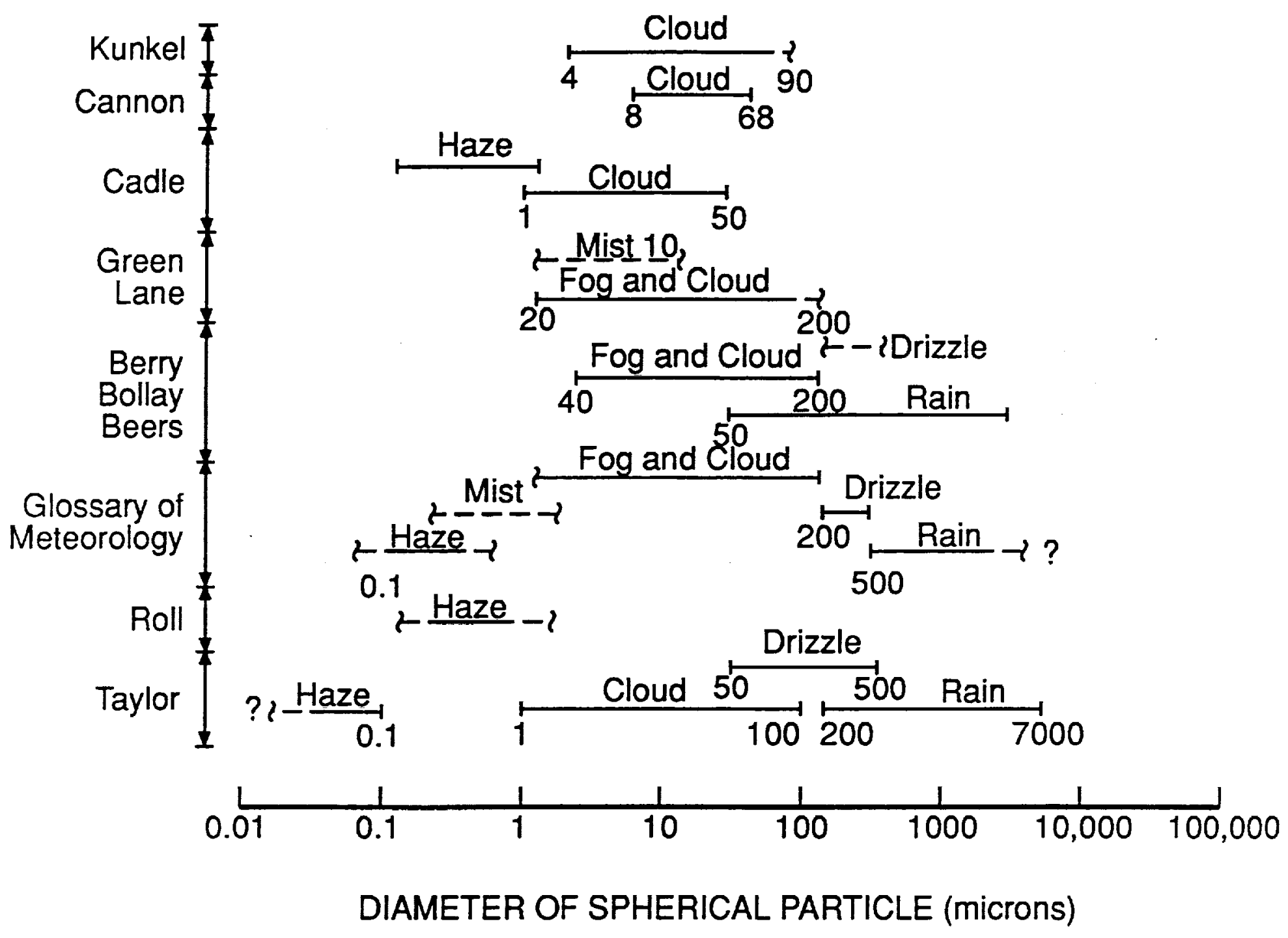

Figure 2.5. Rain Drop Size Distribution. 


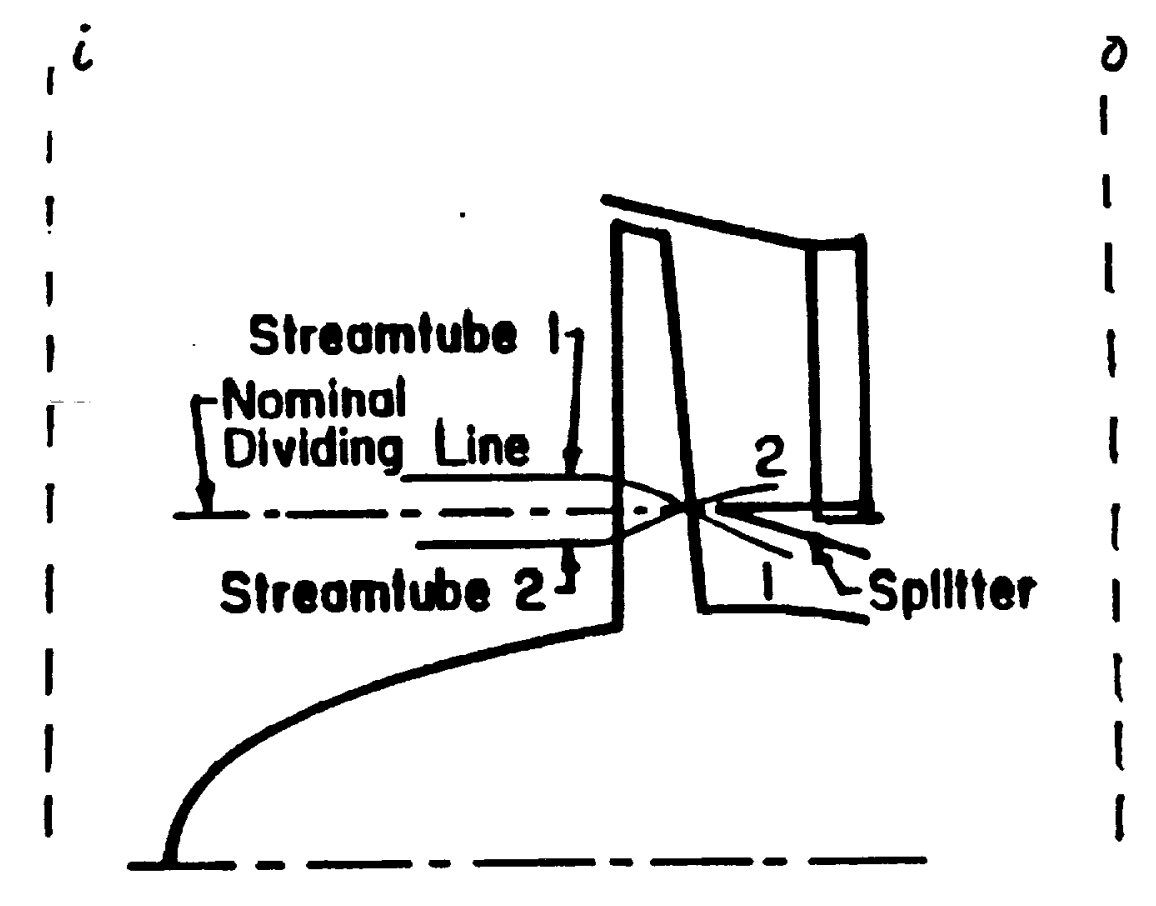

Figure 2.6. Schematic of Flow Pattern in Inlet and Bypass Streams. 


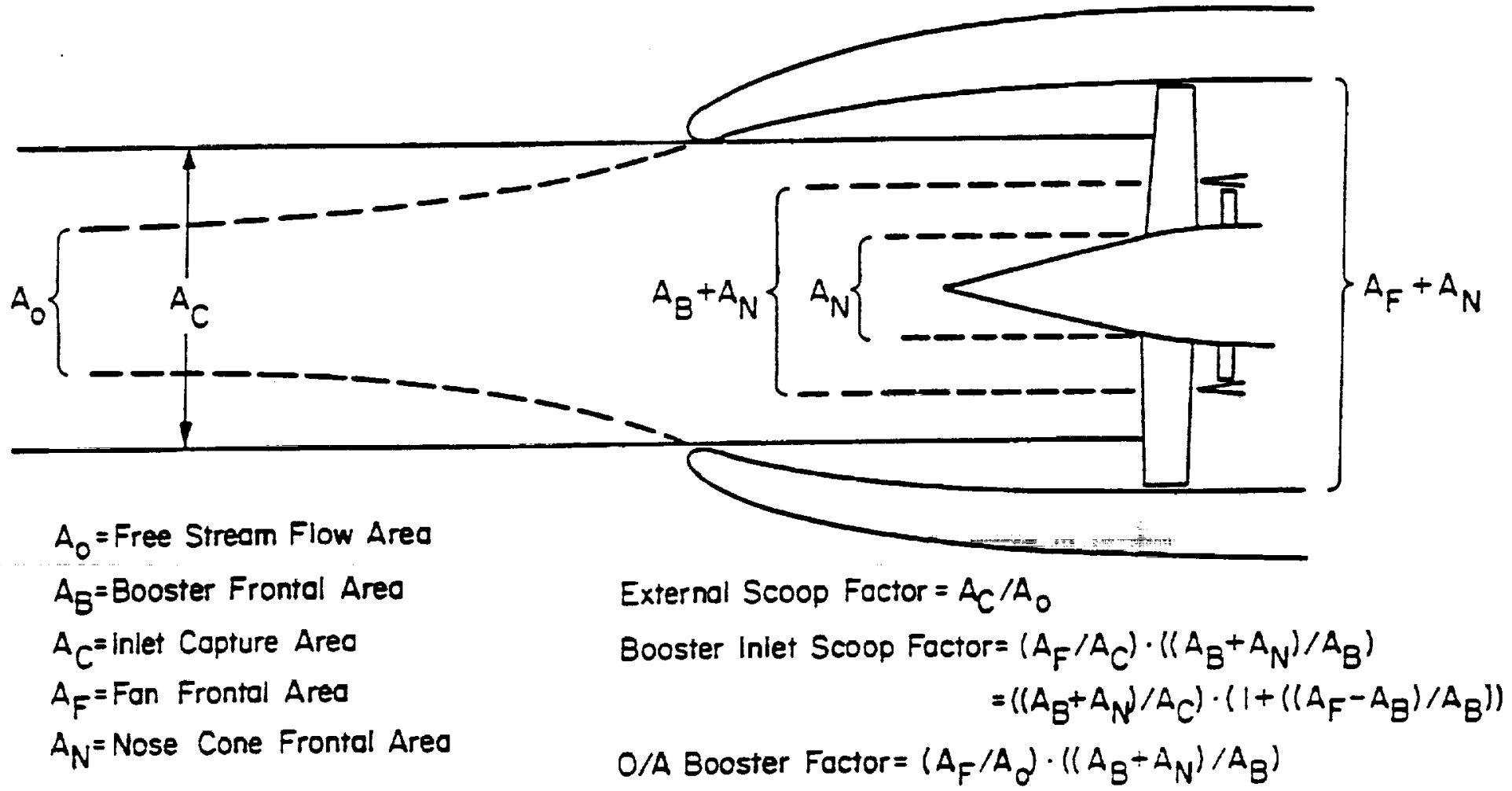

Figure 2.7.(i)

Caption on Figure 2.7.(ii) 


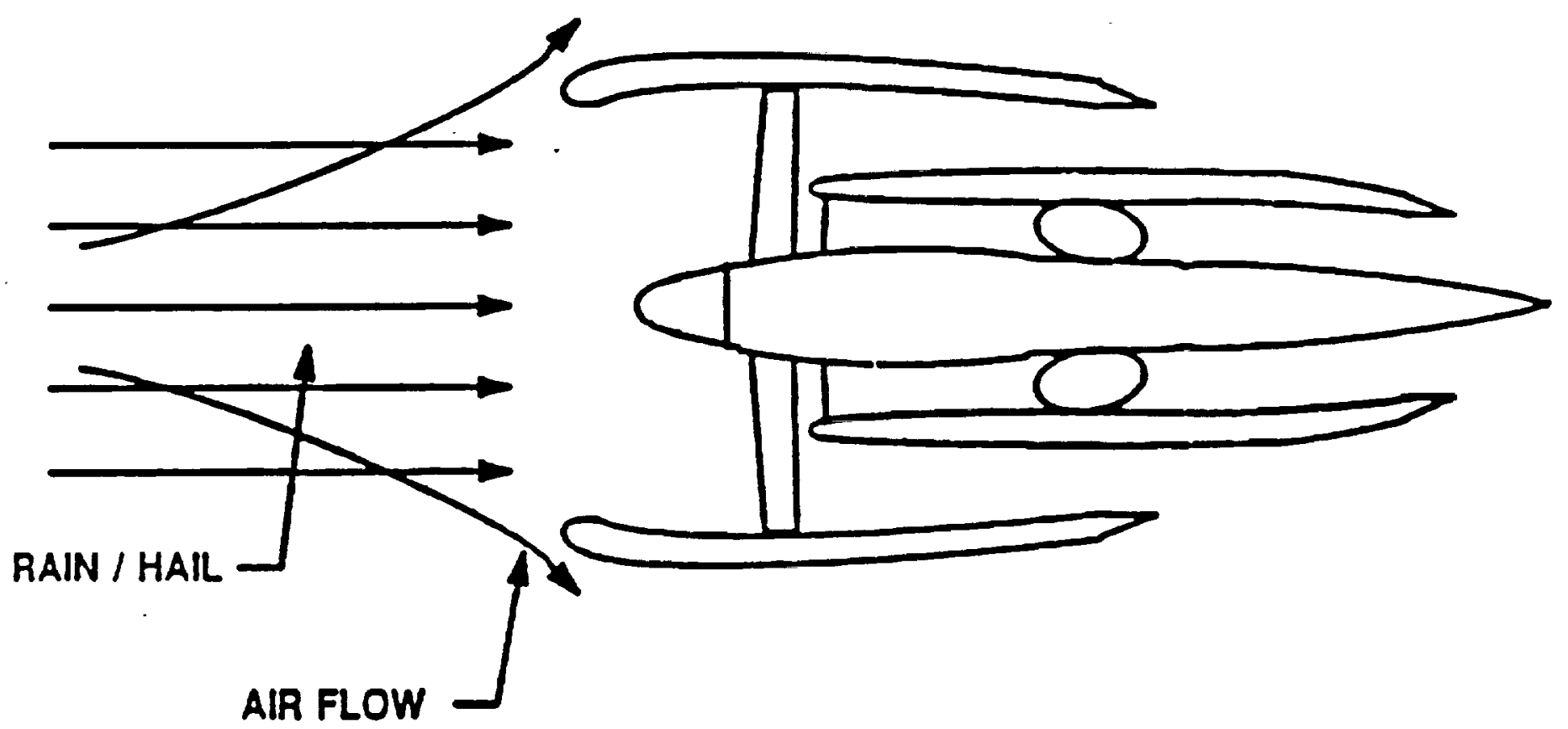

Figure 2.7.(ii)

Figure 2.7. Two Typical Definitions of Scoop Factor: (i) and (ii). 


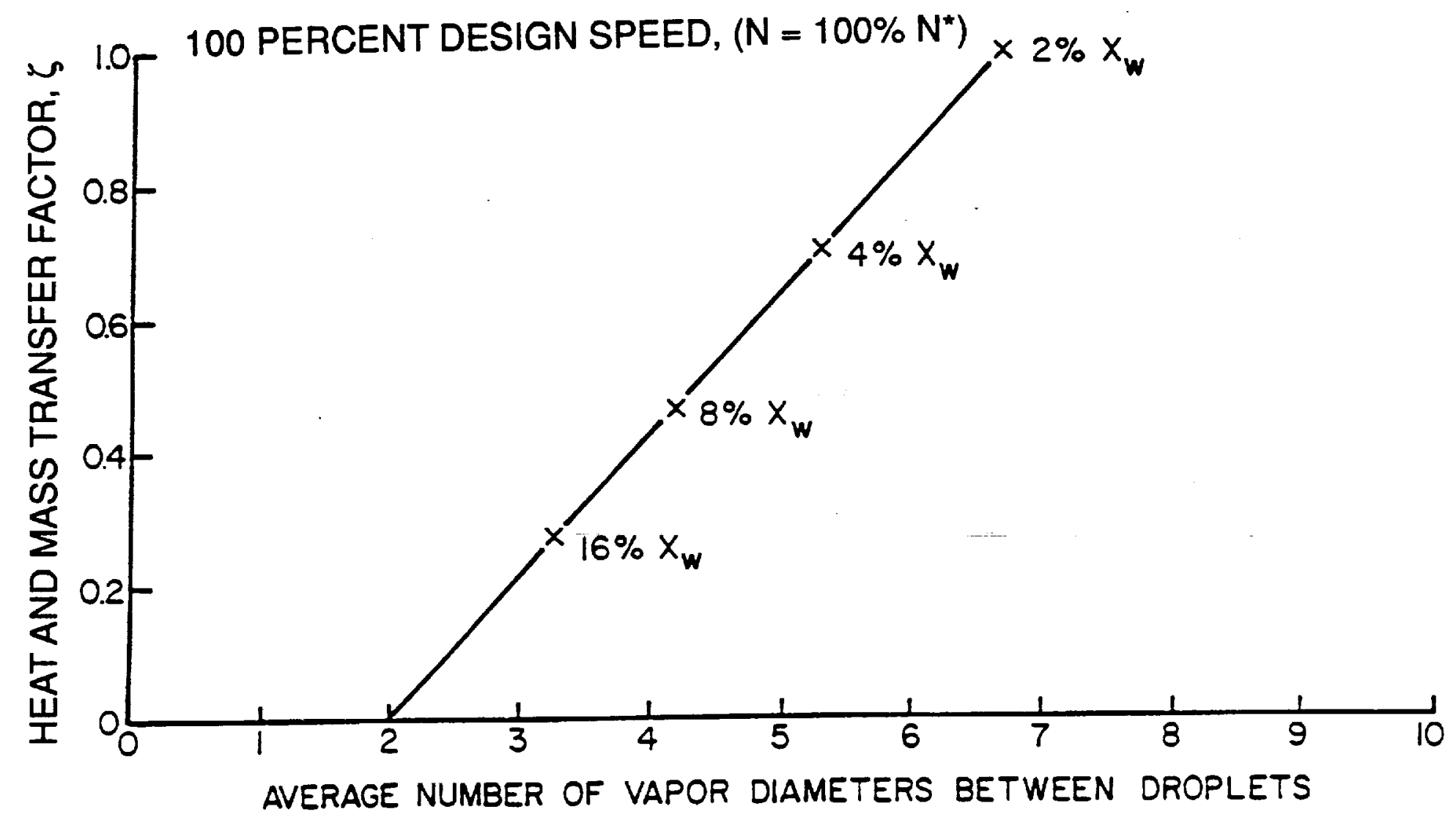

Figure 3.1. Heat and Mass Transfer Factor as a Function of Mass Fraction of Water. 


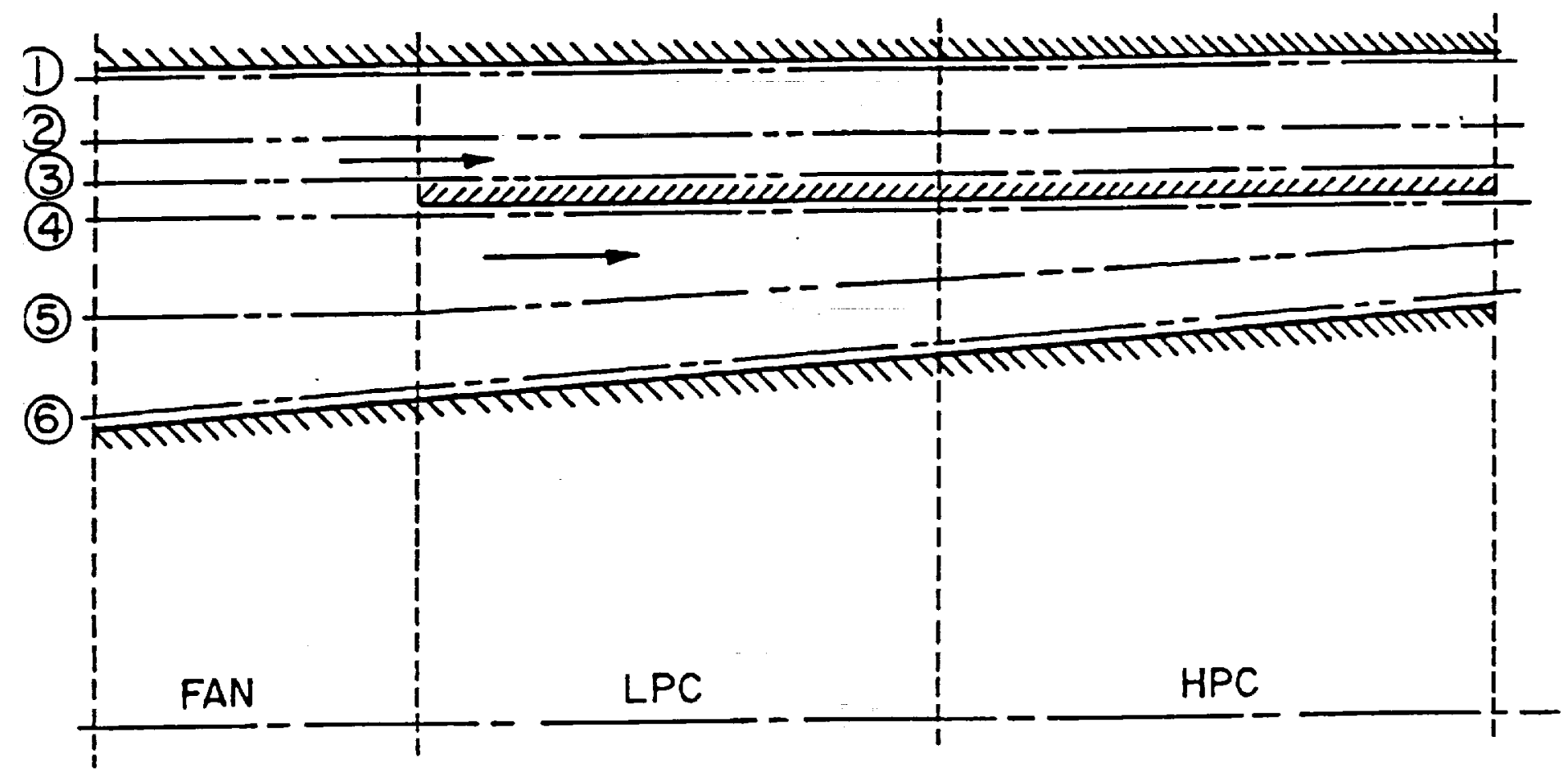

Figure 3.2. Streamtube Designation in a Fan-Compressor Unit. 


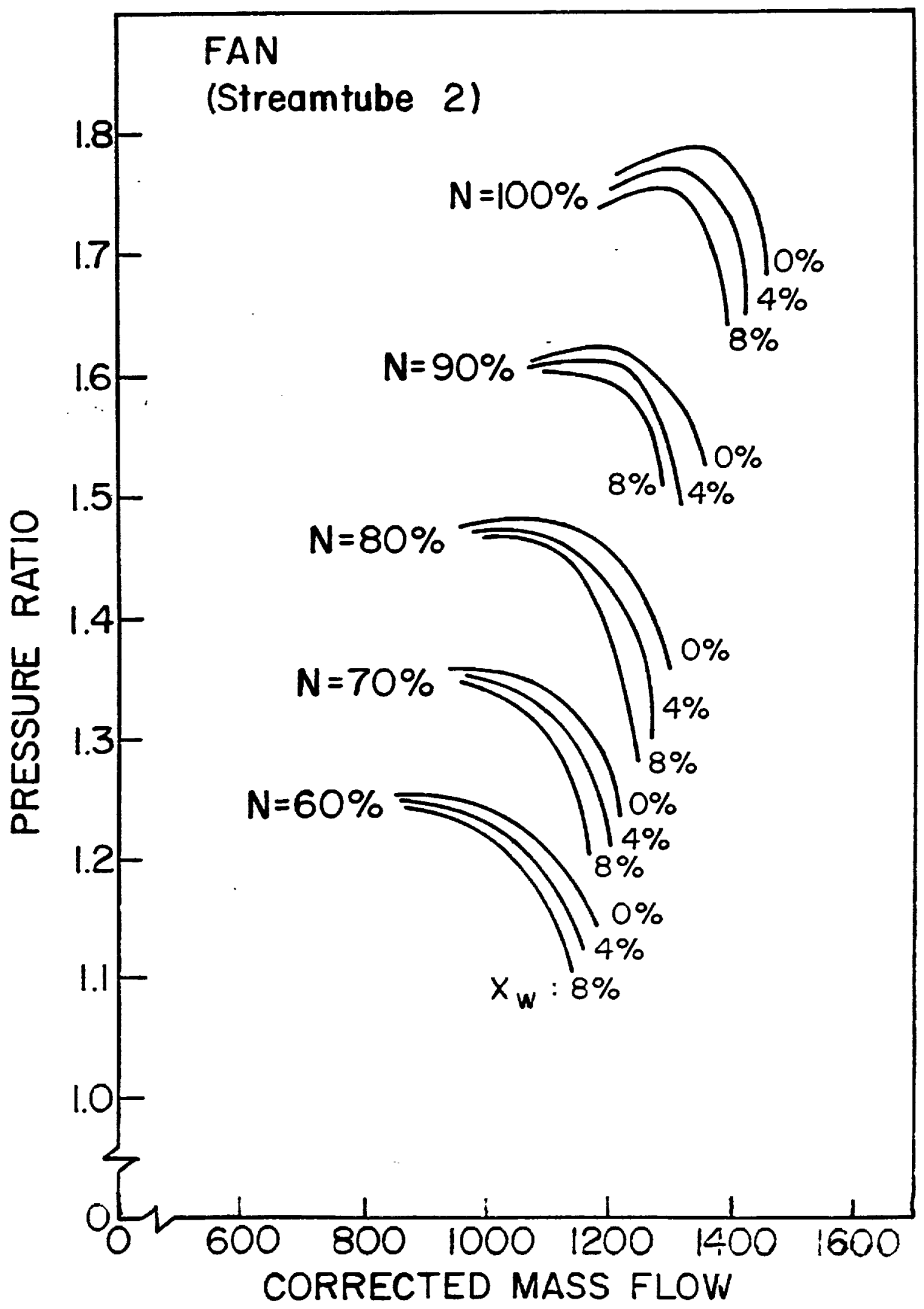

Figure 3.3. Performance of Fan Unit with respect to Streamtube 2: Pressure ratio as a function of corrected mass flow. 


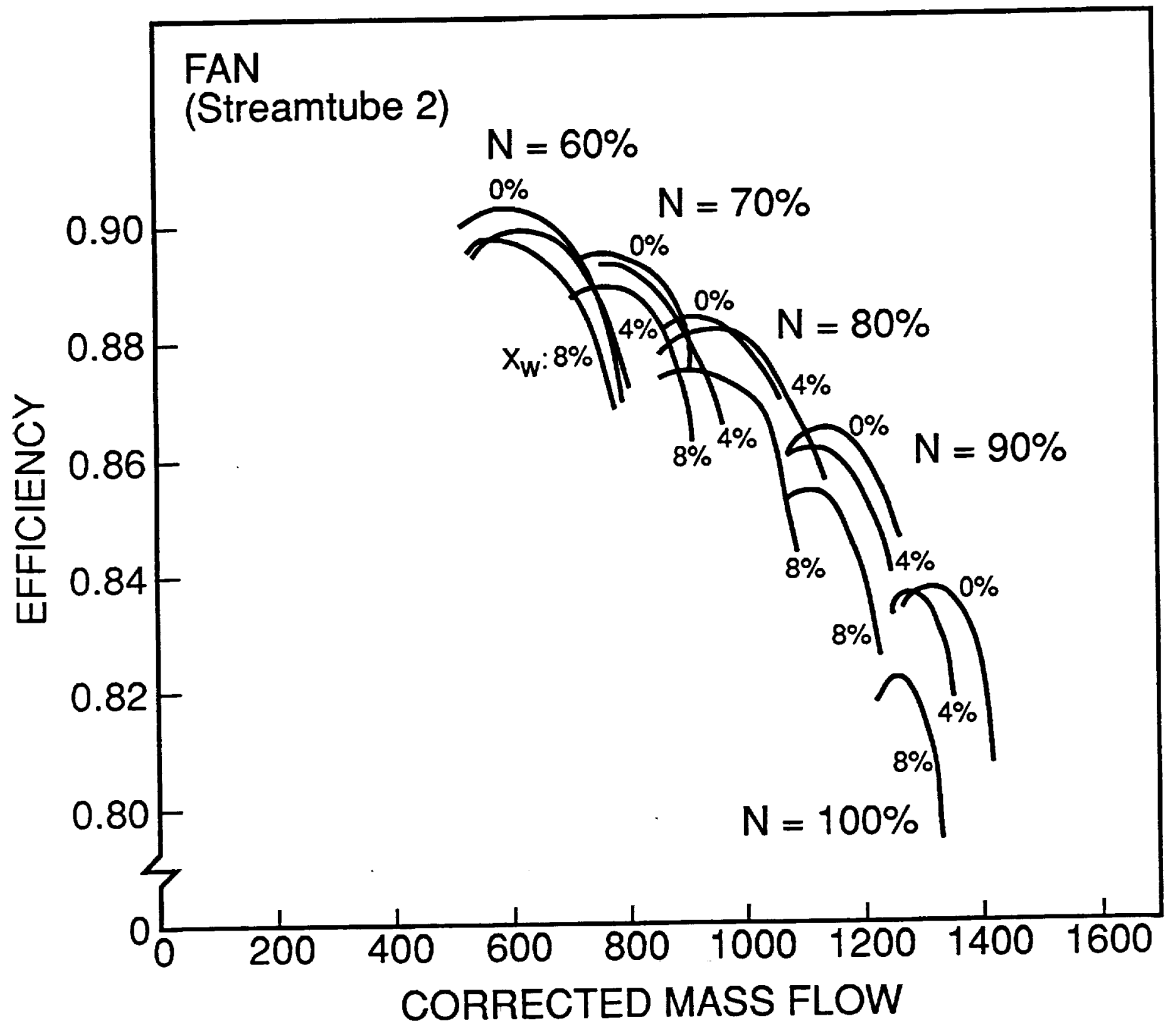

Figure 3.4. Performance of Fan Unit with respect to Streamtube 2: Efficiency as a function of corrected mass flow. 


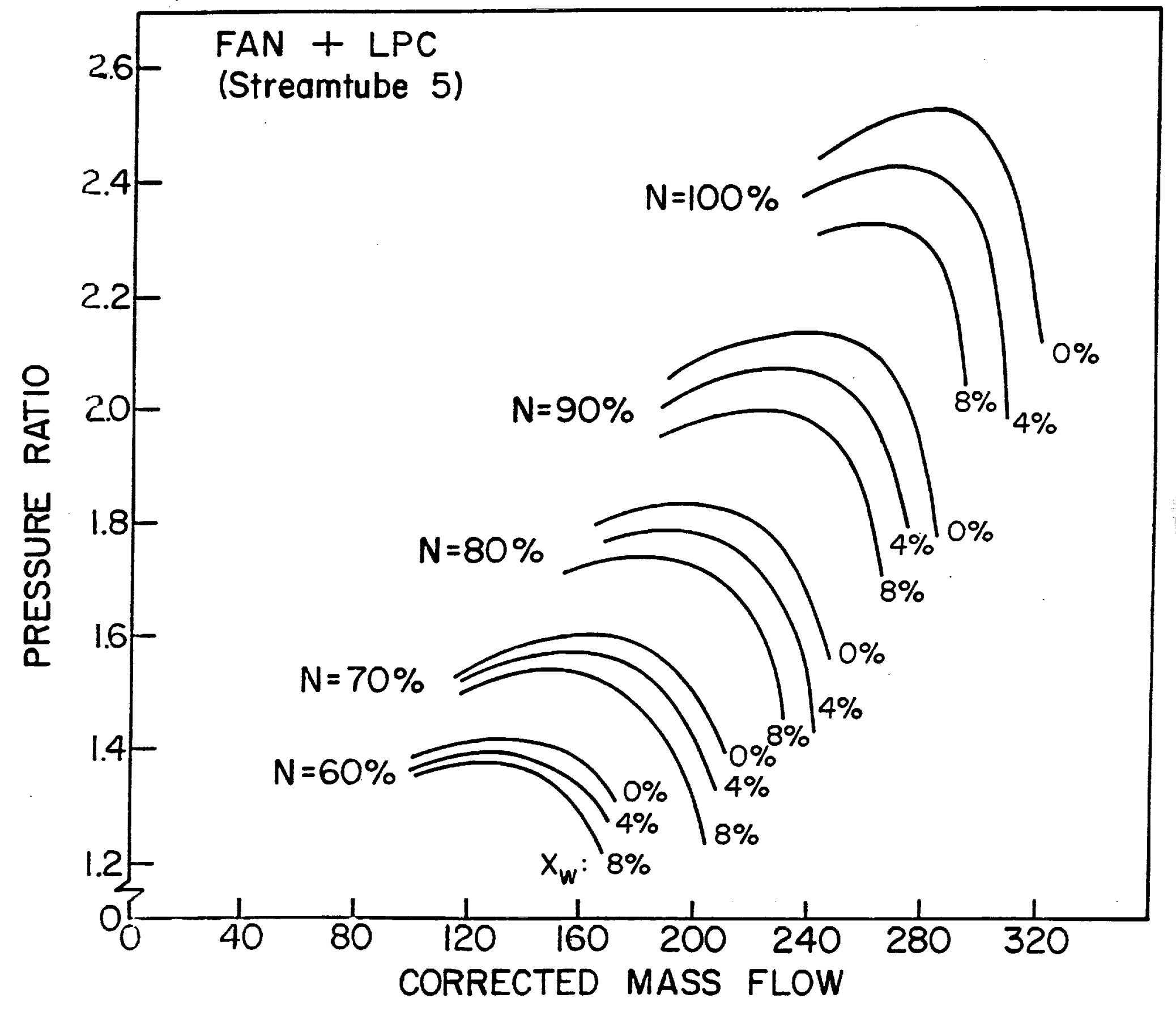

Figure 3.5. Performance of Fan-Low Pressure Compressor Unit with respect to Streamtube 5: Pressure ratio as a function of corrected mass flow. 


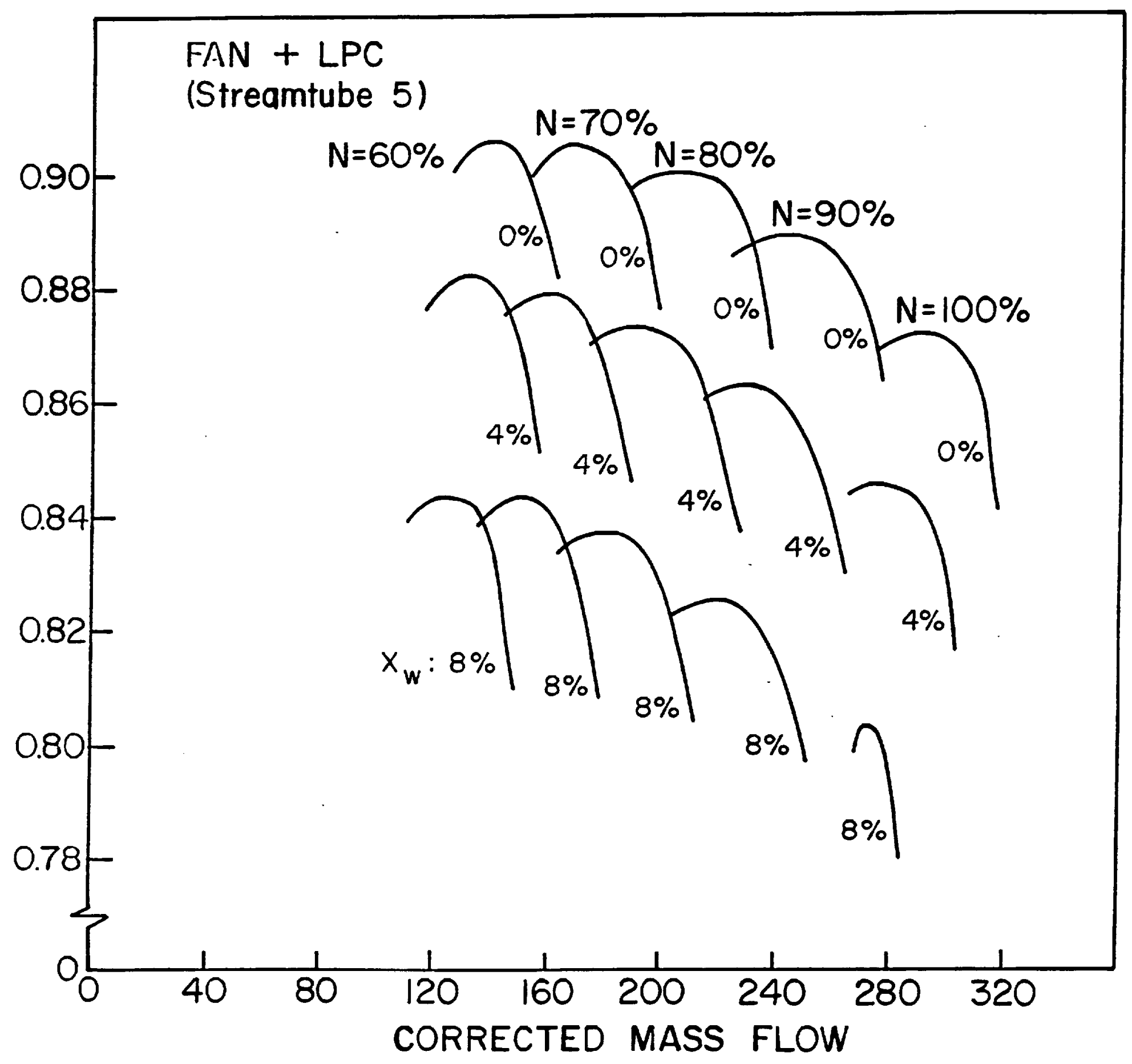

Figure 3.6. Performance of Fan-Low Pressure Compressor Unit with respect to Streamtube 5: Efficiency as a function of corrected mass flow. 


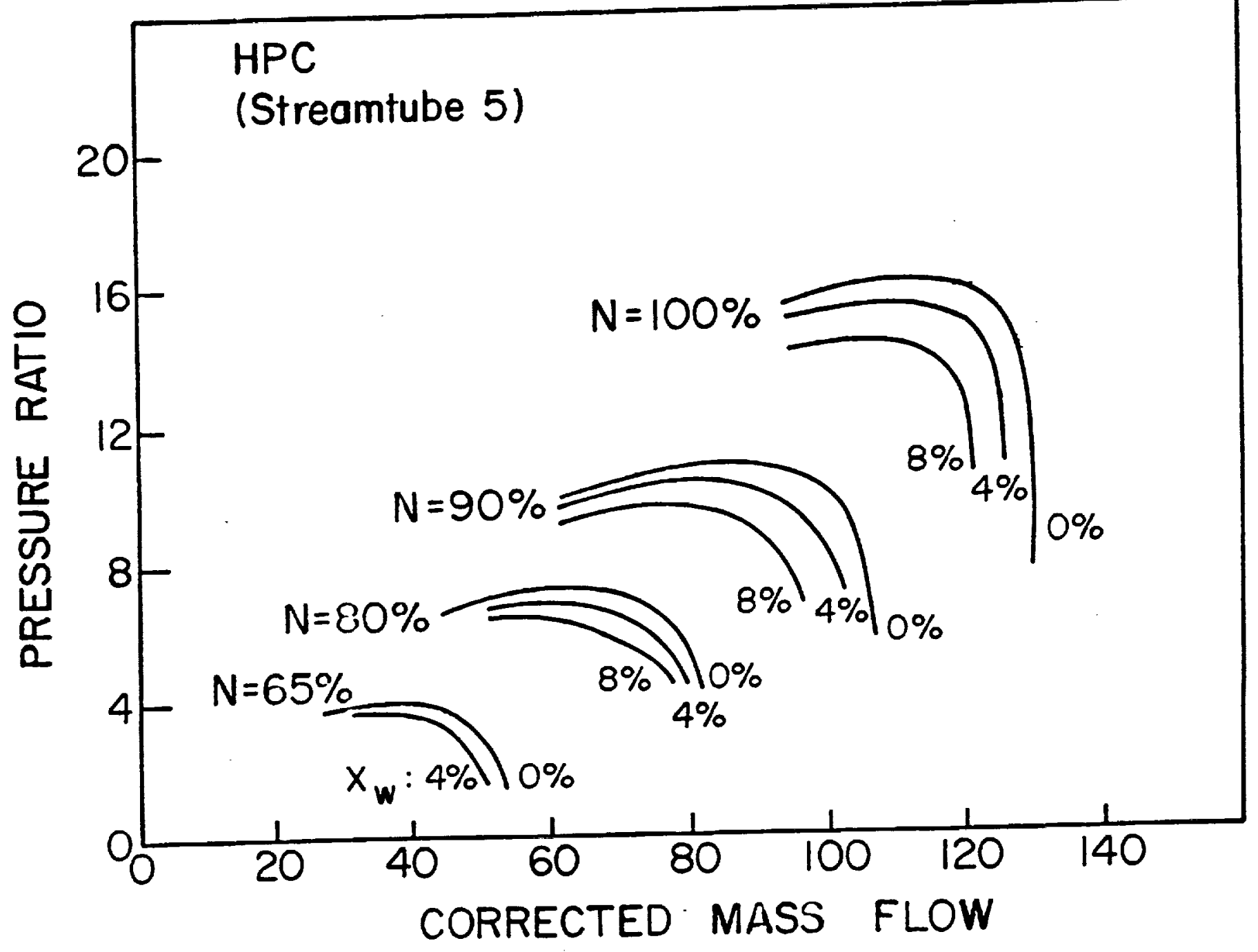

Figure 3.7. Performance of High Pressure Compressor Unit with respect to Streamtube 5: Pressure ratio as a function of corrected mass flow. 


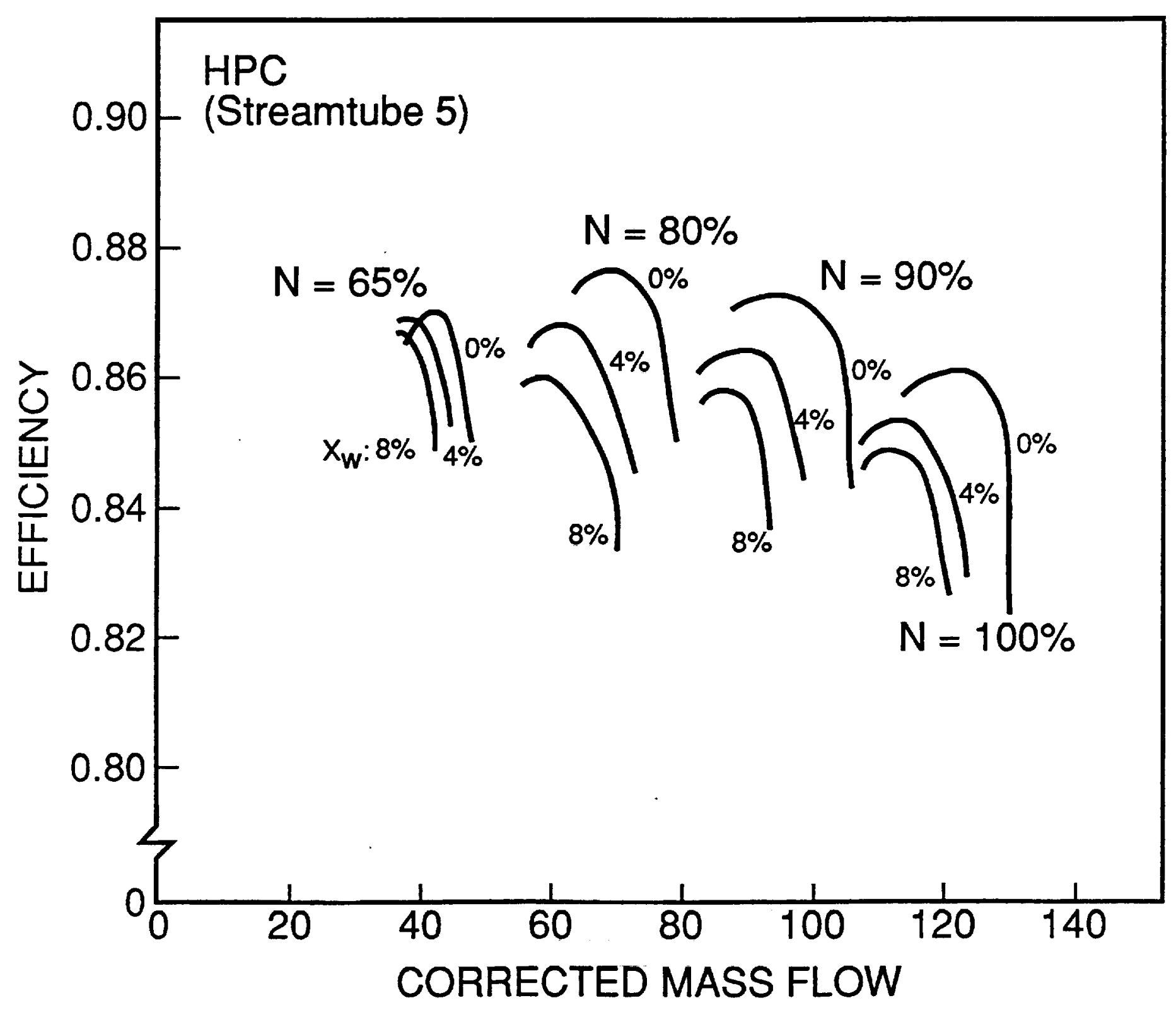

Figure 3.8. Performance of High Pressure Compressor Unit with respect to Streamtube 5: Efficiency as a function of corrected mass flow. 


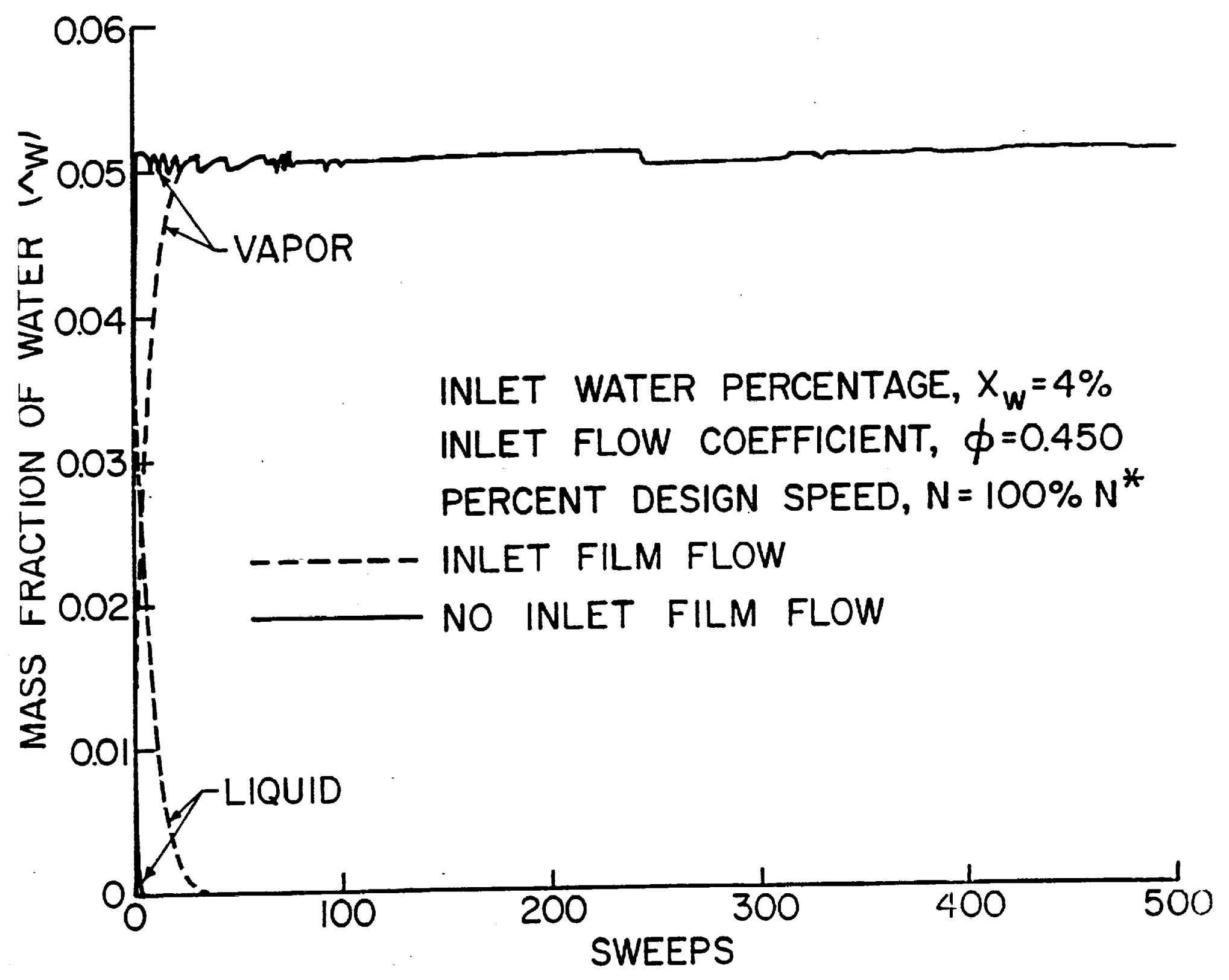

Figure 3.9. Transient Performance of High Pressure Compressor Unit: Mass fraction of water at exit stage of compressor as a function of time. 


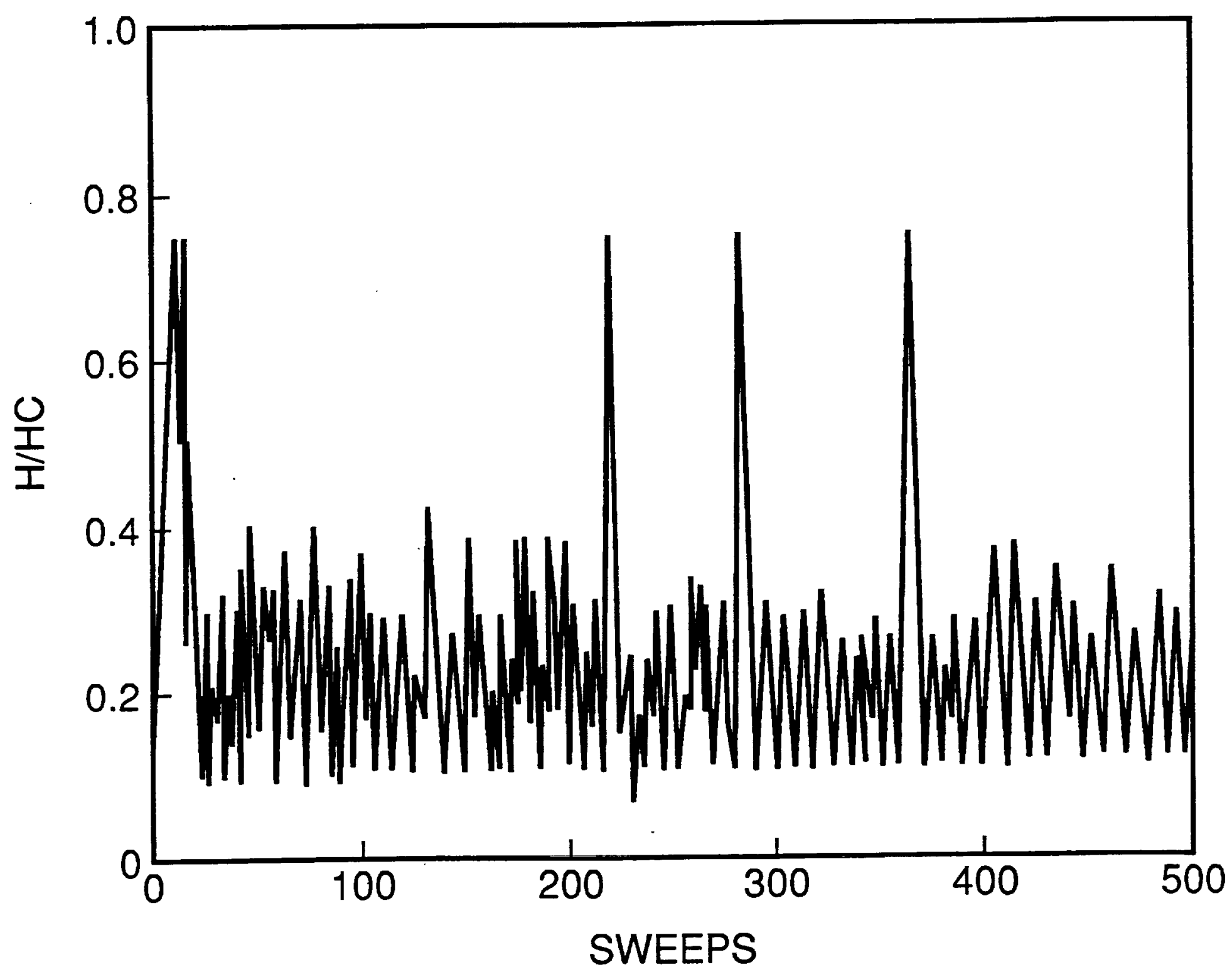

Figure 3.10. Transient Performance of High Pressure Compressor Unit: Height of Film/Height of Clearance at exit stage of compressor, as a function of time. Operating parameters are as in Fig. 3.9. 


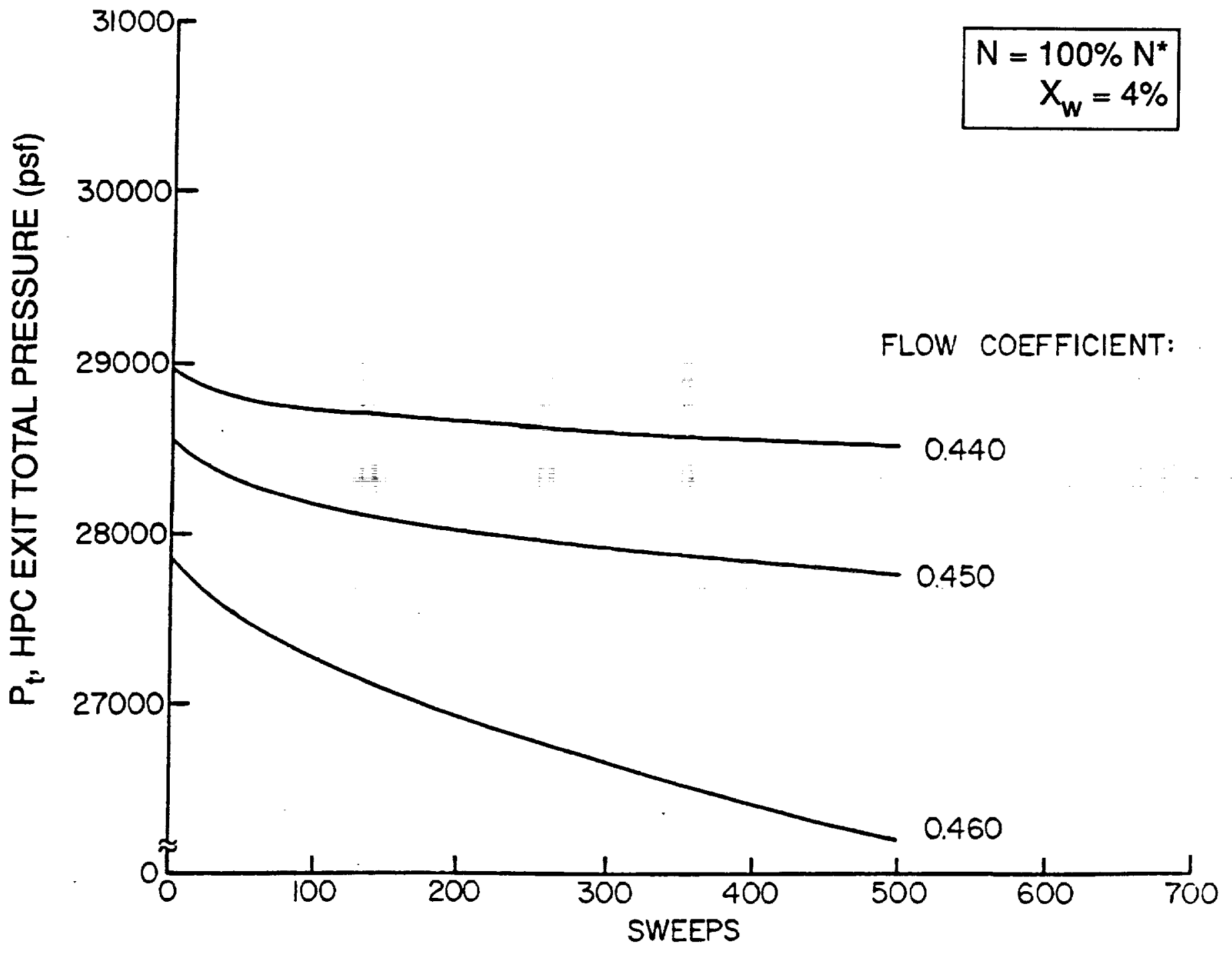

Figure 3.11. Transient Performance of High Pressure Compressor Unit: Exit total pressure as a function of time. Operating parameters as in Fig. 3.9. 


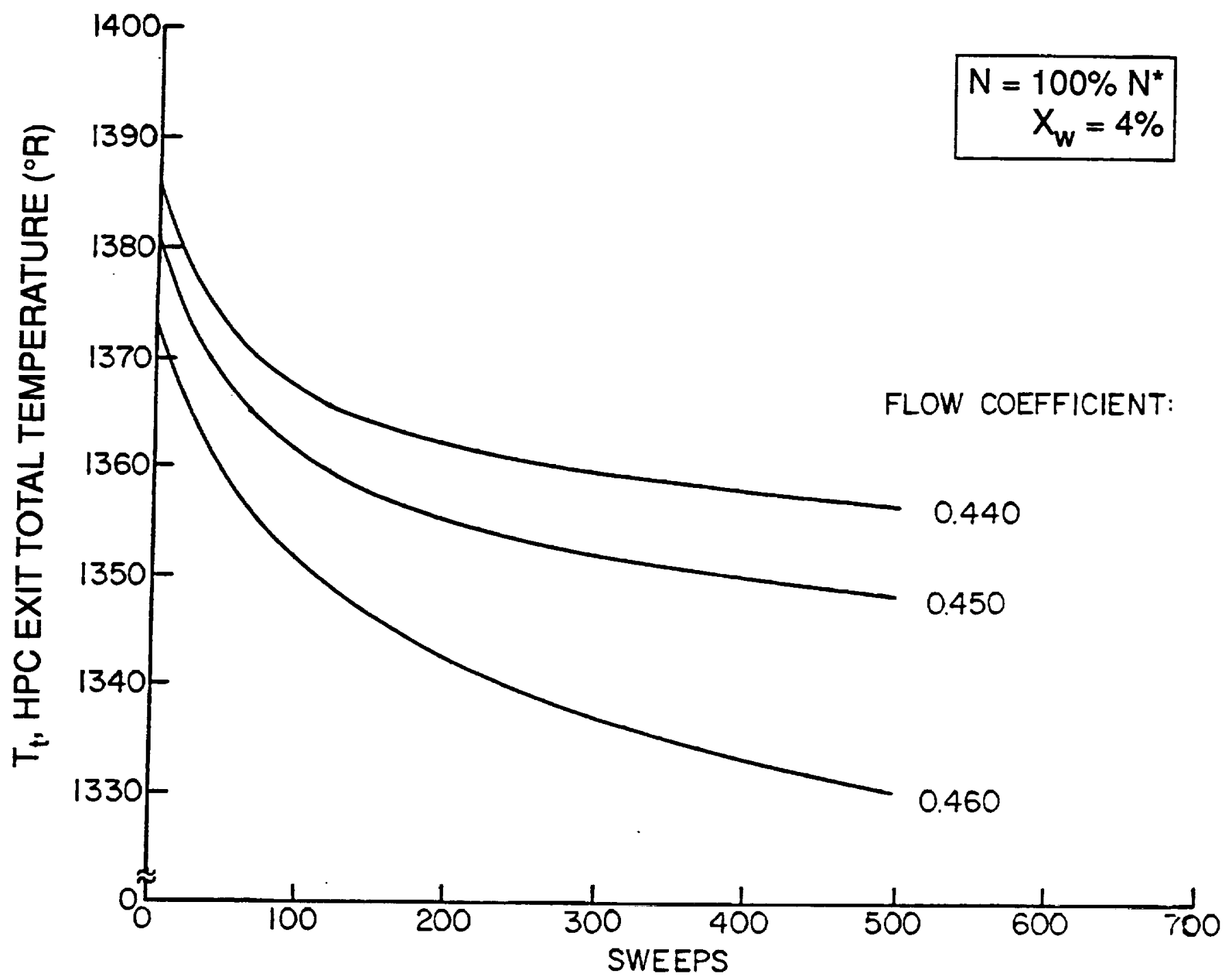

Figure 3.12. Transient Performance of High Pressure Compressor Unit: Exit total temperature as a function of time. Operating parameters as in Fig. 3.9. 


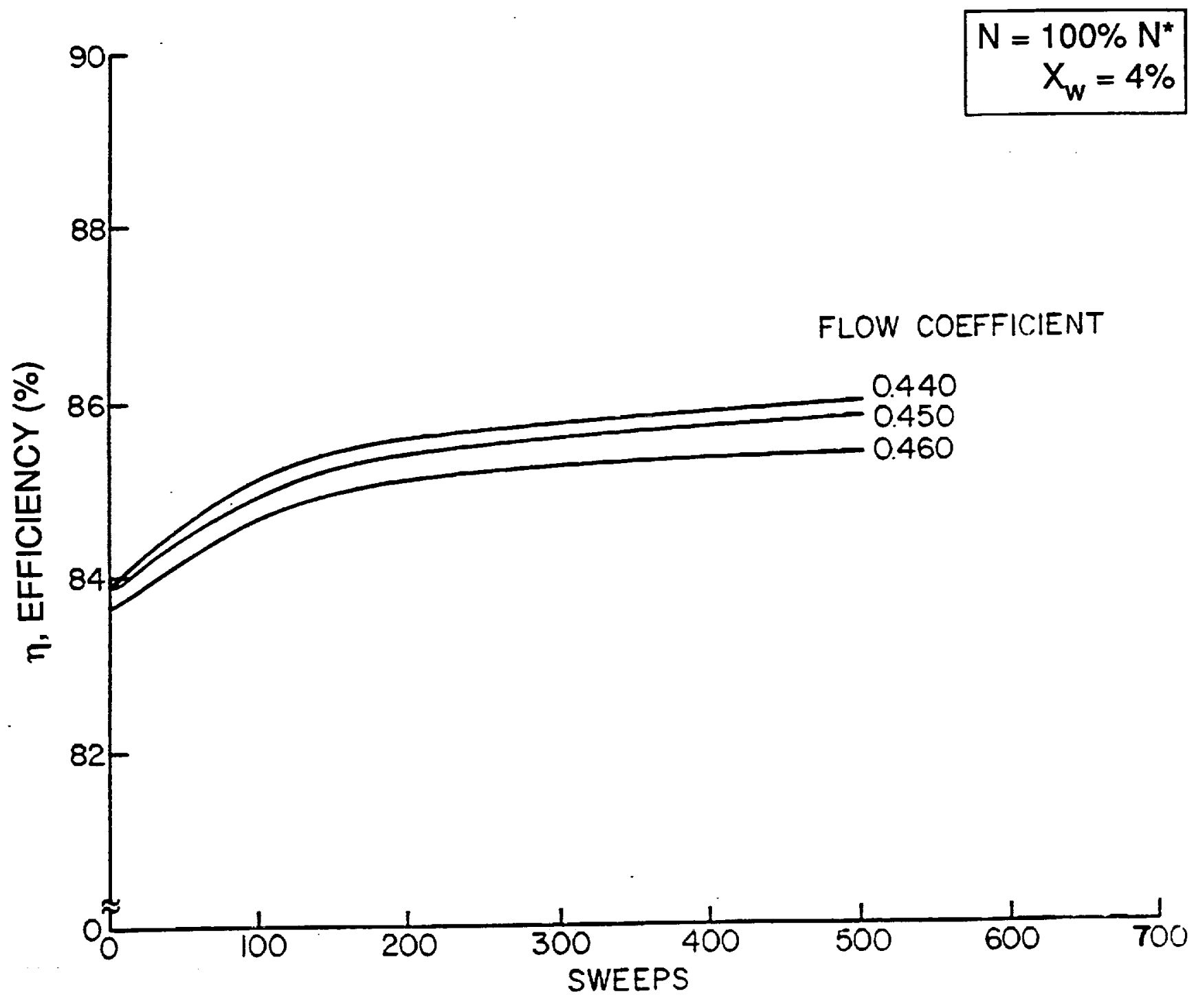

Figure 3.13. Transient Performance of High Pressure Compressor Unit: Efficiency as a function of time. Operating parameters as in Fig. 3.9. 


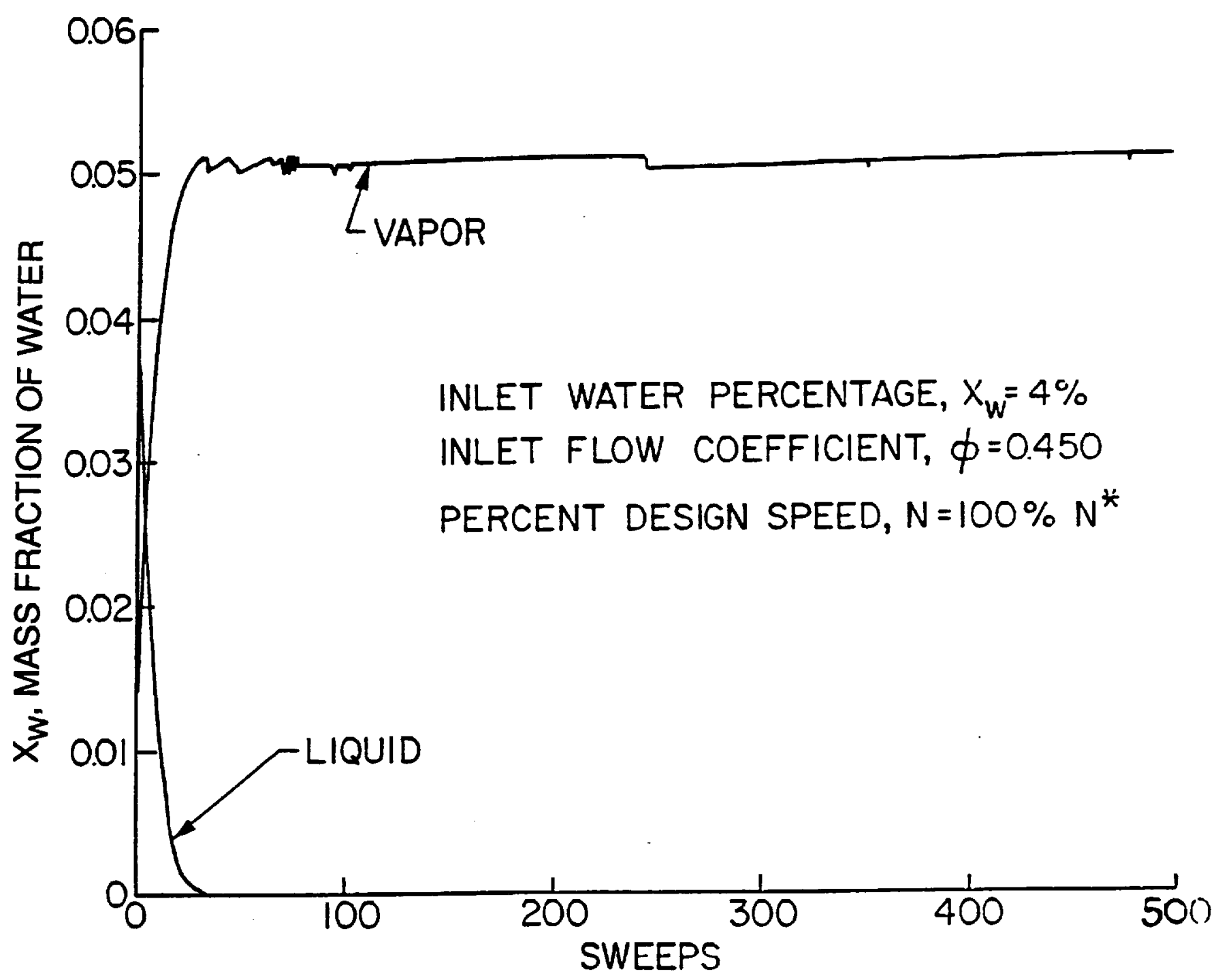

Figure 3.14. Transient Performance of High Pressure Compressor Unit: Mass fraction of water at an intermediate stage as a function of time. Operating parameters same as in Fig. 3.9. 


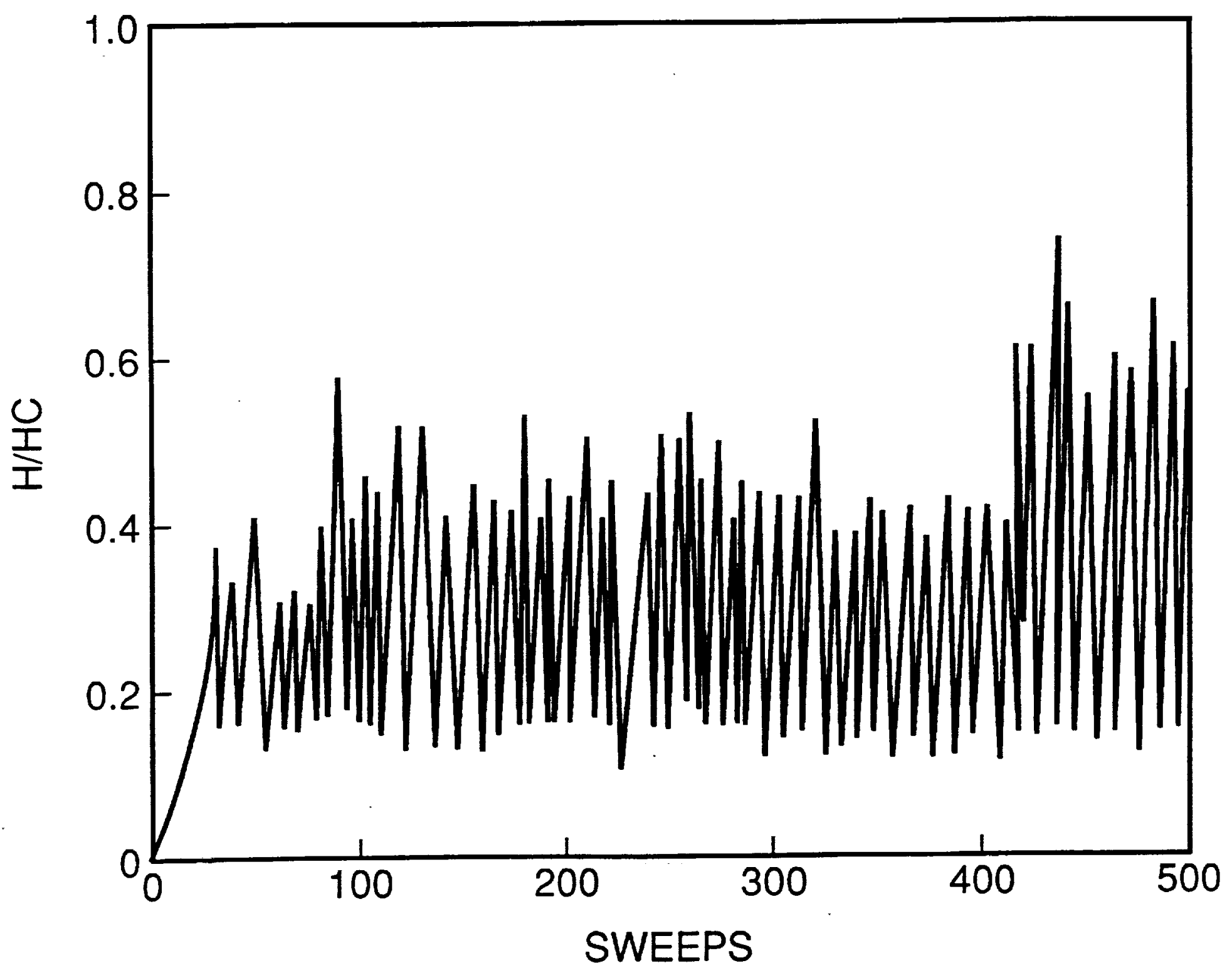

Figure 3.15. Transient Performance of High Pressure Compressor: Height of film over height of clearance of an intermediate stage as a function of time. Operating parameters same as in Fig. 3.9. 


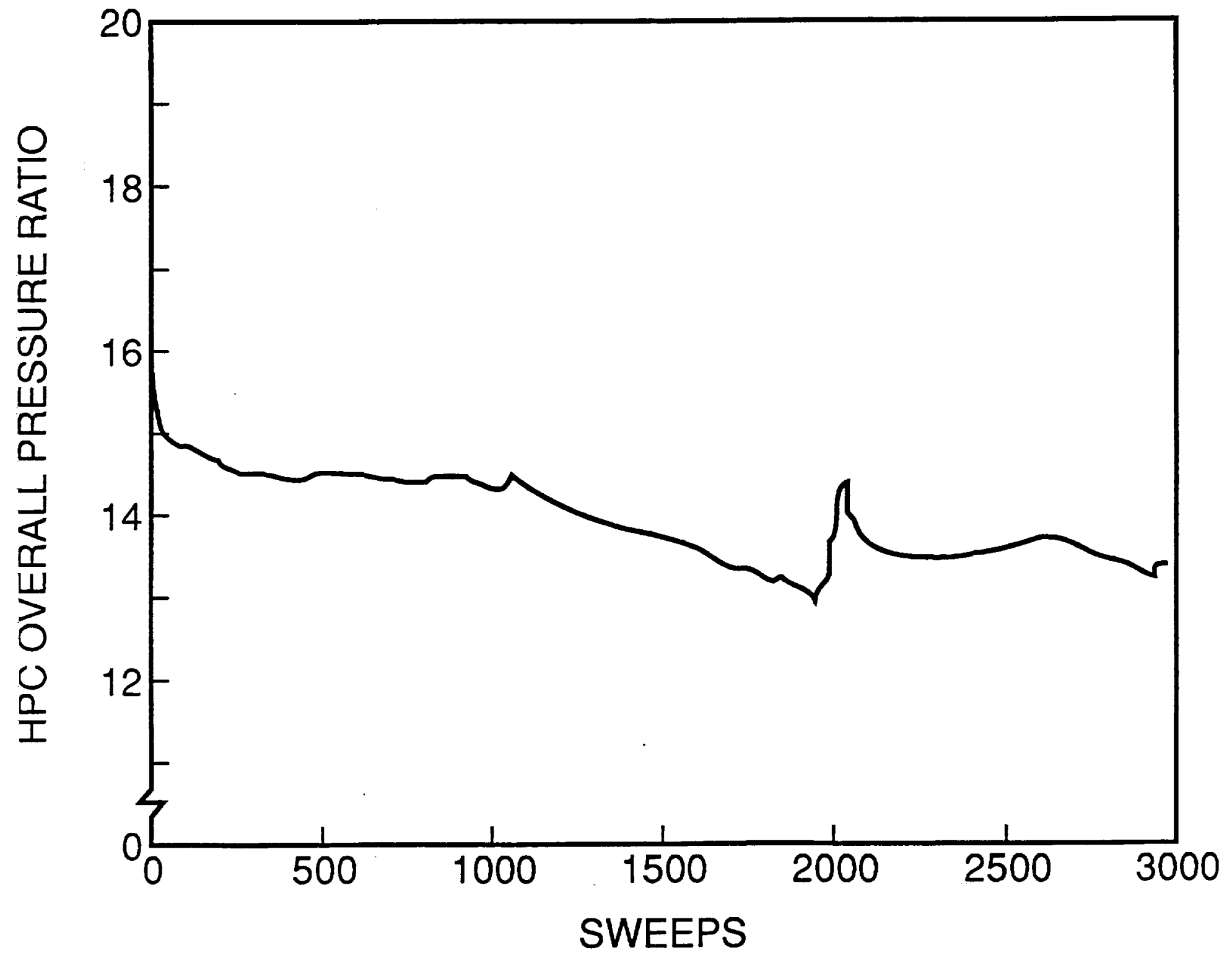

Figure 3.16. Transient Performance of High Pressure Compressor: Overall pressure ratio as a function of time. Operating parameters same as in Fig. 3.9. 


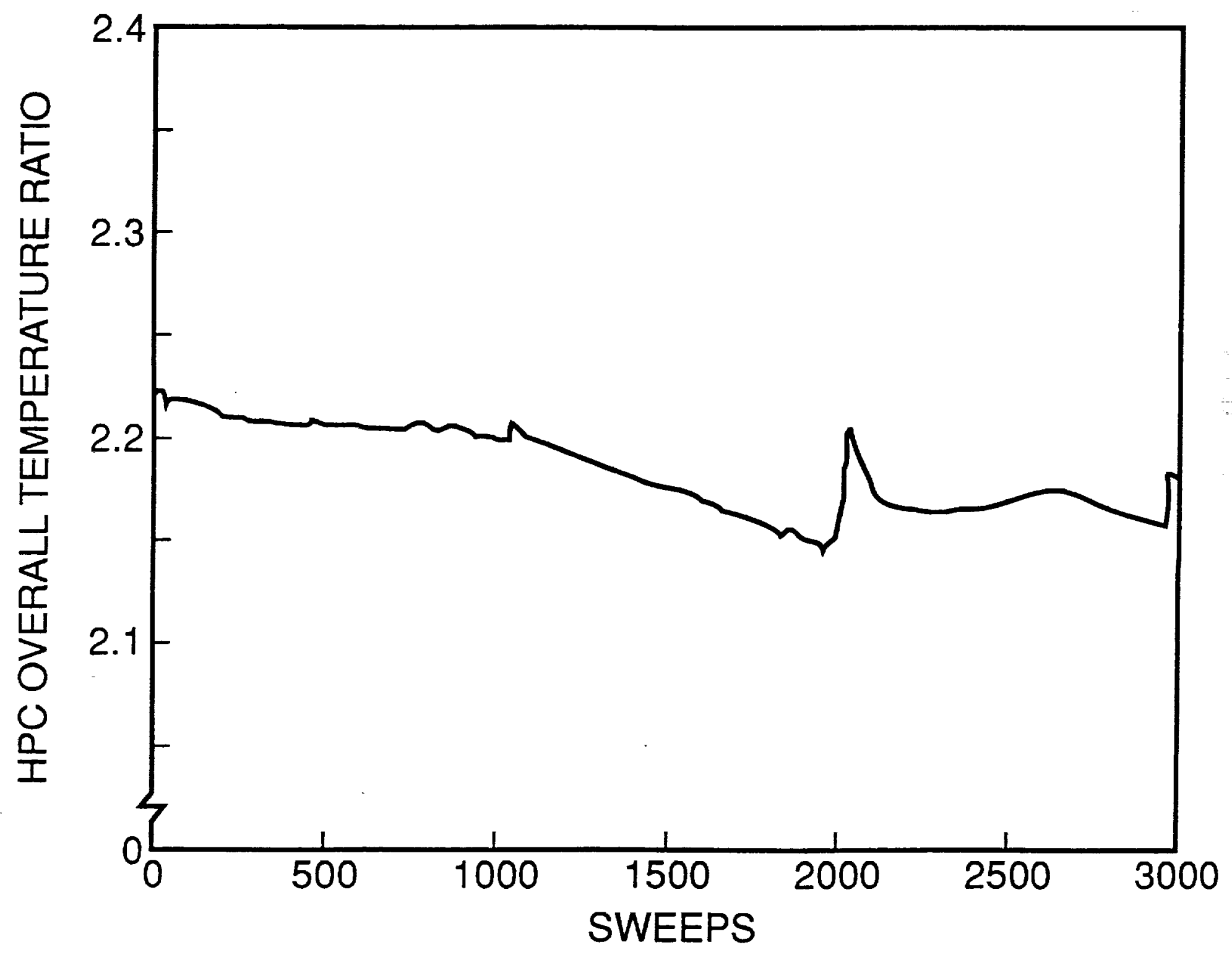

Figure 3.17. Transient Performance of High Pressure Compressor: Overall temperature ratio as a function of time. Operating parameters same as in Fig. 3.9. 


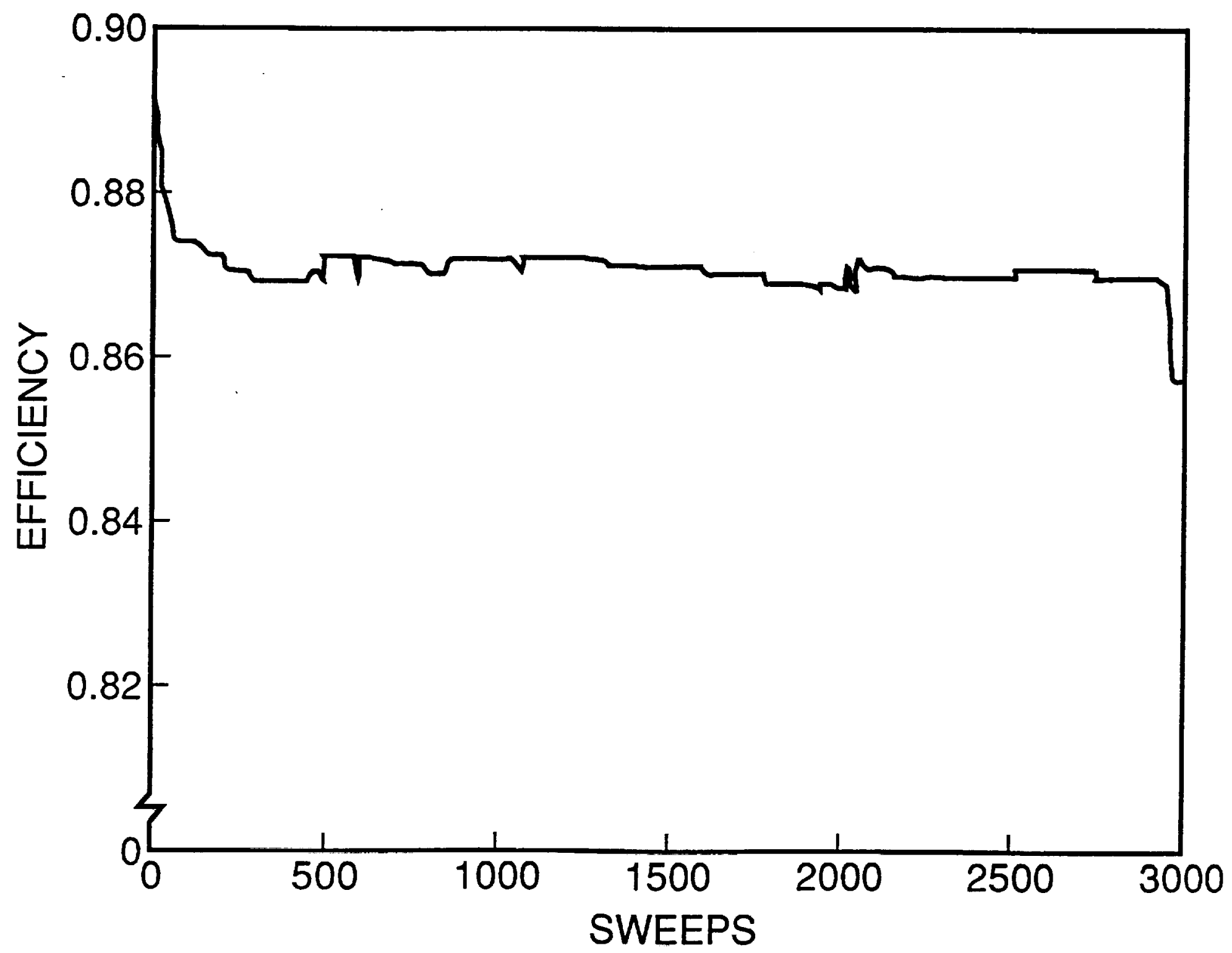

Figure 3.18. Transient Performance of High Pressure Compressor: Efficiency as a function of time. Operating parameters as in Fig. 3.9. 


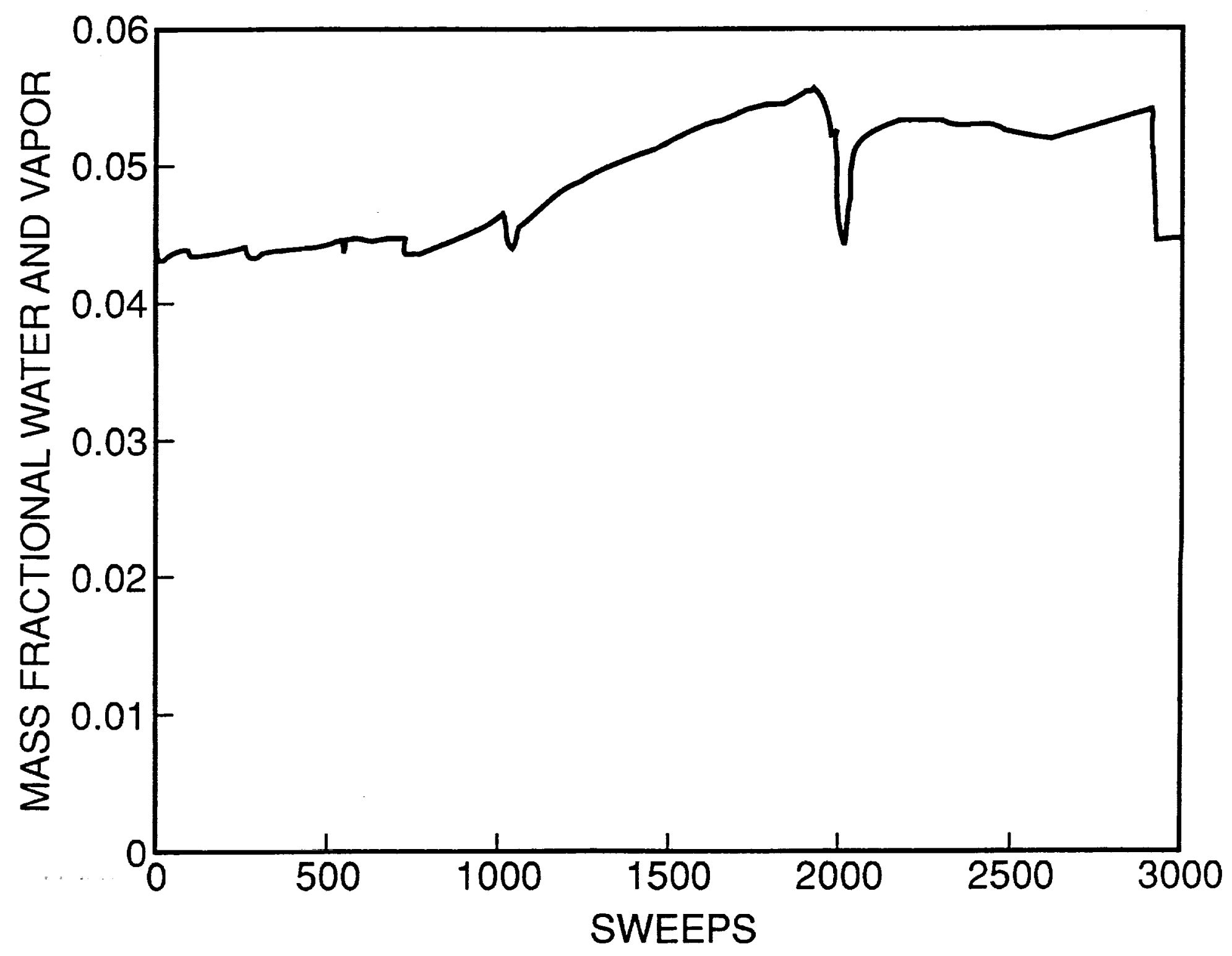

Figure 3.19. Transient Performance of High Pressure Compressor: Mass fraction of water and vapor. Operating parameters as in Fig. 3.9 . 


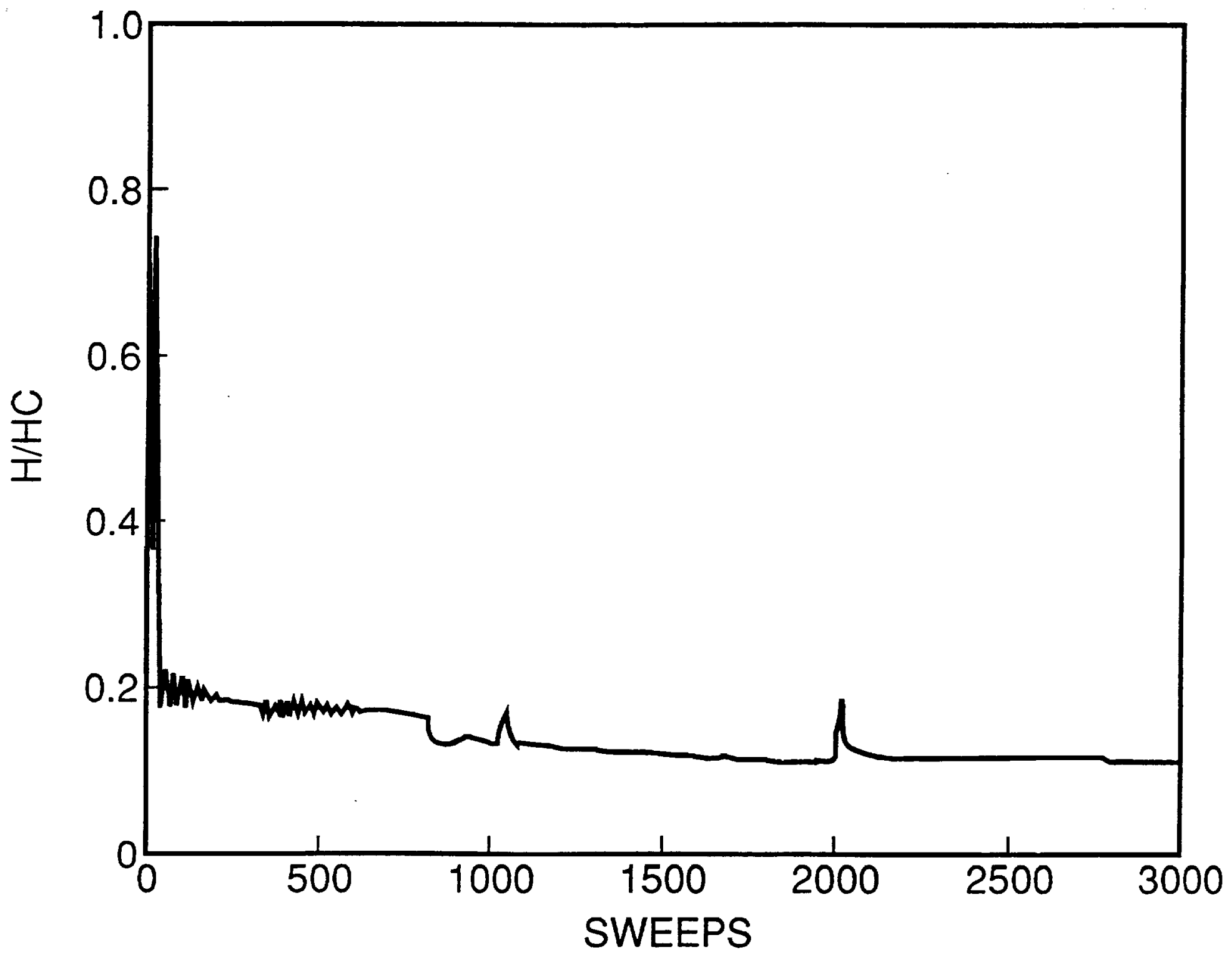

Figure 3.20. Transient Performance of High Pressure Compressor: Height of film over height of clearance as a function of time. Operating parameters as in Fig. 3.9. 


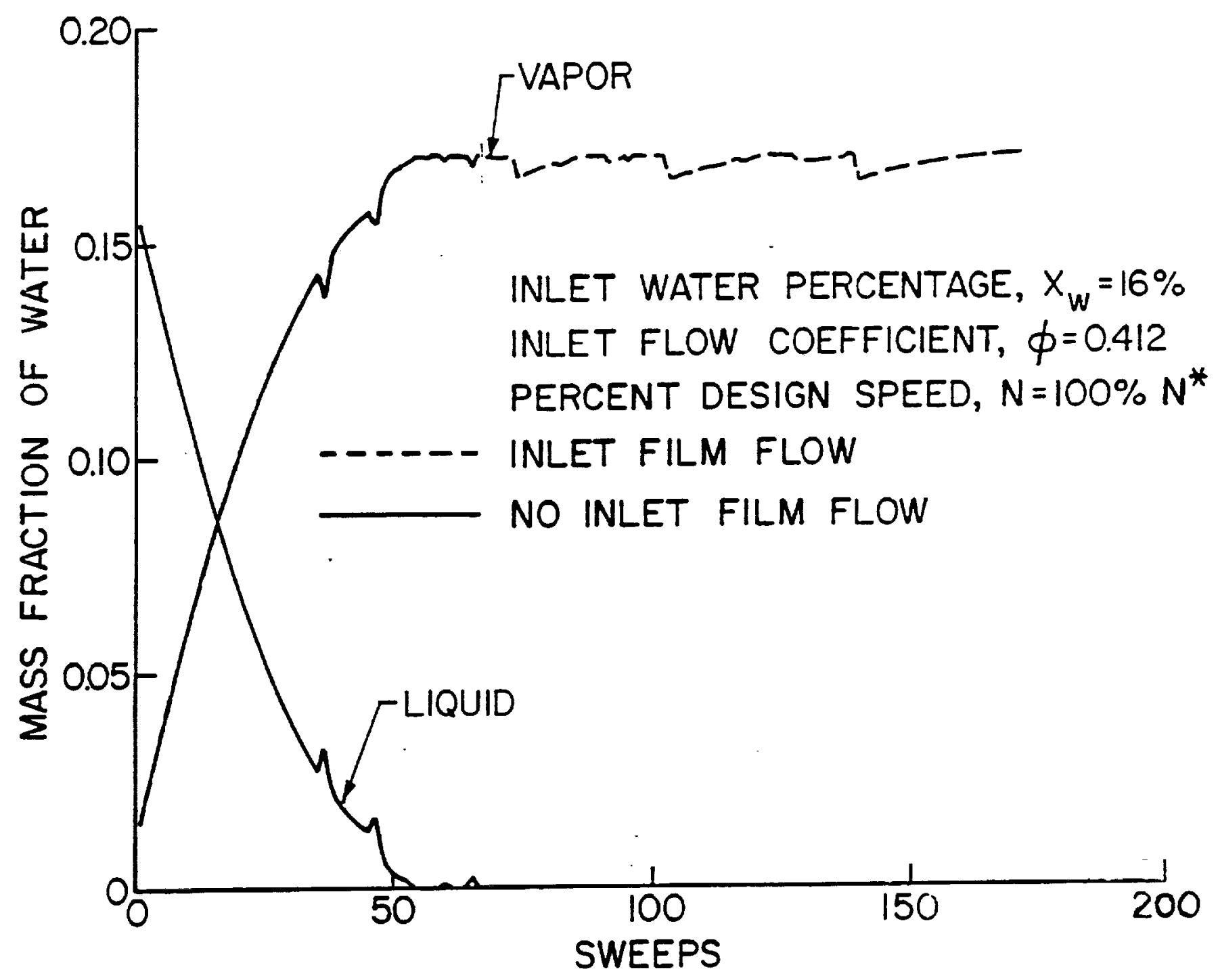

Figure 3.21. Transient Performance of High Pressure Compressor: Mass fraction of water (liquid and vapor) as a function of time. 


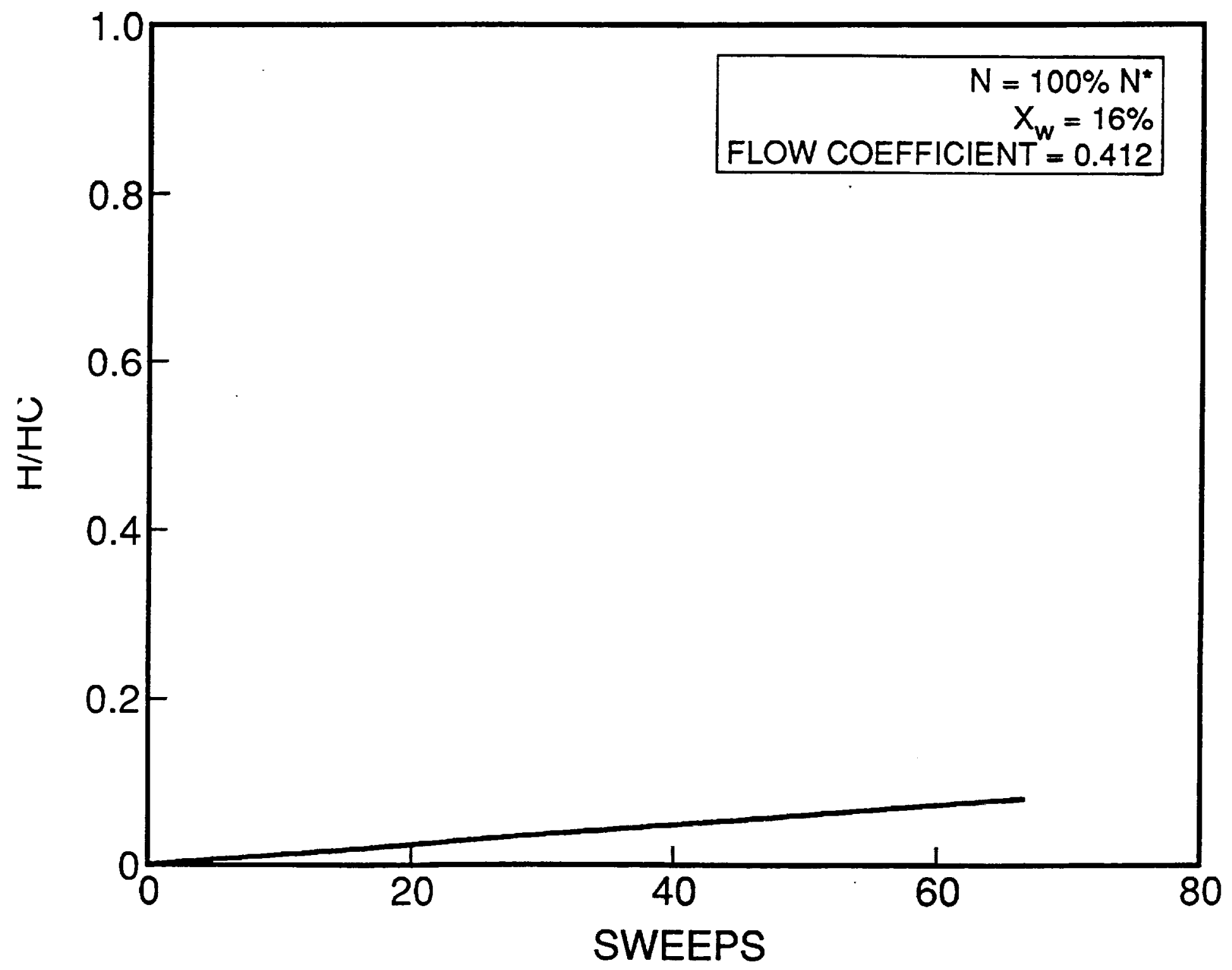

Figure 3.22. Transient Performance of High Pressure Compressor: Height of film over height of clearance as a function of time. Operating parameters as in Fig. 3.1. 


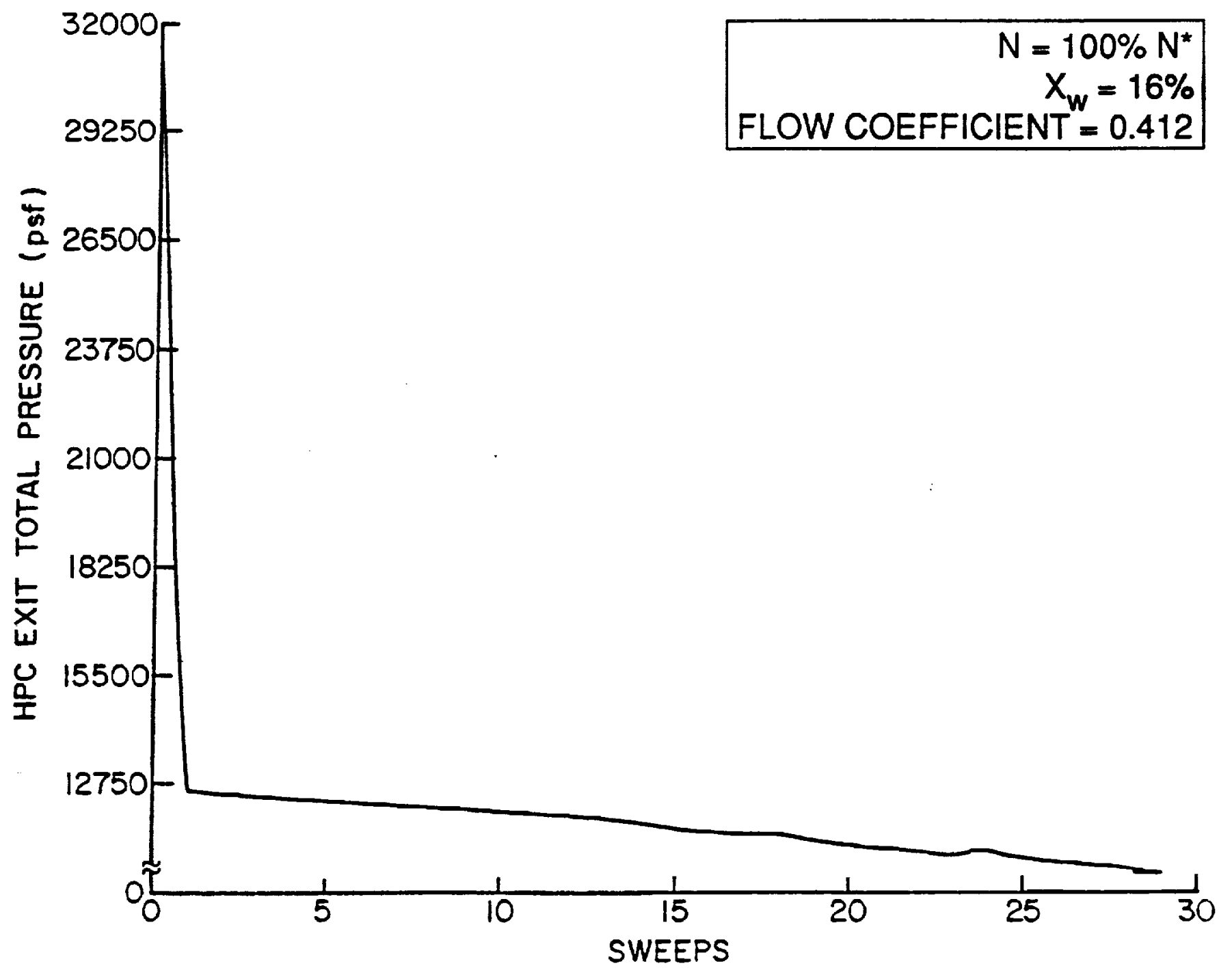

Figure 3.23. Transient Performance of High Pressure Compressor: Exittotal pressure as a function of time. Operating parameters as in Fig. 3.21. 


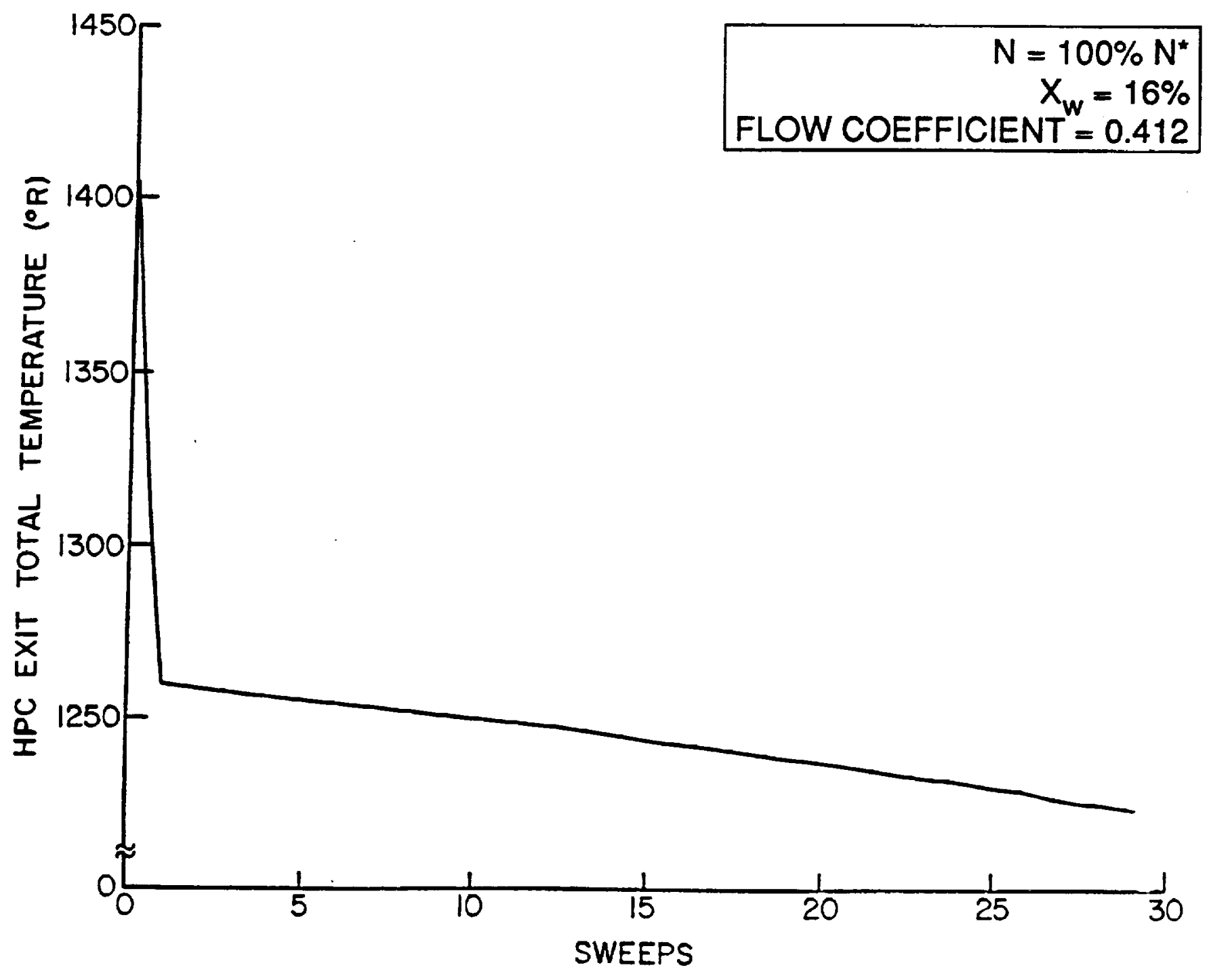

Figure 3.24. Transient Performance of High Pressure Compressor: Exit temperature as a function of time. Operating parameters as in Fig. 3.21. 


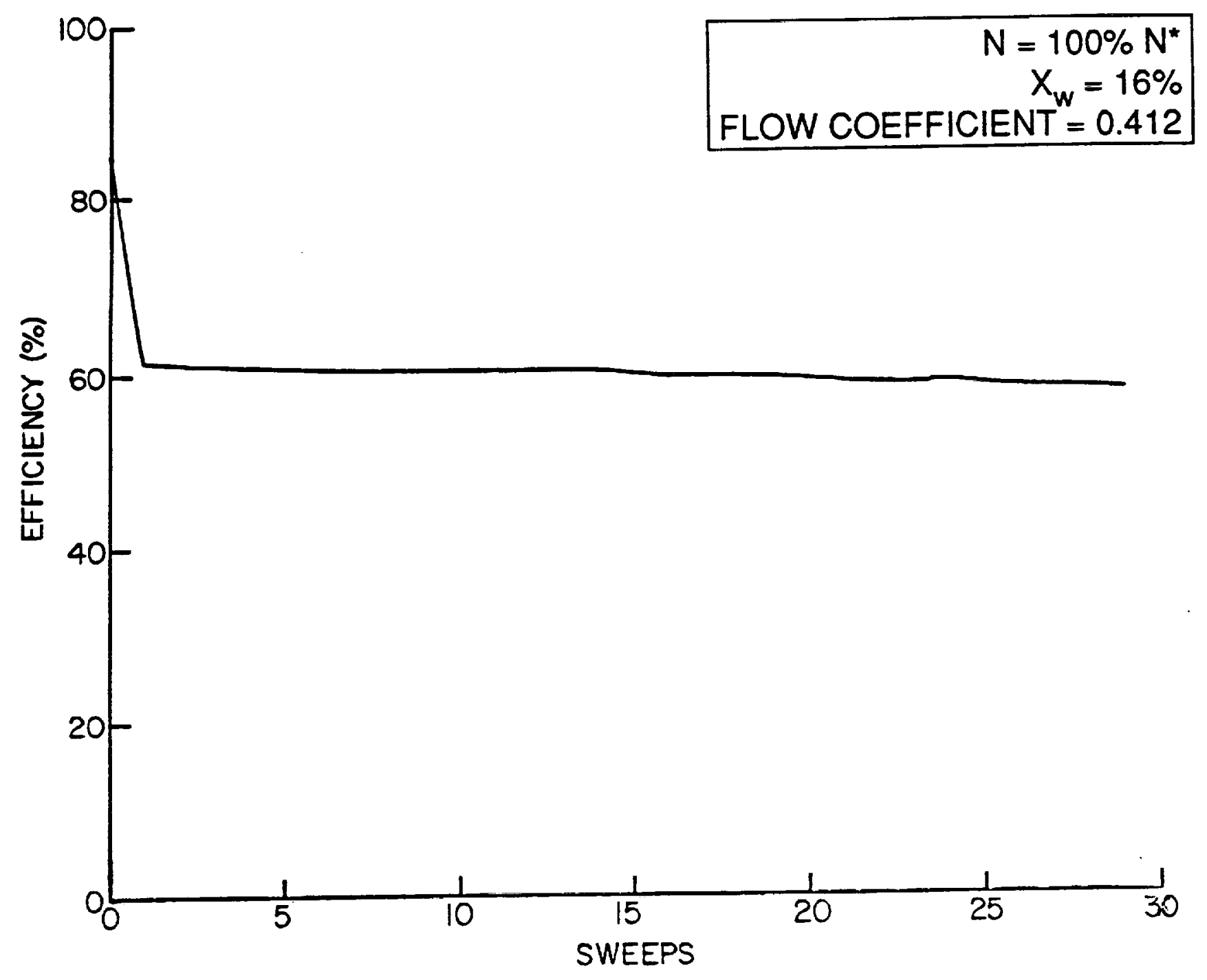

Figure 3.25. Transient Performance of High Pressure Compressor: Efficiency as a function of time. Operating parameters as in Fig. 3.21. 


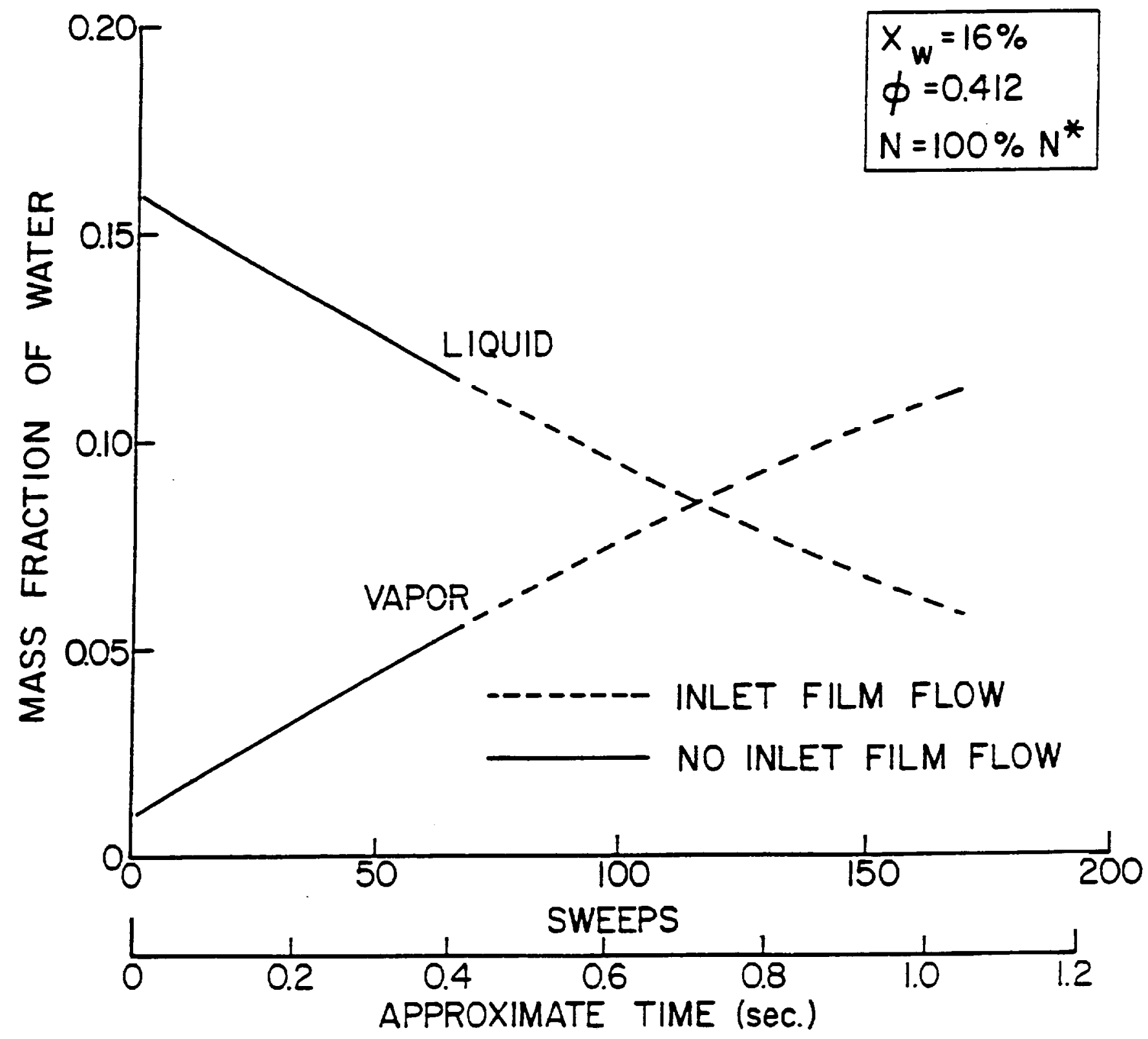

Figure 3.26. Transient Performance of High Pressure Compressor: Mass fraction of water (liquid and vapor) as a function of time at an intermediate stage. Operating parameters as in Fig. 3.21. 


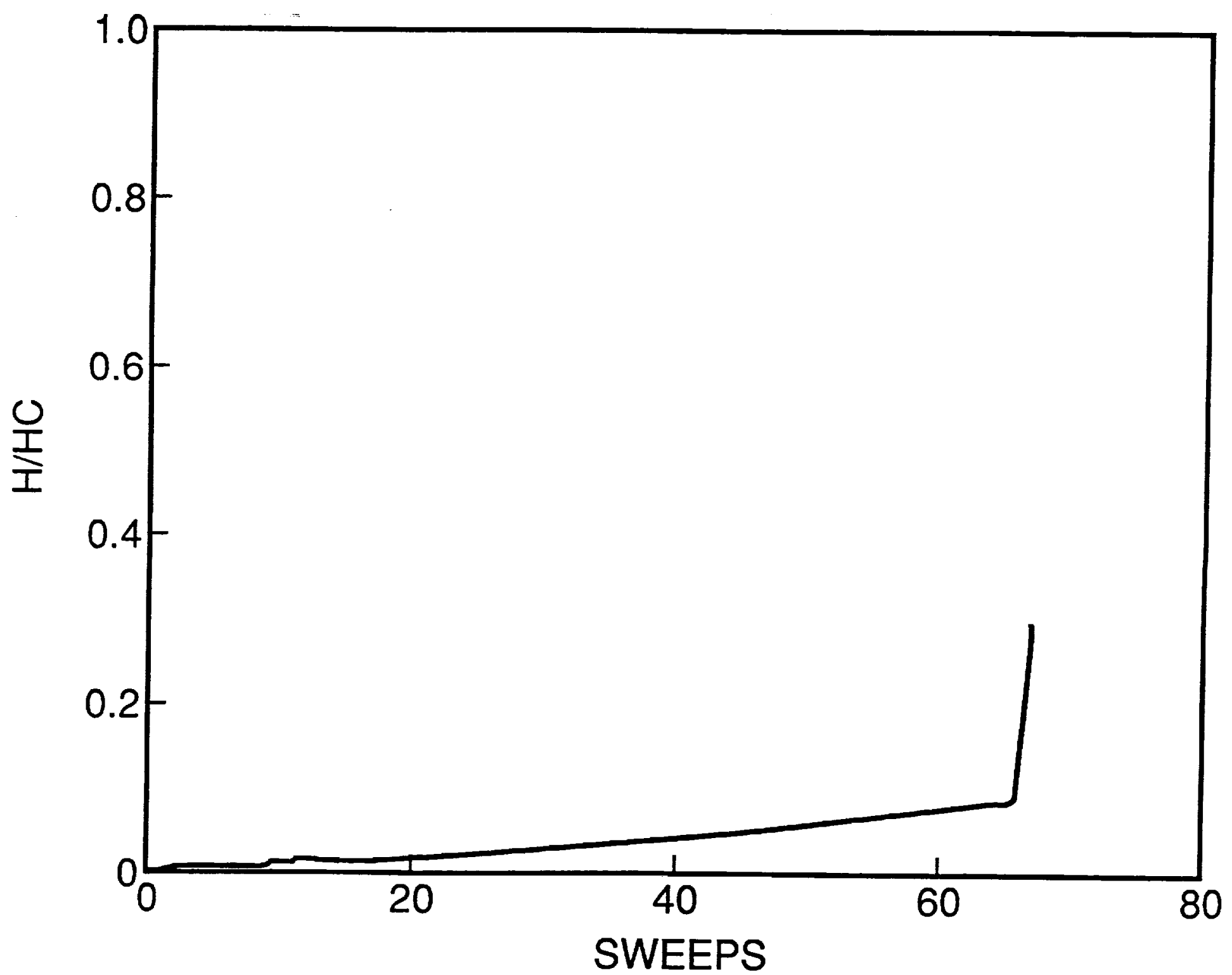

Figure 3.27. Transient Performance of High Pressure Compressor: Height of film over height of clearance as a function of time at an intermediate stage. Operating conditions as in Fig. 3.21 . 

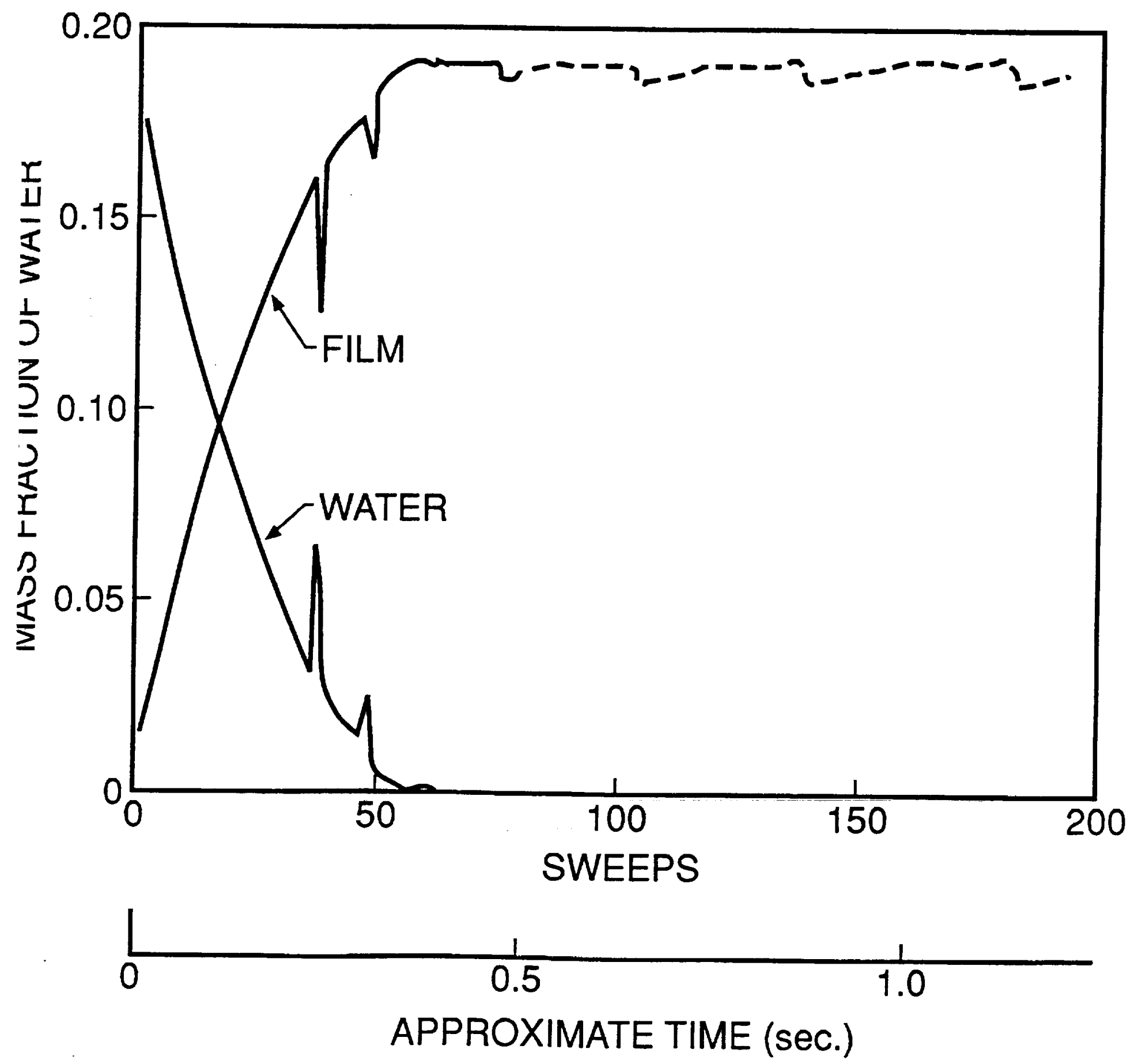

Figure 3.28. Transient Performance of High Pressure Compressor: Mass fraction of water (liquid and vapor) as a function of time. 


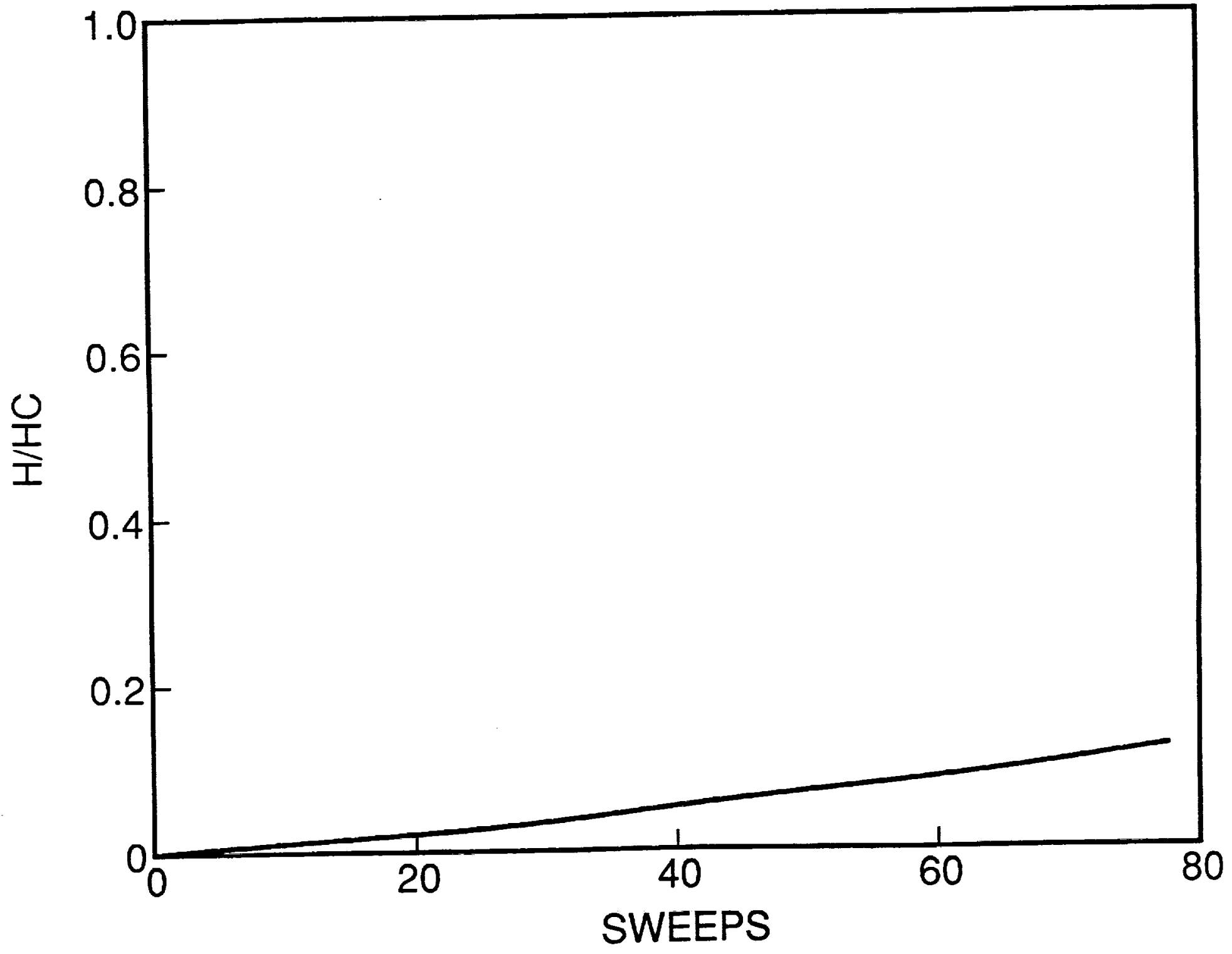

Figure 3.29. Transient Performance of High Pressure Compressor: Height of film over height of clearance as a function of time. Operating parameters as in Fig. 3.28. 


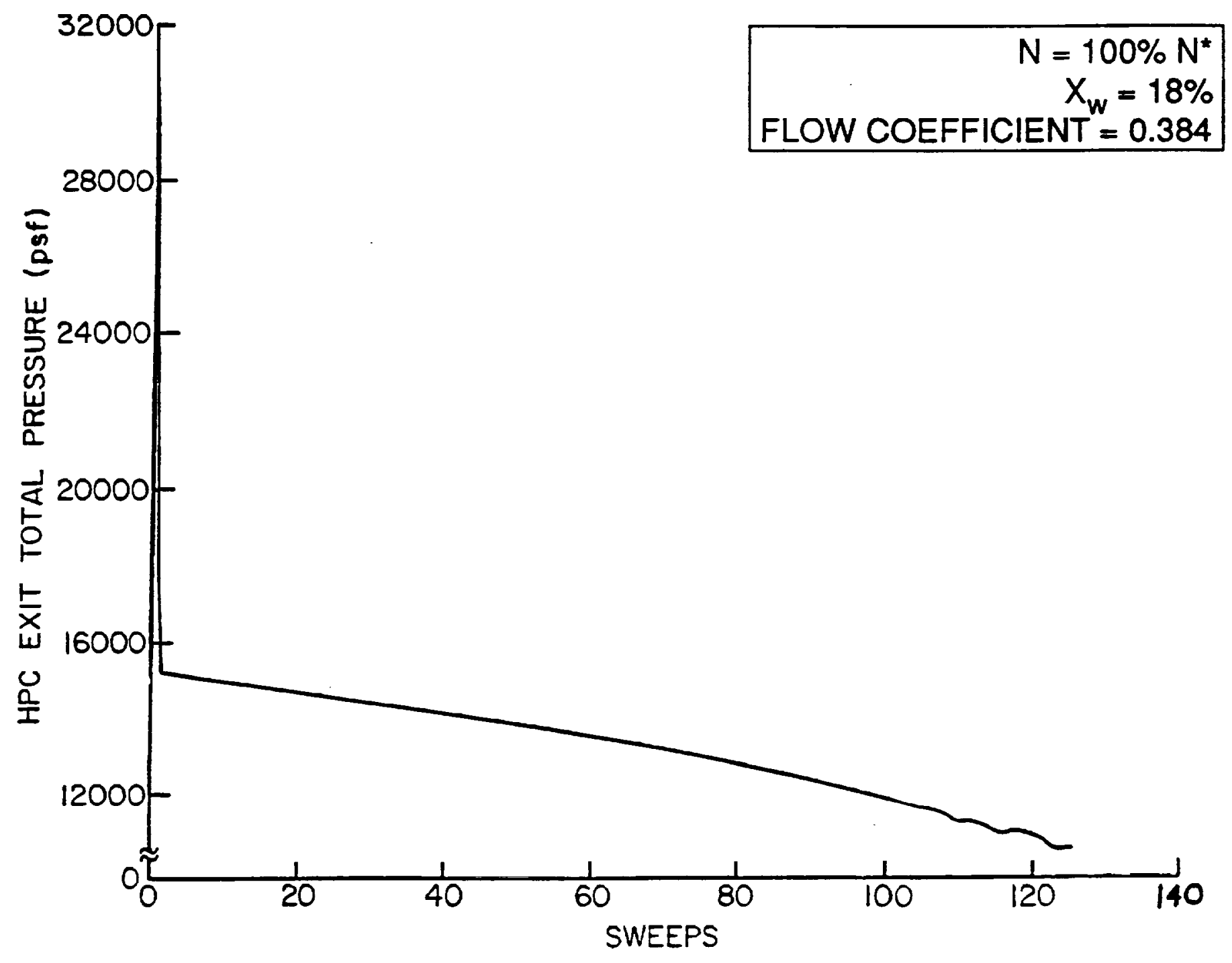

Figure 3.30. Transient Performance of High Pressure Compressor: Exit total pressure as a function of time. Operating parameters as in Fig. 3.28. 


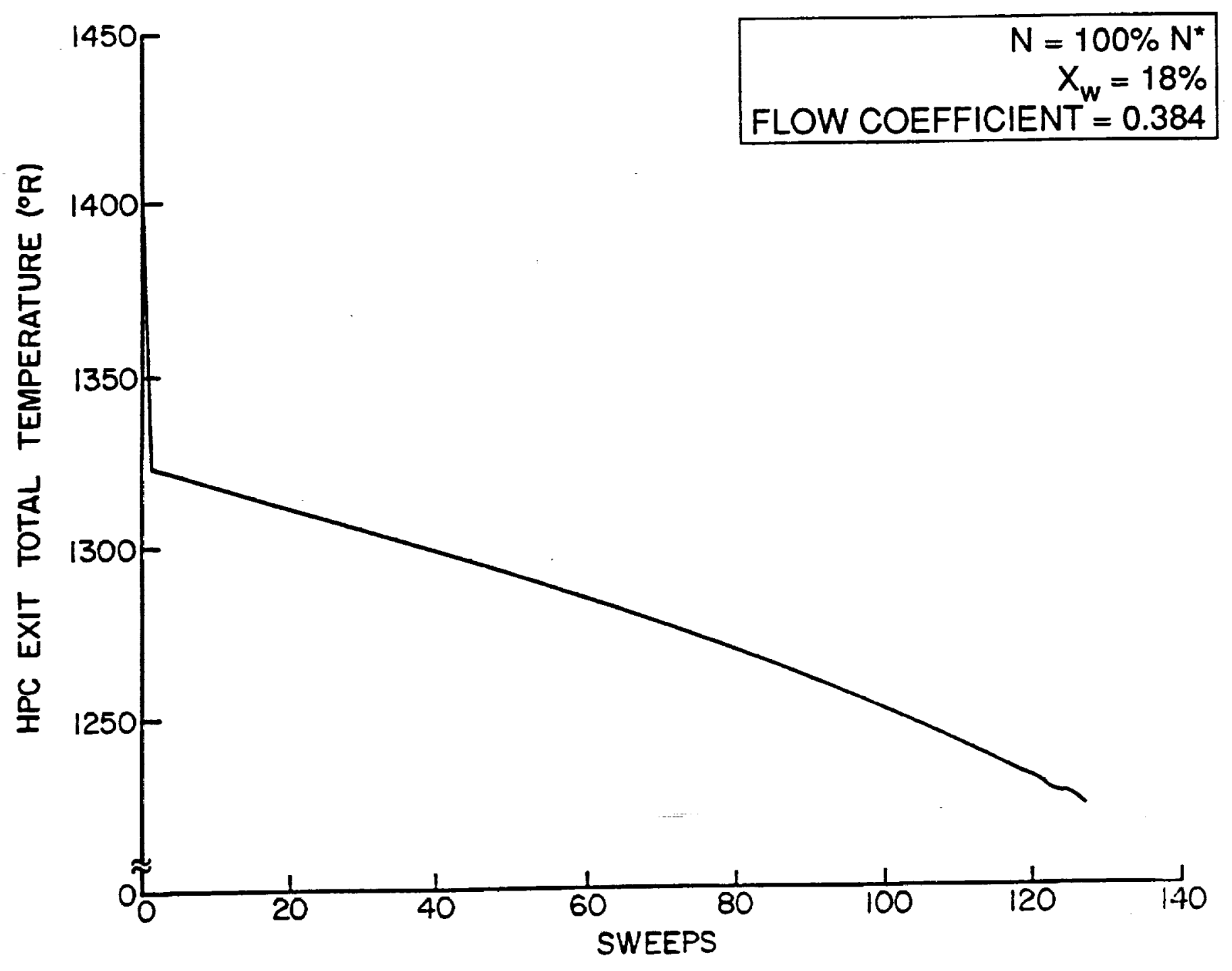

Figure 3.31. Transient Performance of High Pressure Compressor: Exit total temperature as a function of time. Operating parameters as in Fig. 3.28. 


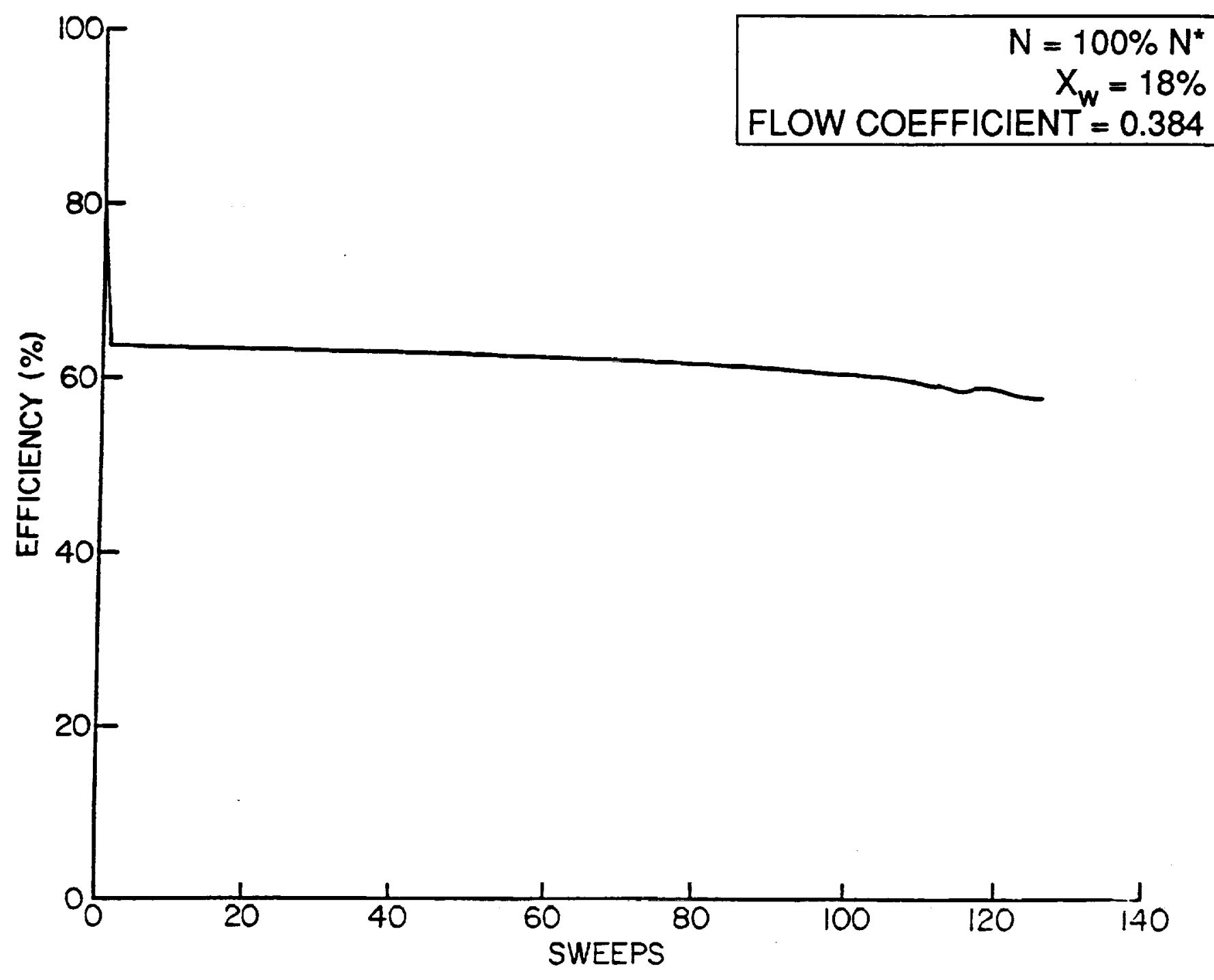

Figure 3.32. Transient Performance of High Pressure Compressor: Efficiency as a function of time. Operating parameters as in Fig. 3.28. 


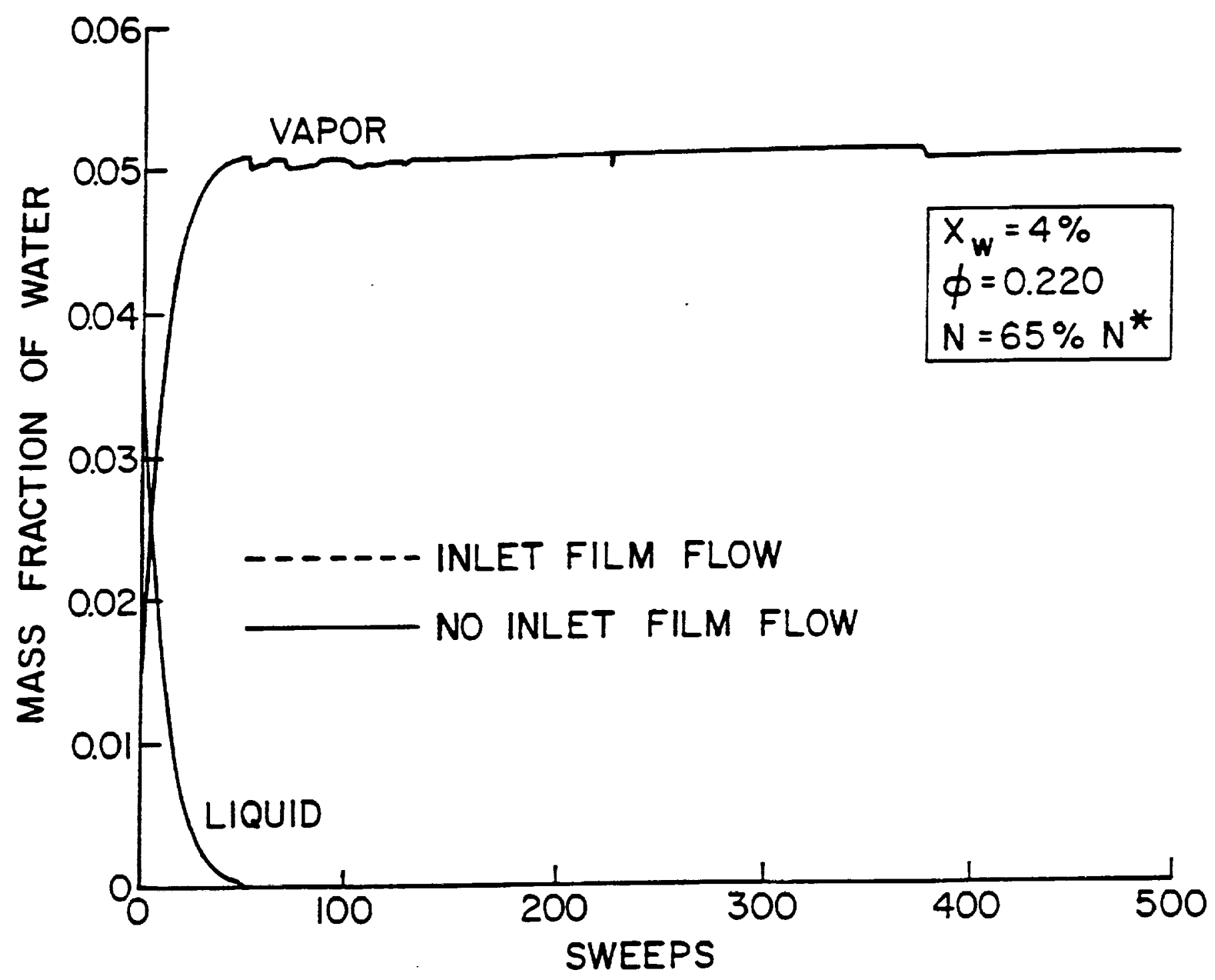

Figure 3.33. Transient Performance of High Pressure Compressor at 65 percent Speed: Mass fraction as a function of time. 


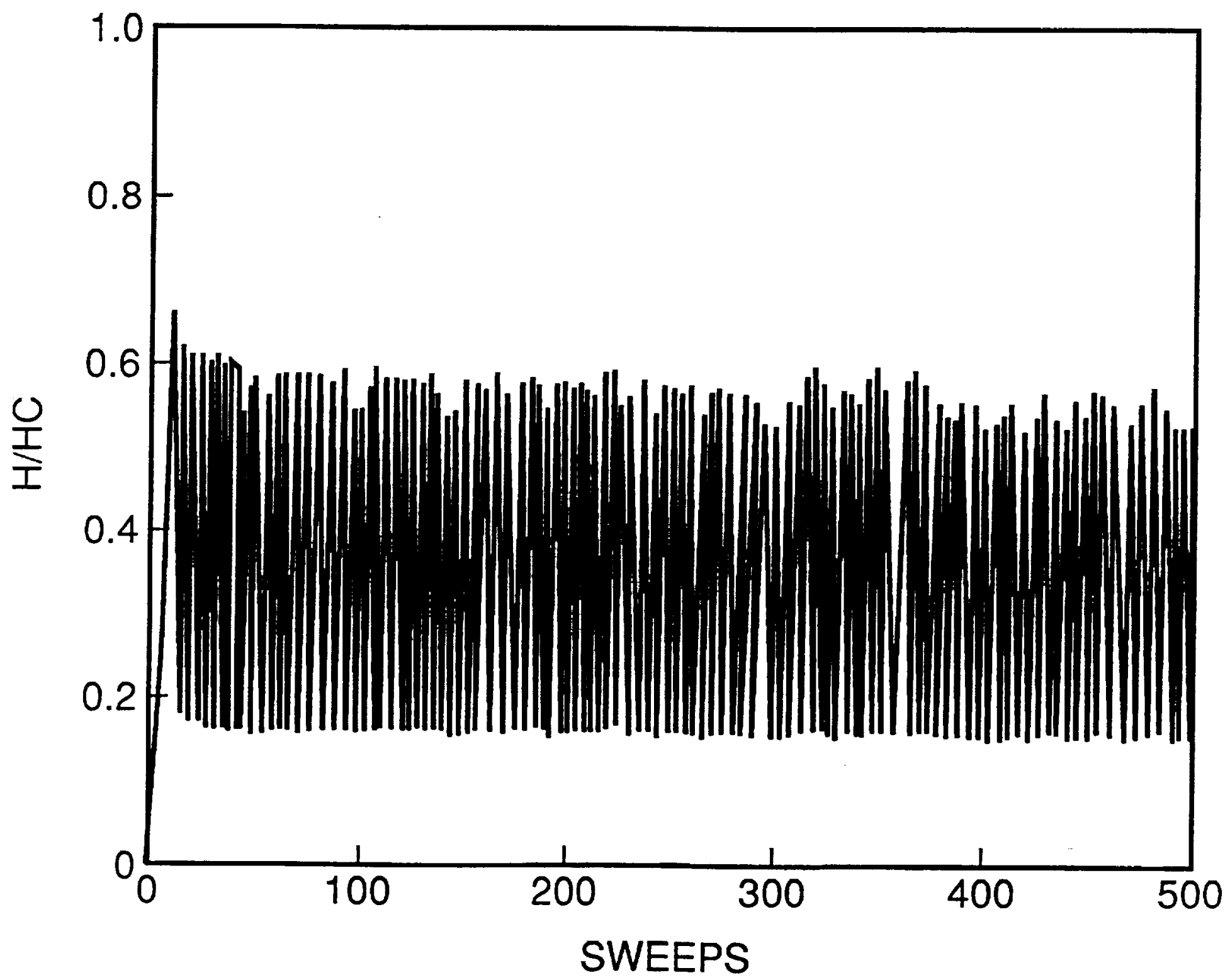

Figure 3.34. Transient Performance of High Pressure Compressor at 65 percent Speed: Height of film over height of clearance as a function of time. Operating parameters same as in Fig. 3.33 . 


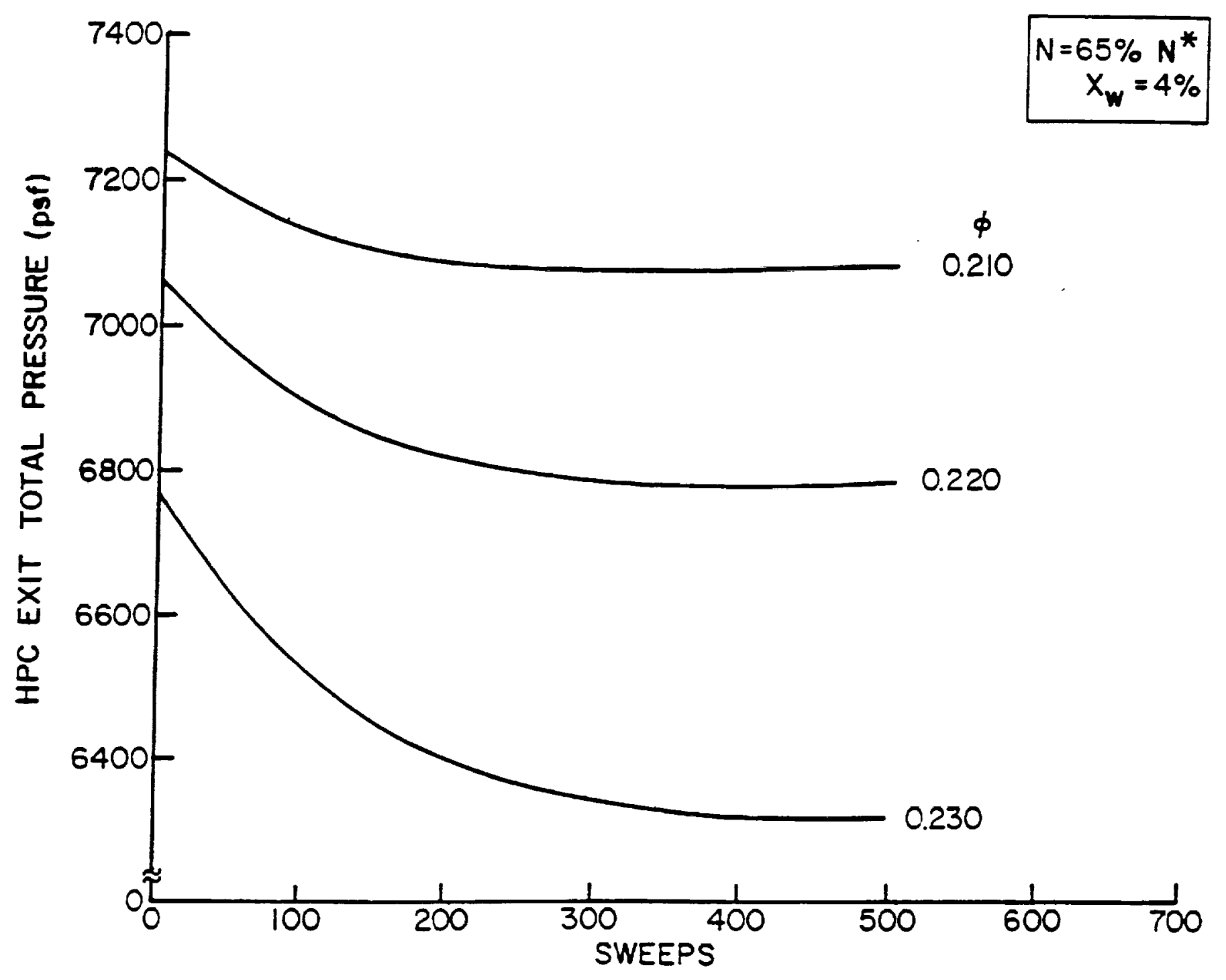

Figure 3.35. Transient Performance of High Pressure Compressor at 65 percent Speed: Exit total pressure as a function of time. Operating parameters as in Fig. 3.33. 


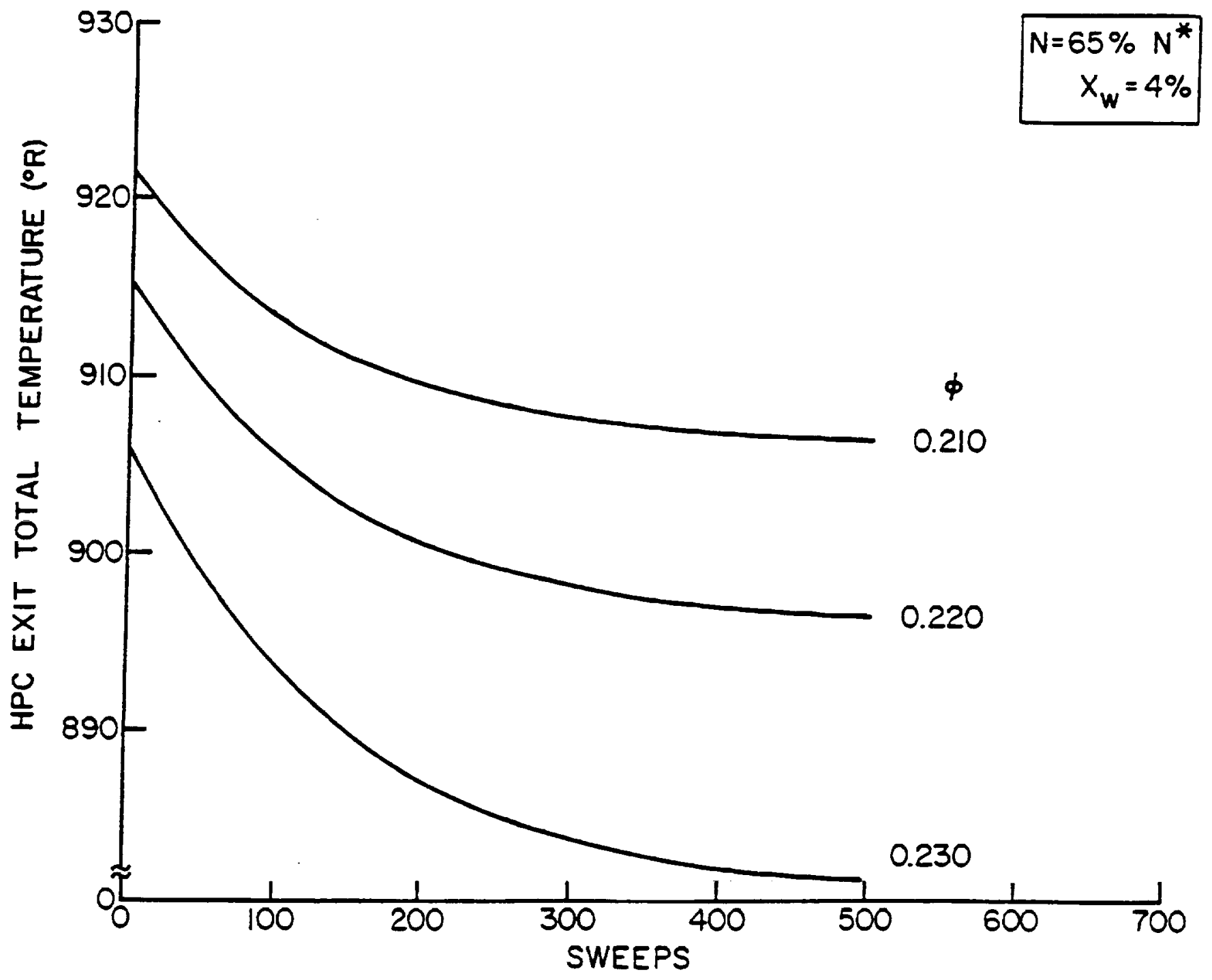

Figure 3.36. Transient Performance of High Pressure Compressor at 65 per cent Speed: Exit total temperature as a function of time. Operating parameters as in Fig. 3.33. 


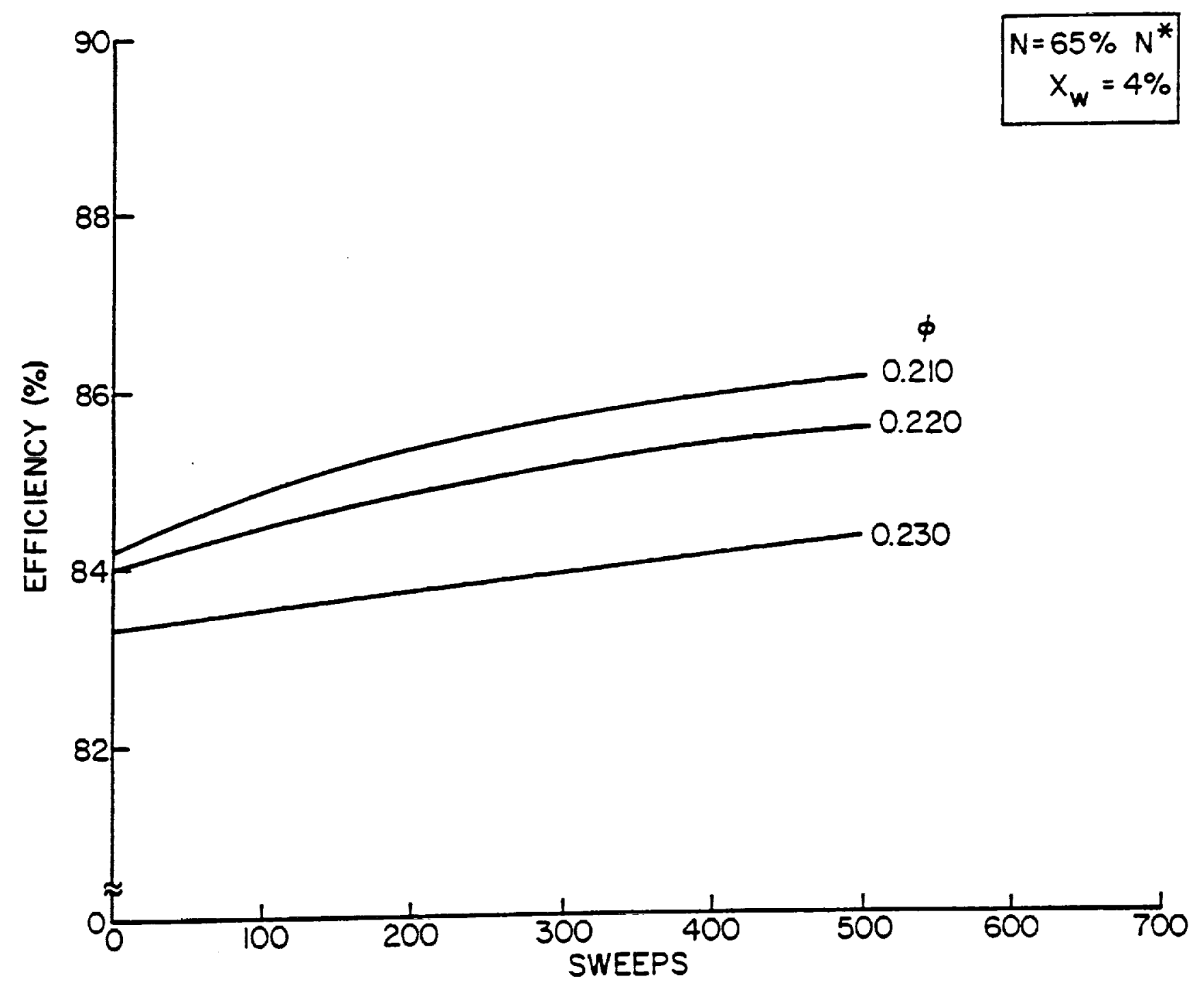

Figure 3.37. Transient Performance of High Pressure Compressor at 65 per cent Speed: Efficiently as a function of time. Operating parameters as in Fig. 3.33. 


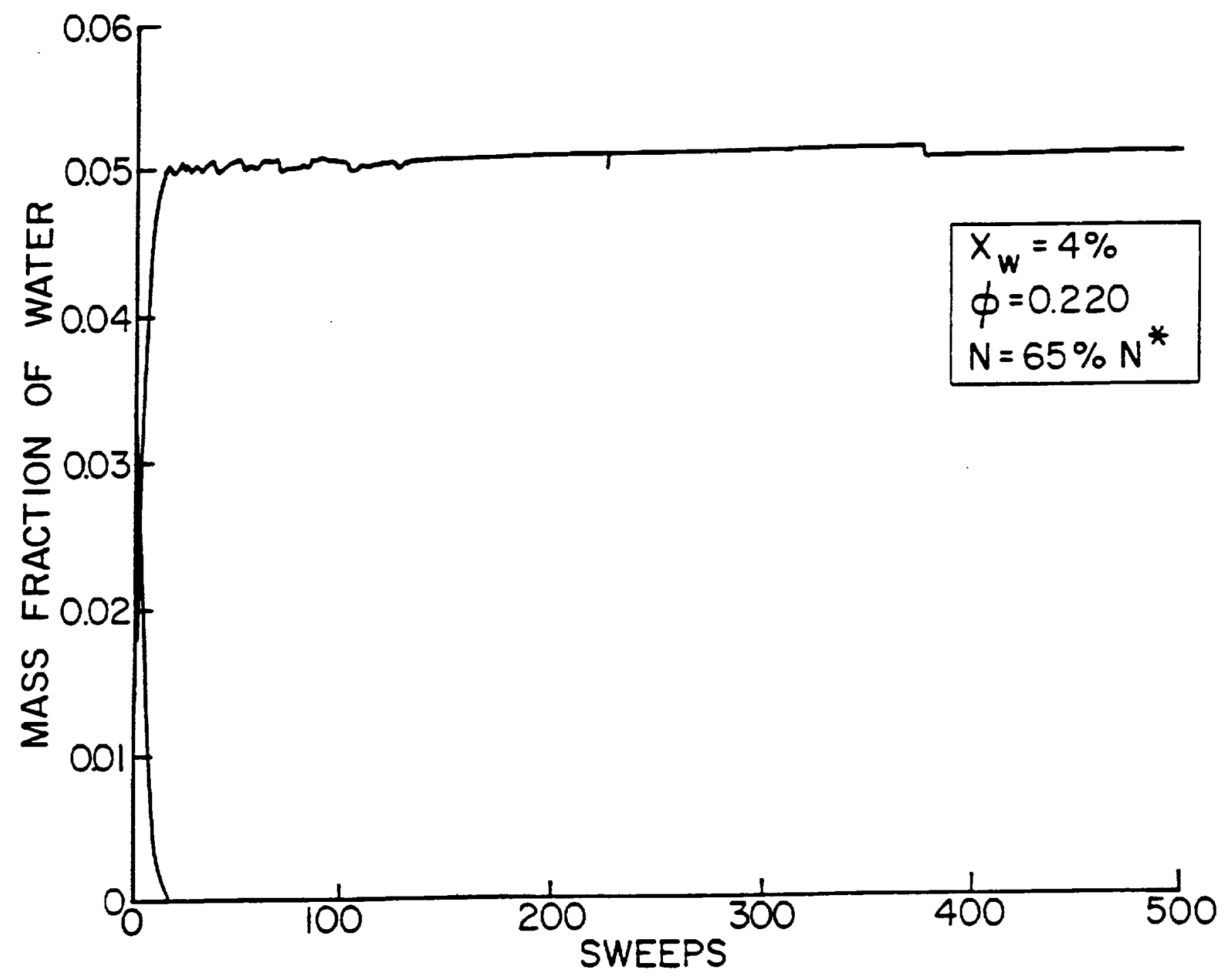

Figure 3.38. Transient Performance of High Pressure Compressor at 65 per cent Speed: Mass fraction of water at an intermediate stage as a function of time. Operating parameters as in Fig. 3.33 . 


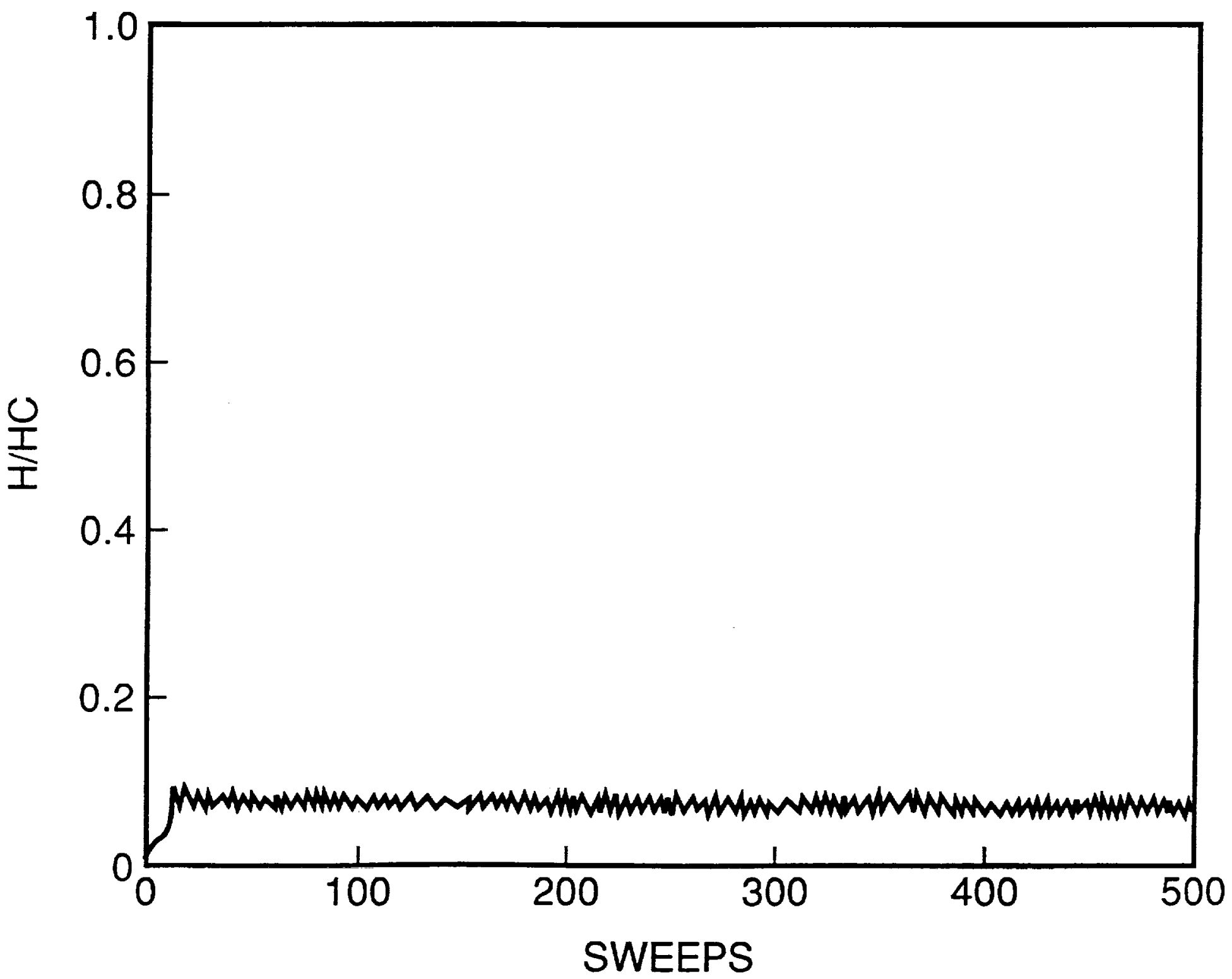

Figure 3.39. Transient Performance of High Pressure Compressor at 65 per cent Speed: Height of film over height of clearance at an intermediate stage as a function of time. Operating parameters as in Fig. 3.33. 


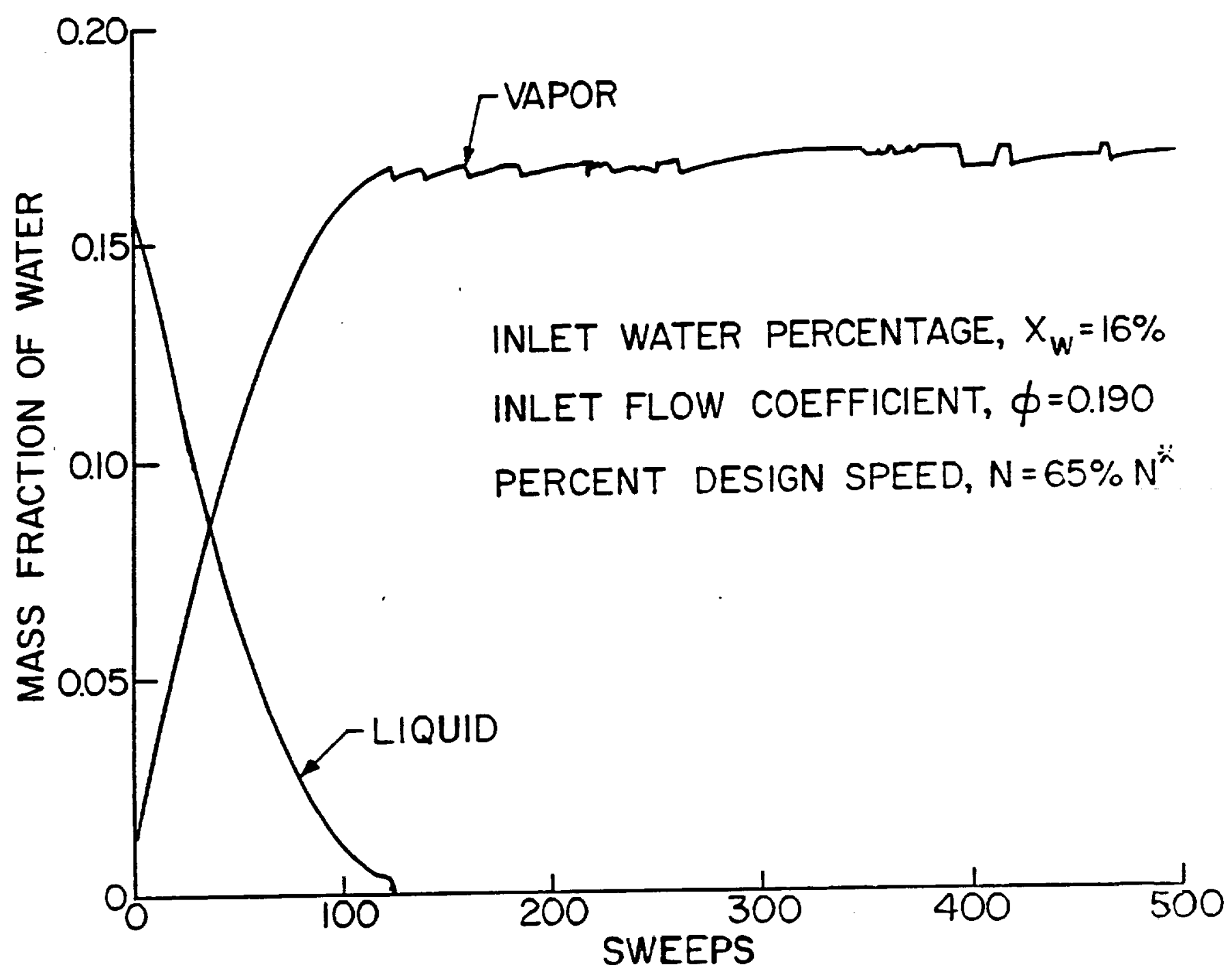

Figure 3.40. Transient Performance of High Pressure Compressor at 65 per cent Speed: Mass fraction of water as a function of time at exit of compressor. 


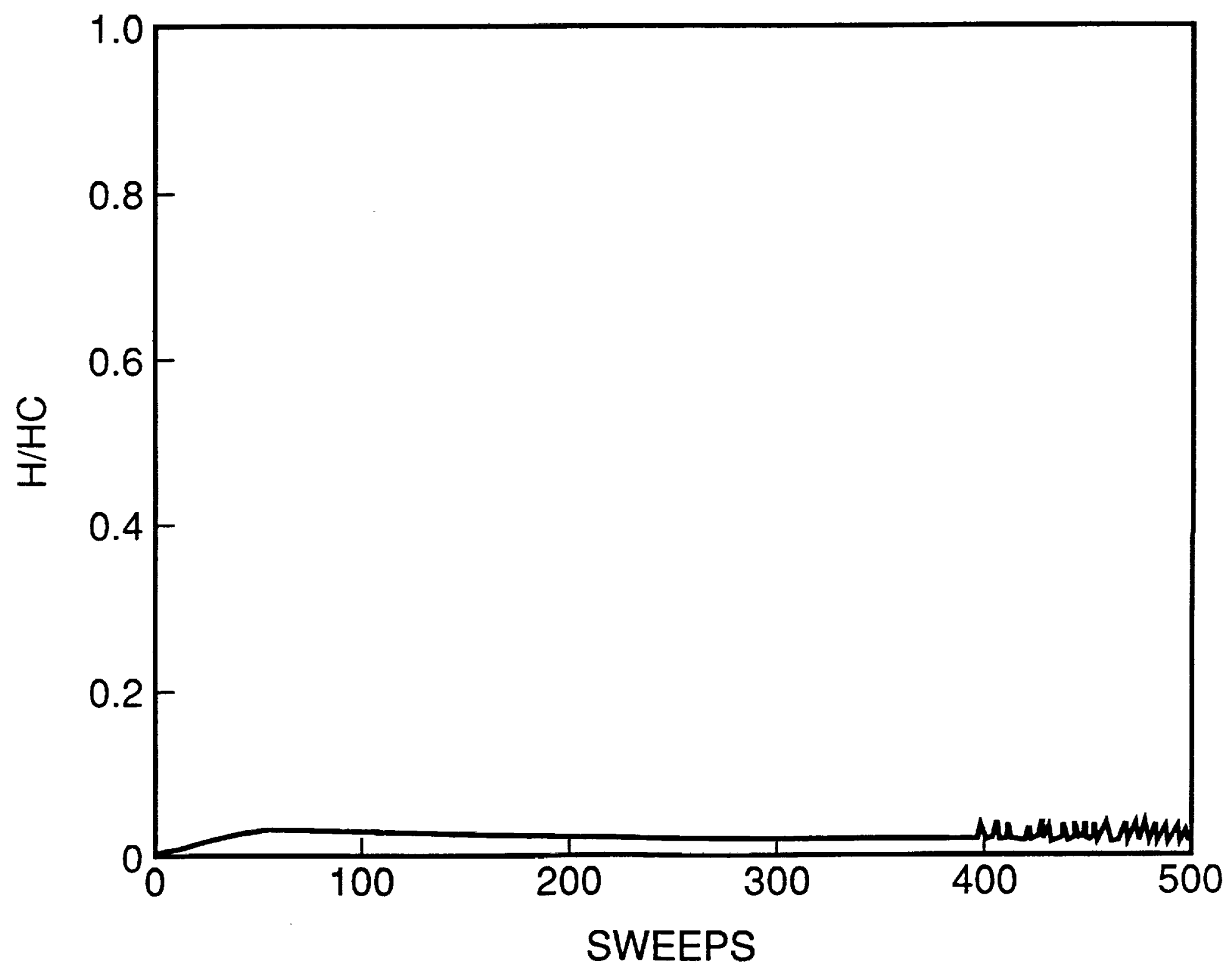

Figure 3.41. Transient Performance of High Pressure Compressor at 65 percent Speed: Height of film over height of clearance as a function of time. Operating parameters as in Fig. 3.40. 


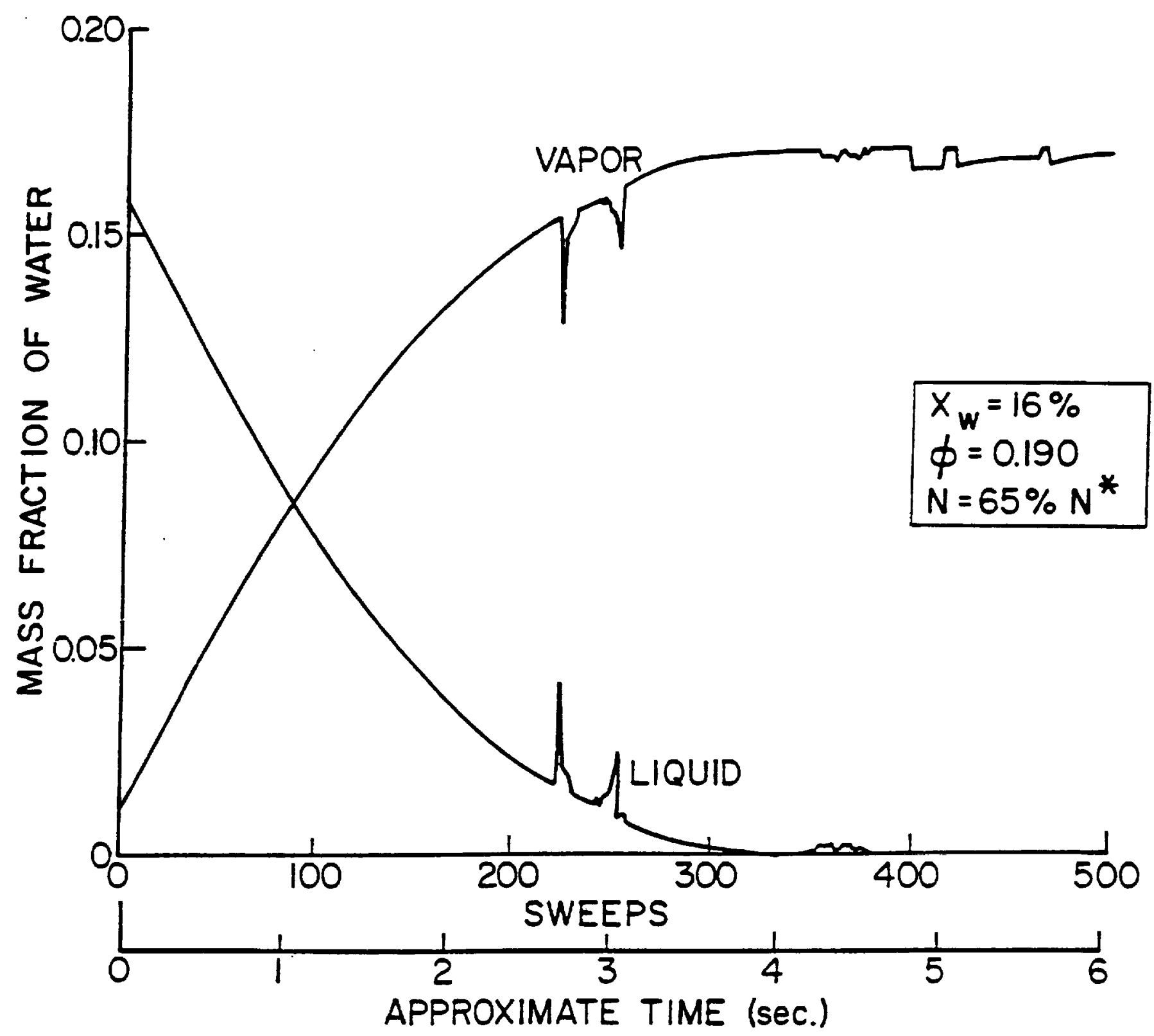

Figure 3.42. Transient Performance of High Pressure Compressor at 65 percent Speed: Mass fraction of water at an intermediate stage as a function of time. Operating parameters as in Fig. 3.40 . 


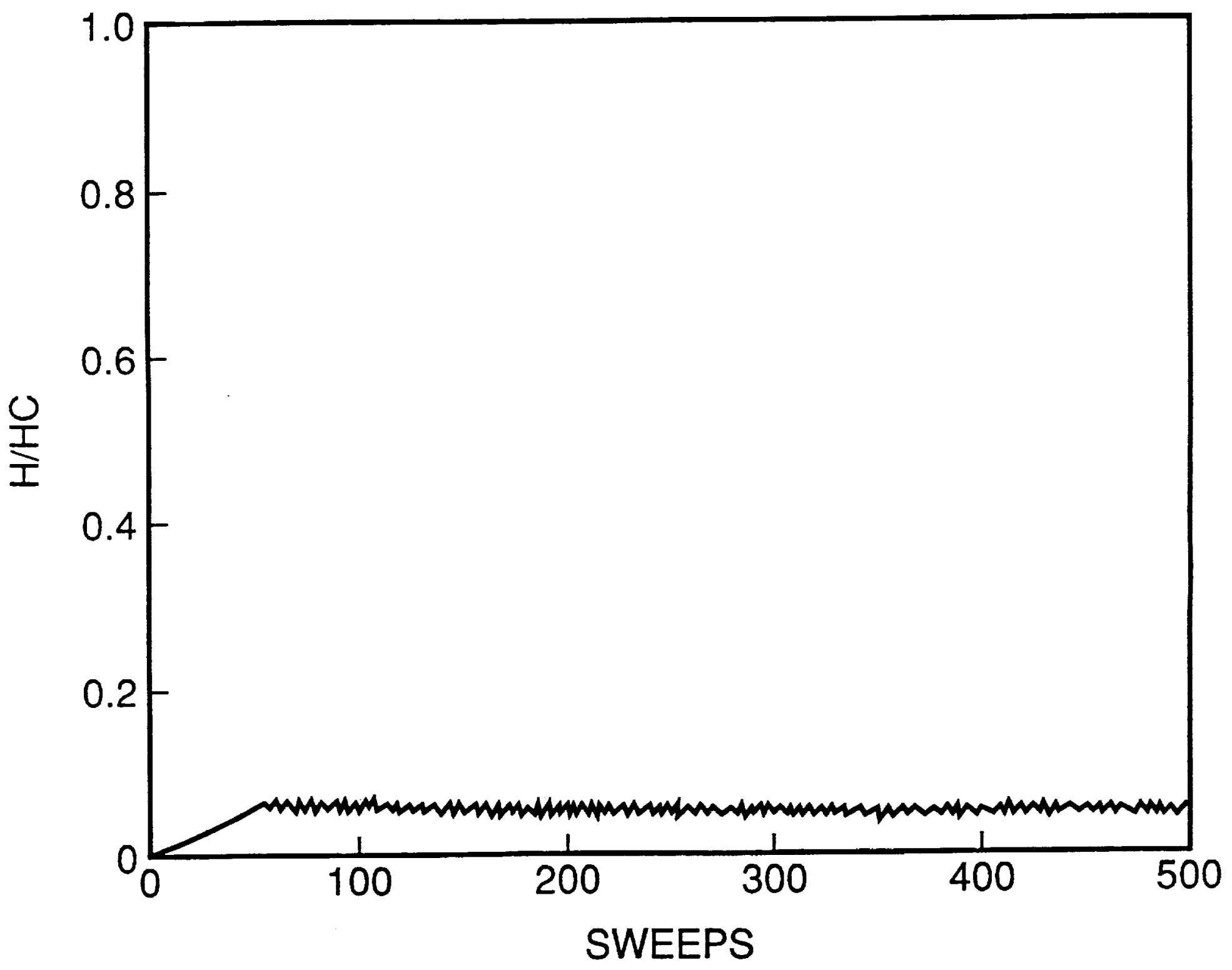

Figure 3.43. Transient Performance of High Pressure Compressor at 65 percent Speed: Height of film over height of clearance at an intermediate stage as a function of time. Operating parameters same as in Fig. 3.40. 


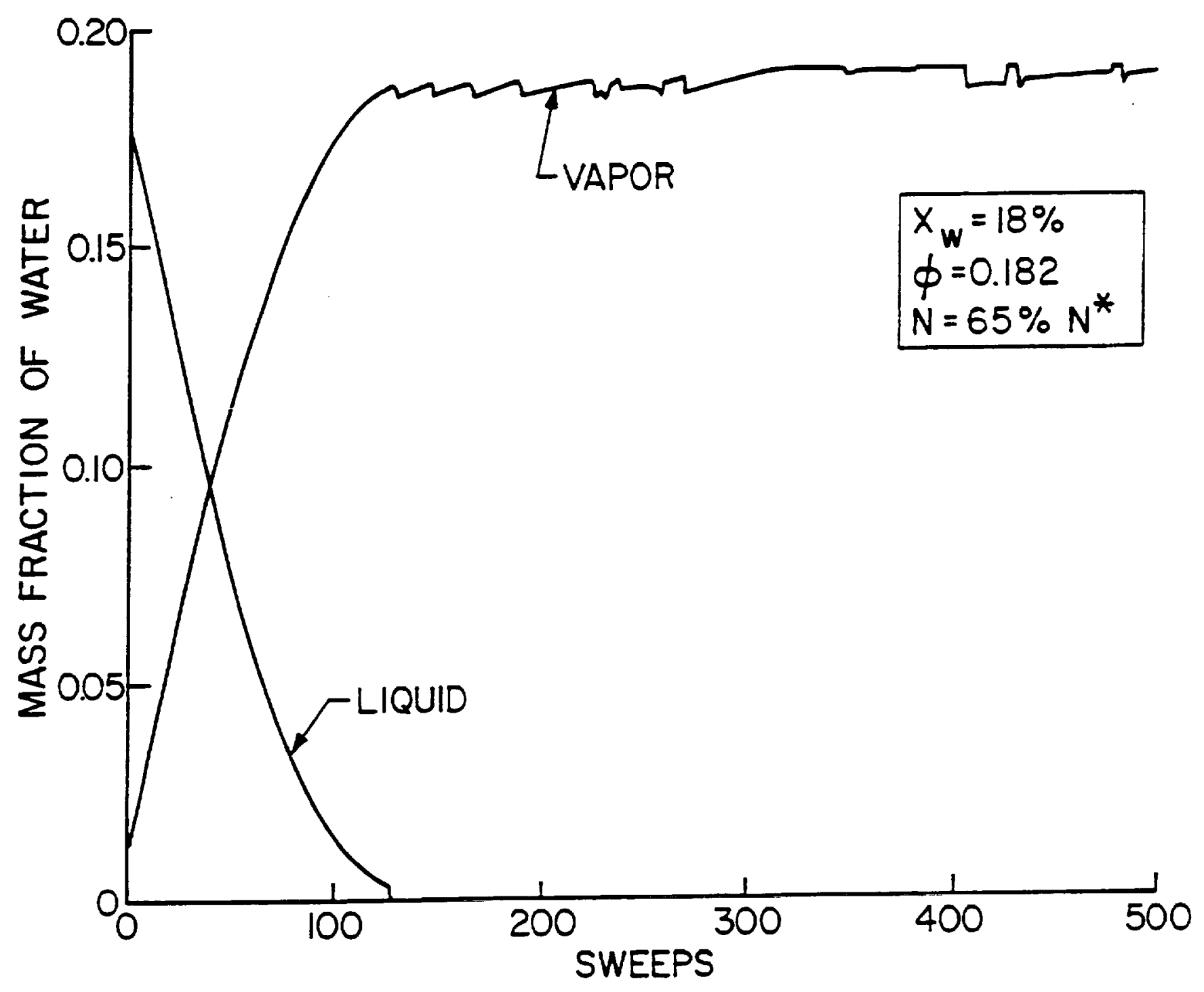

Figure 3.44. Transient Performance of High Pressure Compressor at 65 percent Speed: Mass fraction of water as a function time. Operating parameters as in Fig. 3.40. 


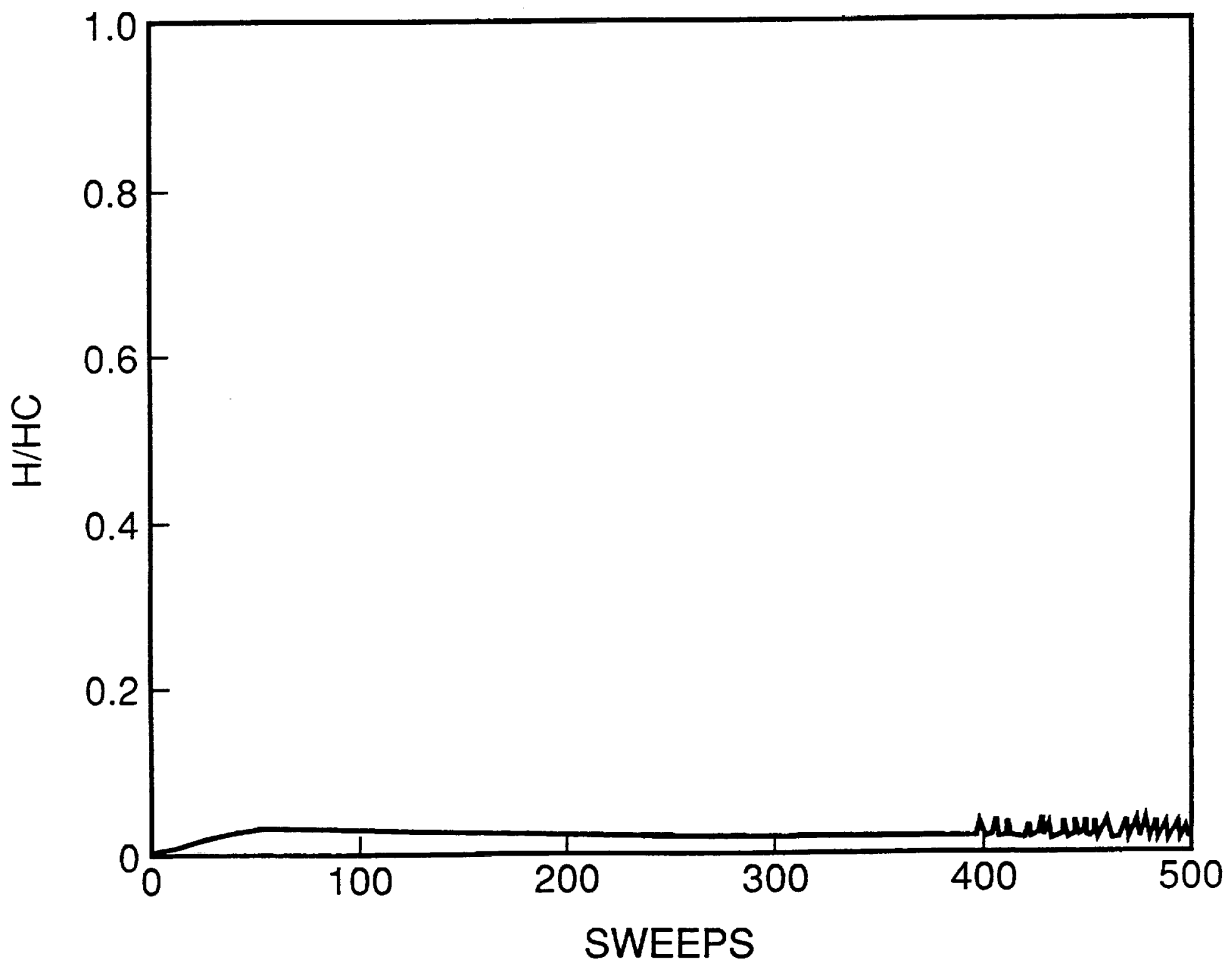

Figure 3.45. Transient Performance of High Pressure Compressor at 65 percent Speed: Height of film over height of clearance as a function of time. Operating parameters same as in Fig. 3.40 . 


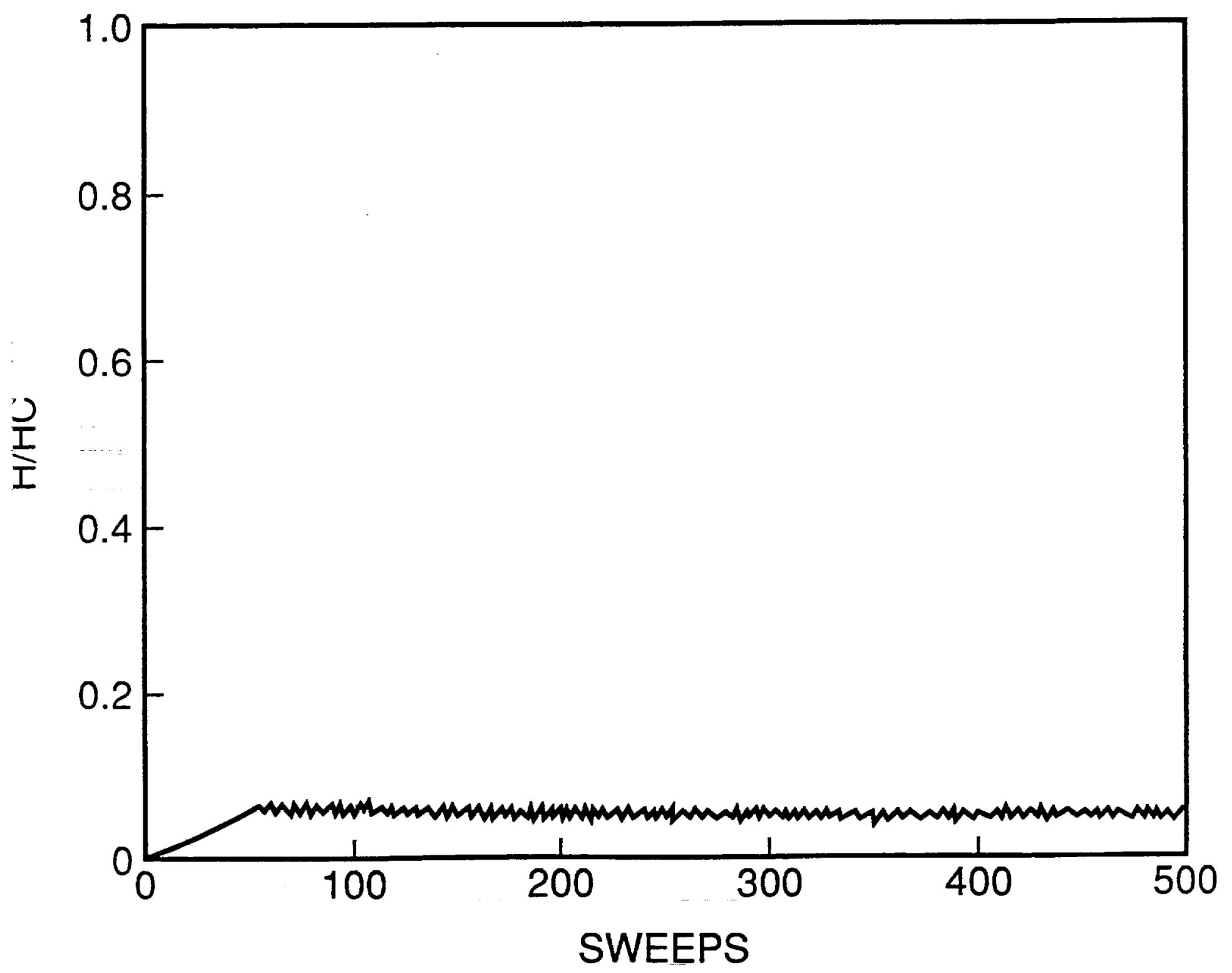

Figure 3.46. Transient Performance of High Pressure Compressor at 65 percent Speed: Height of film over height of clearance at an intermediate stage as a function of time. Operating parameters same as in Fig. 3.40. 


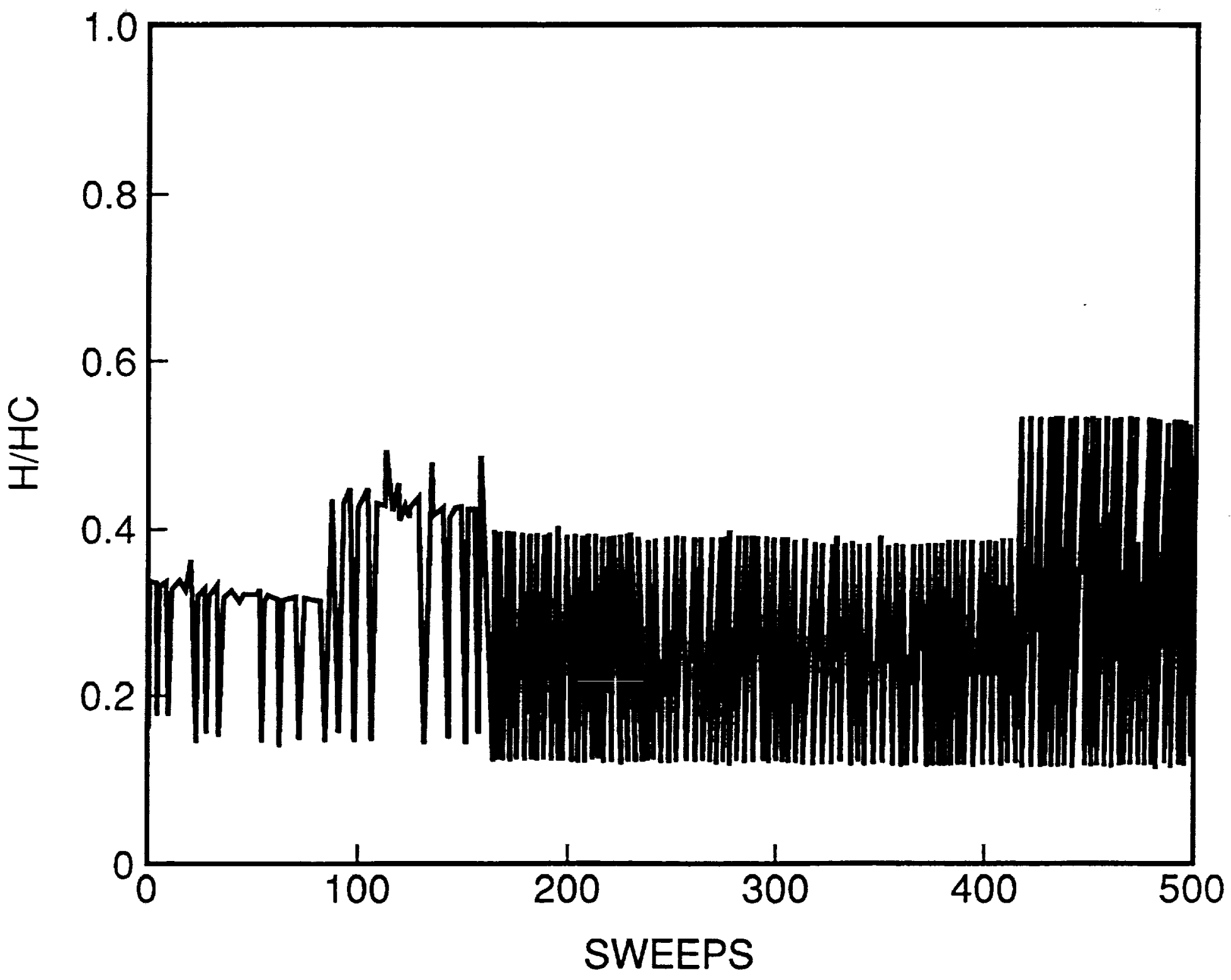

Figure 3.47. Transient Performance of High Pressure Compressor: Height of film over height of clearance as a function of time. Operating parameters same as in Fig. 3.9, but with inlet film. 


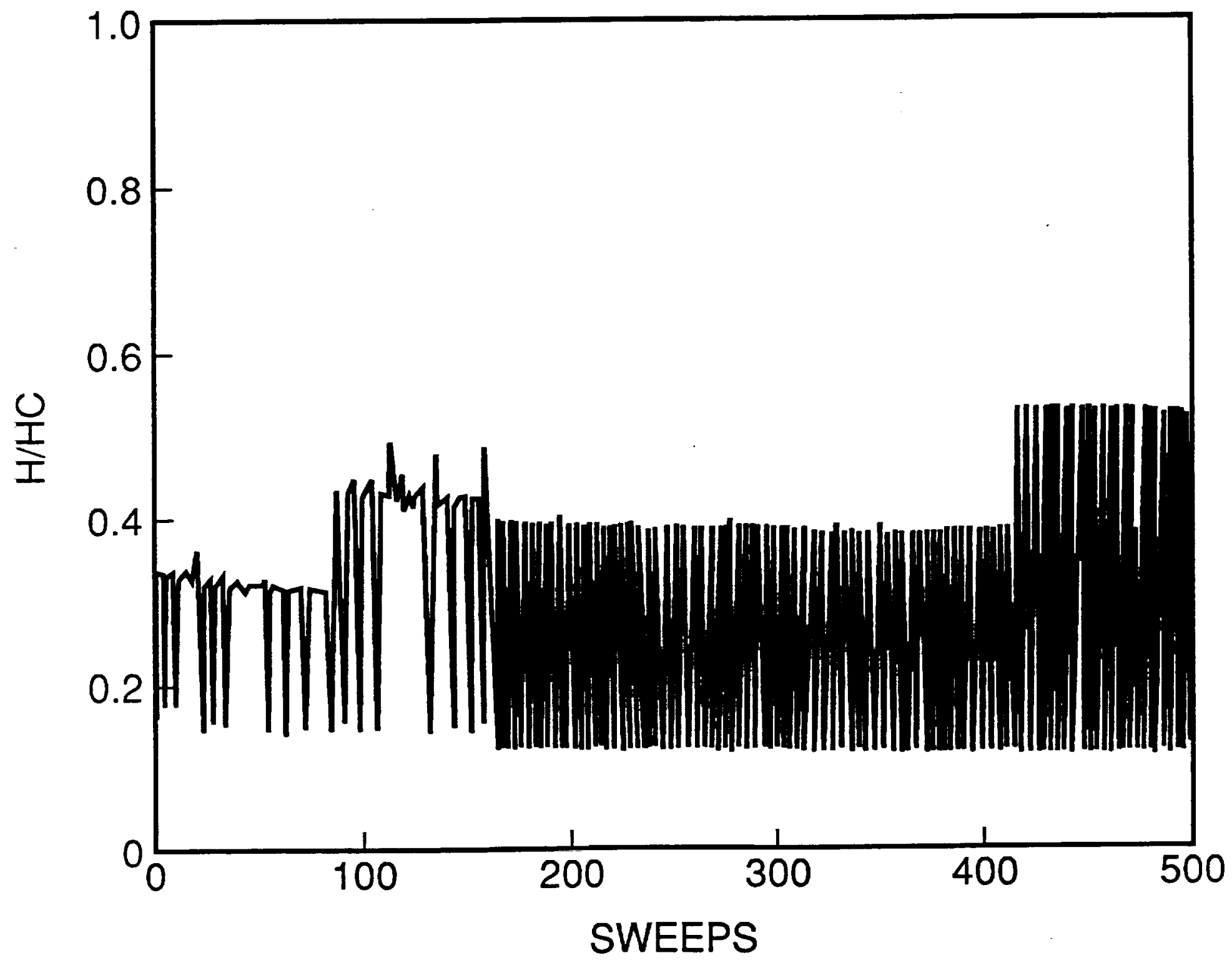

Figure 3.48. Transient Performance of High Pressure Compressor: Height of film over height of clearance at an intermediate stage as a function of time. Operating parameters same as in Fig. 3.9, but with inlet film. 


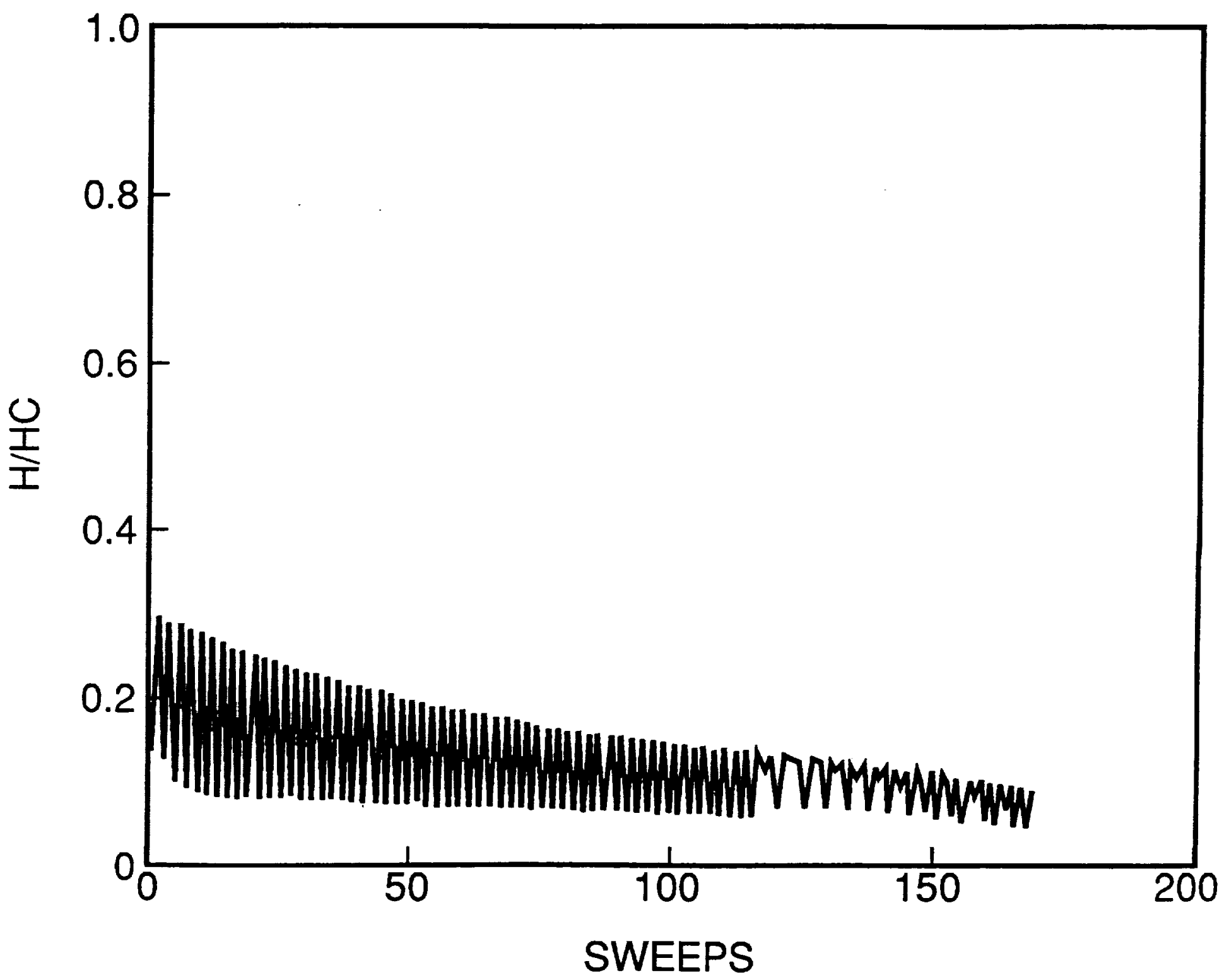

Figure 3.49. Transient Performance of High Pressure Compressor: Height of film over height of clearance as a function of time. Operating parameters same as in Fig. 3.21, but with inlet film. 


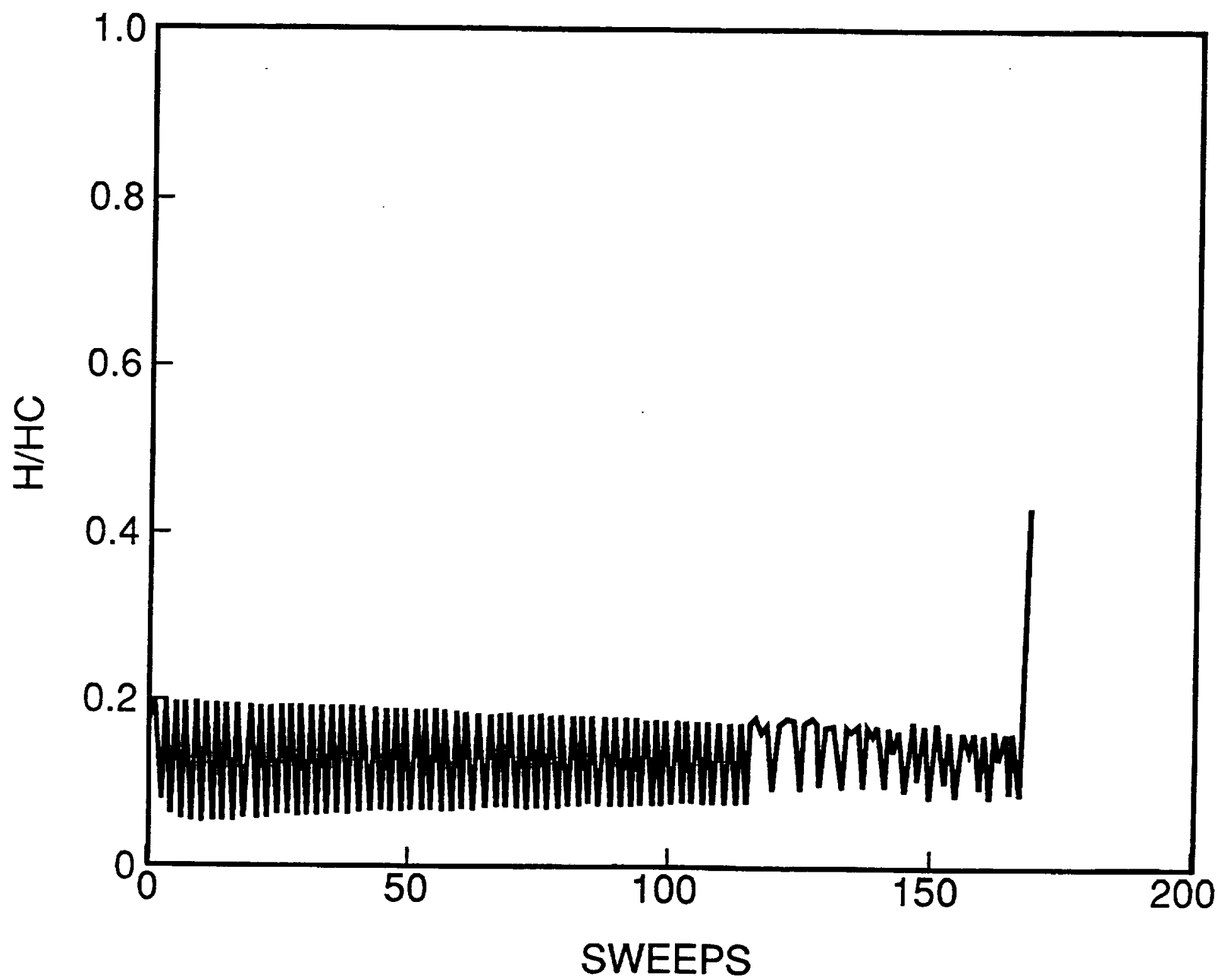

Figure 3.50. Transient Performance of High Pressure Compressor: Height of film over height of clearance at an intermediate stage as a function of time. Operating parameters same as in Fig. 3.21, but with inlet film. 


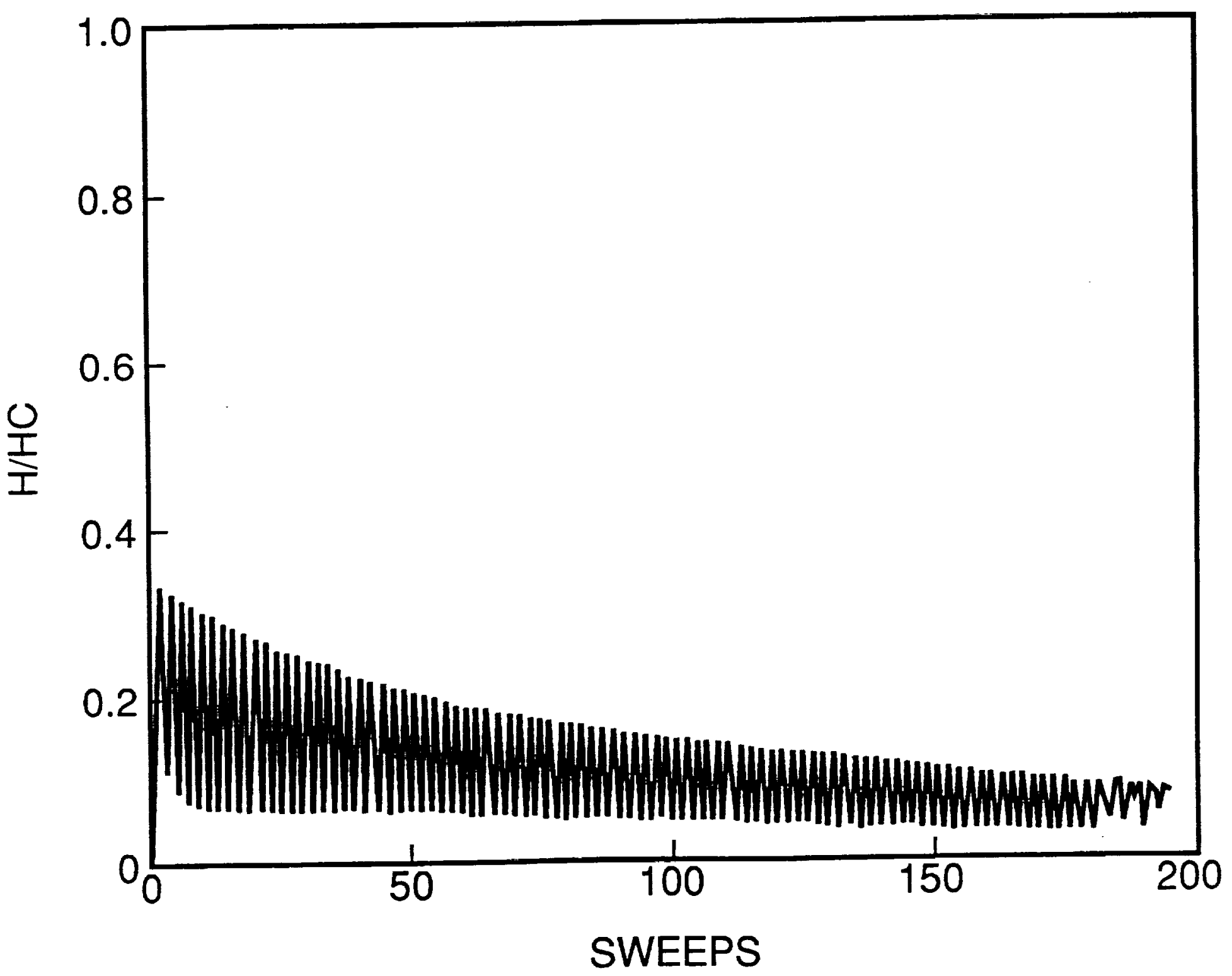

Figure 3.51. Transient Performance of High Pressure Compressor: Height of film over height of clearance as a function of time. Operating conditions as in Fig. 3.28, but with inlet film. 


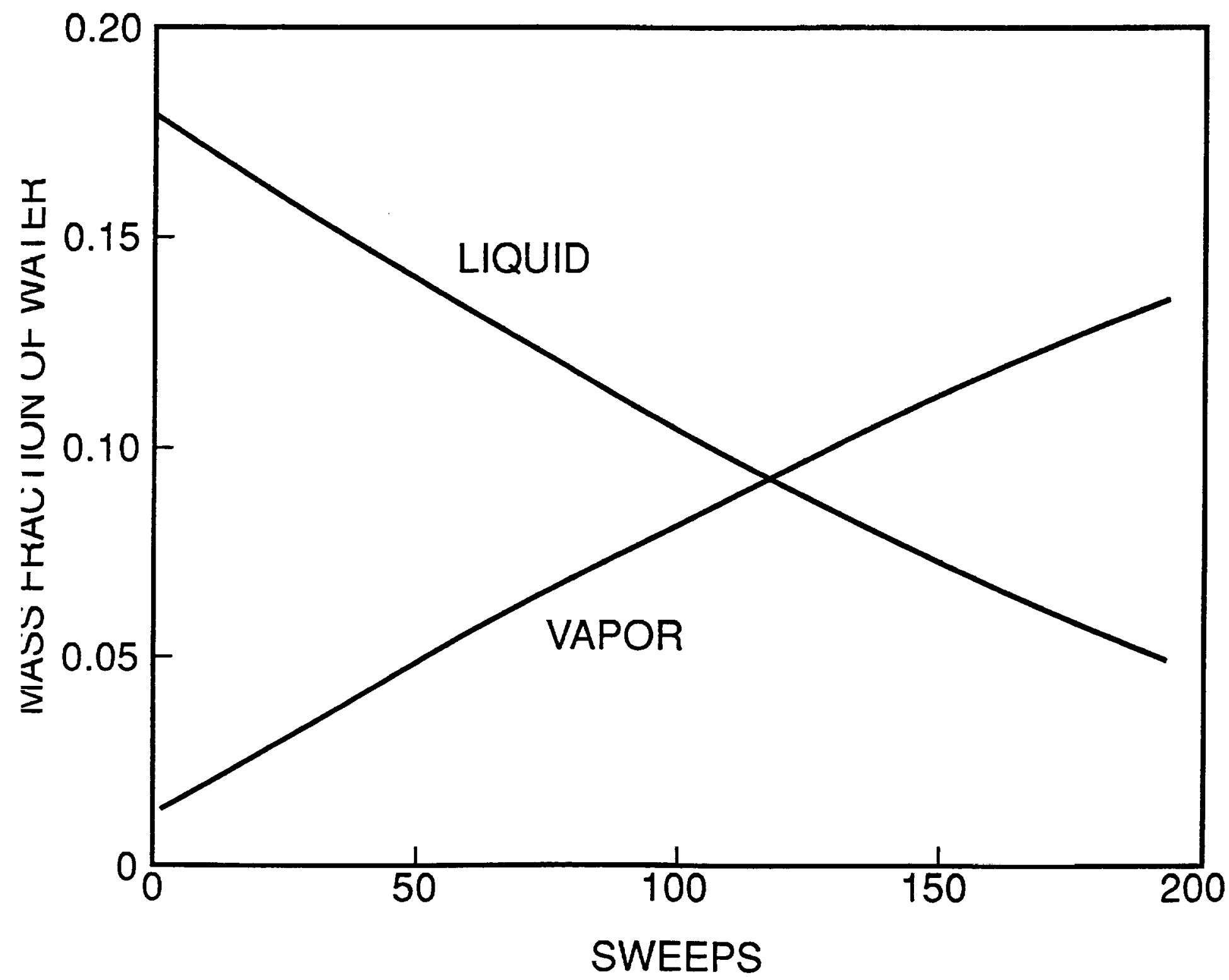

Figure 3.52. Transient Performance of High Pressure Compressor: Mass fraction of water at an intermediate stage as a function of time. Operation conditions same as in Fig. 3.28, but with inlet film. 


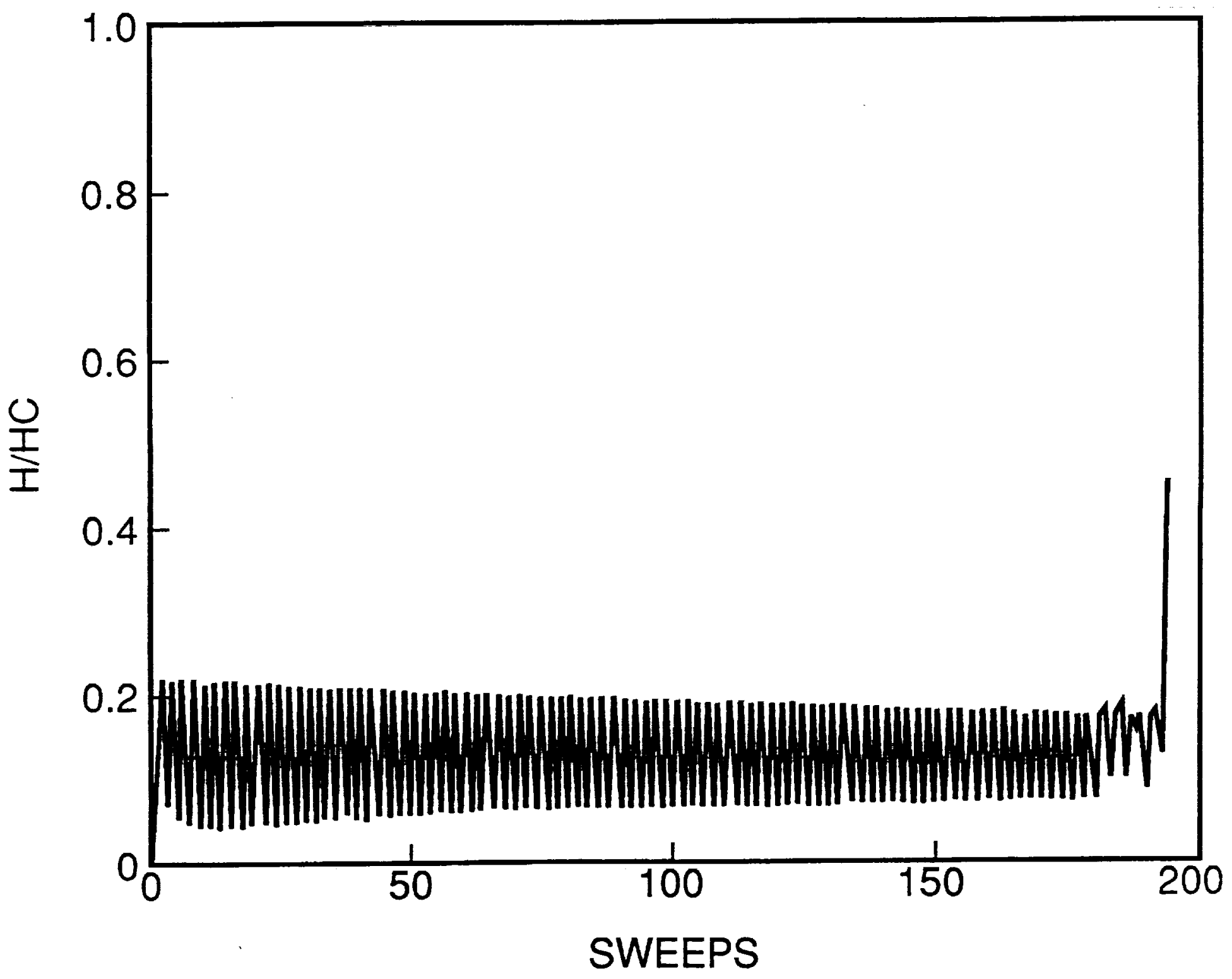

Figure 3.53. Transient Performance of High Pressure Compressor: Height of film over height of clearance at an intermediate stage as a function of time. Operating conditions same as in Fig. 3.28, but with inlet film. 


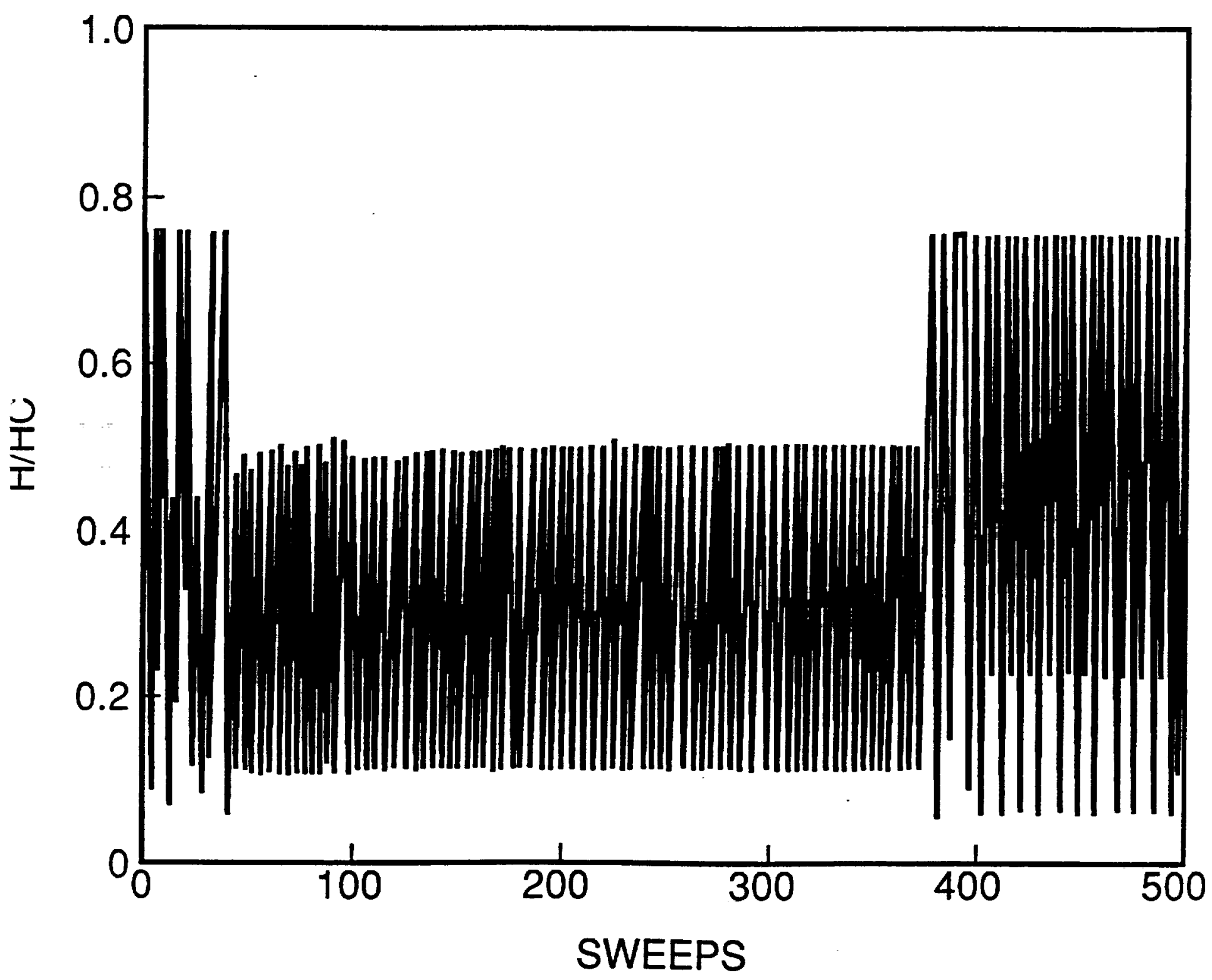

Figure 3.54. Transient Performance of High Pressure Compressor at 65 per cent Speed: Height of film over height of clearance as a function of time. Operating conditions same as in Fig. 3.33, but with inlet film. 


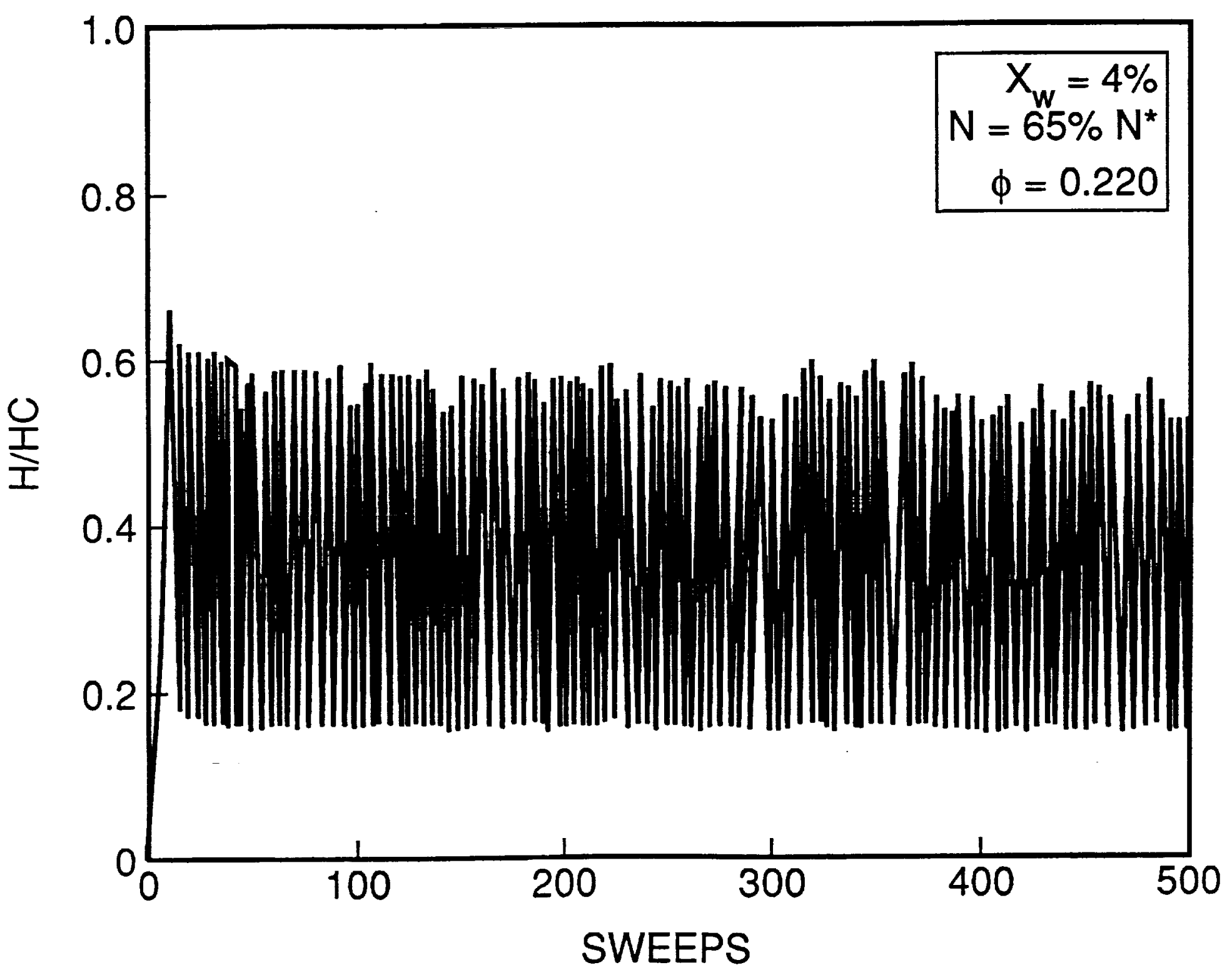

Figure 3.55. Transient Performance of High Pressure Compressor at 65 per cent Speed: Height of film over height of clearance at an intermediate stage as a function of time. Operating conditions same as in Fig. 3.33, but with inlet film. 


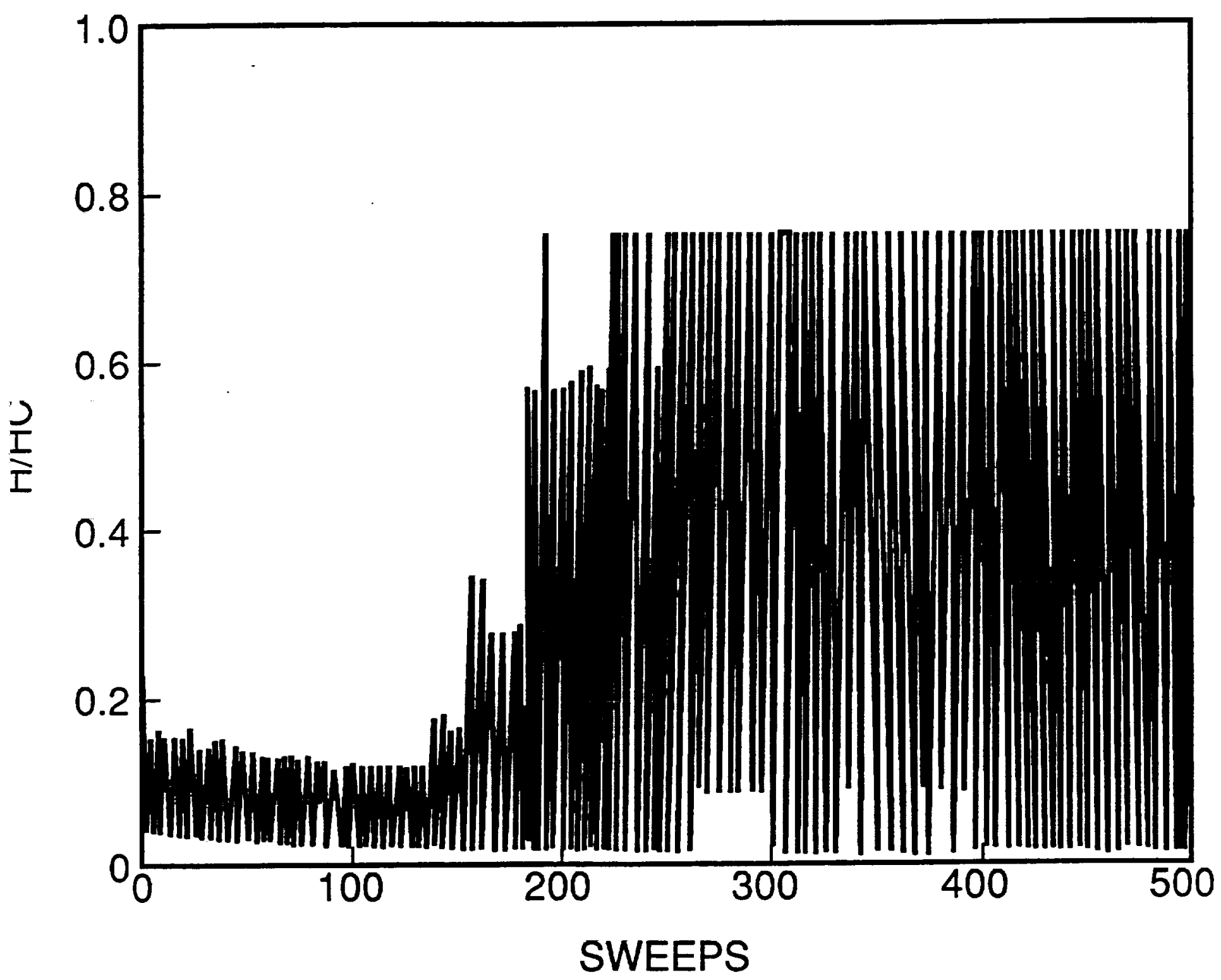

Figure 3.56. Transient Performance of High Pressure Compressor at 65 per cent Speed: Height of film over height of clearance as a function of time. Operating conditions same as in Fig. 3.40, but with inlet film. 


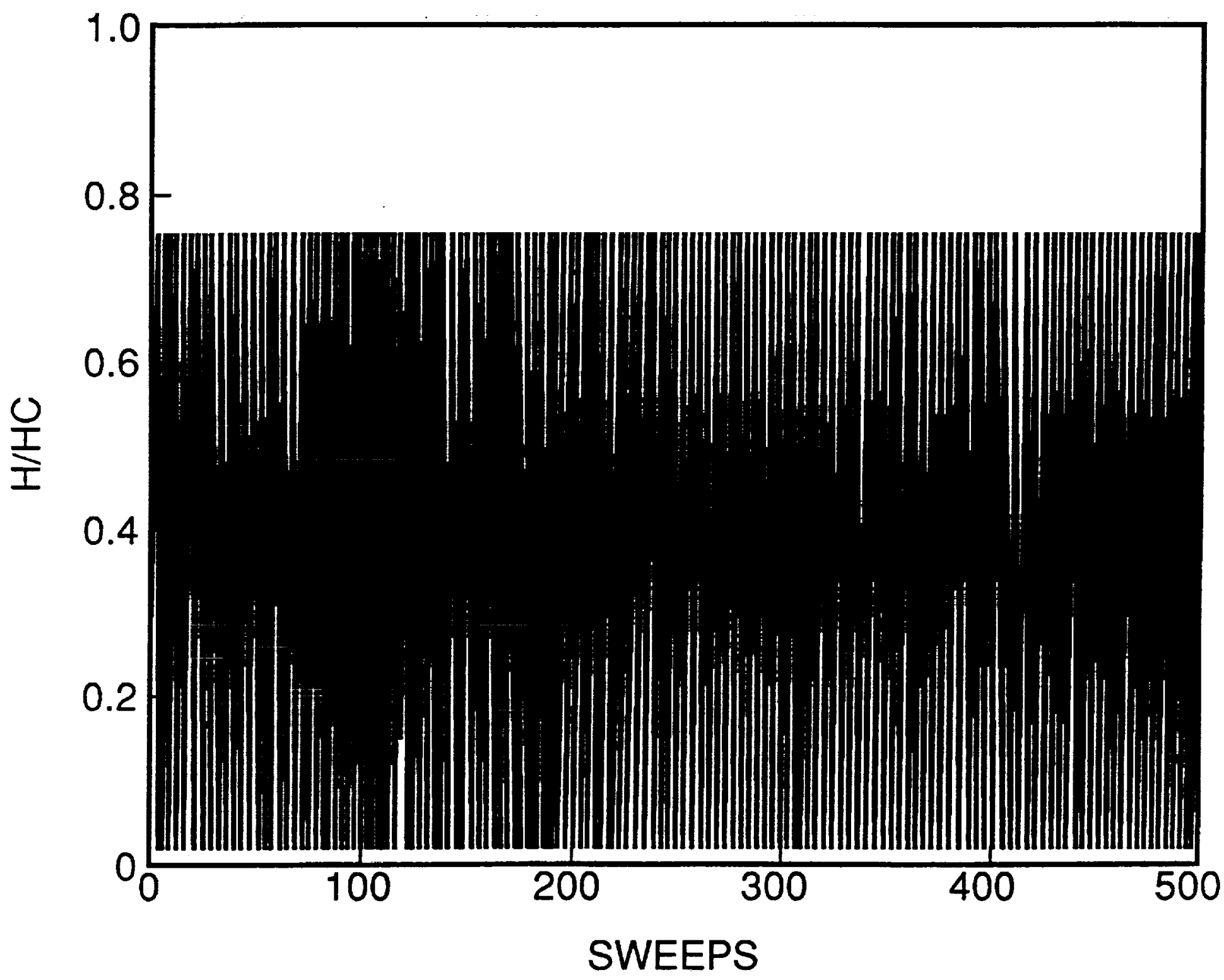

Figure 3.57. Transient Performance of High Pressure Compressor at 65 per cent Speed: Height of film over height of clearance at an intermediate stage as a function of time. Operating conditions same as in Fig. 3.40, but with inlet film. 


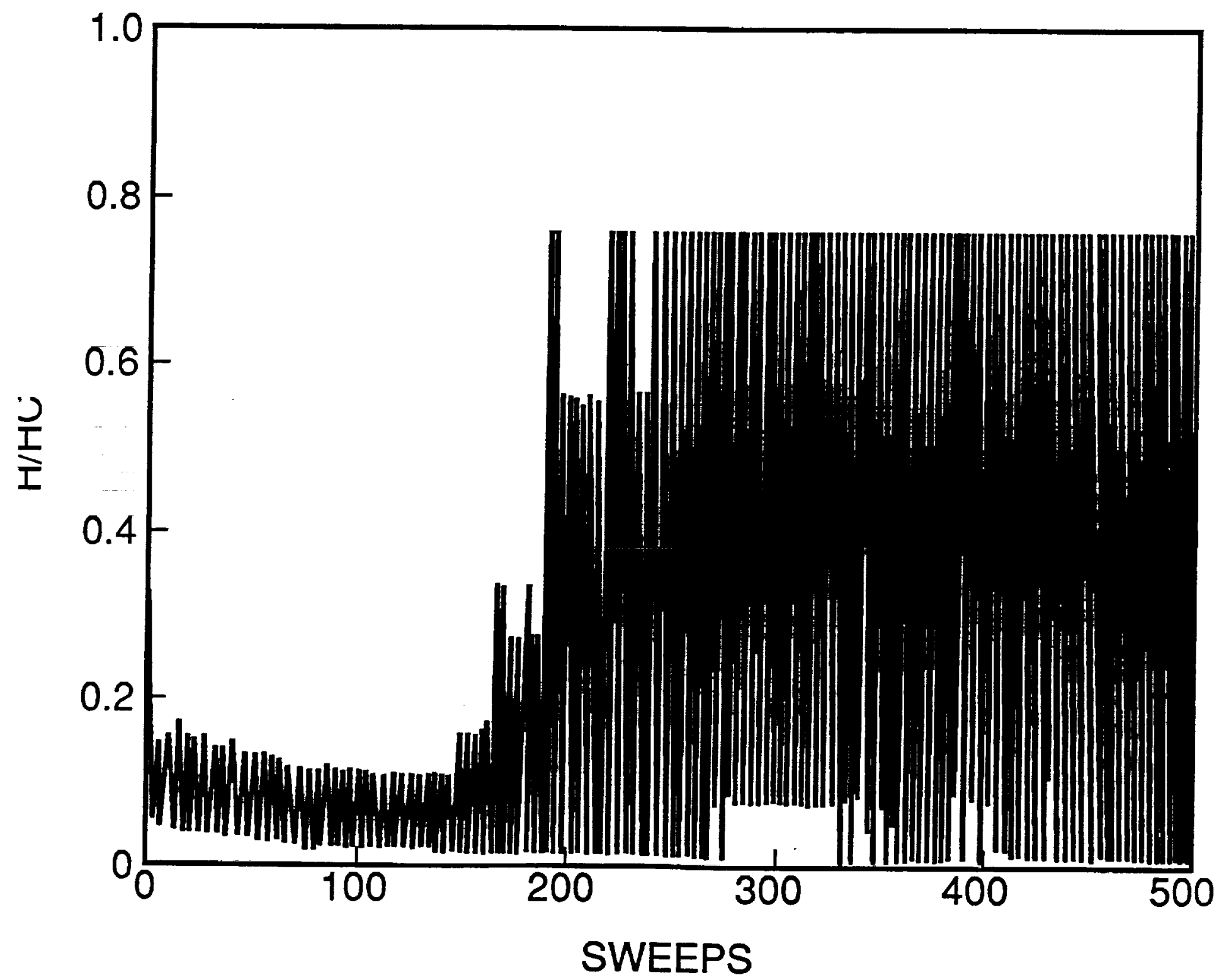

Figure 3.58. Transient Performance of High Pressure Compressor at 65 per cent Speed: Height of film over height of clearance as a function of time. Operating conditions same as in Eg. 3.44, but with inlet film. 


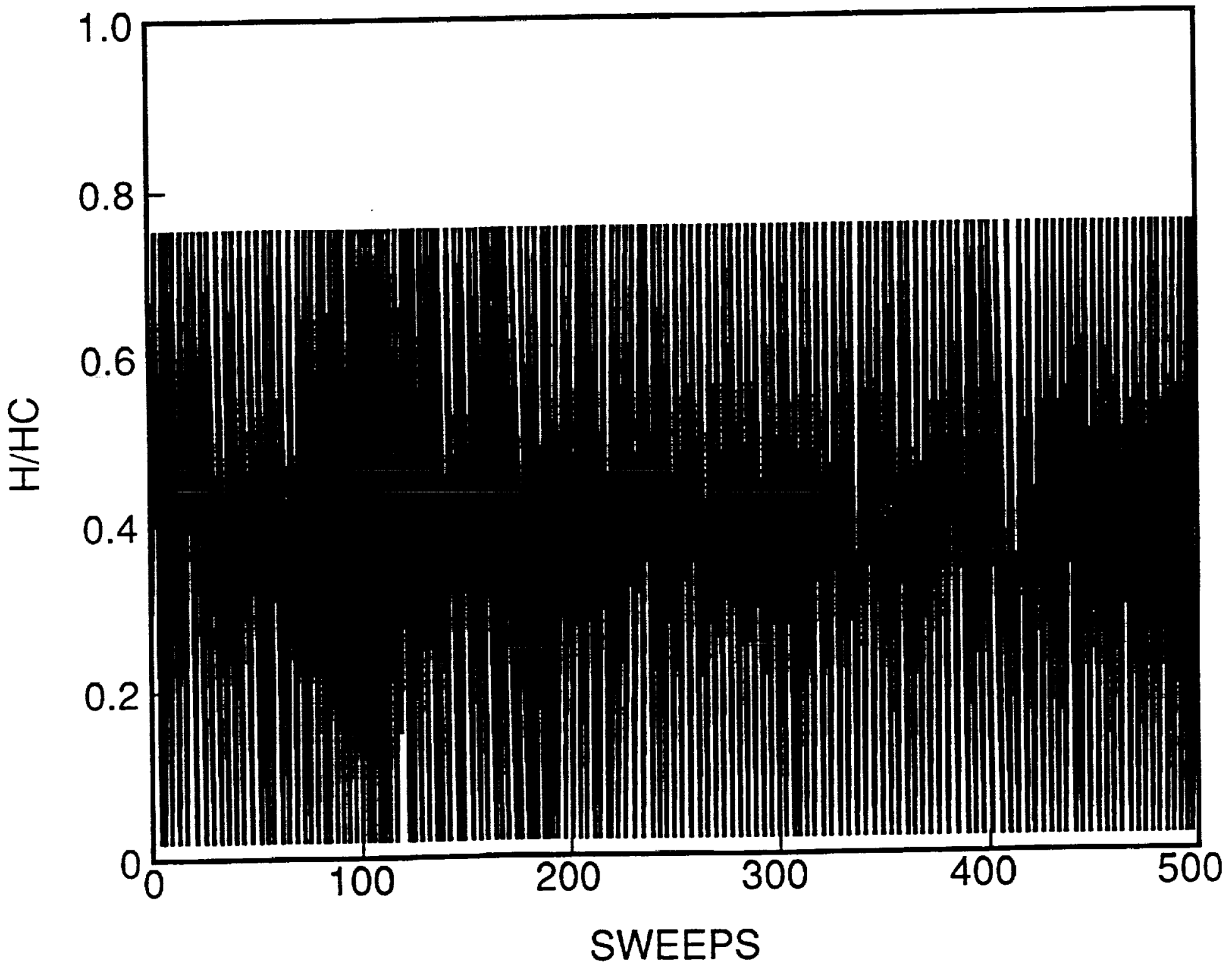

Figure 3.59. Transient Performance of High Pressure Compressor at 65 per cent Speed: Height of film over height of clearance at an intermediate stage as a function of time. Operating conditions as in Fig. 3.44, but with inlet film. 


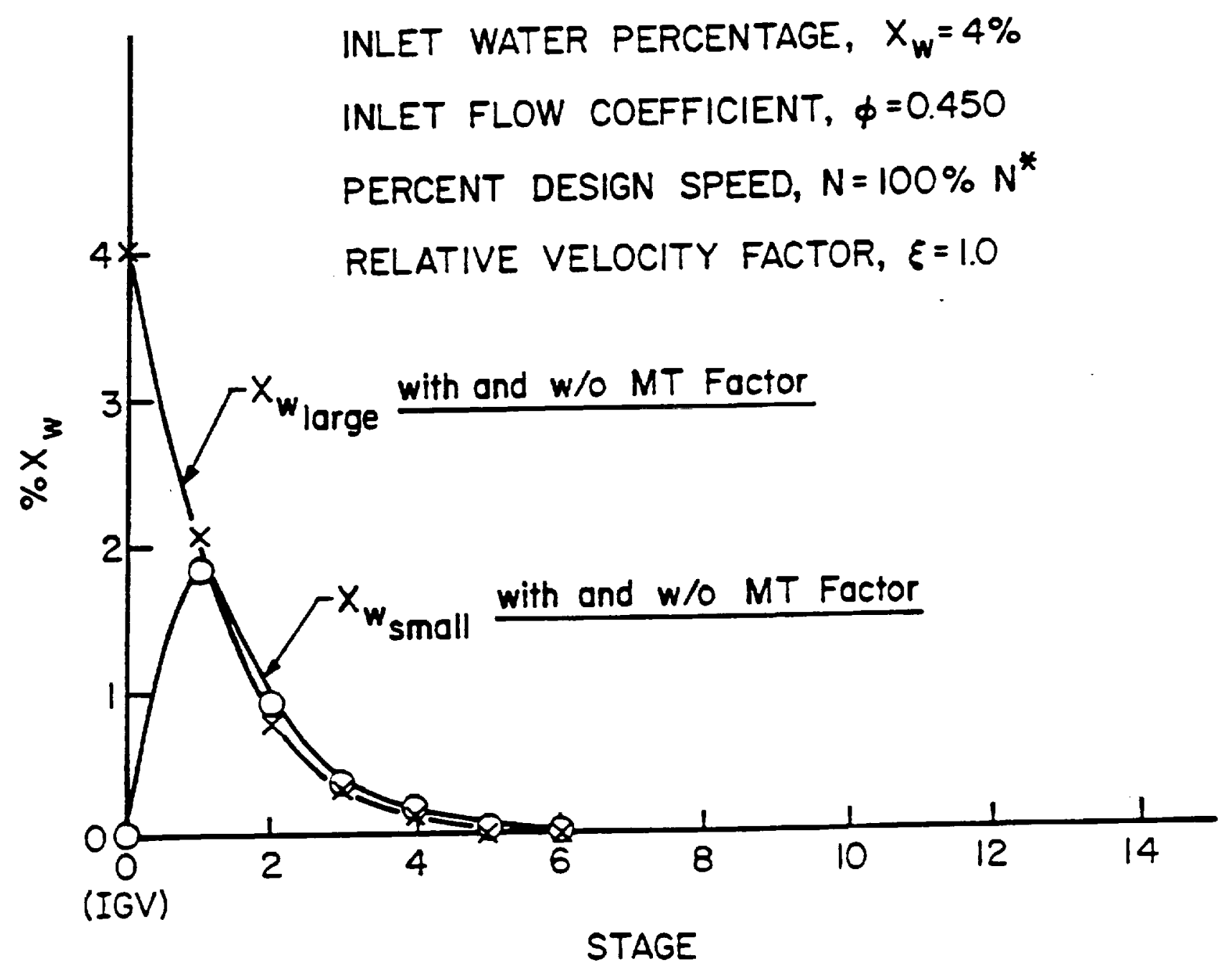

Figure 3.60.(i)

Caption on Figure 3.60.(ii) 


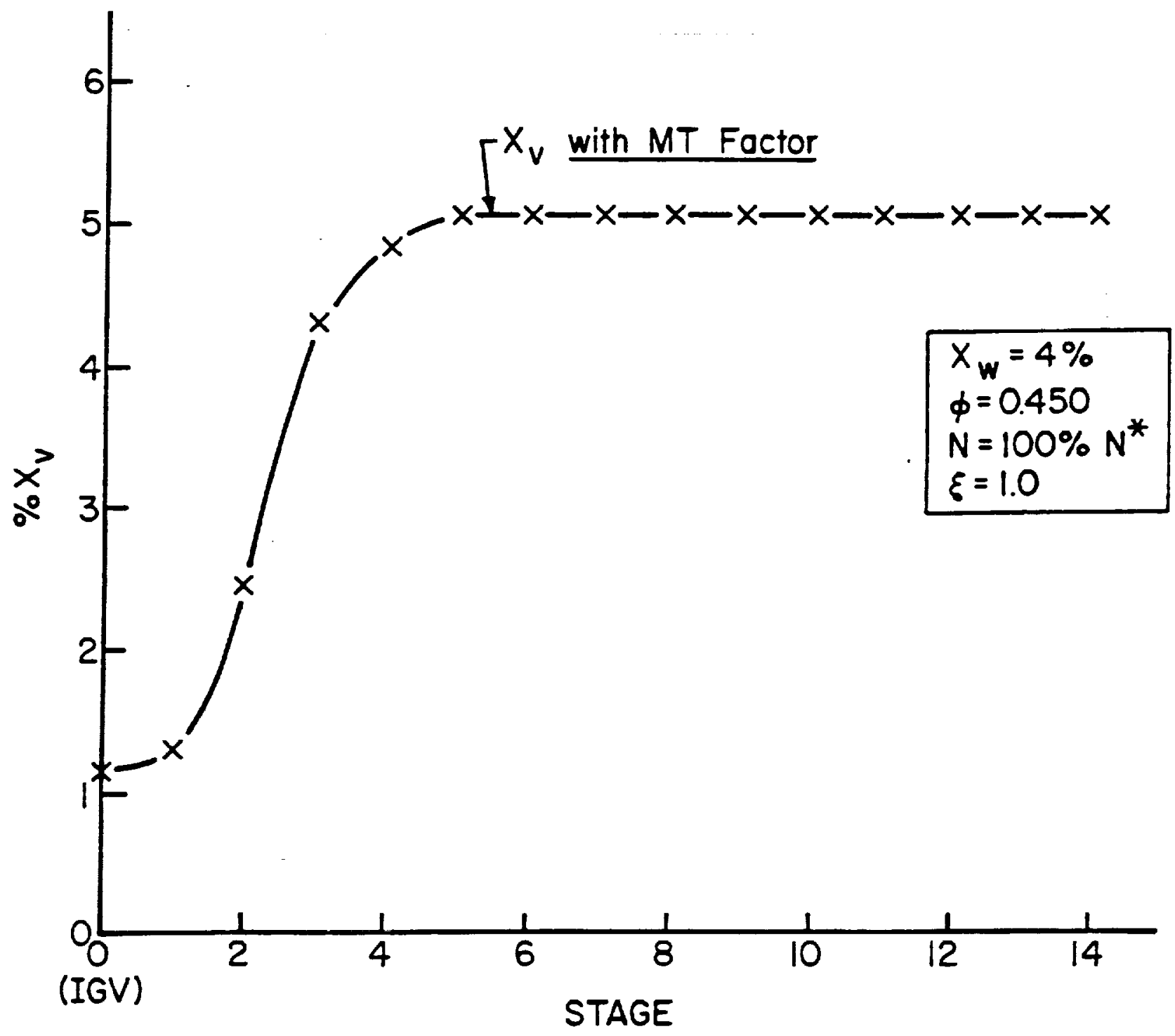

Figure 3.60.(ii)

Figure 3.60. Performance of High Pressure Compressor: Variation of mass fraction of water from stage to stage along compressor. Large droplets at entry. (i) water and (ii) vapor . $\xi=1.0 ; \zeta$ as given. 


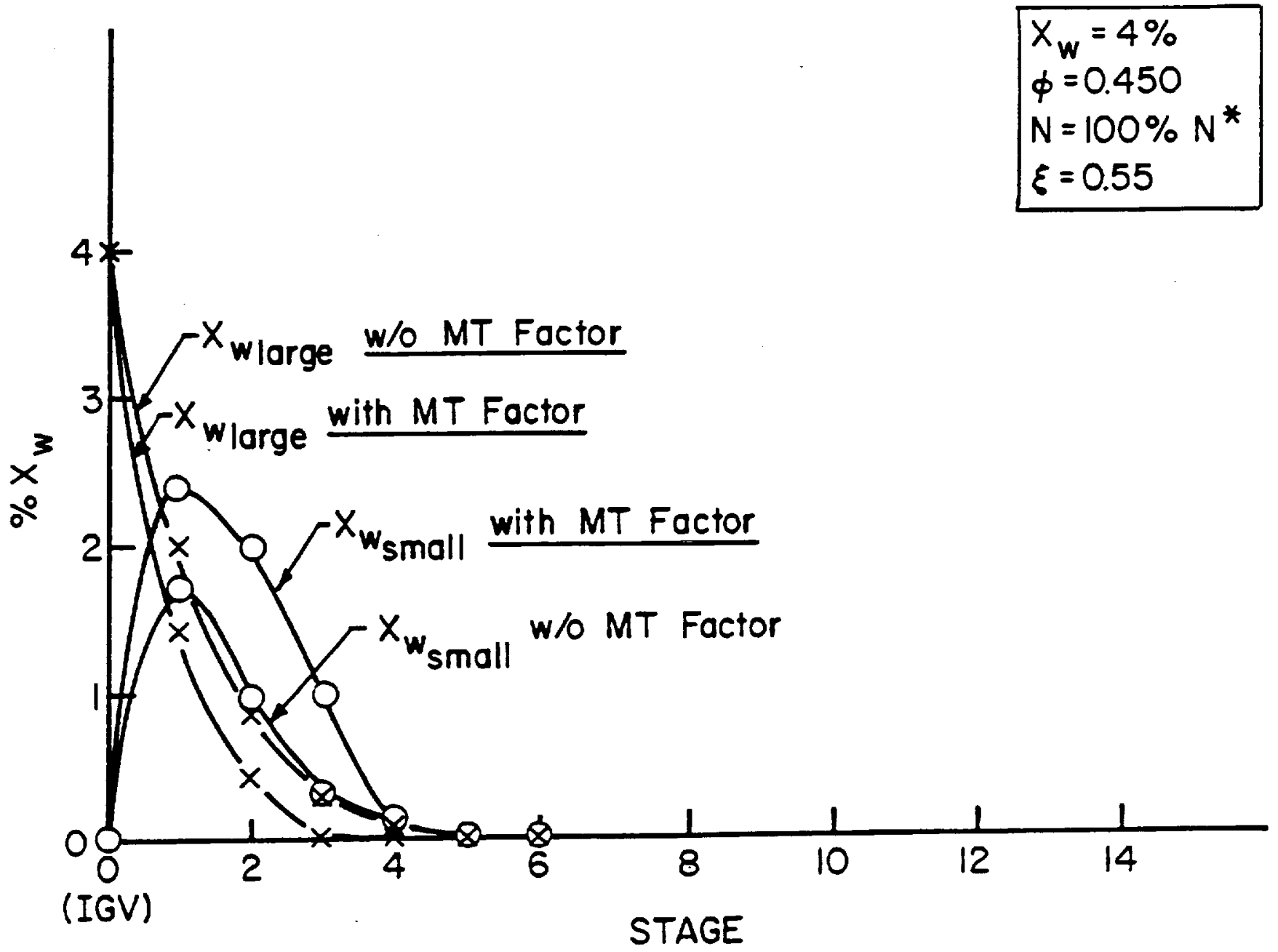

Figure 3.61. Performance of High Pressure Compressor: Variation of mass fraction of water from stage to stage along compress. Large droplets at entry. $\xi=0.55 ; \zeta$ as given. 


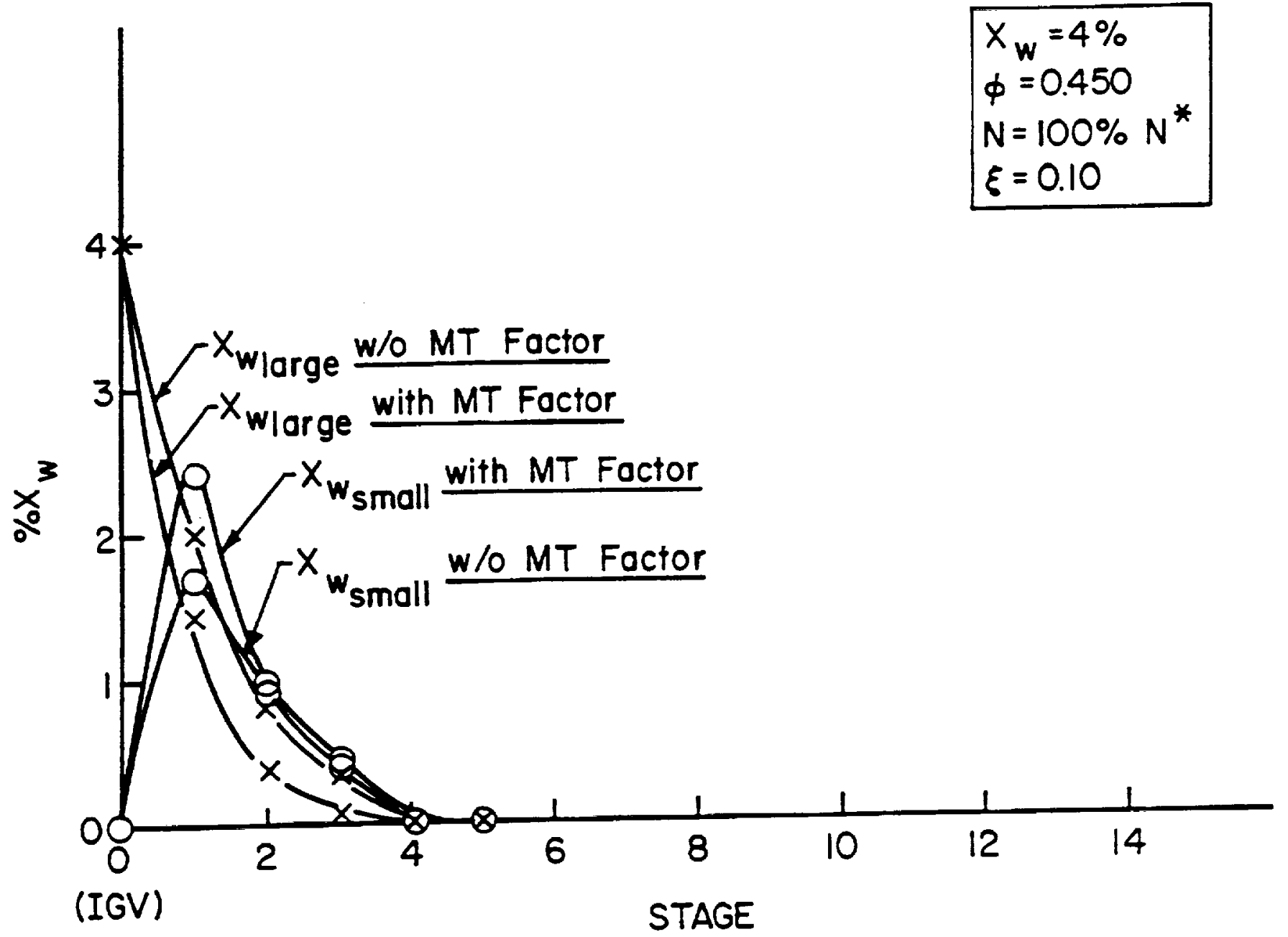

Figure 3.62. Performance of High Pressure Compressor: Variation of mass fraction of water from stage to stage along compressor. Large droplets at entry. $\xi=0.10 ; \zeta$ as given. 


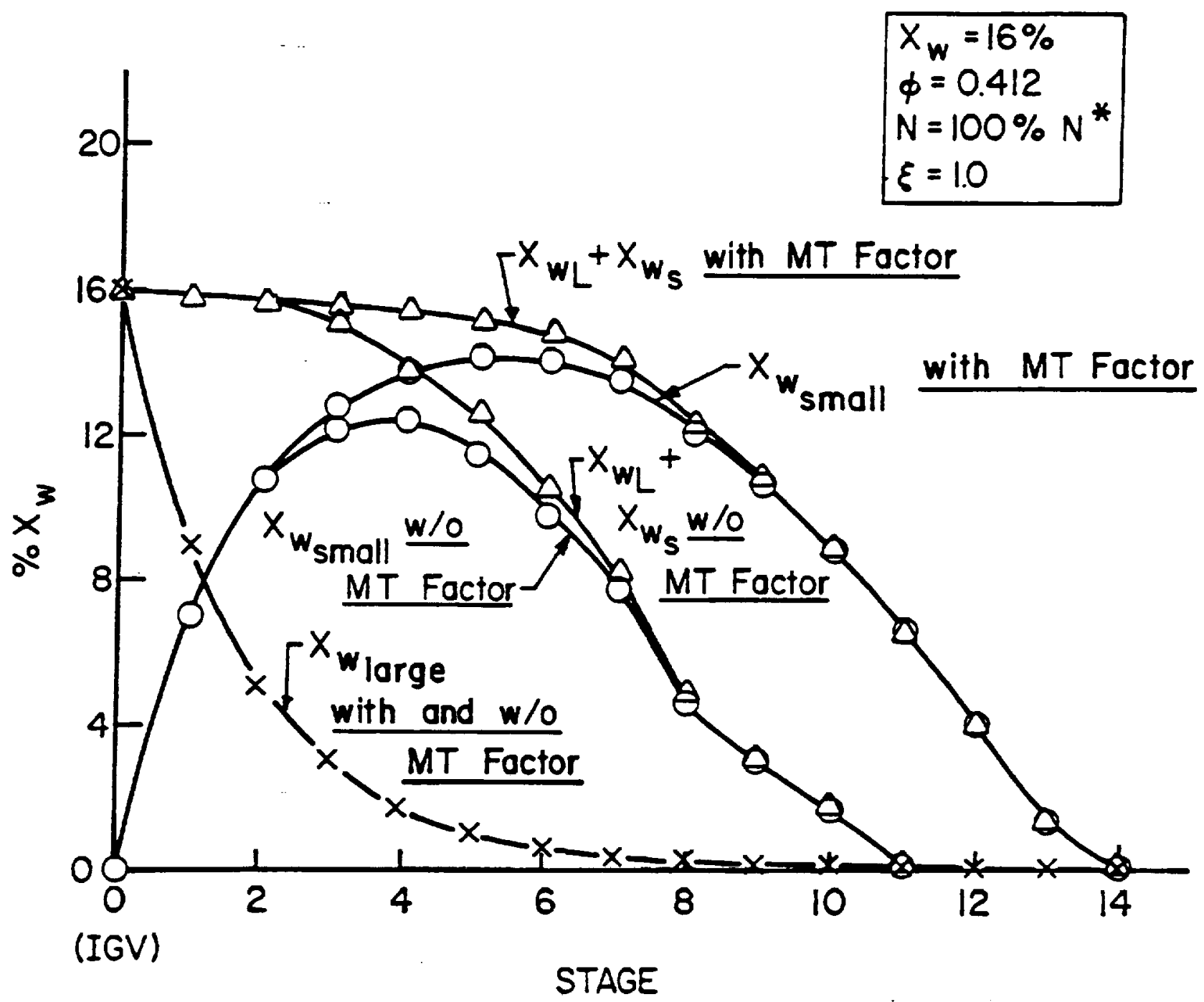

Figure 3.63. Performance of High Pressure Compressor: Variation of mass fraction of water from stage to stage along compressor. Operating conditions as in Fig. 3.21. Large droplets at entry. $\xi=1.0 ; \zeta$ as given. 


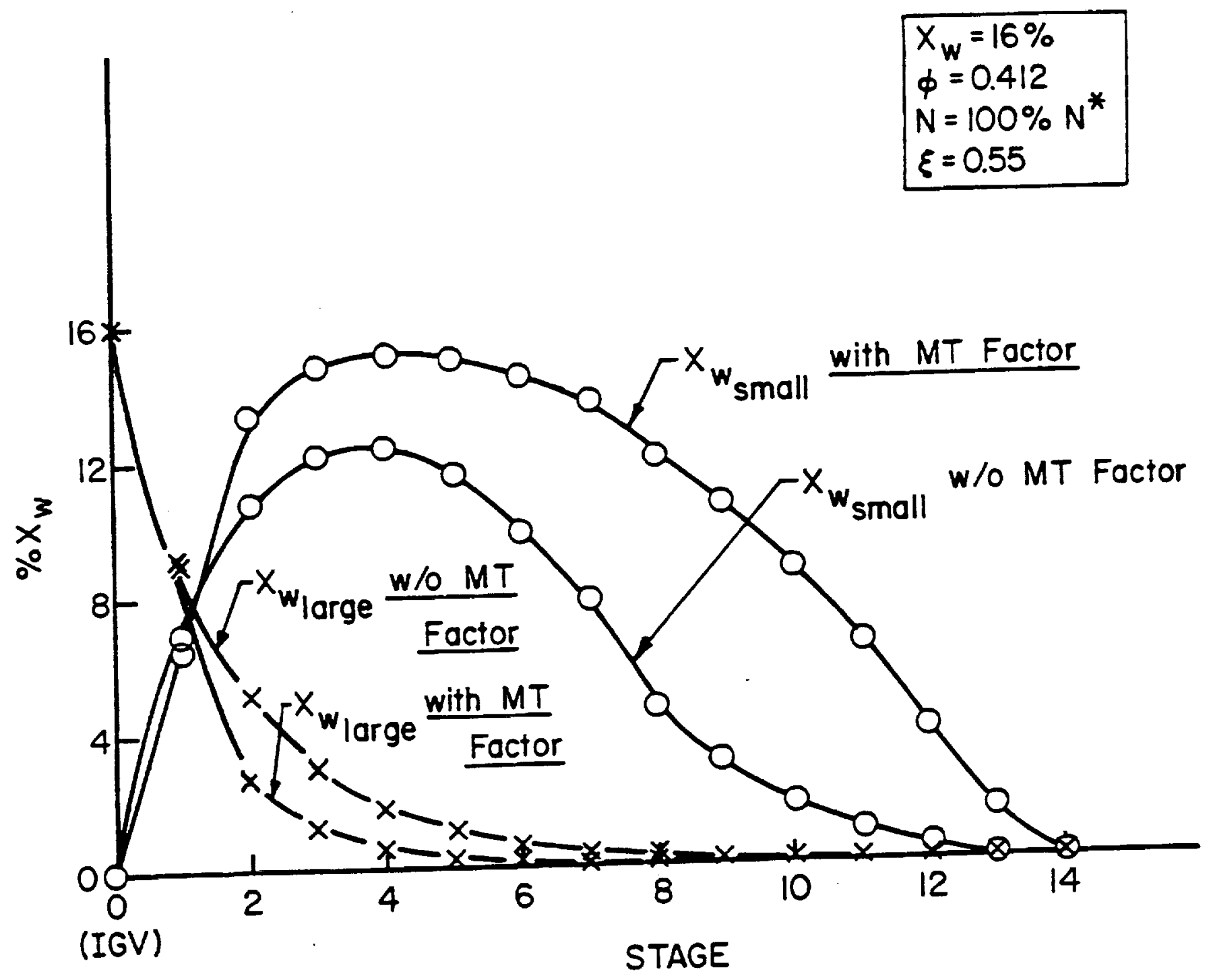

Figure 3.64. Performance of High Pressure Compressors: Variation of mass fraction of water from stage to stage along compressor. Operating conditions as in Fig. 3.21. Large droplets at entry. $\xi=0.55 ; \zeta$ as given. 

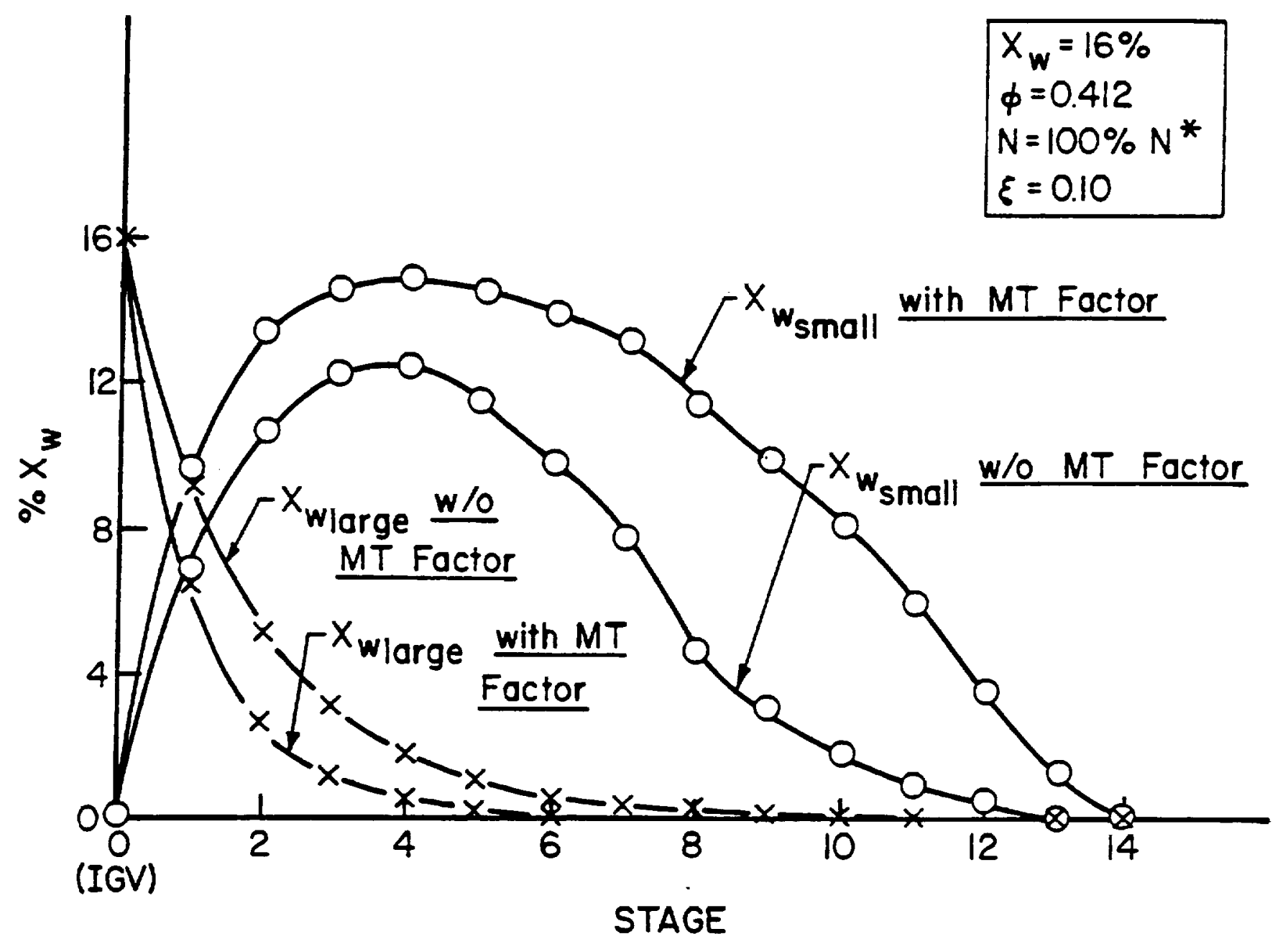

Figure 3.65. Performance of High Pressure Compressor: Variation of mass fraction of water from stage to stage along compressor. Operating conditions as in Fig. 3.21. Large droplets at entry. $\xi=0.10 ; \zeta$ as given. 


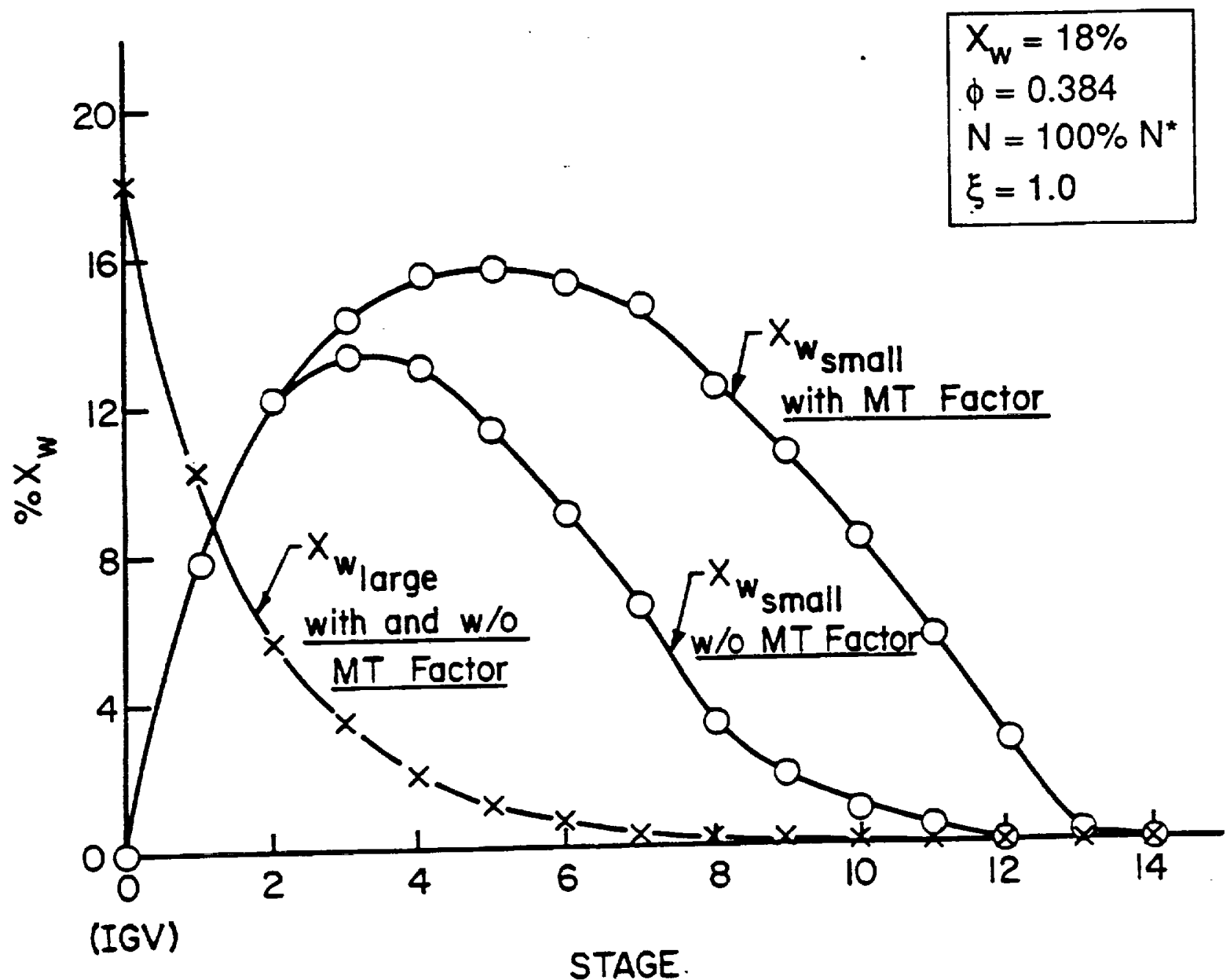

Figure 3.66. Performance of High Pressure Compressor: Variation of mass fraction of water from stage to stage along compressor. Operating conditions as in Fig. 3.28. Large droplets at entry. $\xi=1.0 ; \zeta$ as given. 

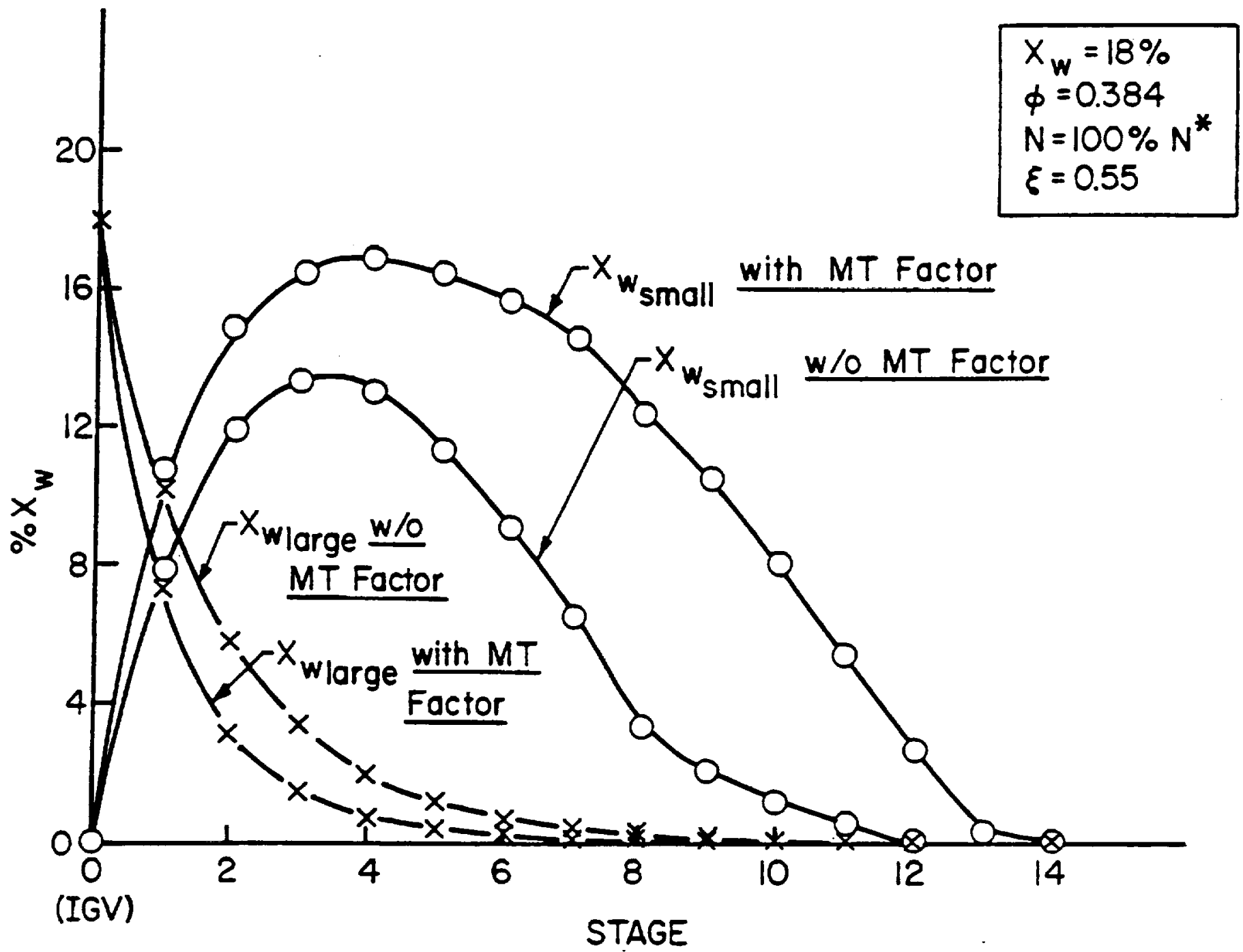

Figure 3.67. Performance of High Pressure Compressor: Variation of mass fraction of water from stage to stage along compressor. Operating conditions as in Fig. 3.28. Large droplets at entry. $\xi=0.55 ; \zeta$ as given. 


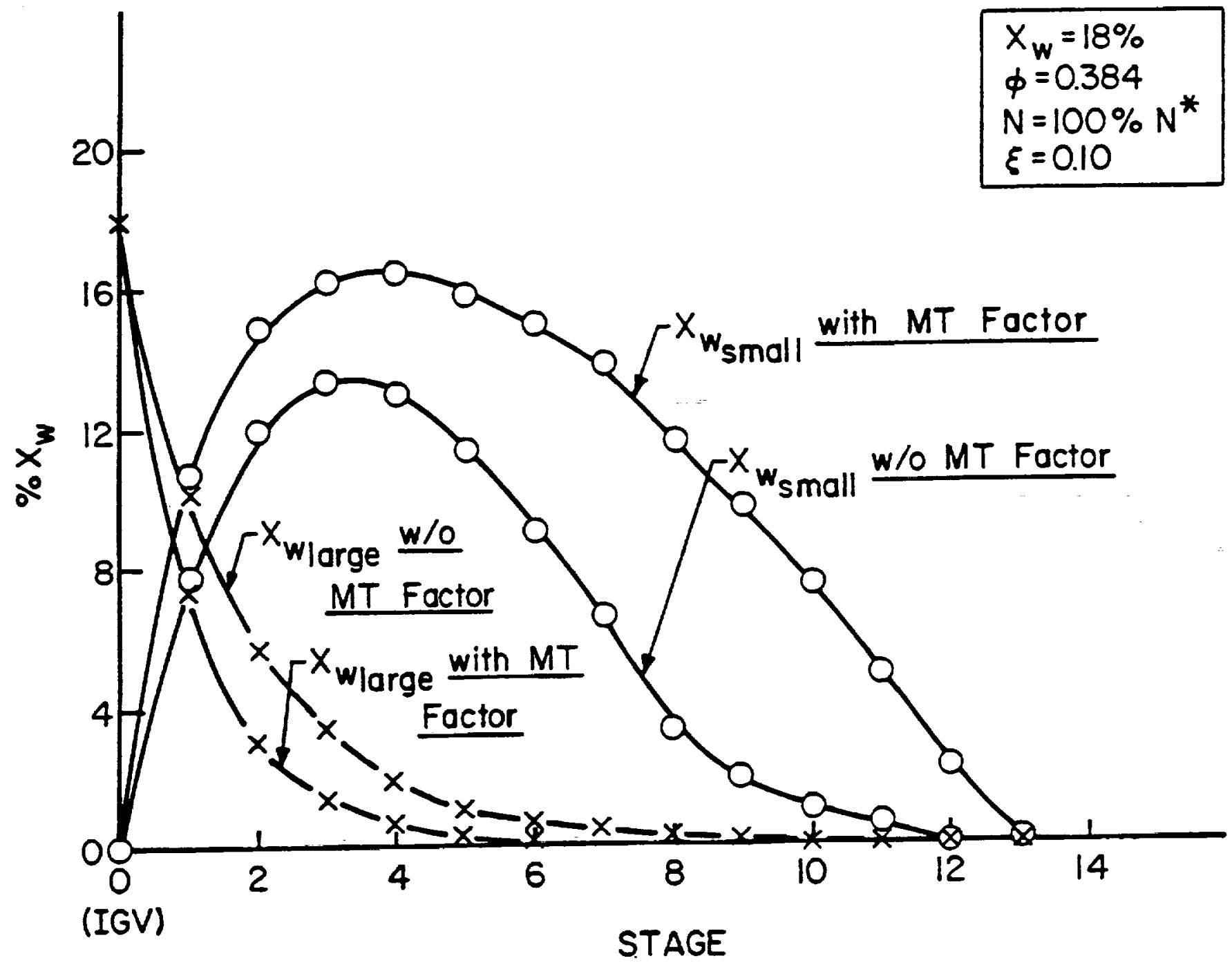

Figure 3.68. Performance of High Pressure Compressor: Variation of mass fraction of water from stage to stage along compressor. Operating conditions as in Fig. 3.28. Large droplets at entry. $\xi=0.10 ; \zeta$ as given. 


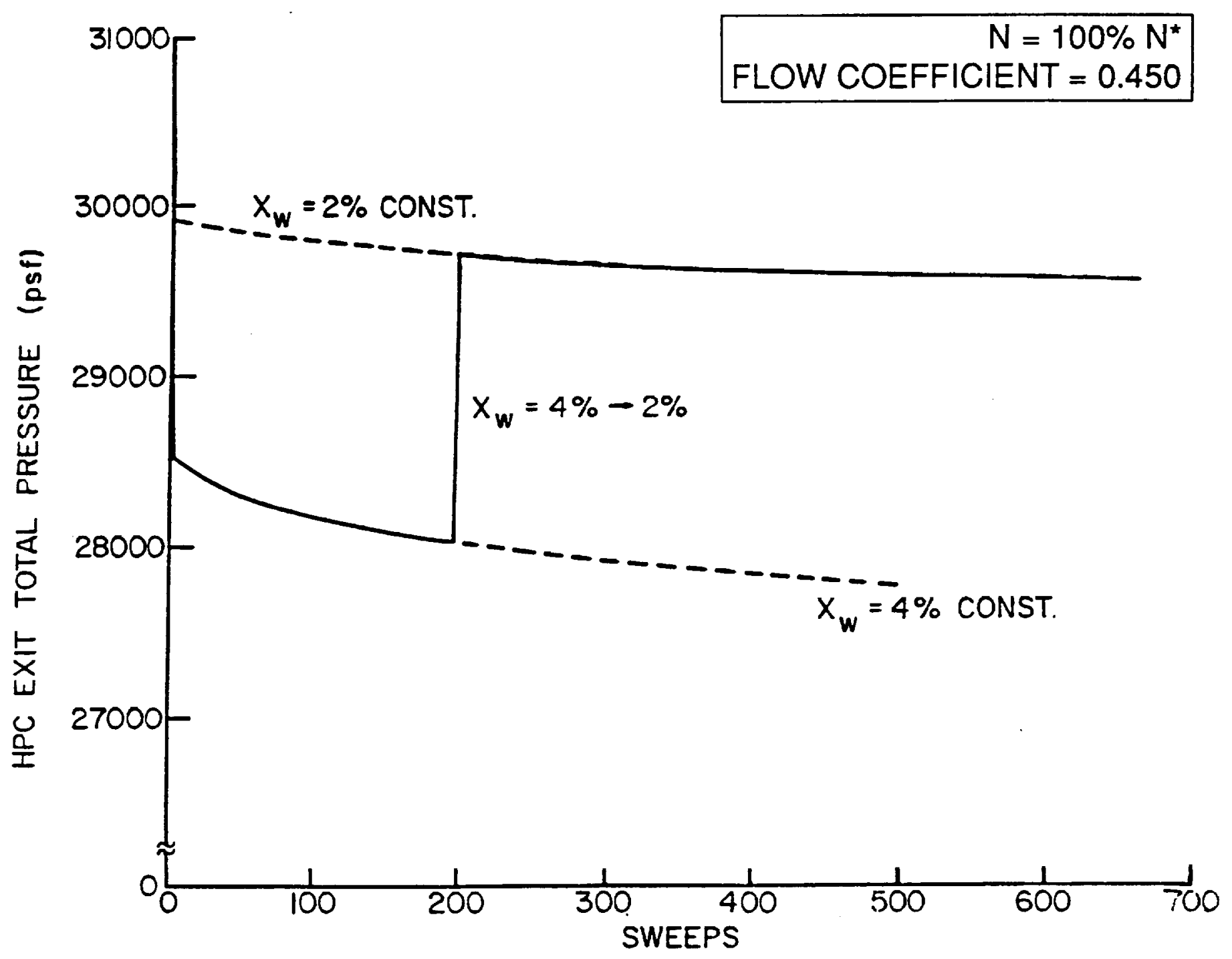

Figure 3.69. Performance of High Pressure Compressor: Variation of exit total pressure as a function of time. Operating conditions as in Fig. 3.60. Mass fraction of water ingested changing from 4.0 to 2.0 per cent. 


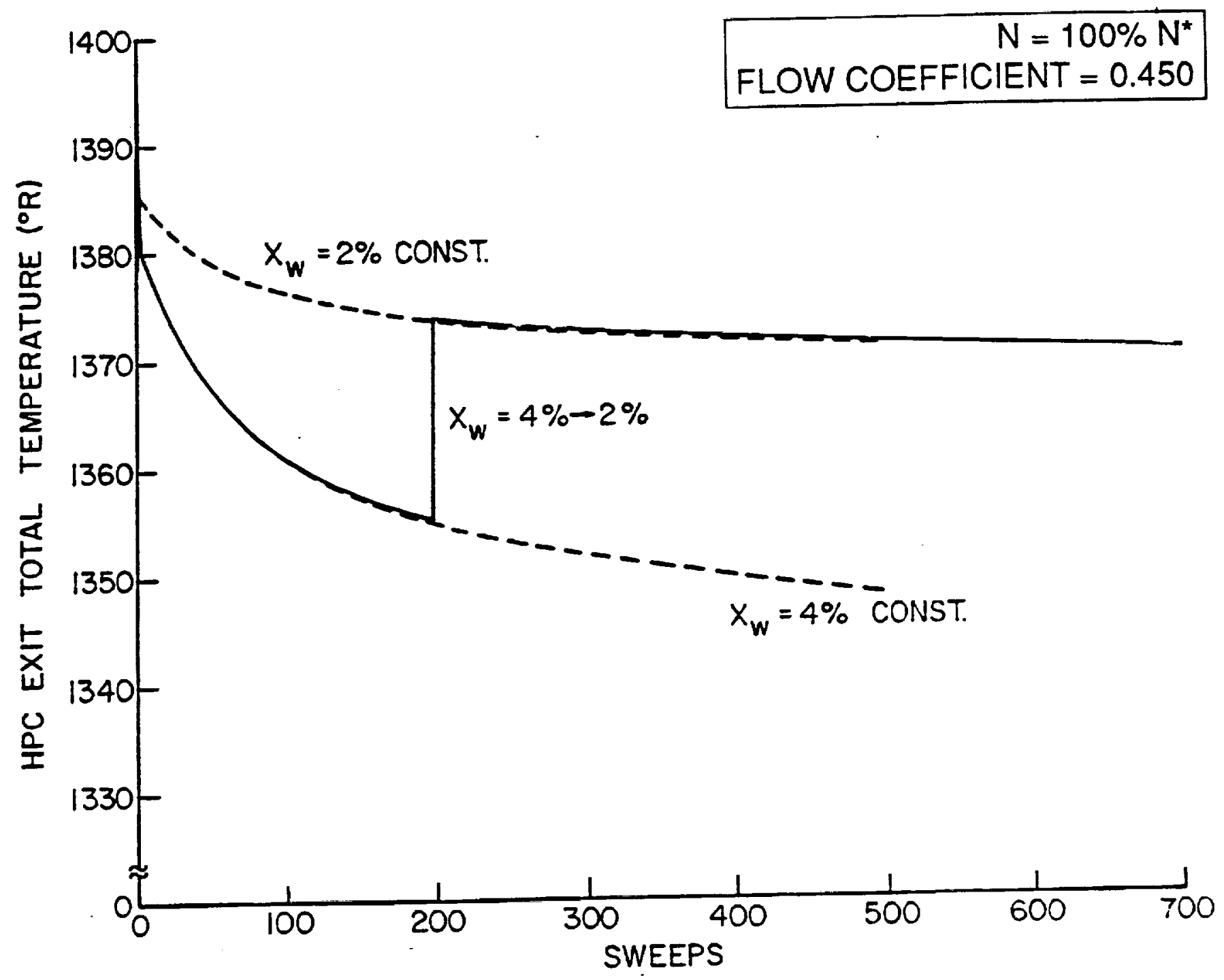

Figure 3.70. Performance of High Pressure Compressor: Variation of exit total temperature with respect to time, corresponding to operation as in Fig. 3.69. 


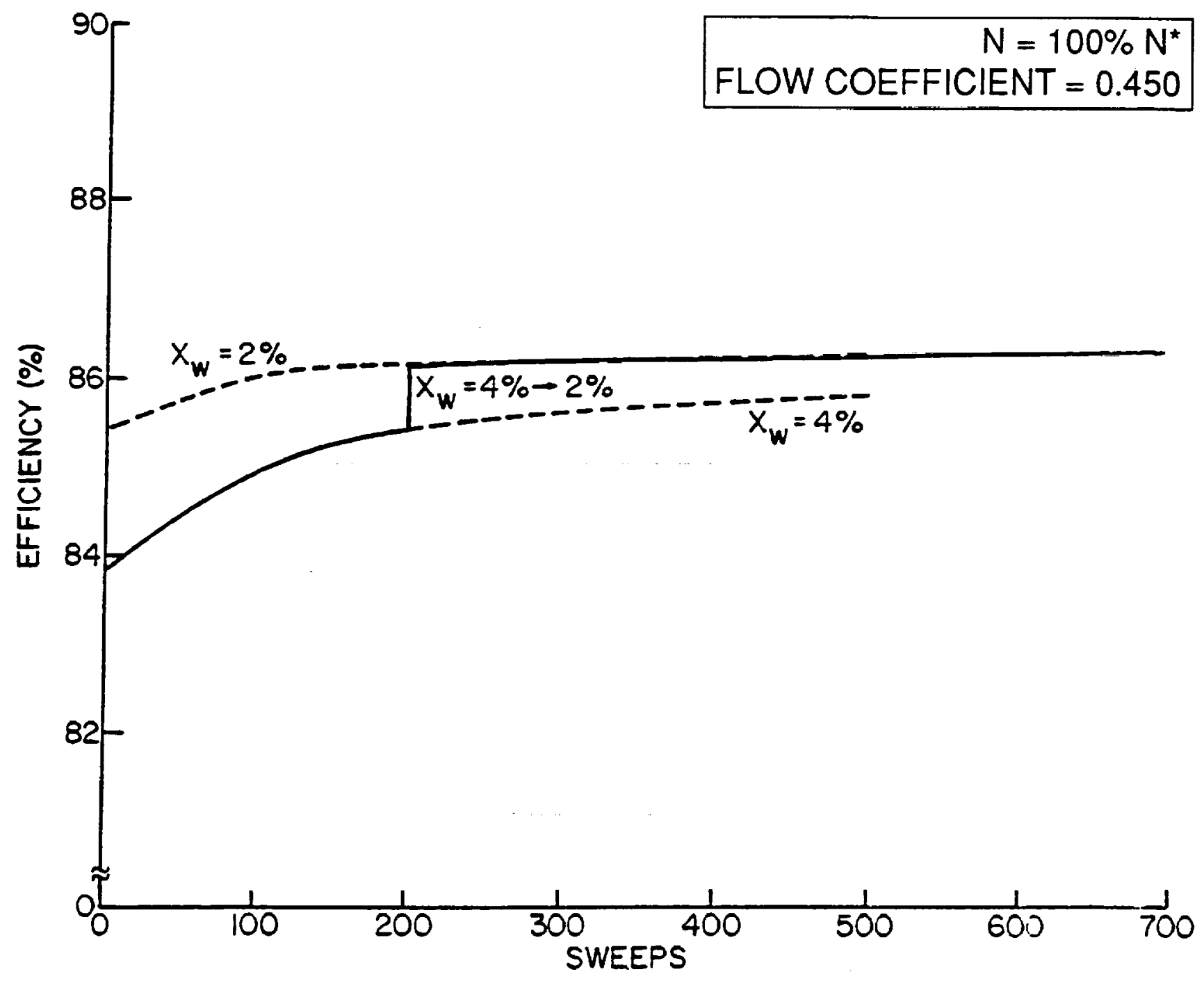

Figure 3.71. Performance of High Pressure Compressor: Variation of efficiency with respect to time. Operating conditions as in Fig. 3.69. 


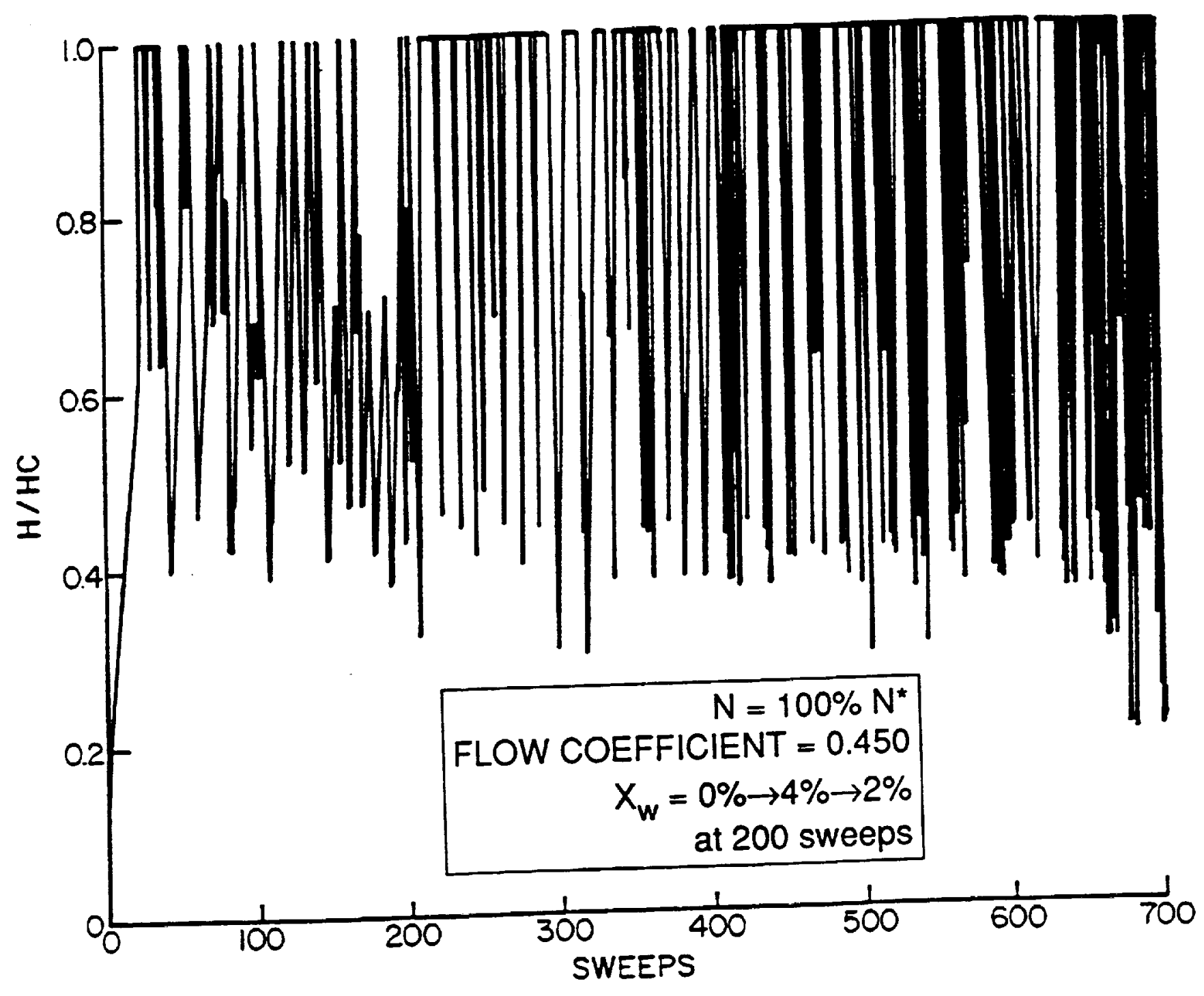

Figure 3.72. Performance of High Pressure Compressor: Variation of height of film over height of clearance as a function of time. Operating conditions as in Fig. 3.69. 


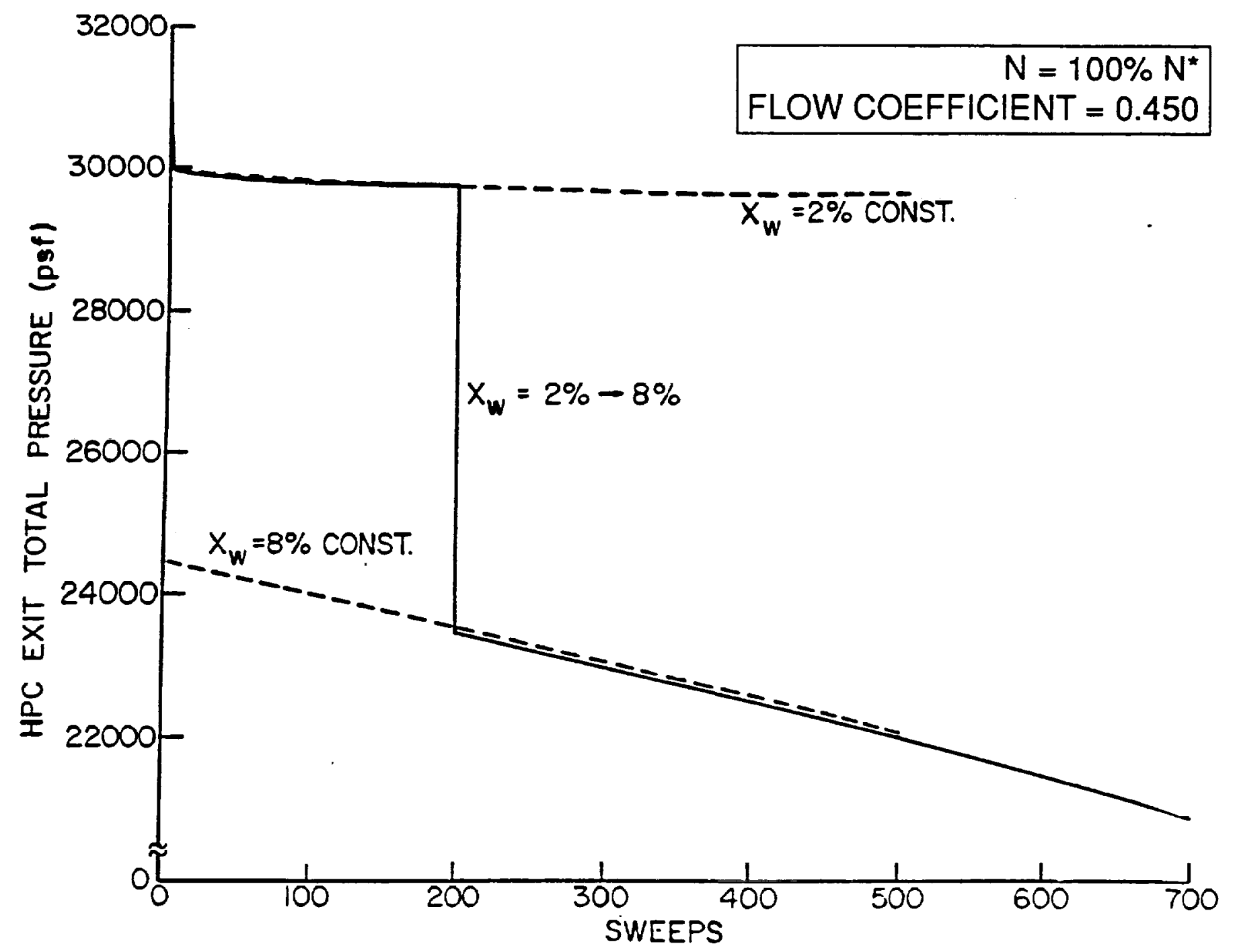

Figure 3.73. Performance of High Pressure Compressor: Variation of exit total pressure as a function of time. Operating conditions as in Fig. 3.60. Mass fraction of water ingested changing from 2.0 to 8.0 per cent. 


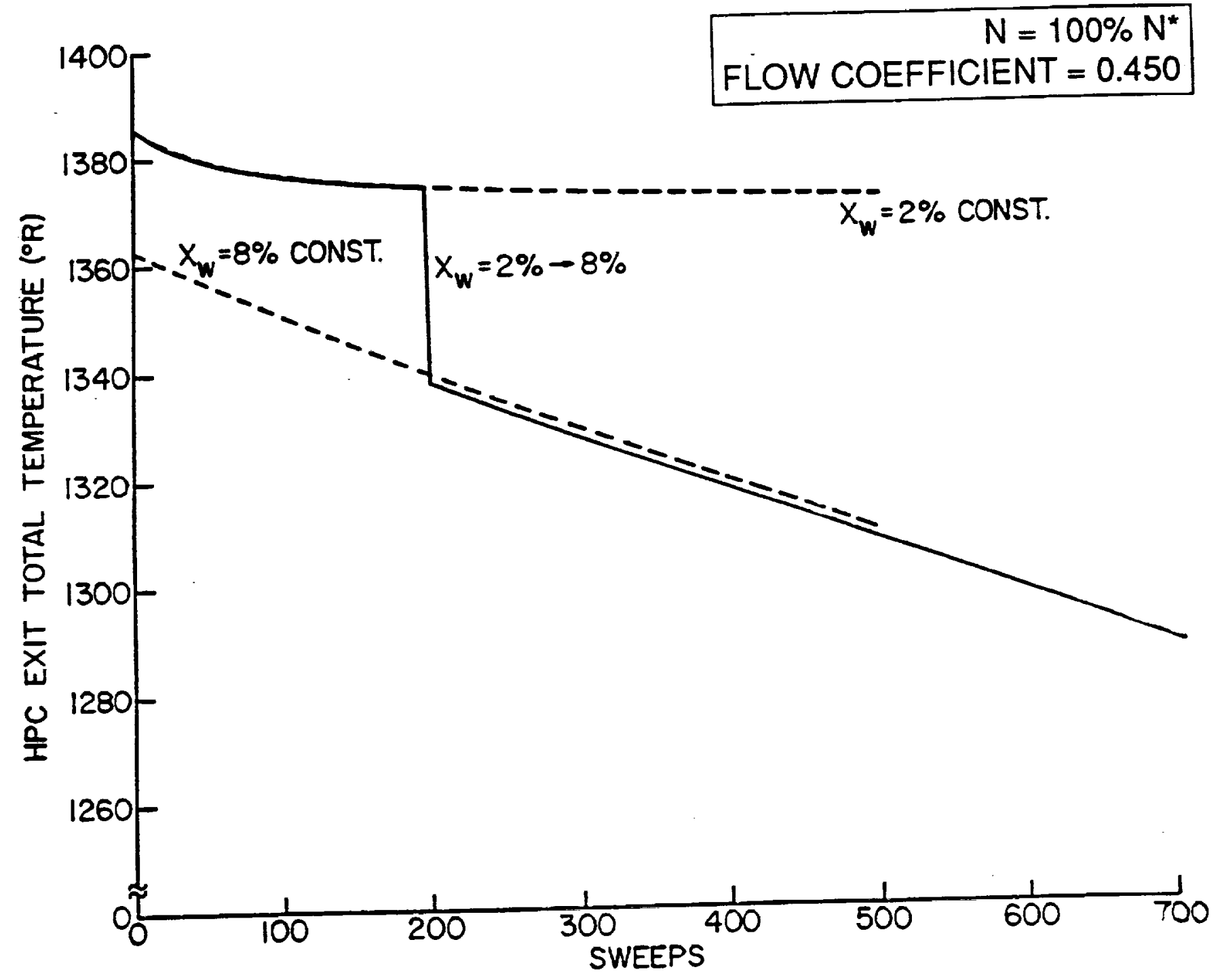

Figure 3.74. Performance of High Pressure Compressor: Variation of exit total temperature as a function of time. Operating conditions as in Fig. 3.73. 


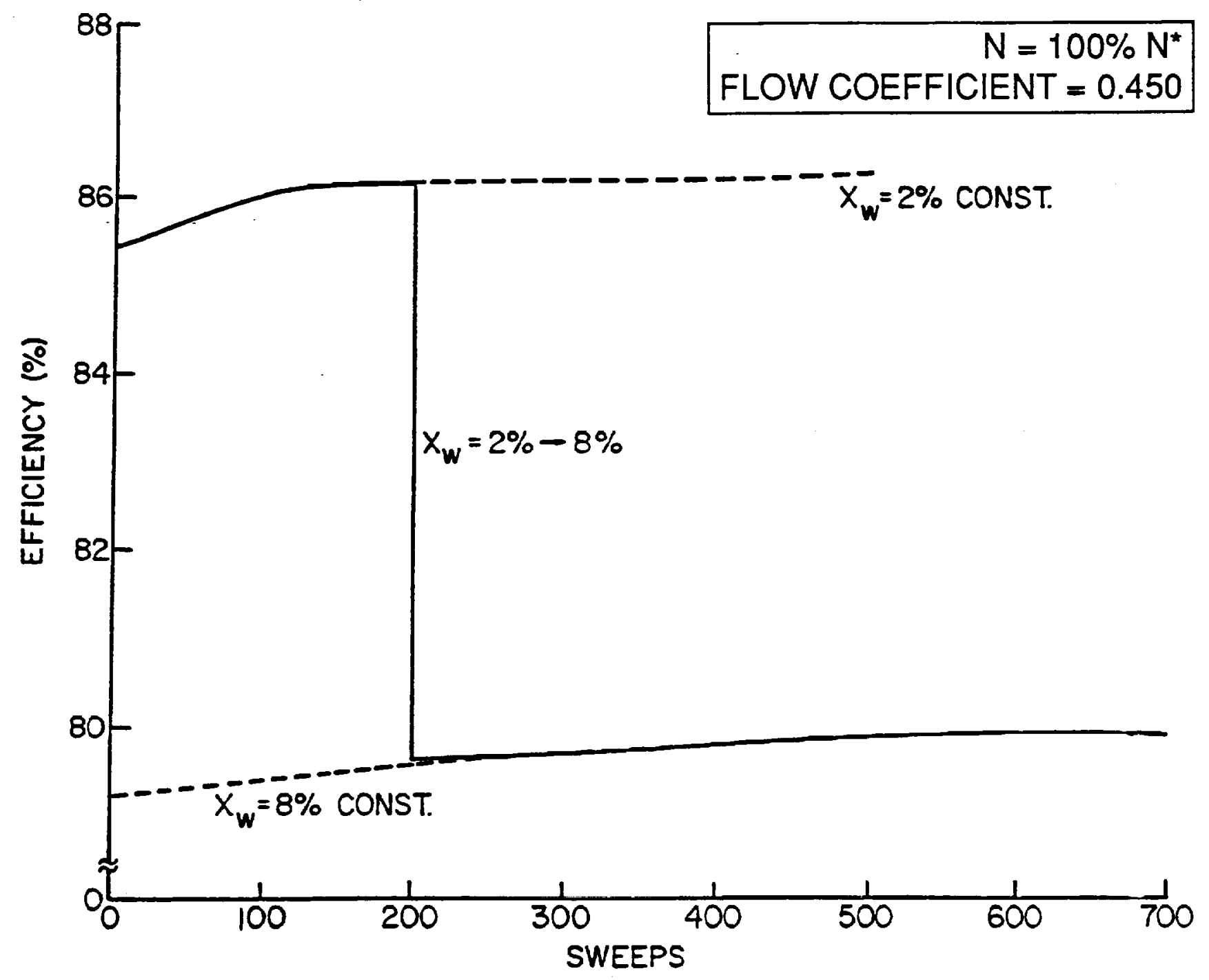

Figure 3.75. Performance of High Pressure Compressor. Variation of efficiency as a function of time. Operating conditions as in Fig. 3.73. 


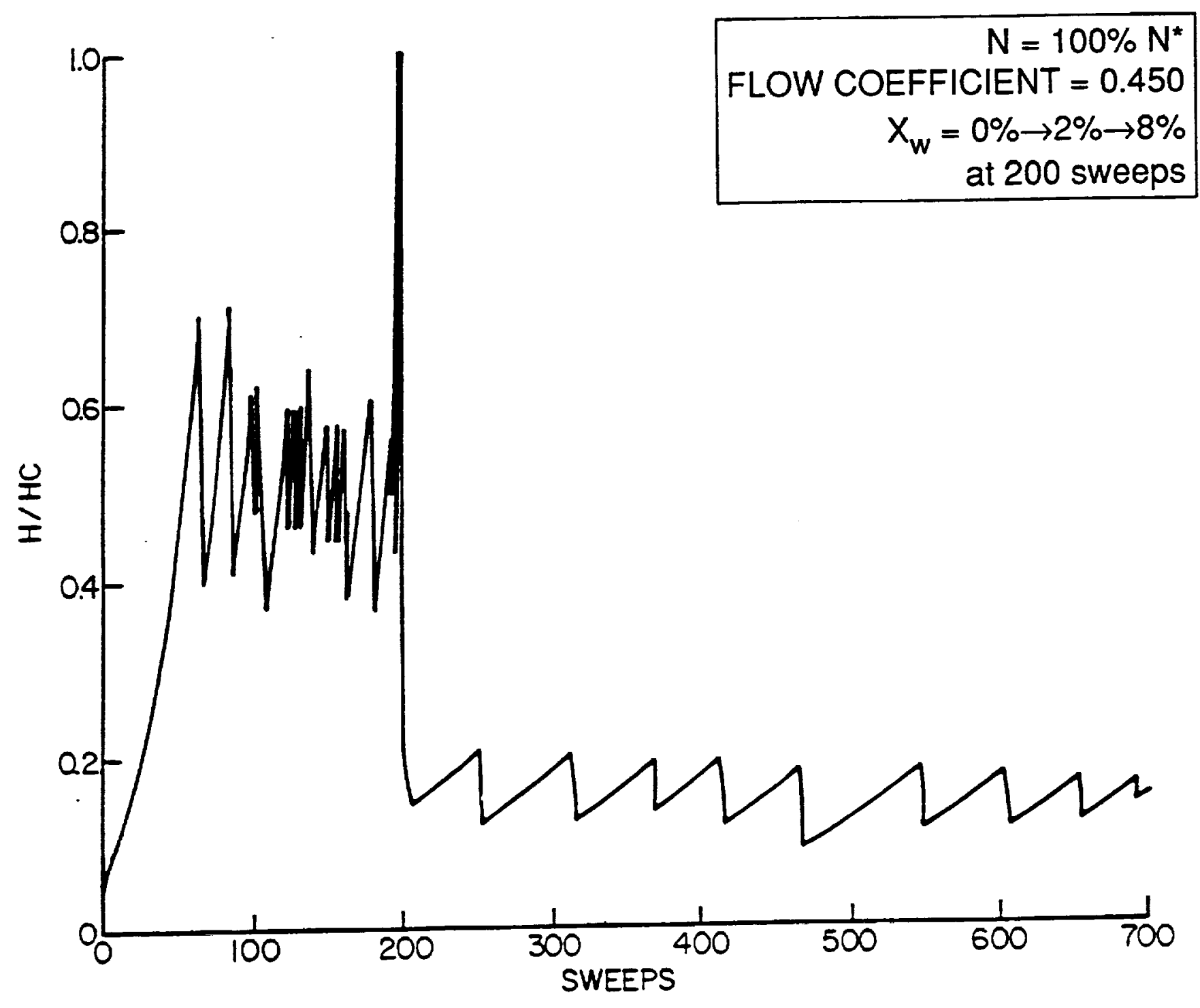

Figure 3.76. Performance of High Pressure Compressor: Variation of height of film over height of clearance as a function of time. Operating conditions as in Fig. 3.73. 


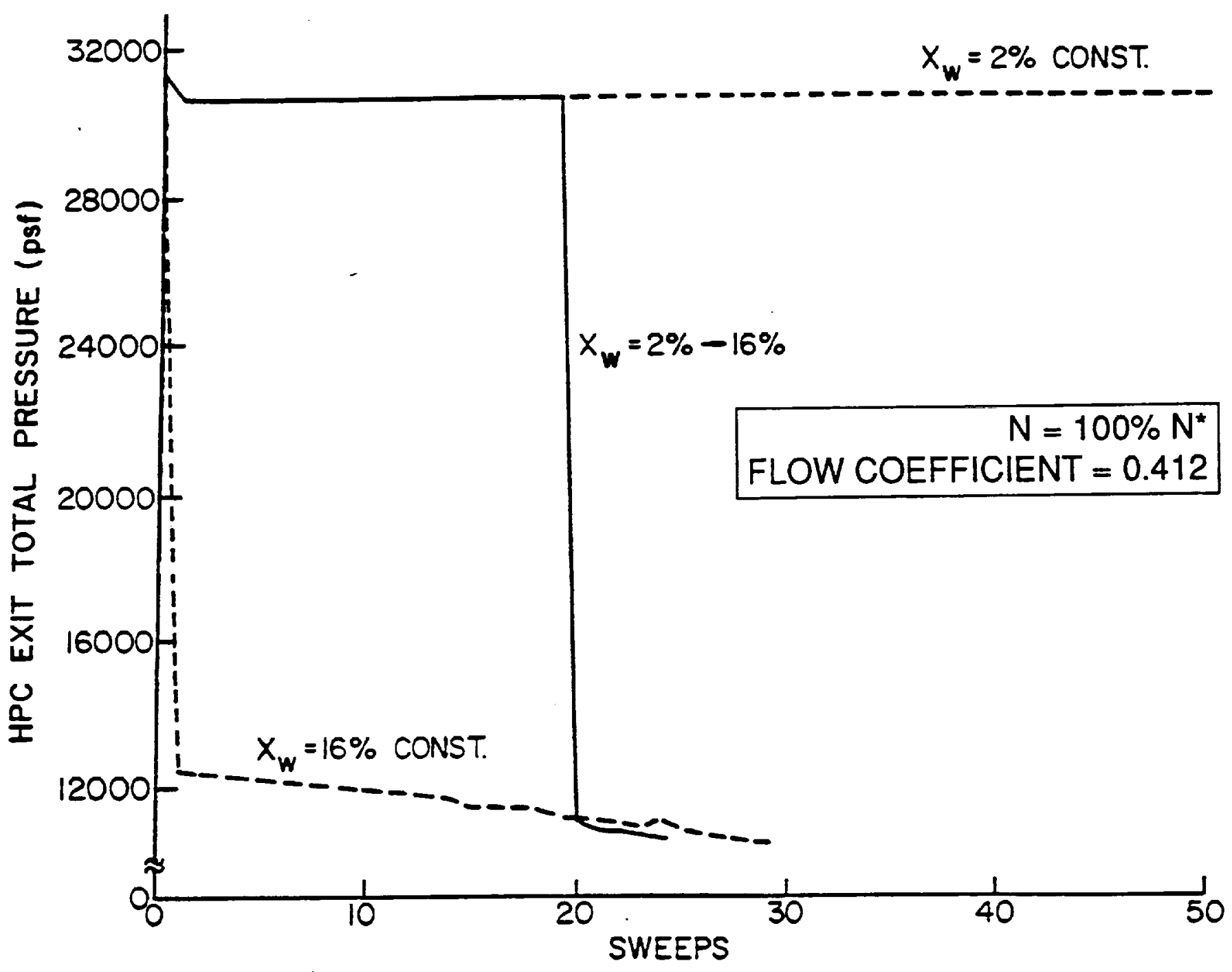

Figure 3.77. Performance of High Pressure Compressor: Variation of exit total pressure as a function of time. Operating conditions as in Fig. 3.63. Mass fraction of water ingested changing from 2.0 to 16.0 per cent. 


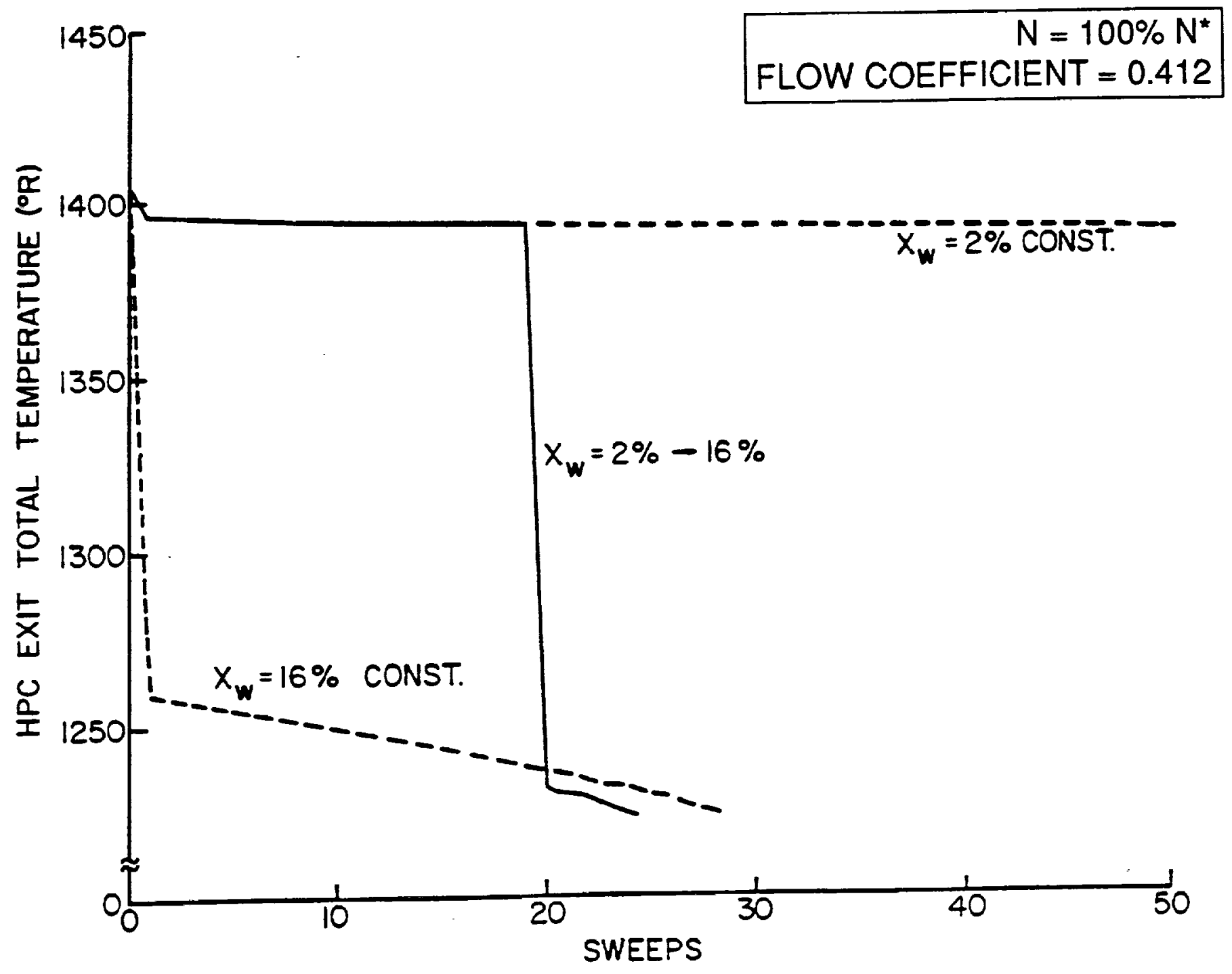

Figure 3.78. Performance of High Pressure Compressor: Variation of exit total temperature as a function of time. Operating conditions as in Fig. 3.77. 


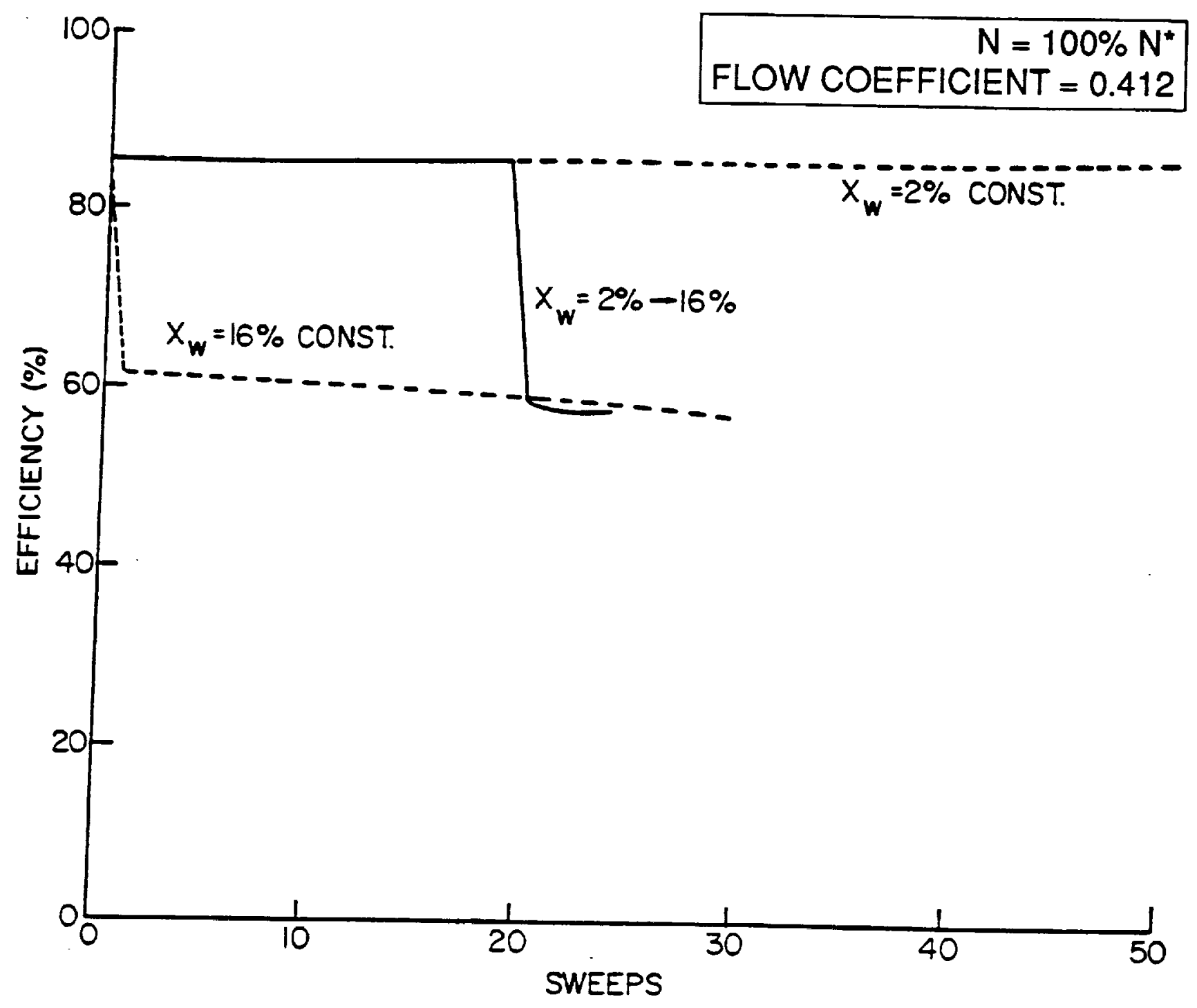

Figure 3.79. Performance of High Pressure Compressor: Variation of efficiency as a function of time. Operating conditions as in Fig. 3.77. 


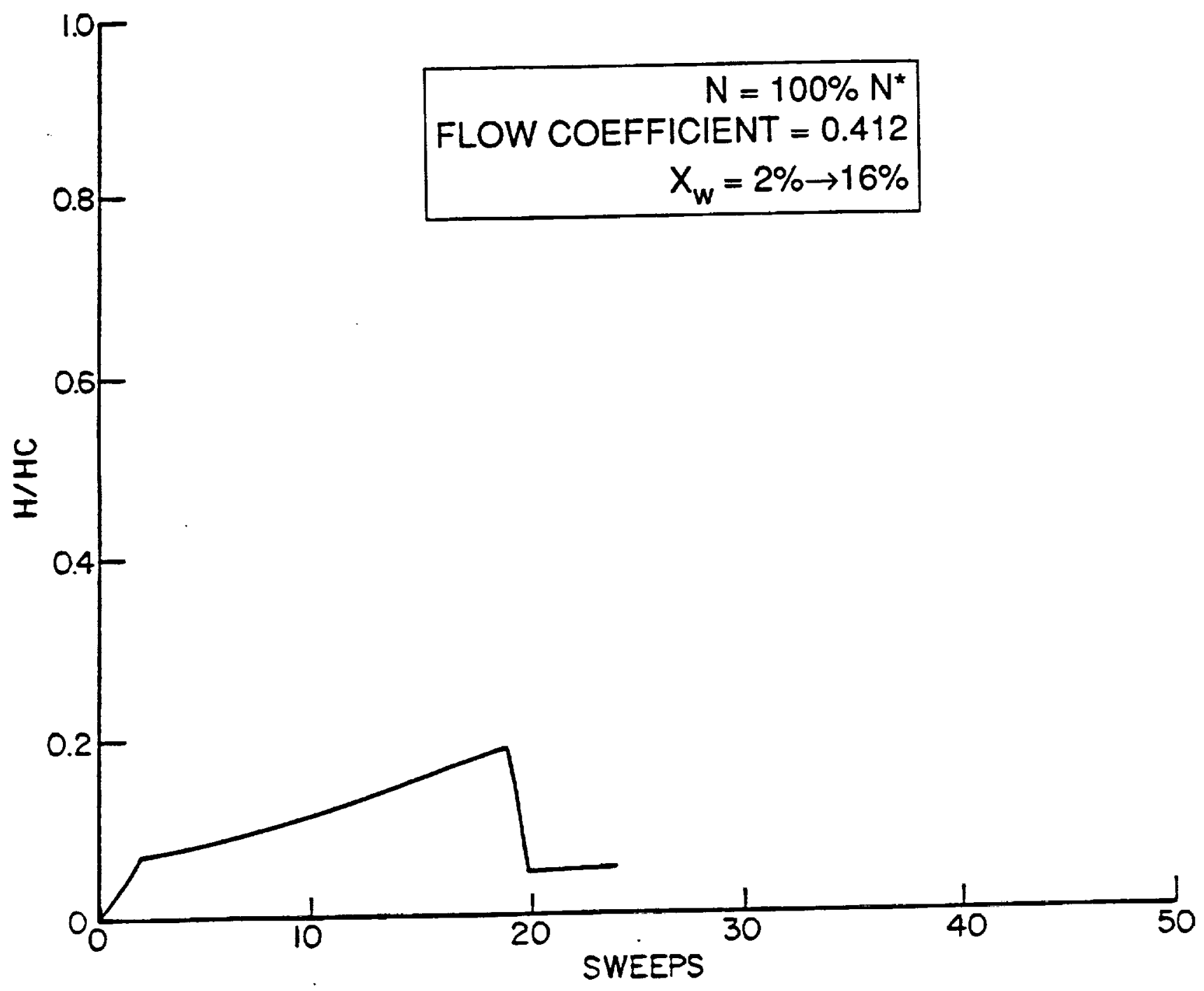

Figure 3.80. Performance of High Pressure Compressor: Variation of height of film over height of clearance as a function of time. Operating conditions as in Fig. 3.77. 


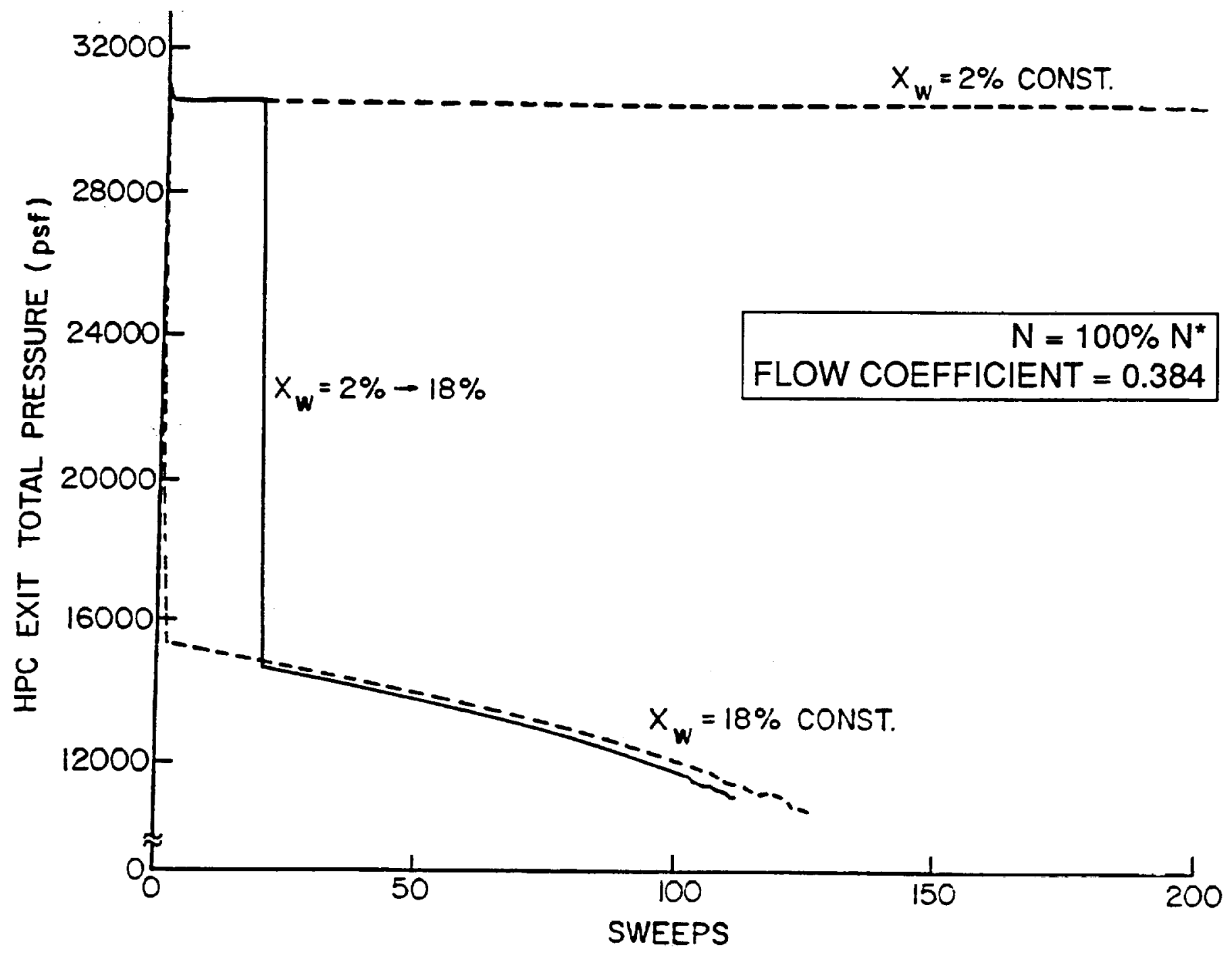

Figure 3.81. Performance of High Pressure Compressor: Variation of exit total pressure as a function of time. Operating conditions as in Fig. 3.66. Mass fraction of water ingested changing from 2.0 to 18.0 per cent. 


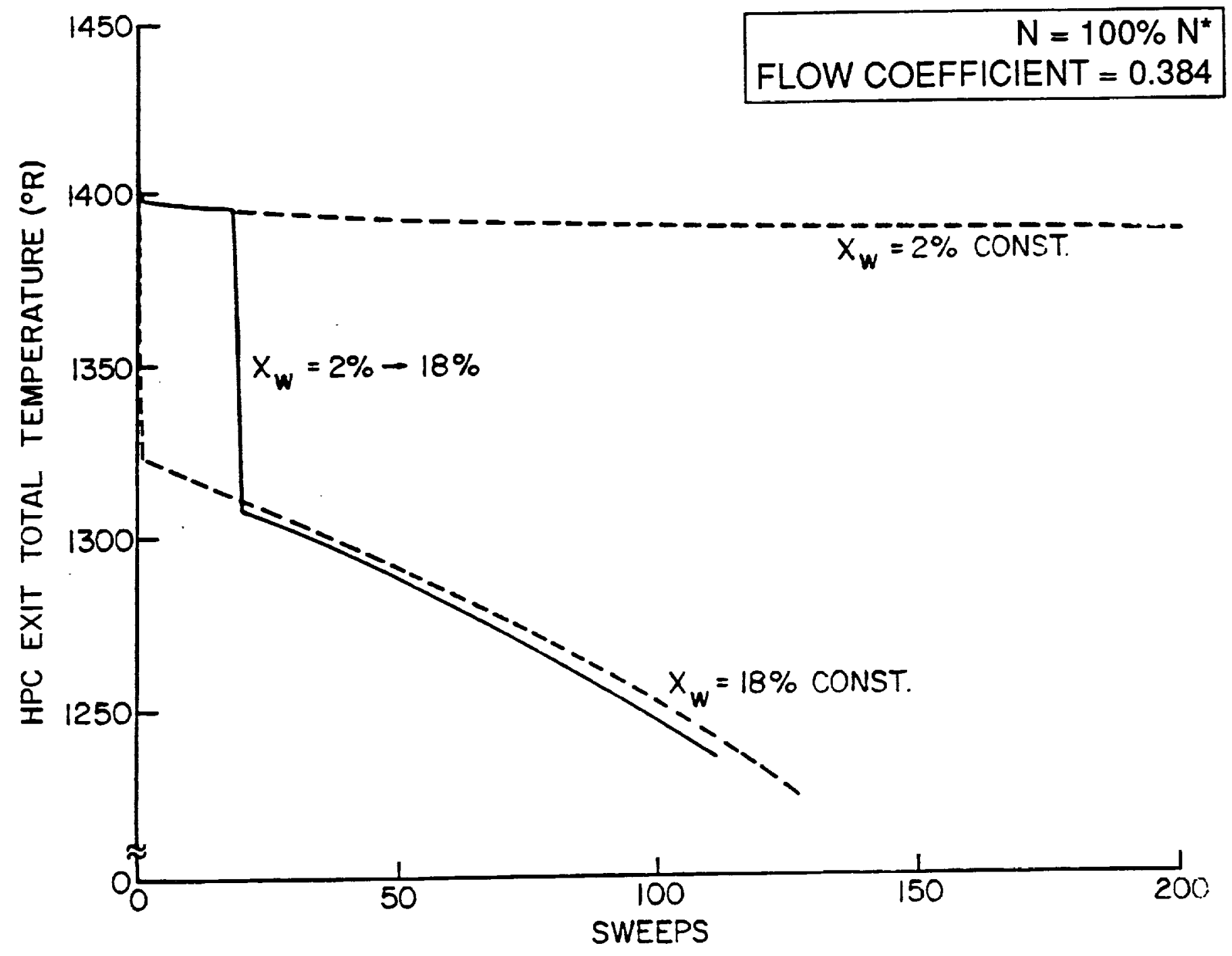

Figure 3.82. Performance of High Pressure Compressor: Variation of exit total temperature as a function of time. Operating conditions as in Fig. 3.81. 


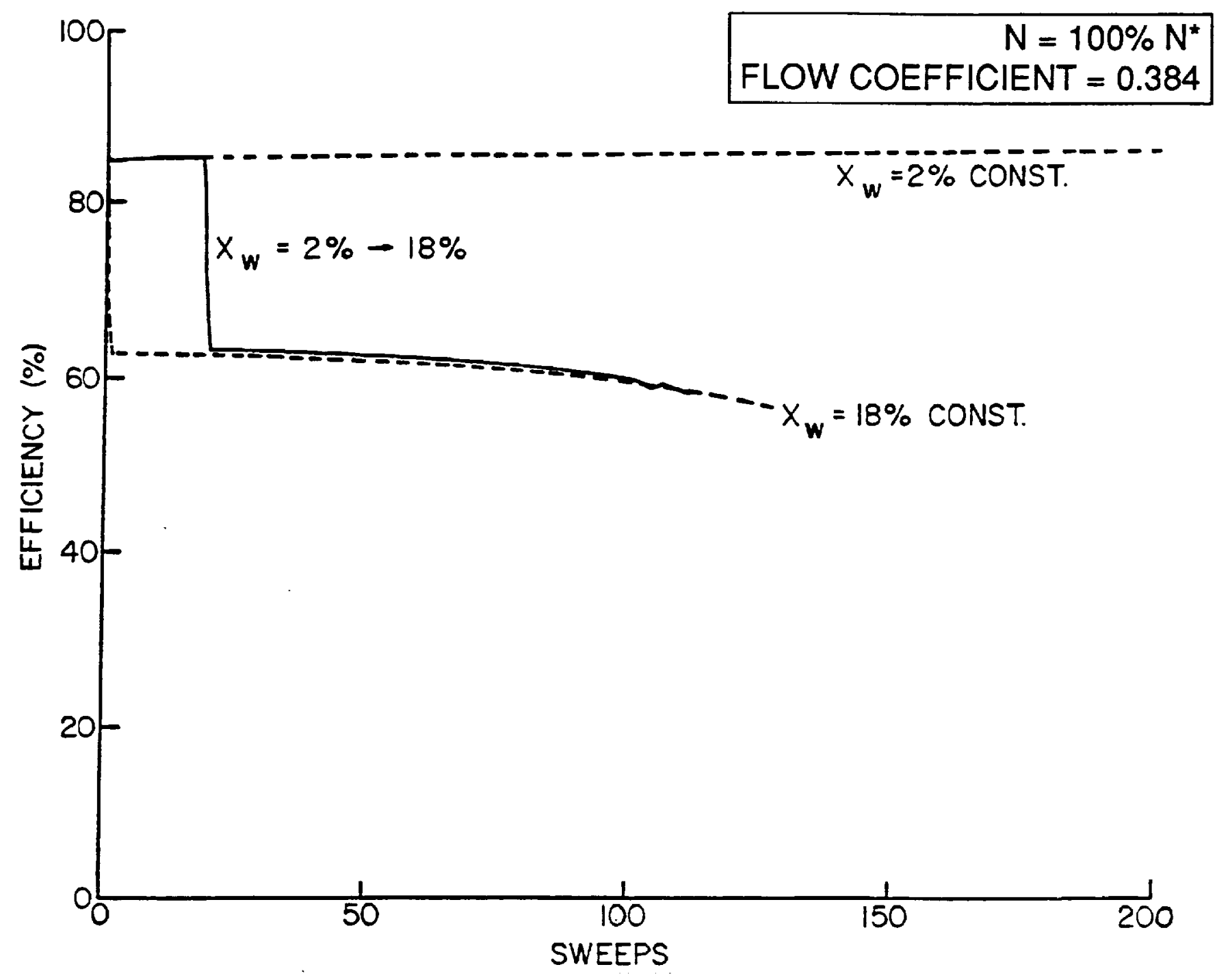

Figure 3.83. Performance of High Pressure Compressor: Variation of effficiency as a function of time. Operating conditions as in Fig. 3.81. 


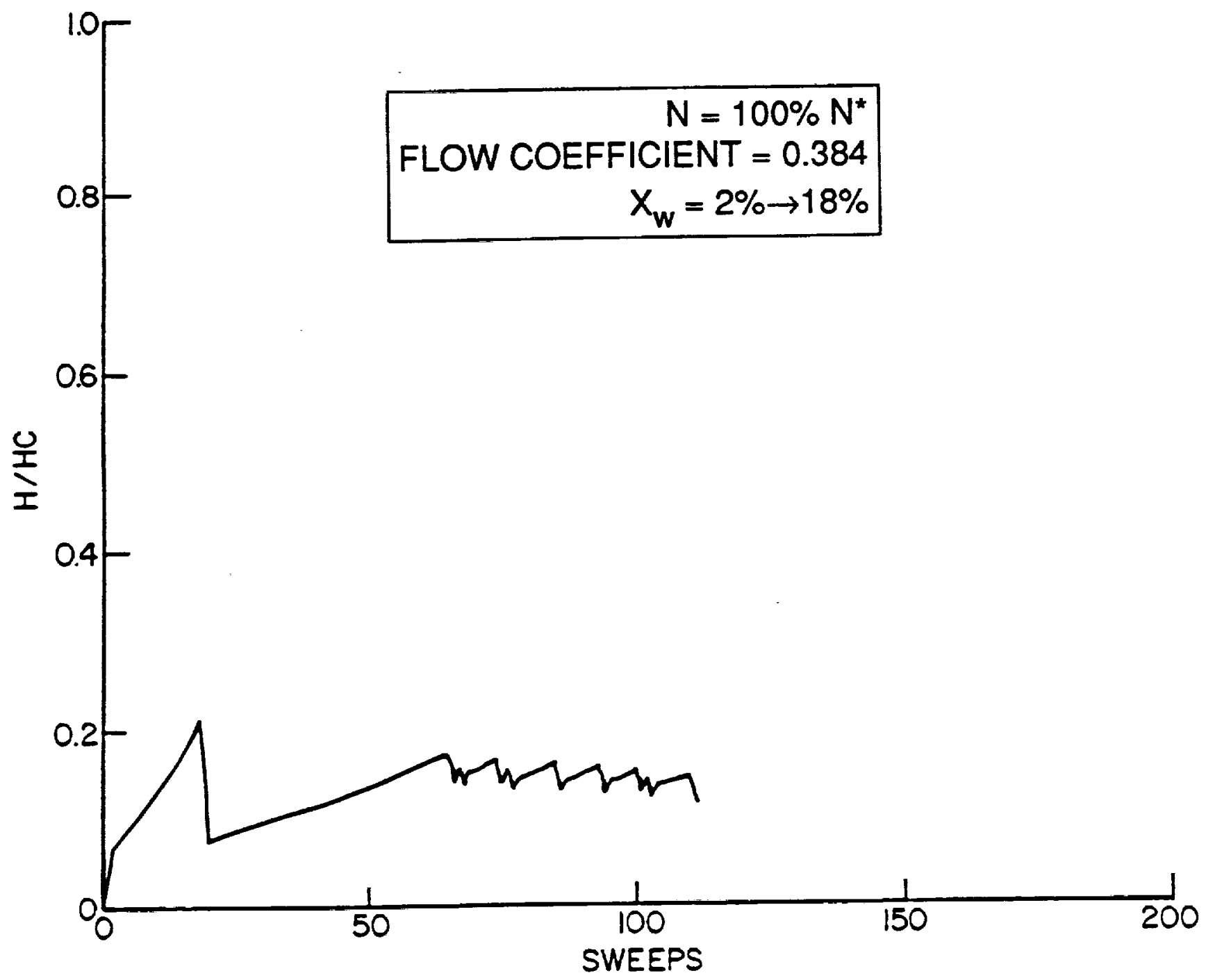

Figure 3.84. Performance of High Pressure Compressor: Variation of height of film over height of film over height of clearance as a function of time. Operating conditions as in Fig. 3.81. 


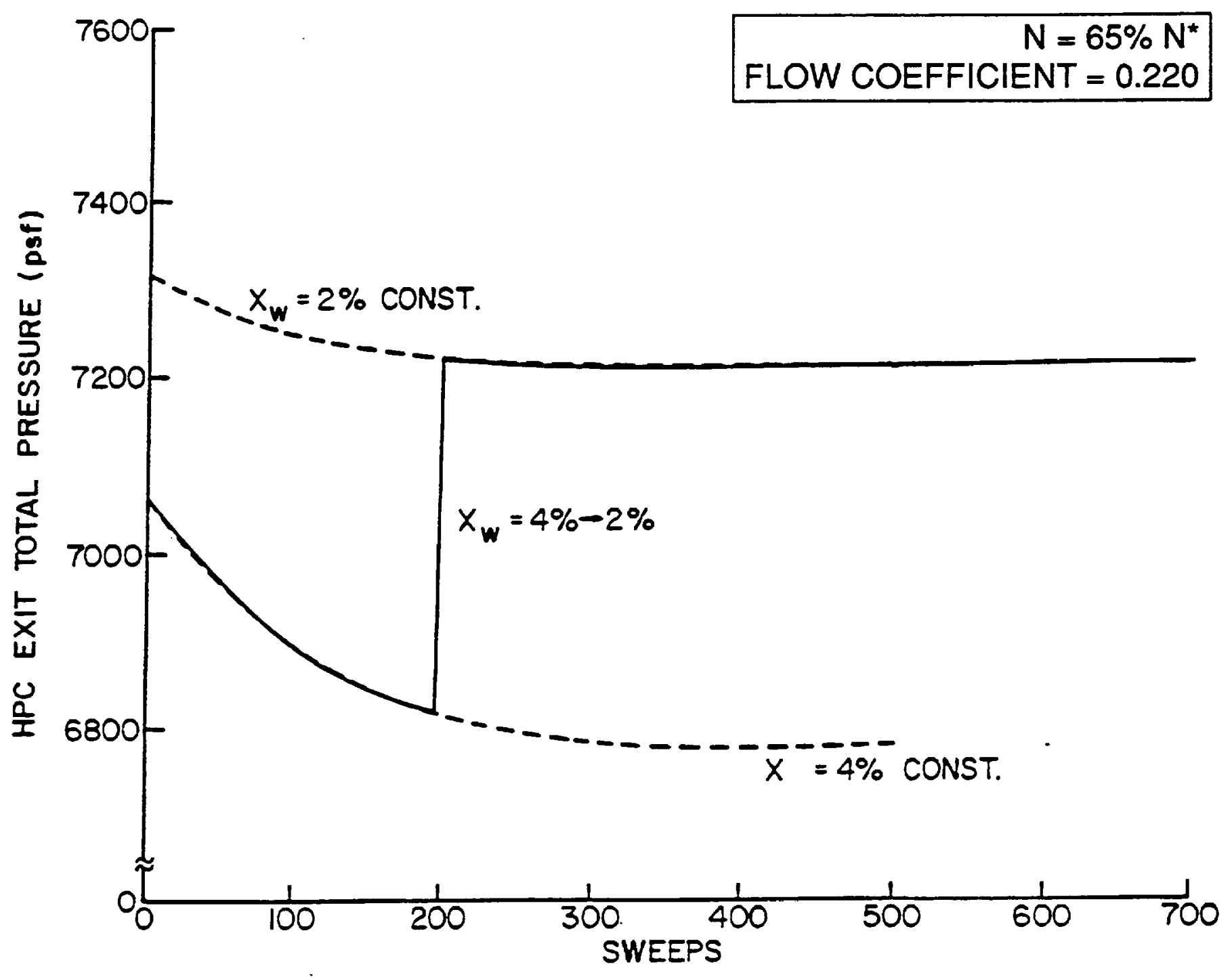

Figure 3.85 Performance of High Pressure Compressor at 65 per cent Speed: Variation of exit total pressure as a function of time. Operating conditions as in Fig. 3.33. Mass fraction of water ingested changing from 4.0 to 2.0 per cent. 


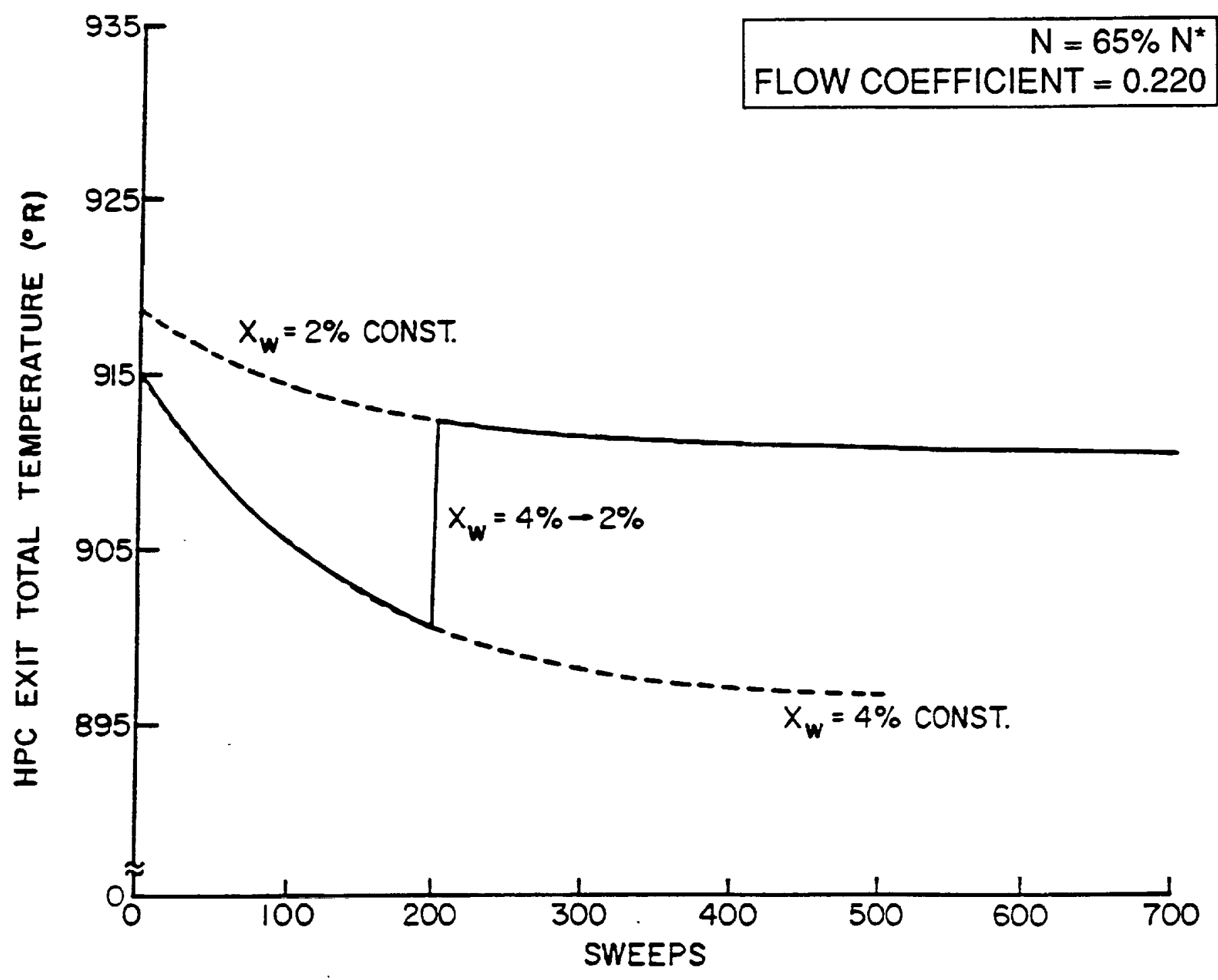

Figure 3.86. Performance of High Pressure Compressor: Variation of exit temperature as a function of time. Operating conditions as in Fig. 3.85. 


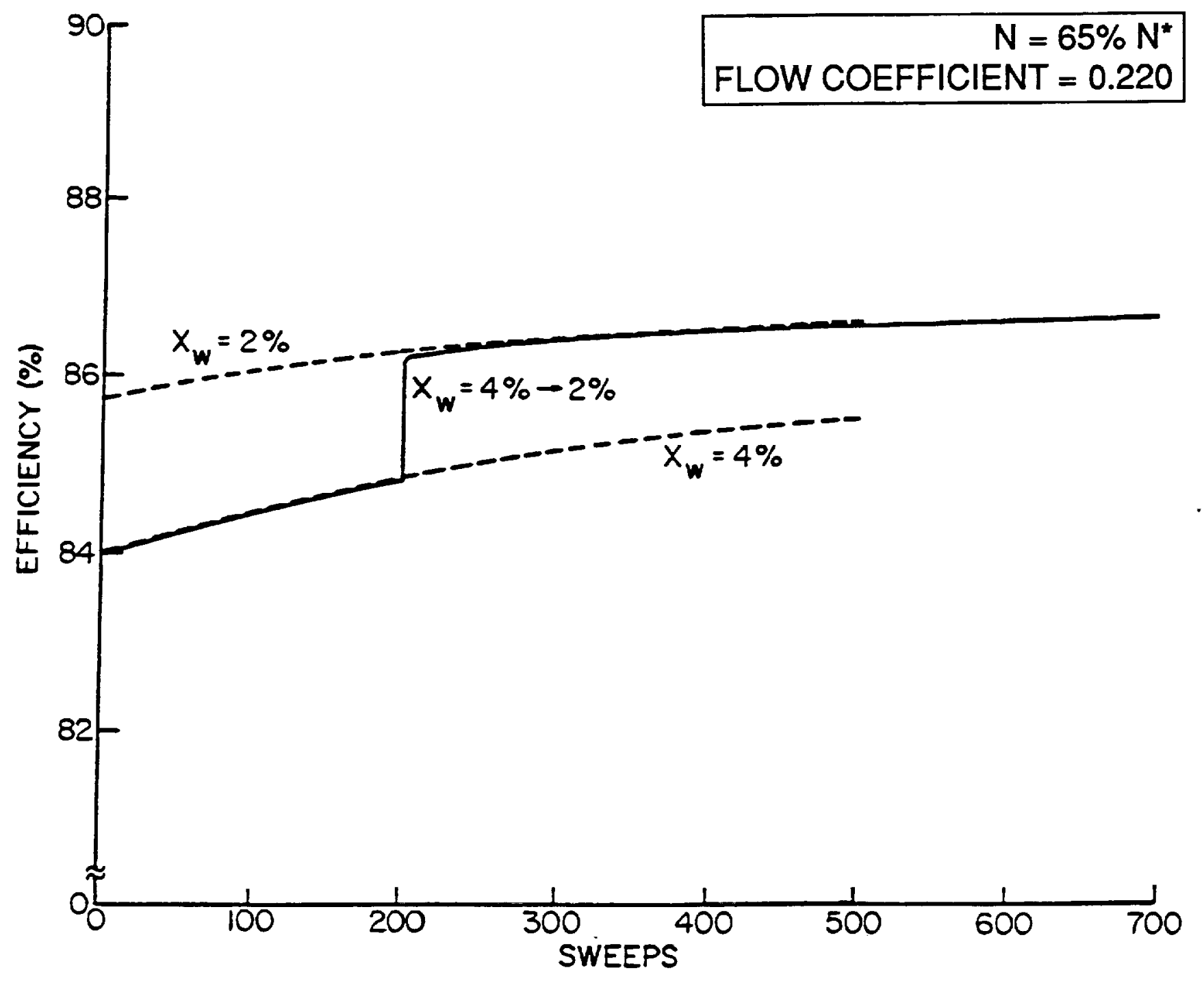

Figure 3.87. Performance of High Pressure Compressor: Variation ofefficiency as a function of time. Operating conditions as in Fig. 3.85. 


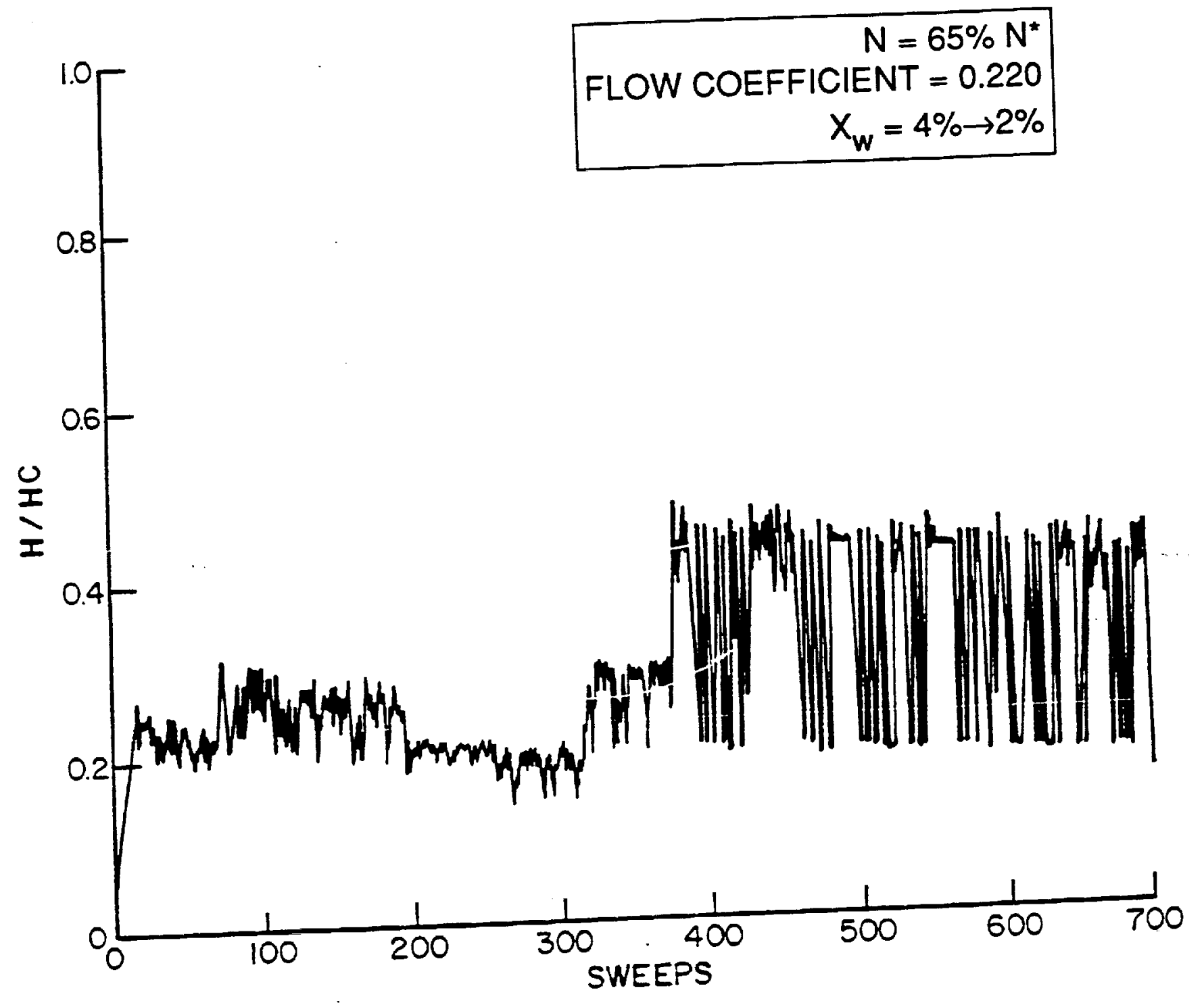

Figure 3.88. Performance of High Pressure Compressor: Variation ofheight of film over height of clearance as a function of time. Operating conditions as in Fig. 3.85. 


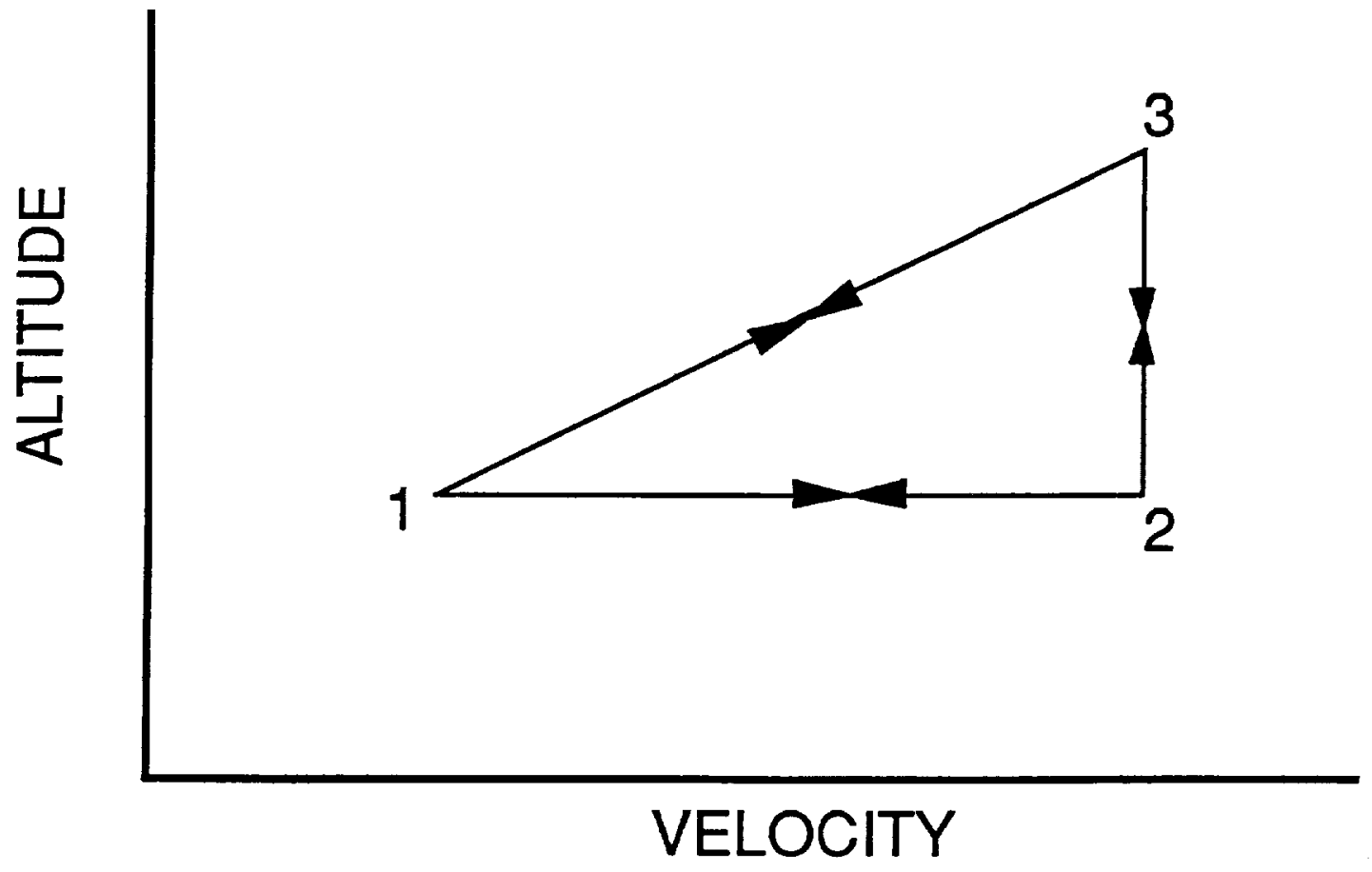

Figure 4.2. Flight Paths 


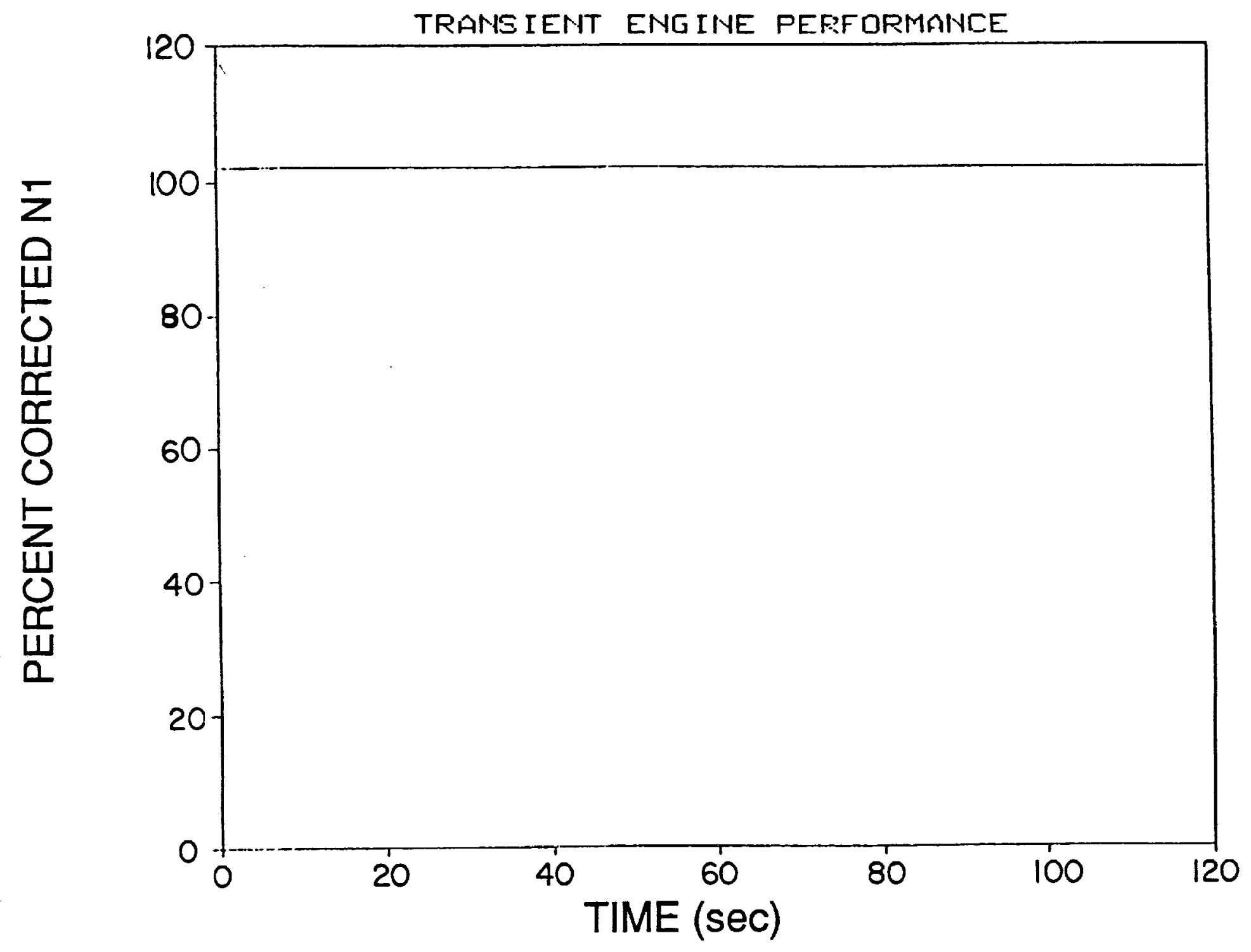

Figure 4.3.(i)

Caption on Figure 4.3.(iv) 
TRANSIENT ENG INE PERFORMANCE

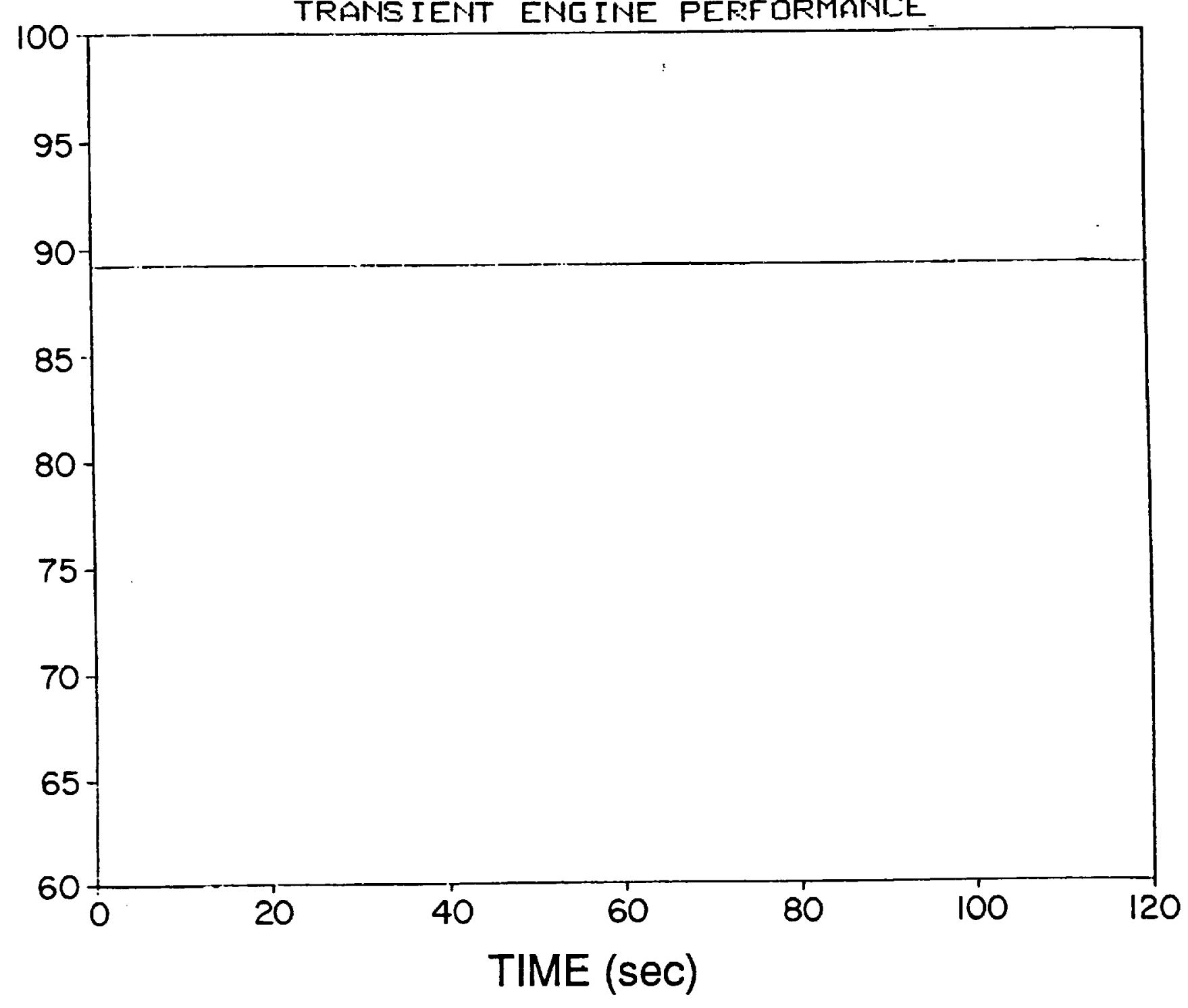

Figure 4.3.(ii)

Caption on Figure 4.3.(iv) 


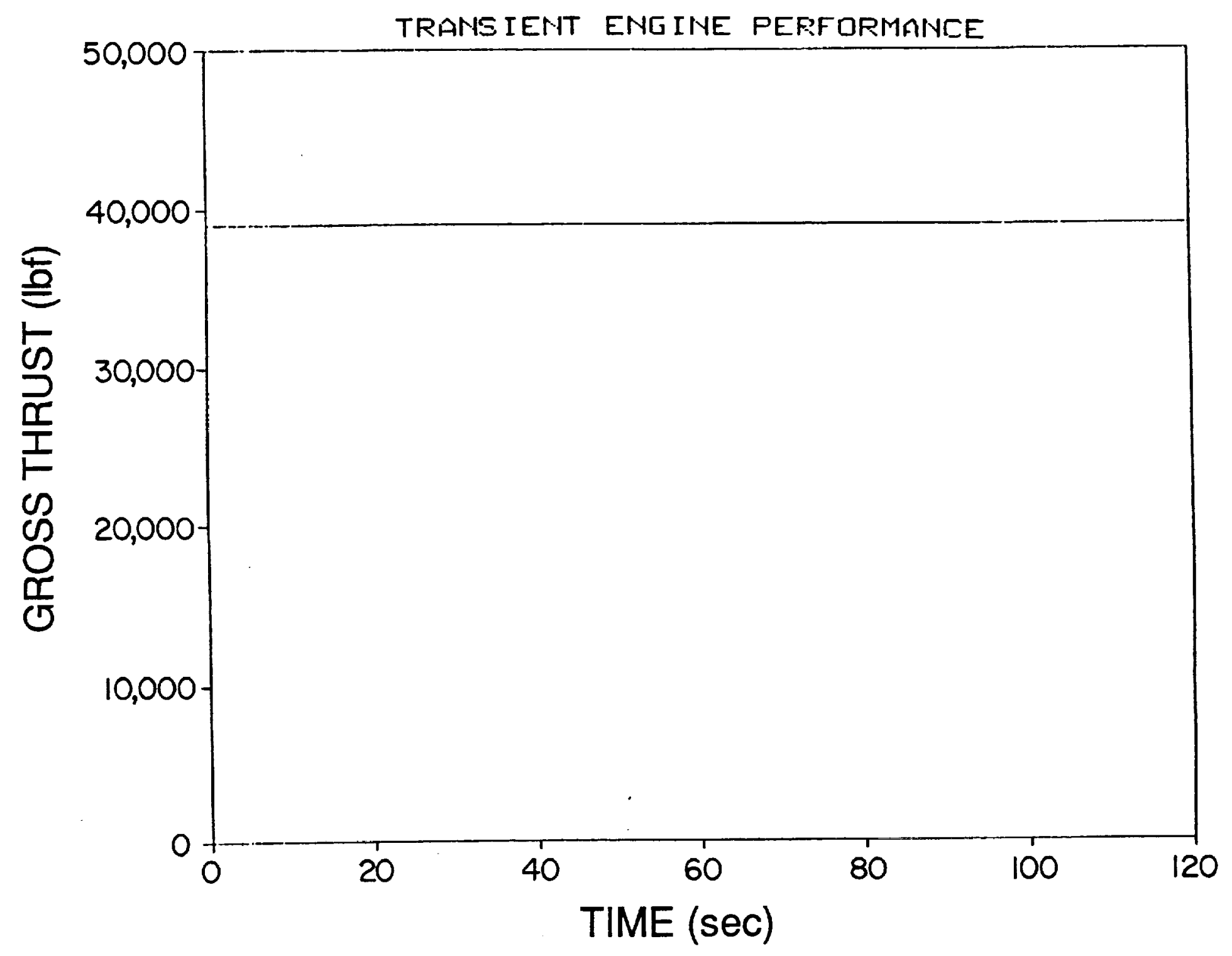

Figure 4.3.(iii)

Caption on Figure 4.3.(iv) 


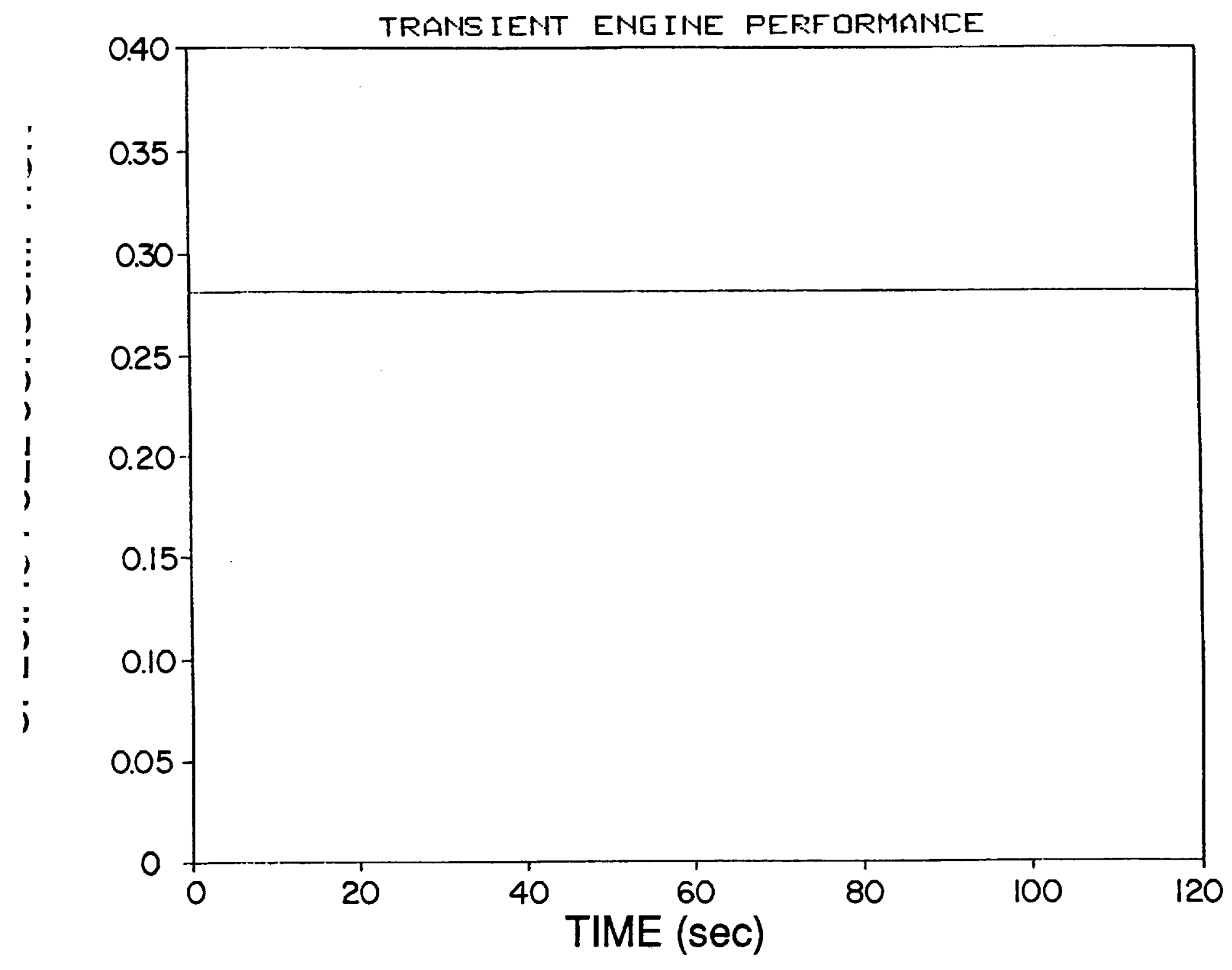

Figure 4.3.(iv)

Figure 4.3. Transient Performance of Engine: (i), (ii), (iii) and (iv). Engine at cruise power setting. Mass fraction of water ingested is zero. 


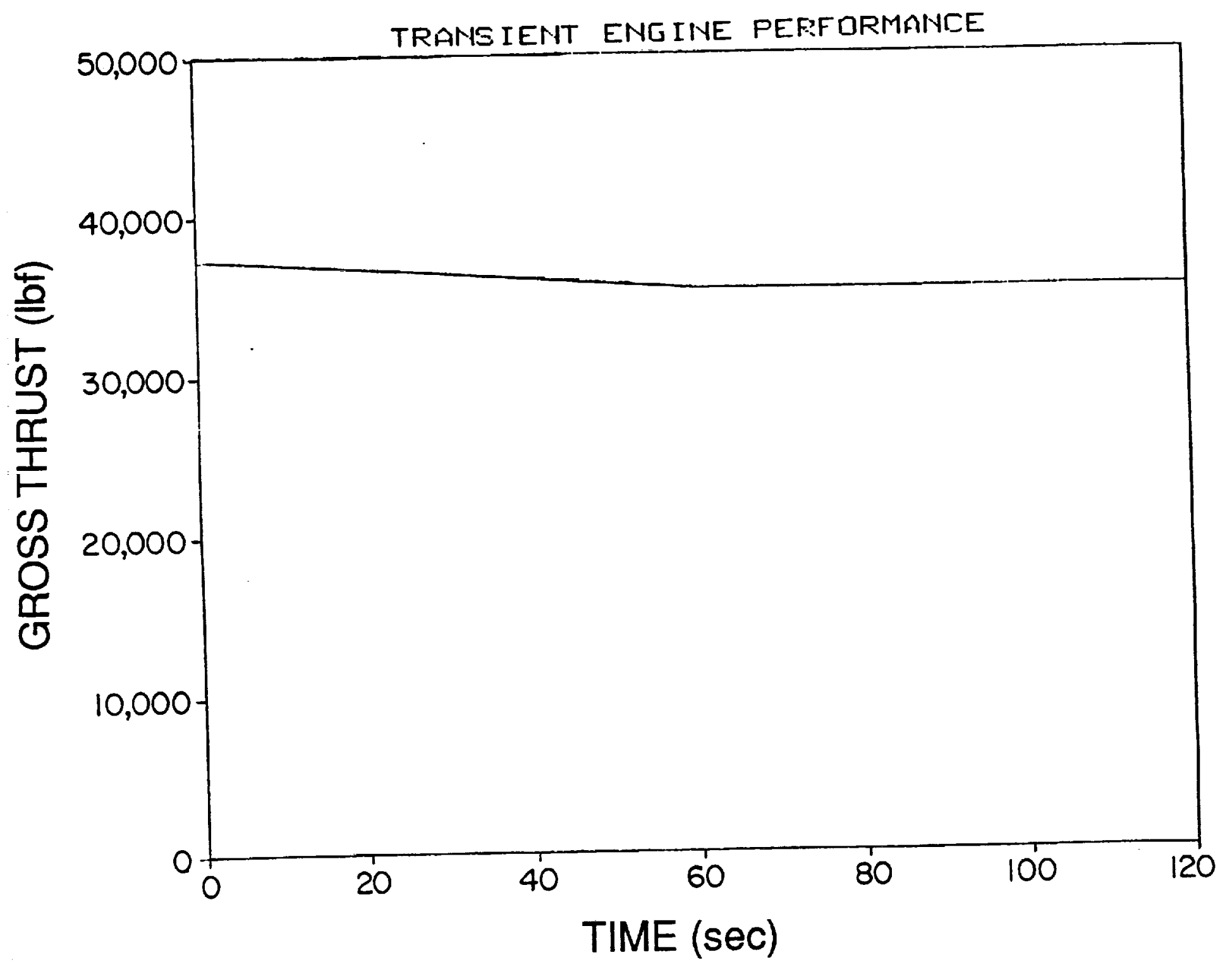

Figure 4.4.(i)

Caption on Figure 4.4.(iv) 


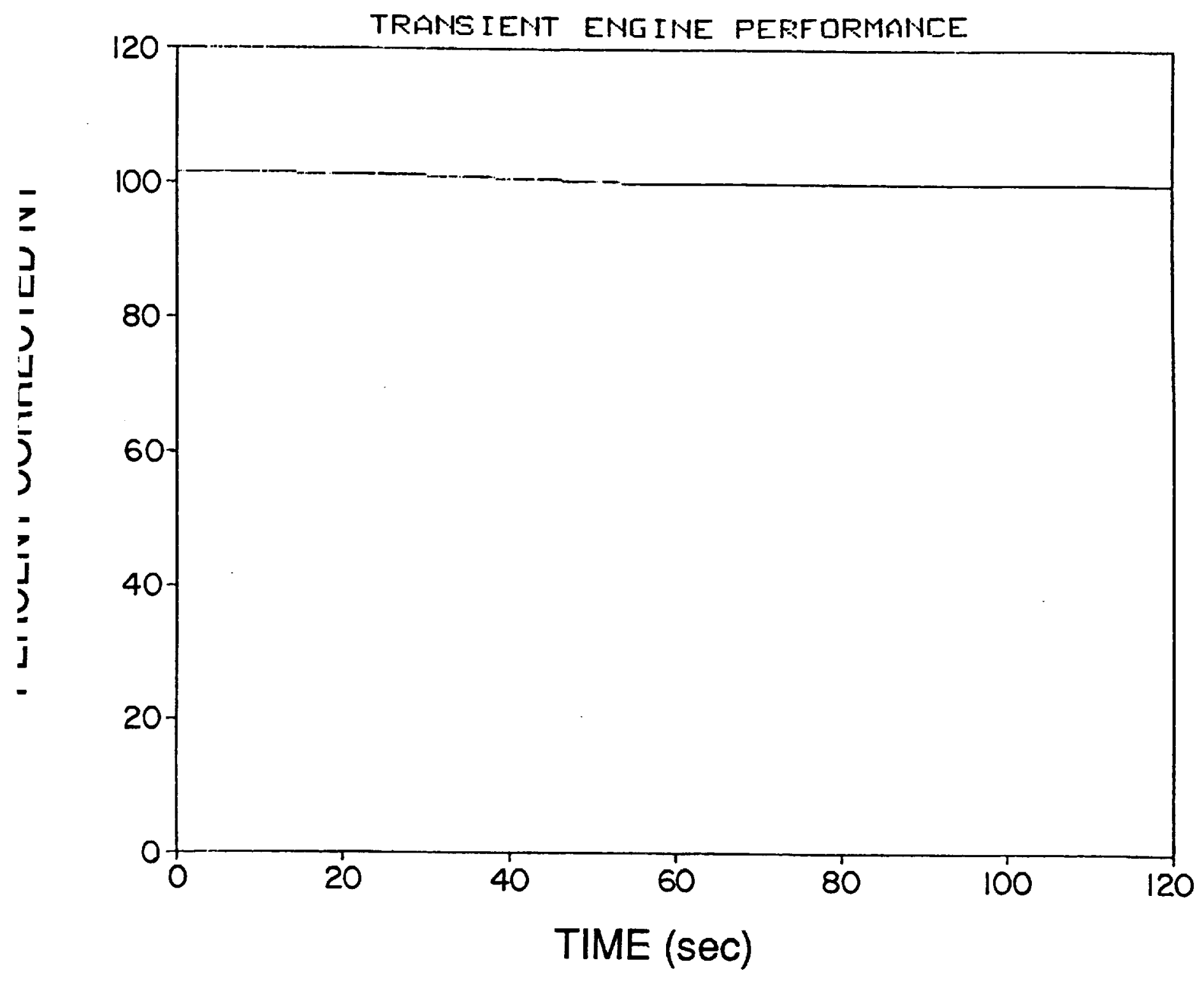

Figure 4.4.(ii)

Caption on Figure 4.3.(iv) 


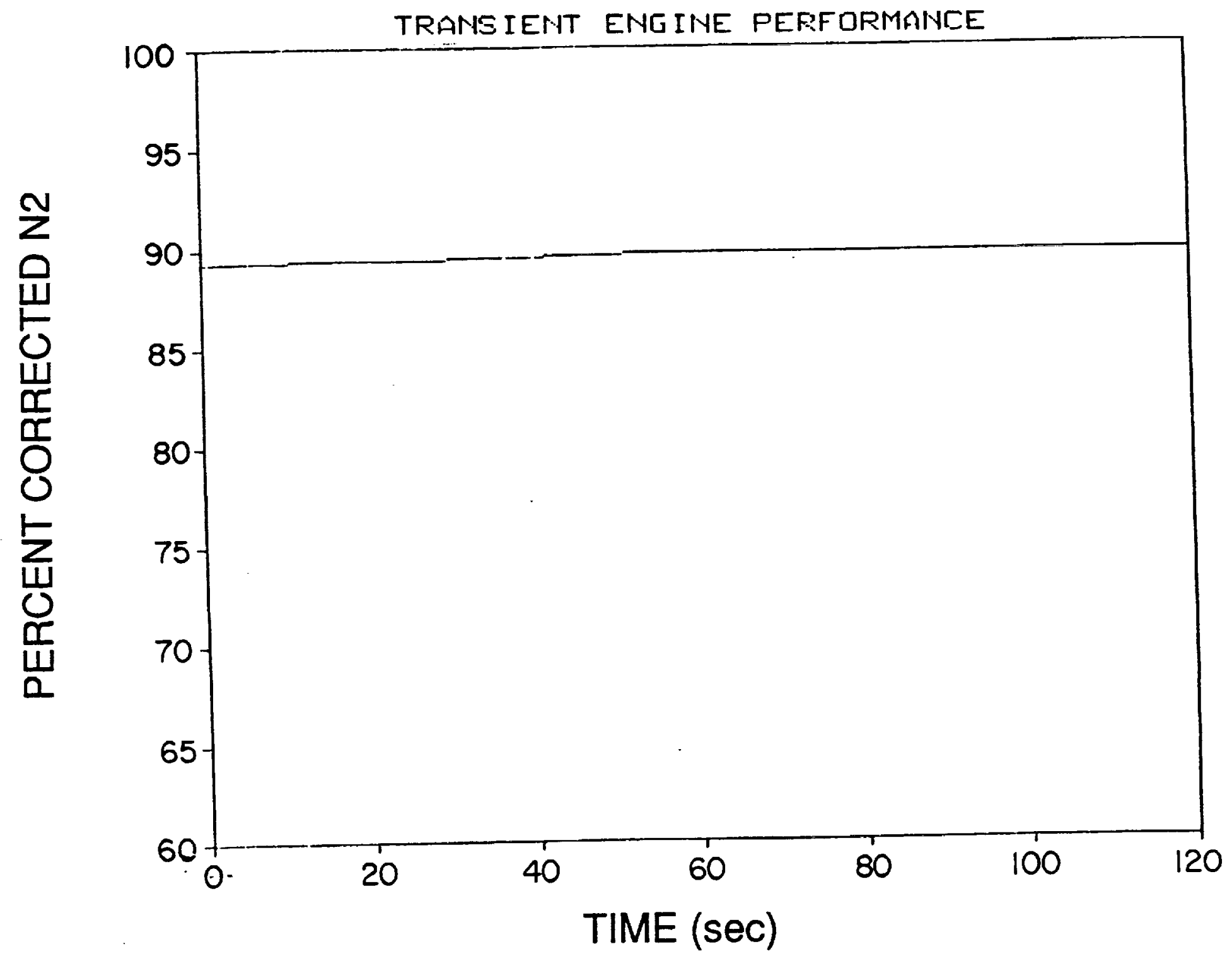

Figure 4.4.(iii)

Caption on Figure 4.4.(iv) 
TRANSIENT ENGINE PEFFORMANCE

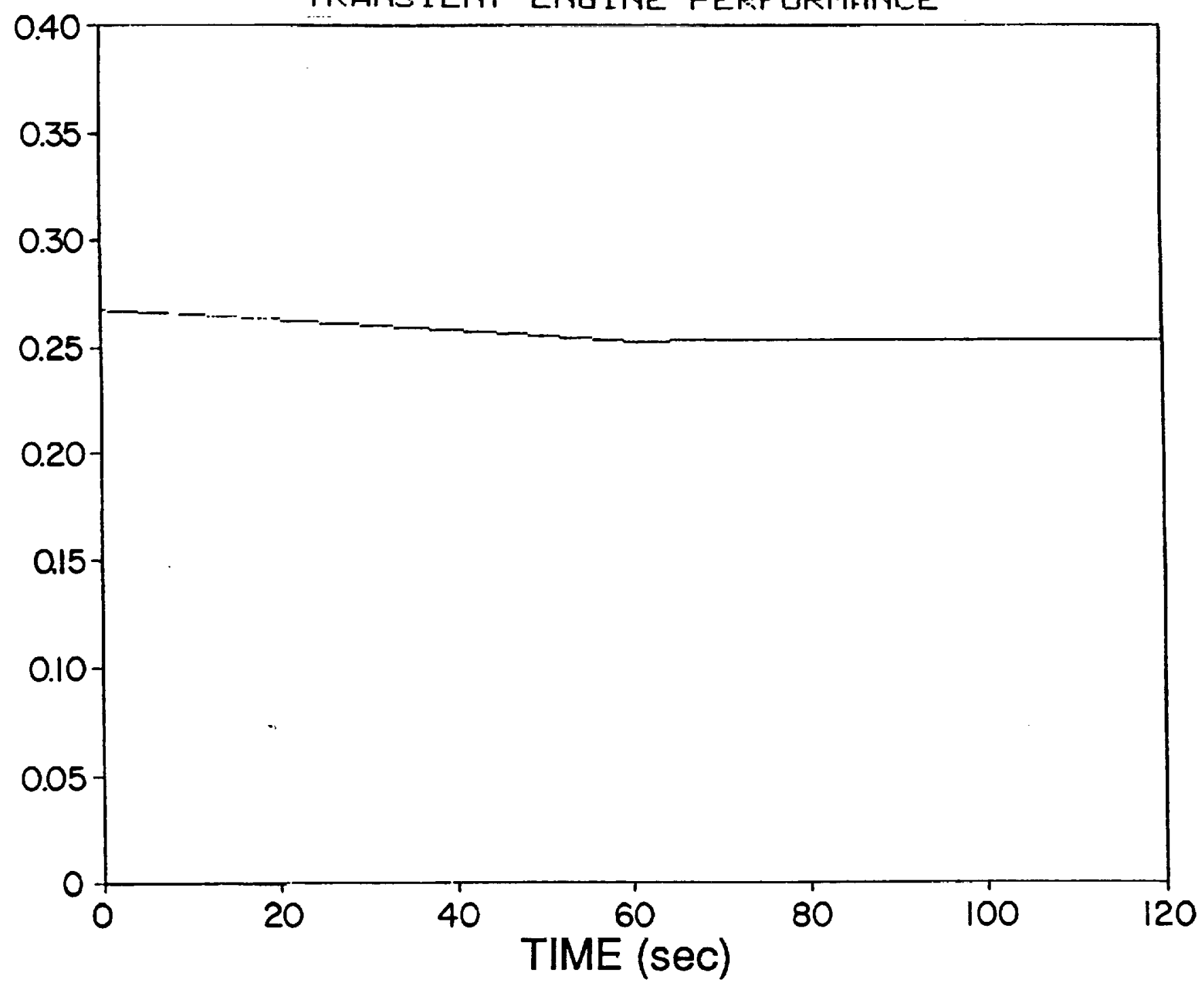

Figure 4.4.(iv)

Figure 4.4 Transient Performance of Engine: (i), (ii), (iii), and (iv). Engine at cruise power setting. Mass fraction of water ingested equal to 2.0 per cent. 


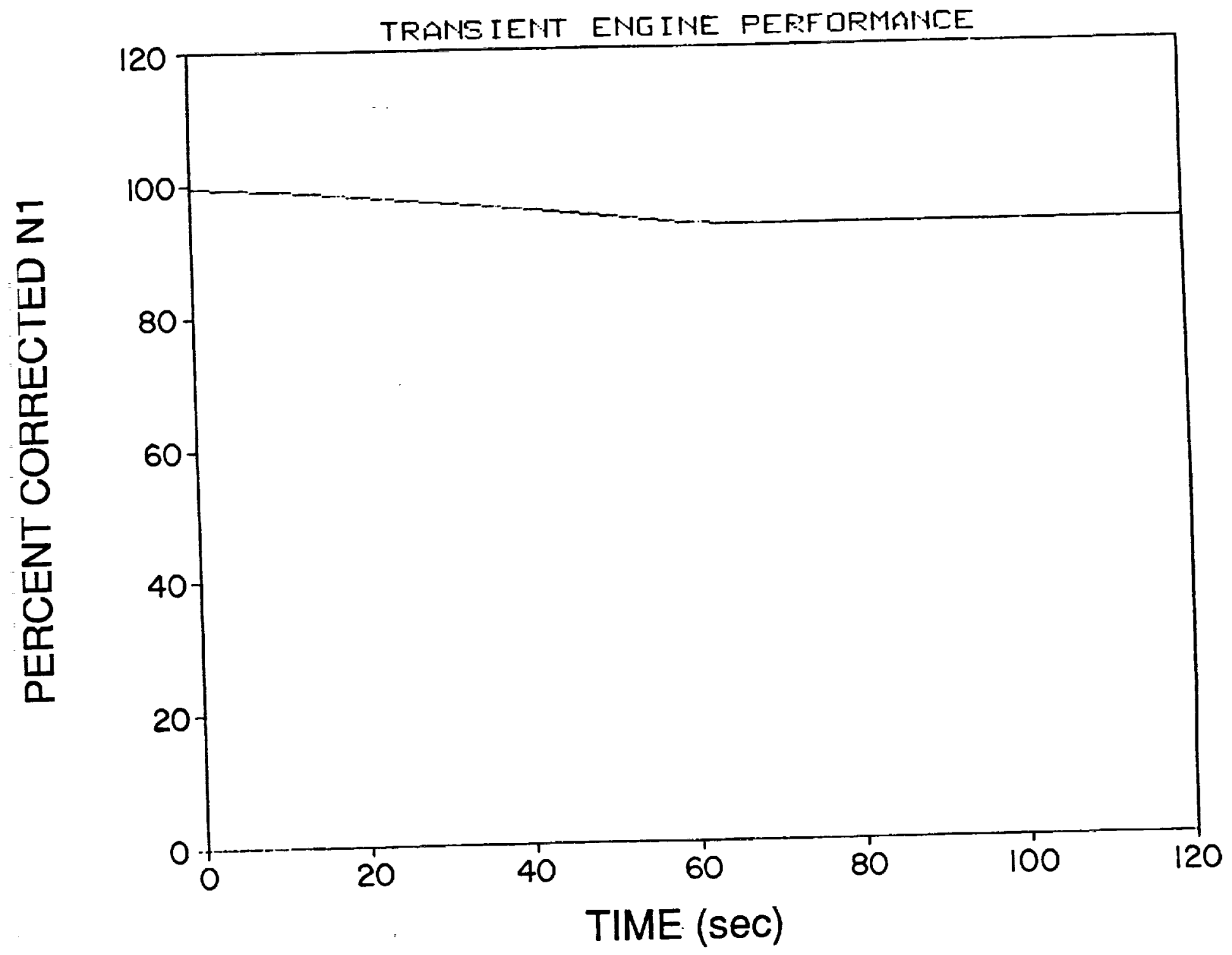

Figure 4.5.(i)

Caption on Figure 4.5.(iv) 


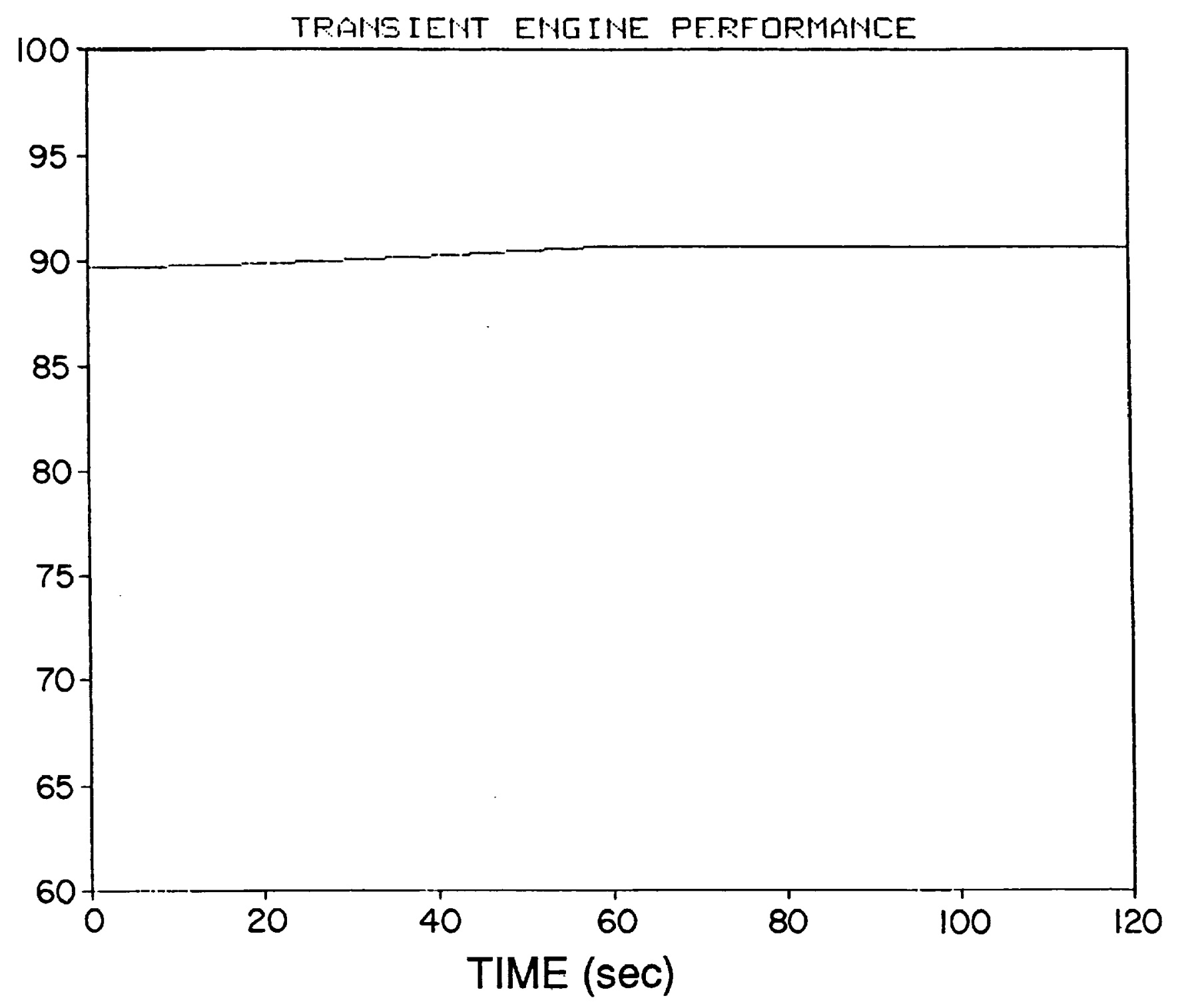

Figure 4.5.(ii)

Caption on Figure 4.5.(iv) 


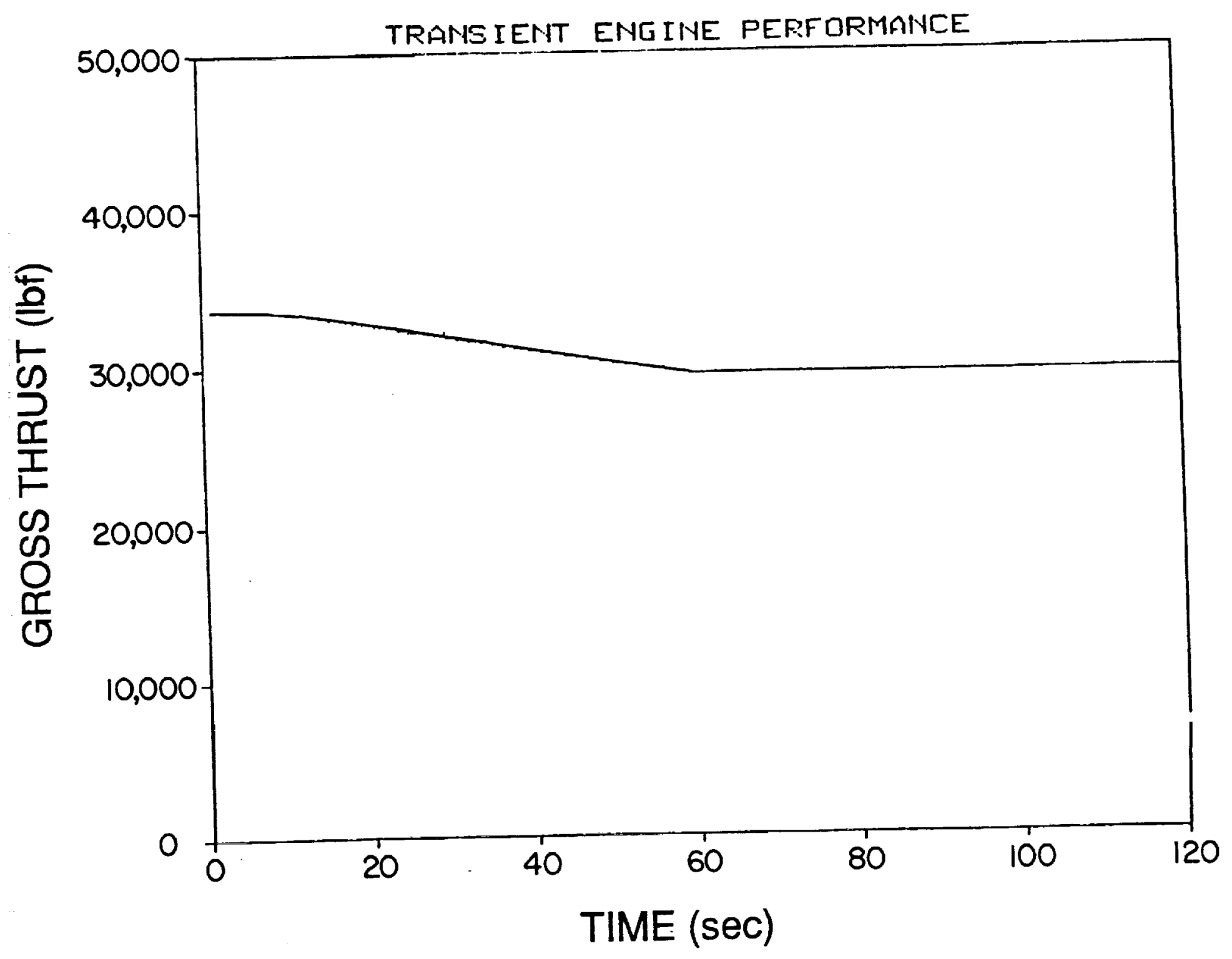

Figure 4.5.(iii)

Caption on Figure 4.5.(iv) 


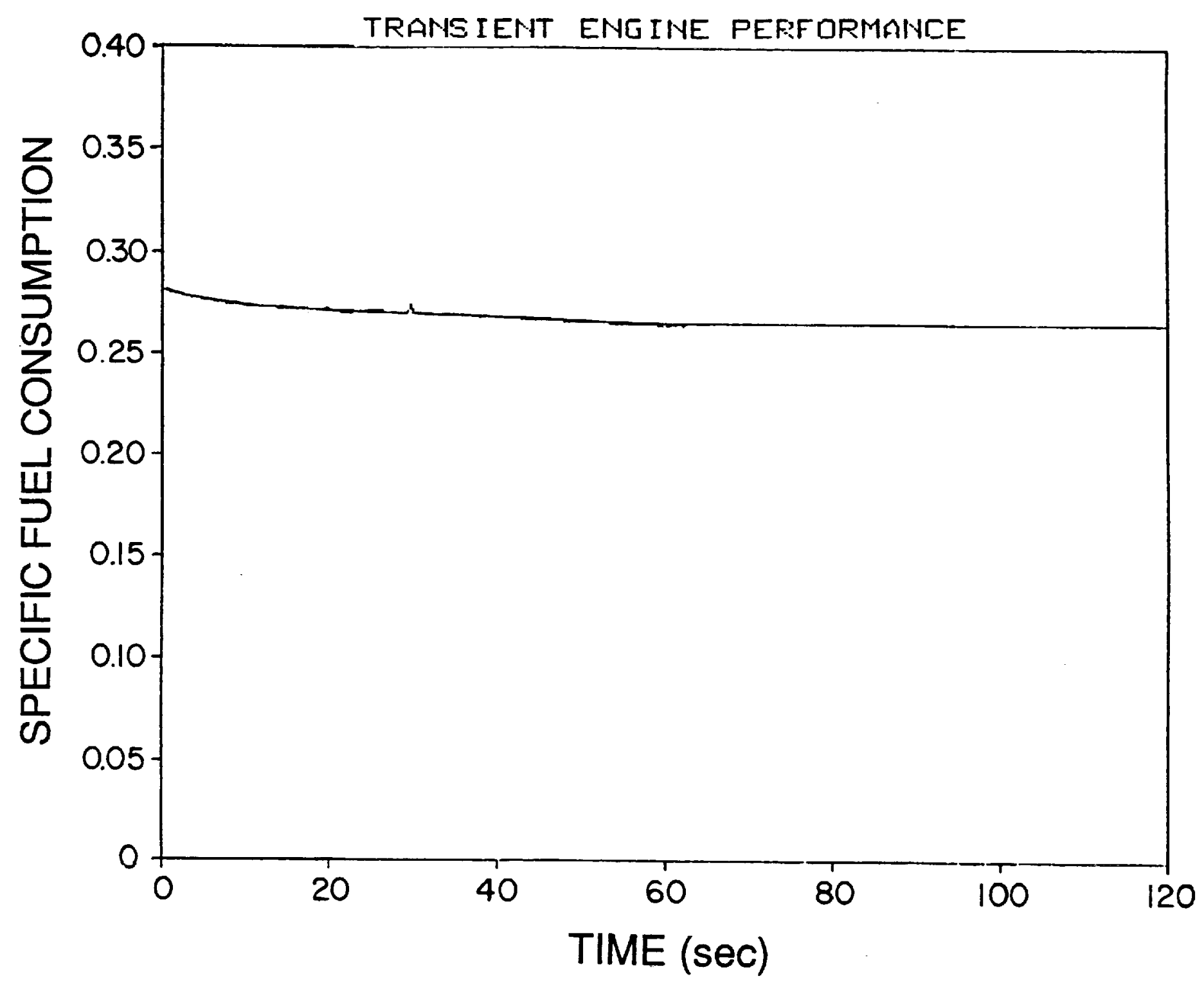

Figure 4.5.(iv)

Figure 4.5 Transient Performance of Engine: (i), (ii), (iii), and (iv). Engine at cruise power setting. Mass fraction of water ingested equal to 8.0 per cent. 


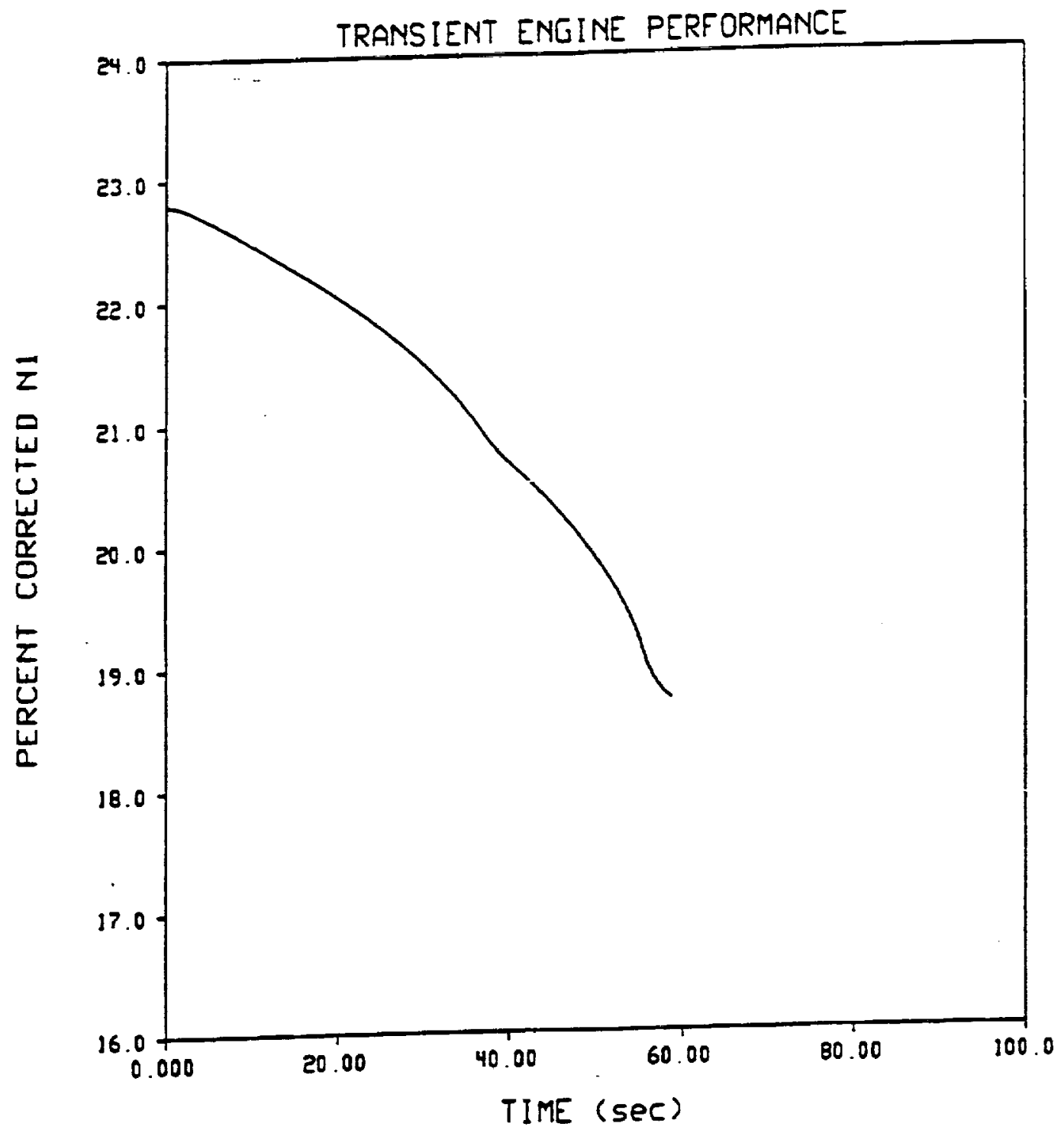

Figure 4.6.(i)

Caption on Figure 4.6.(iv) 


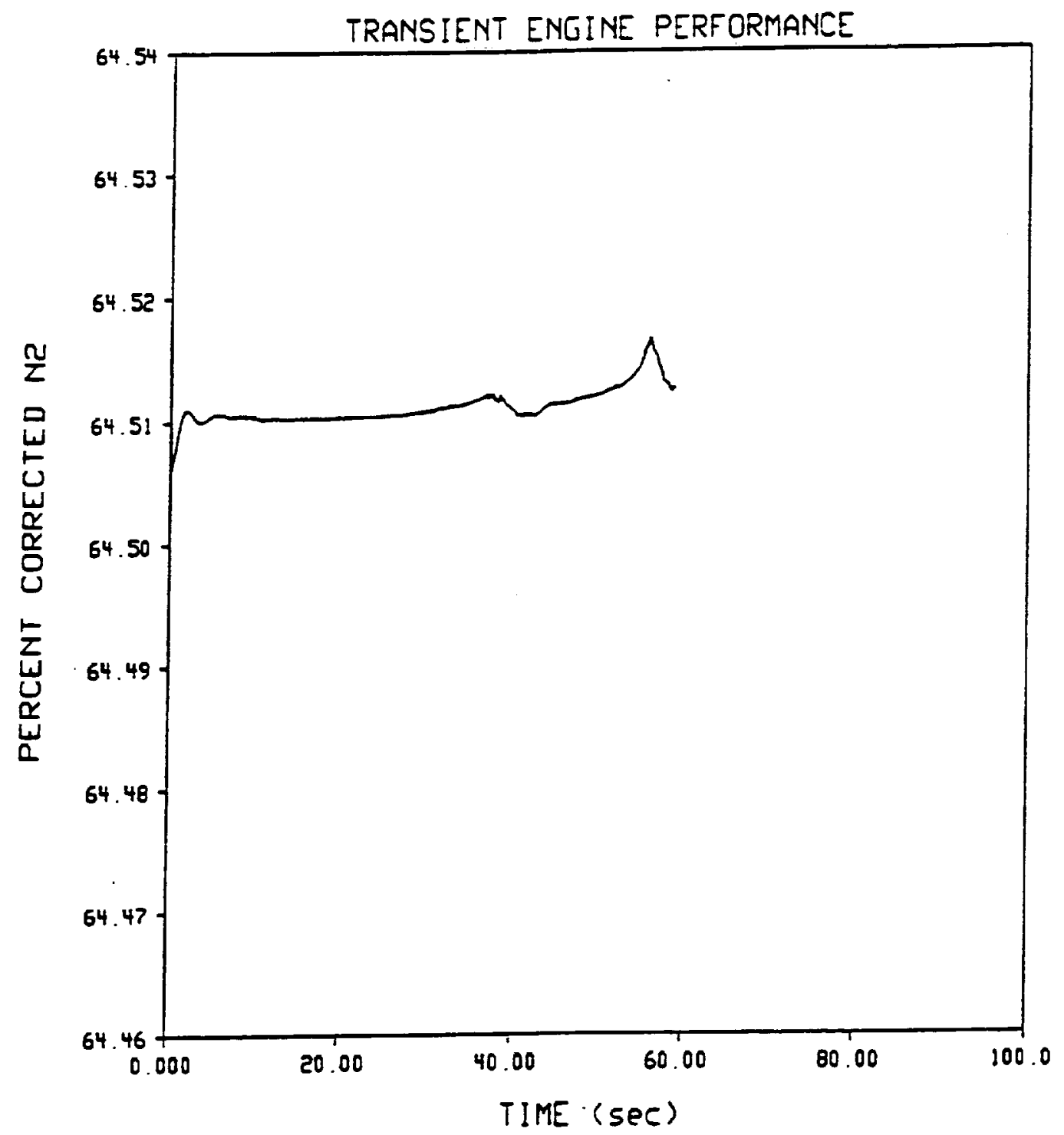

Figure 4.6.(ii)

Caption on Figure 4.6.(iv) 


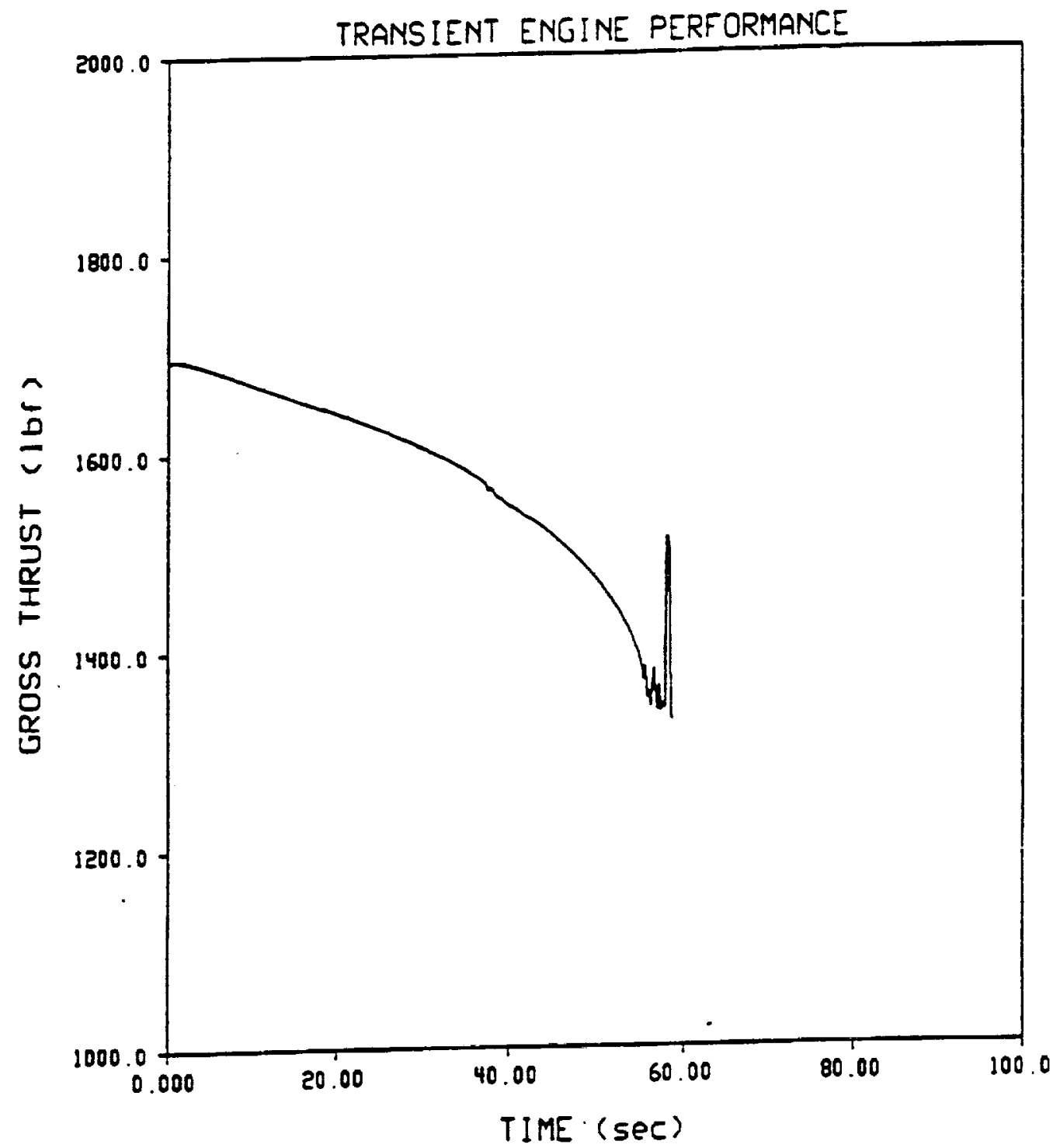

Figure 4.6.(iii)

Caption on Figure 4.6.(iv) 


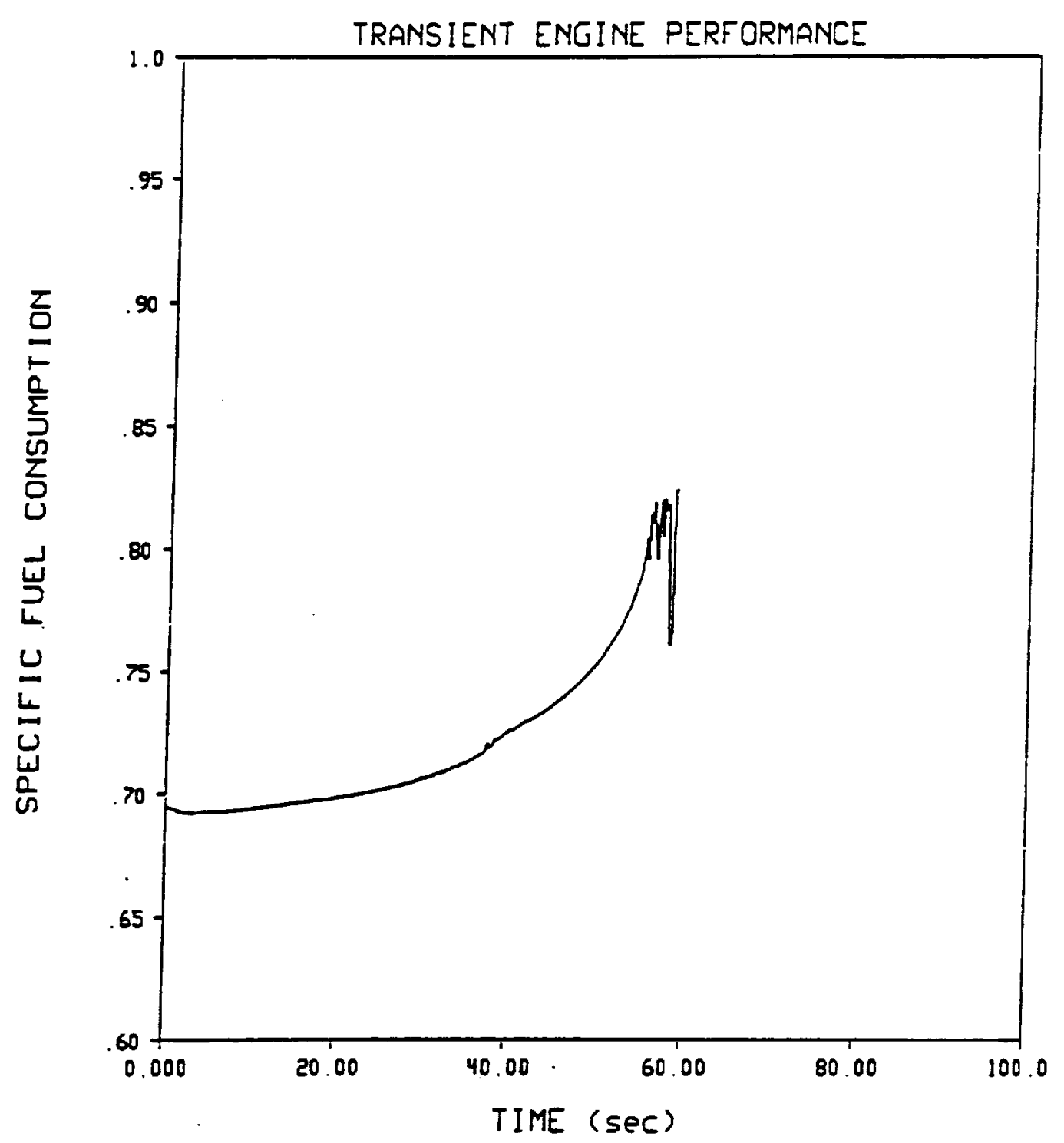

Figure 4.6.(iv)

Figure 4.6. Transient Performance of Engine: (i), (ii), (iii), and (iv). Engine at flight idle power setting. Mass fraction of water ingested held constant at 4.0 per cent. 


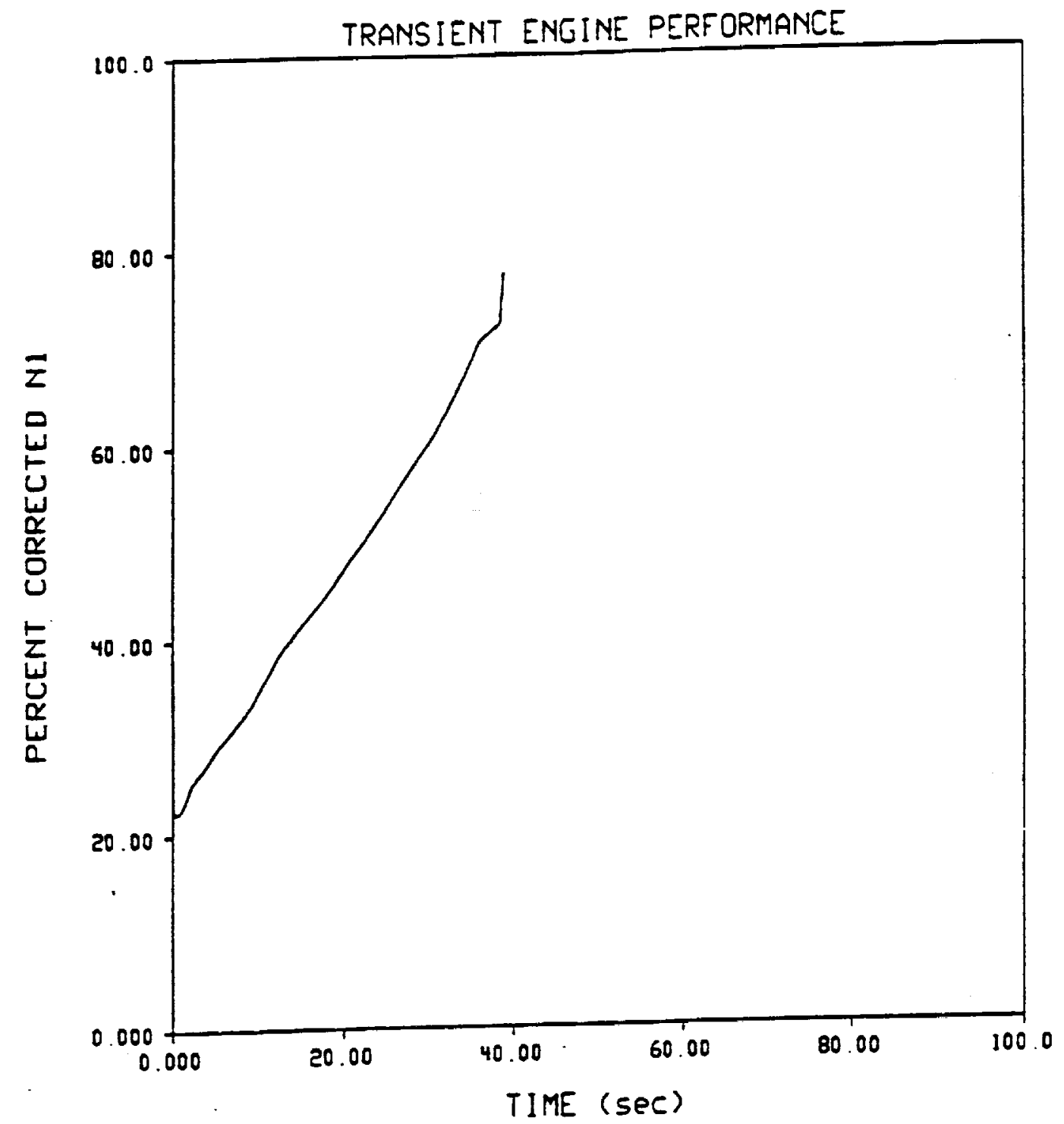

Figure 4.7.(i)

Caption on Figure 4.7.(iv) 


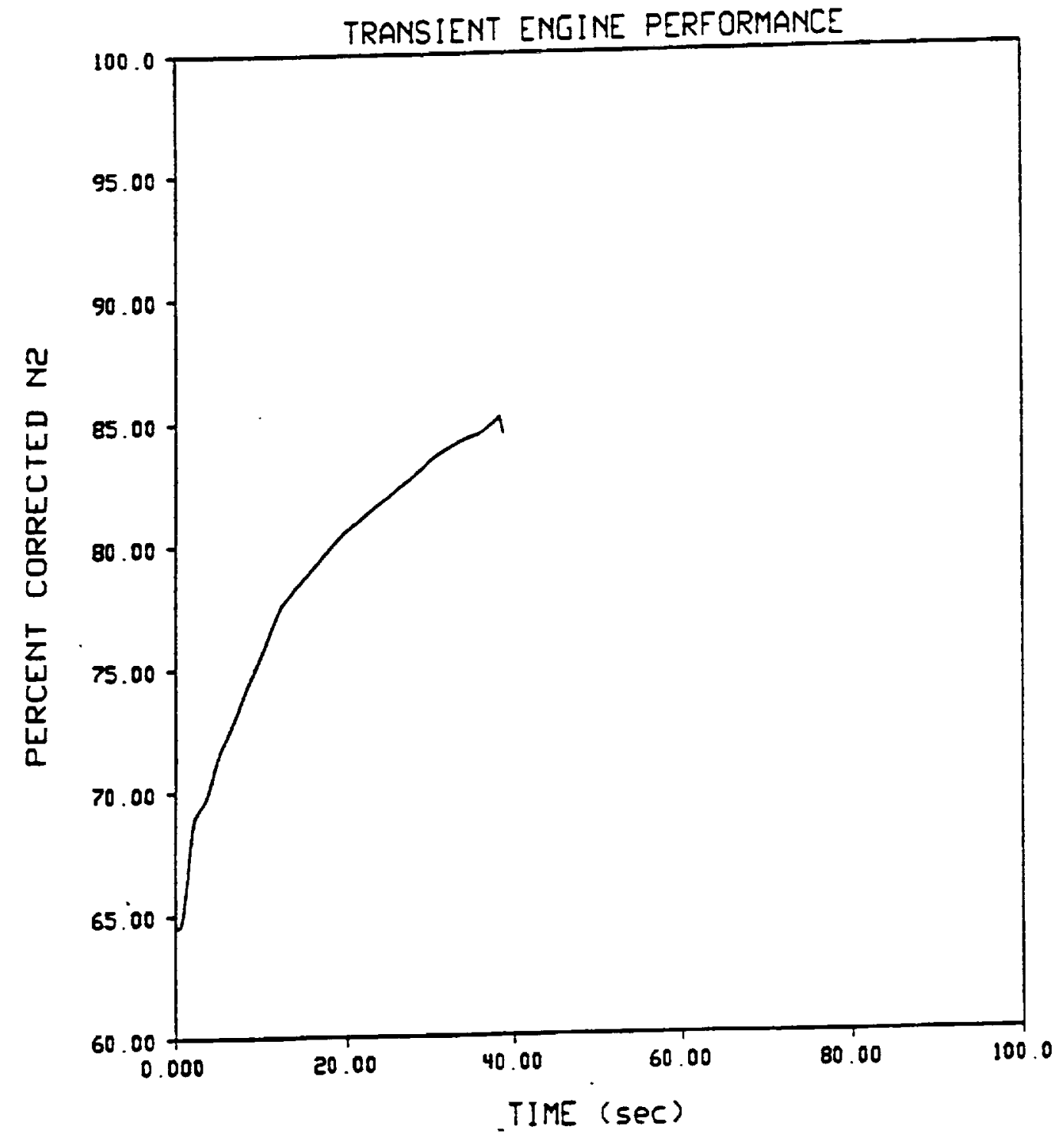

Figure 4.7.(ii)

Caption on Figure 4.7.(iv) 


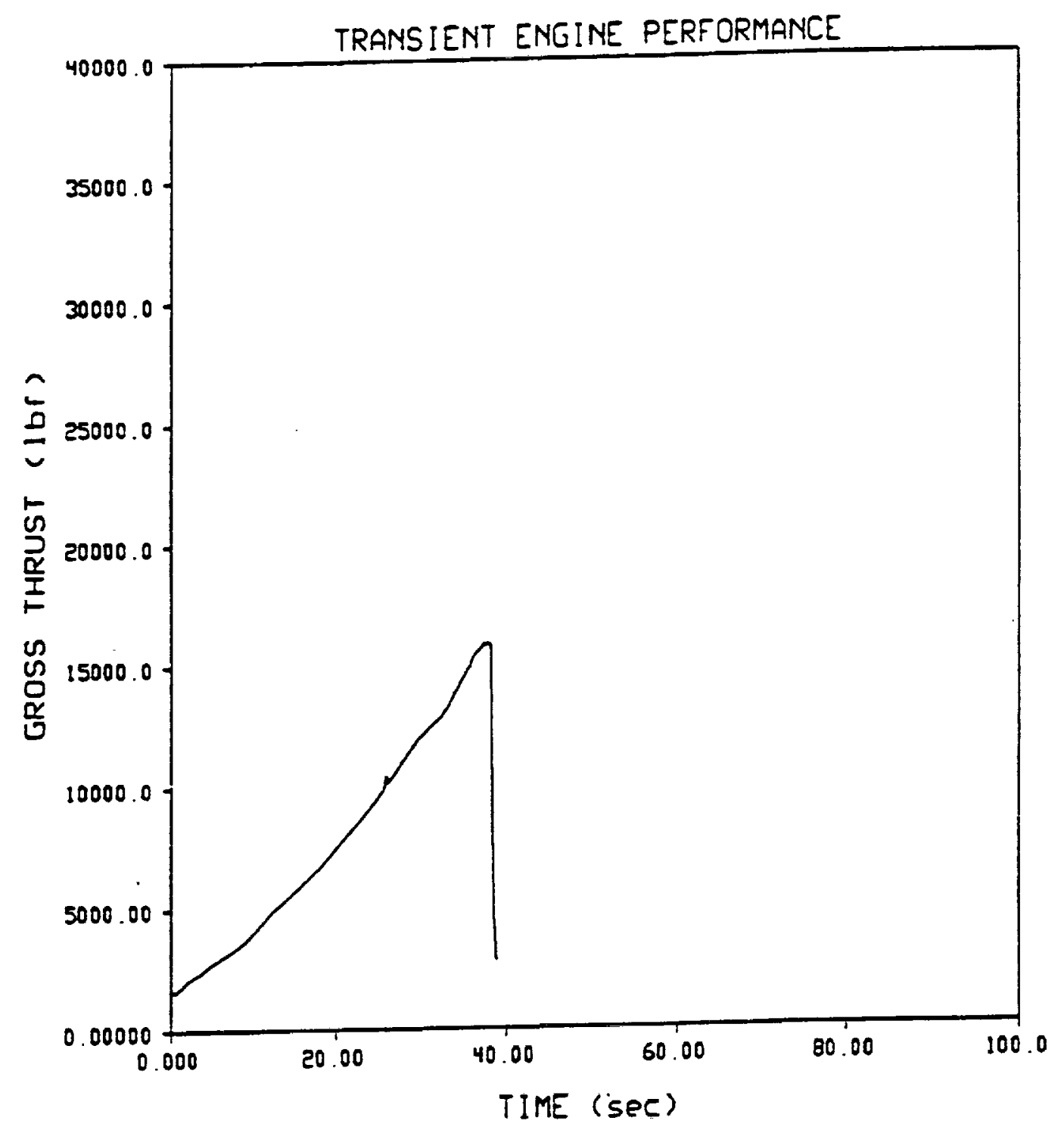

Figure 4.7.(iii)

Caption on Figure 4.7.(iv) 


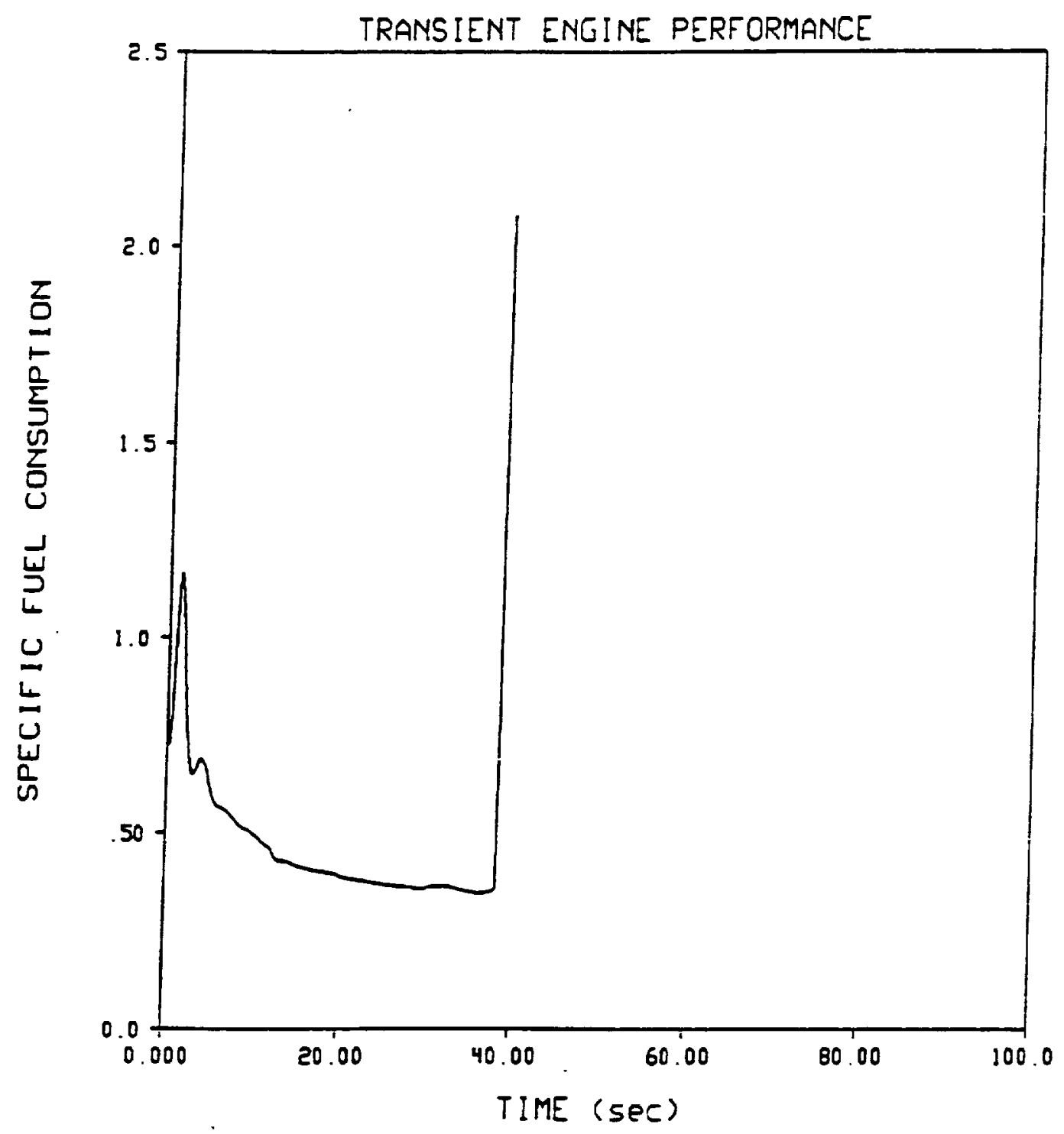

Figure 4.7.(iv)

Figure 4.7. Transient Engine Performance: (i), (ii), (iii), and (iv). Engine power setting changed from flight idle to maximum power setting. Mass fraction of water ingested equal to 4.0 per cent. 


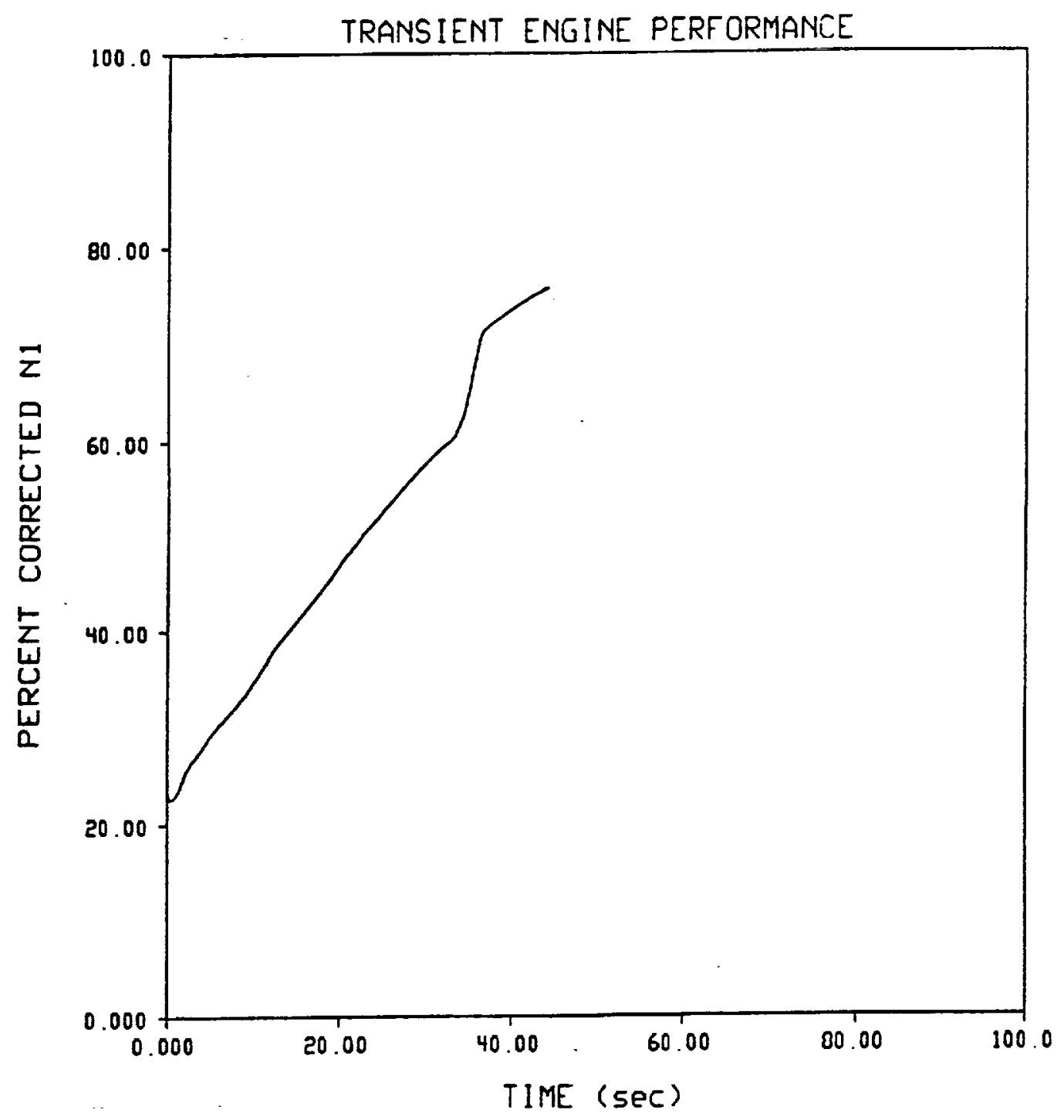

Figure 4.8.(i)

Caption on Figure 4.8.(iv) 


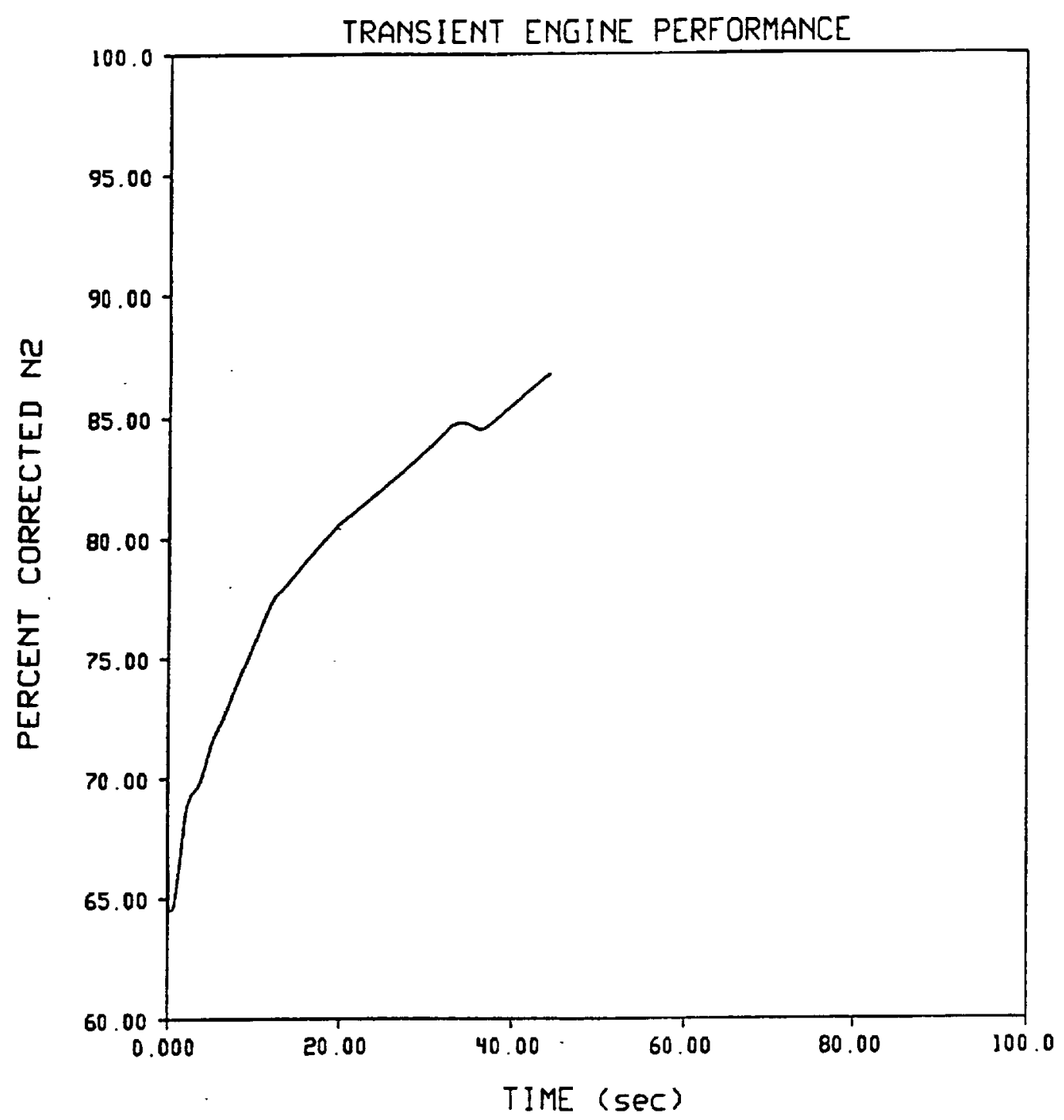

Figure 4.8.(ii)

Caption on Figure 4.8.(iv) 


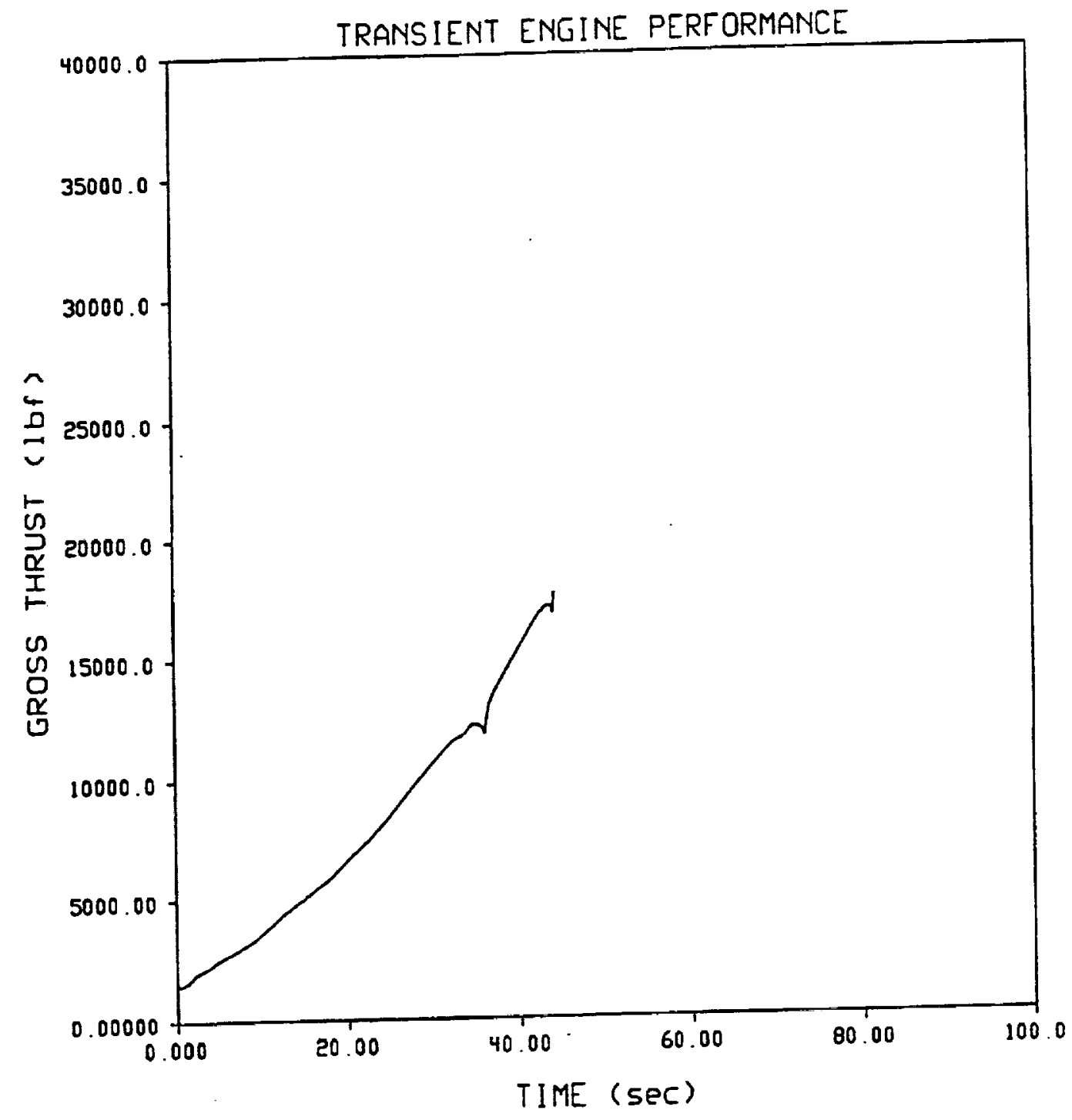

Figure 4.8.(iii)

Caption on Figure 4.8.(iv) 


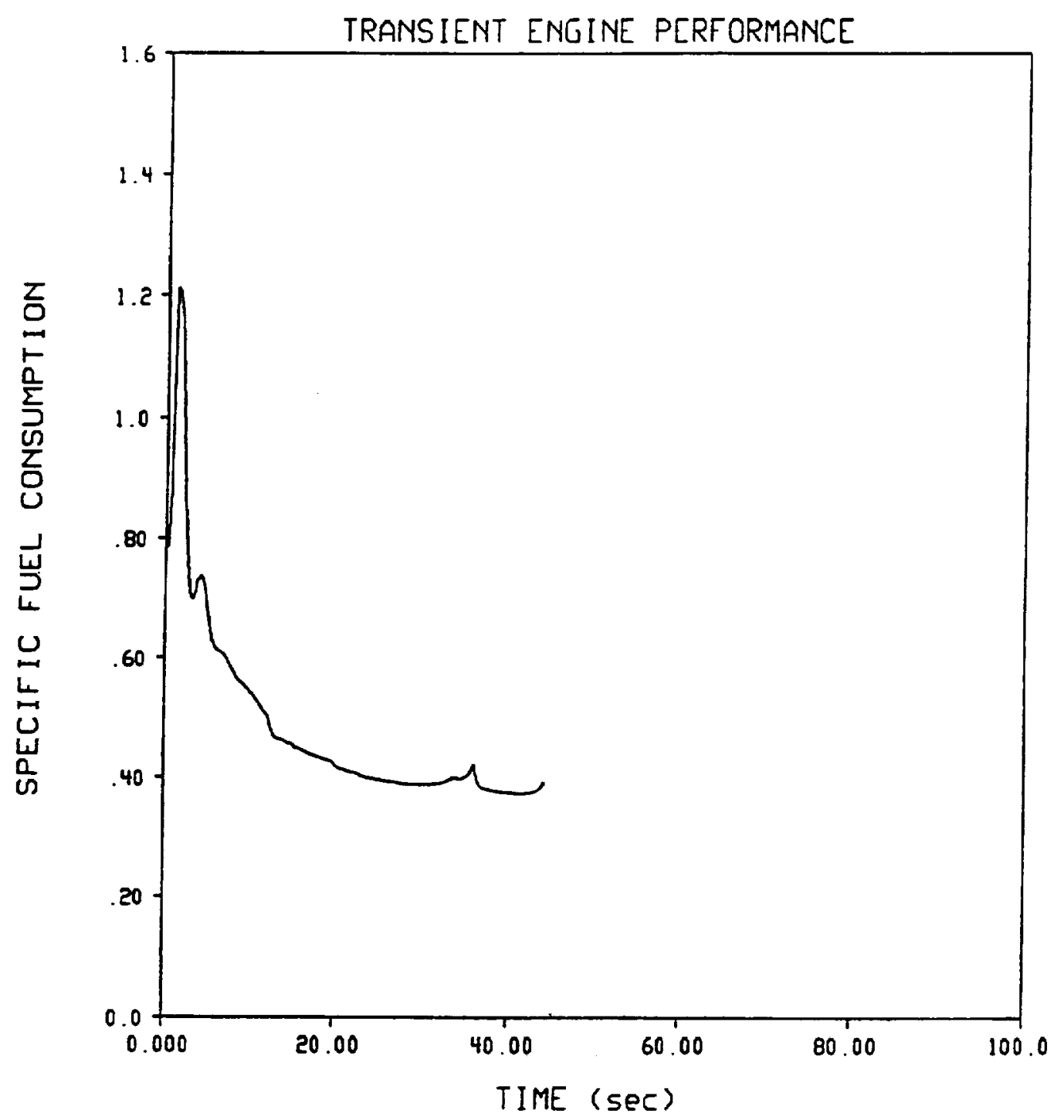

Figure 4.8.(iv)

Figure 4.8. Transient Engine Performance: (i), (ii), (iii), and (iv). Engine power setting as in Fig. 4.7. Mass fraction of water ingested equal to 8.0 per cent. 


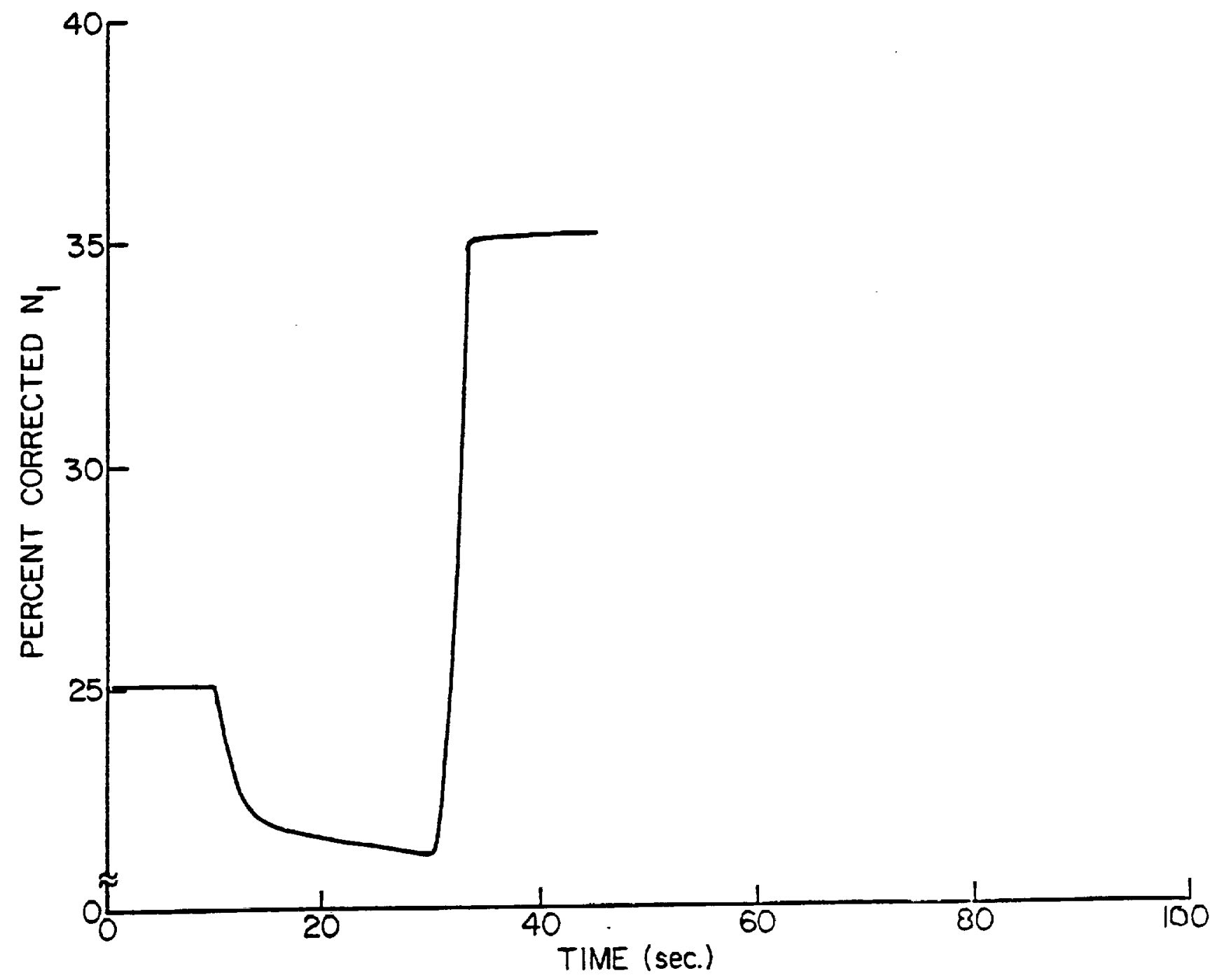

Figure 4.9.(i)

Caption on Figure 4.9.(iv) 


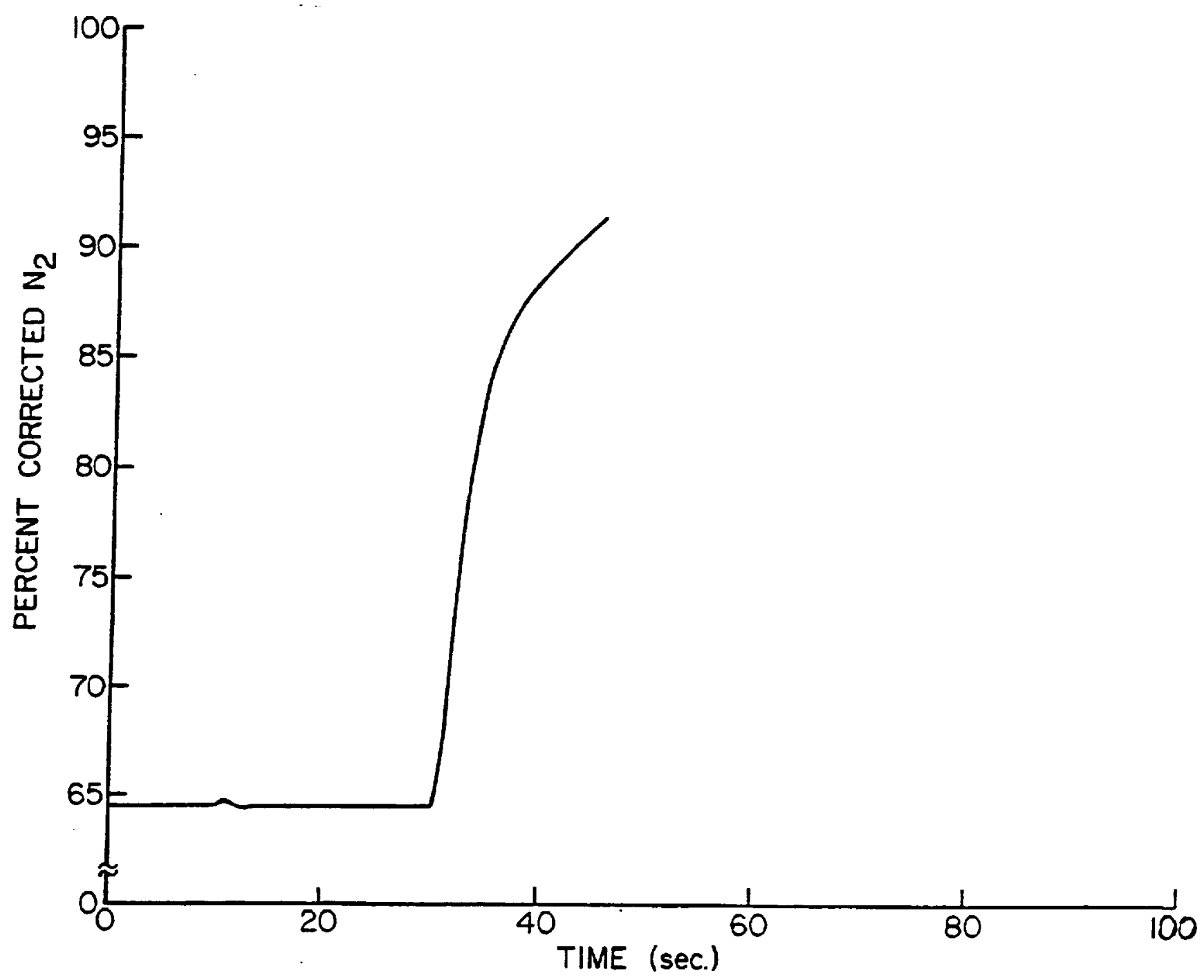

Figure 4.9.(ii)

Caption on Figure 4.9.(iv) 


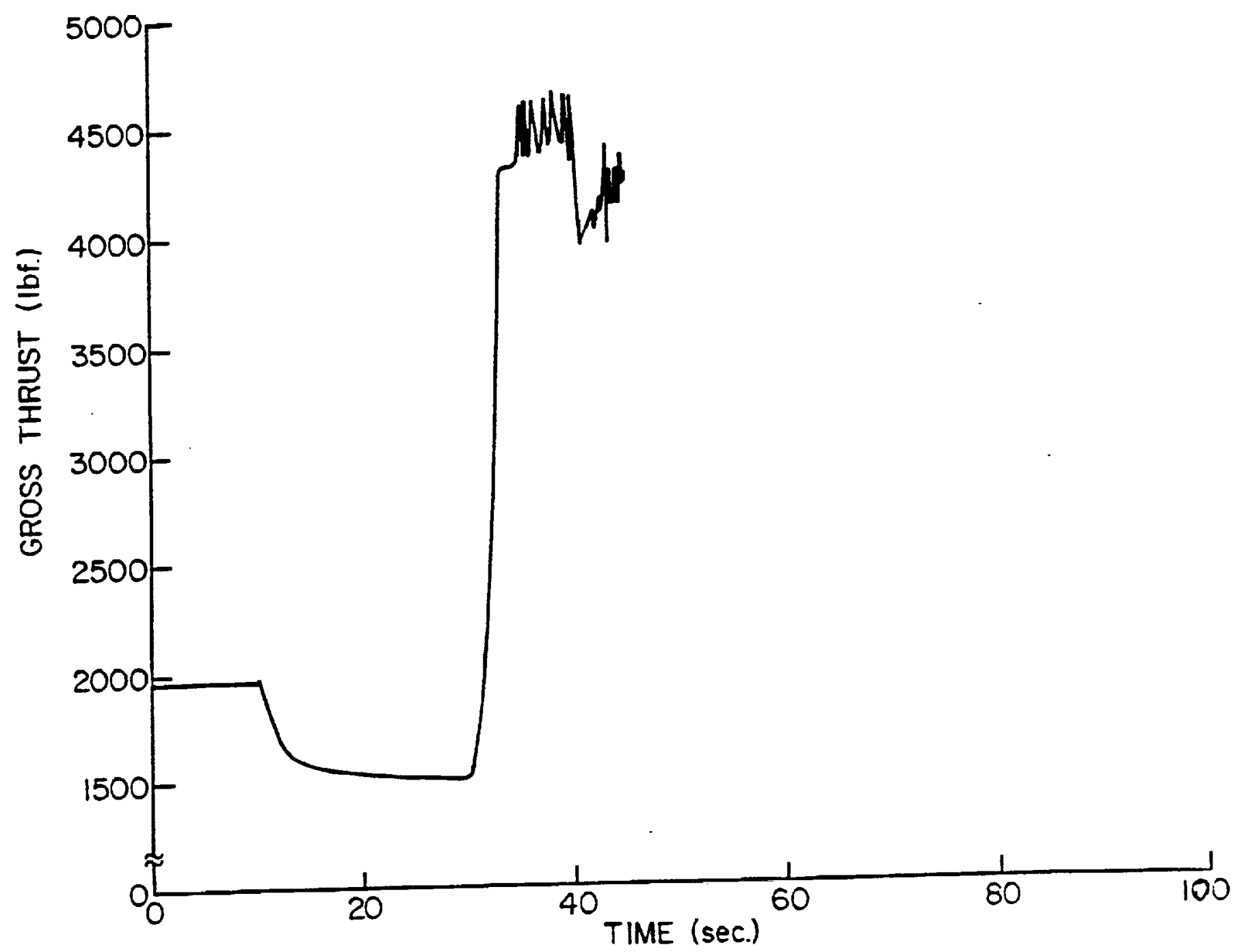

Figure 4.9.(iii)

Caption on Figure 4.9.(iv) 


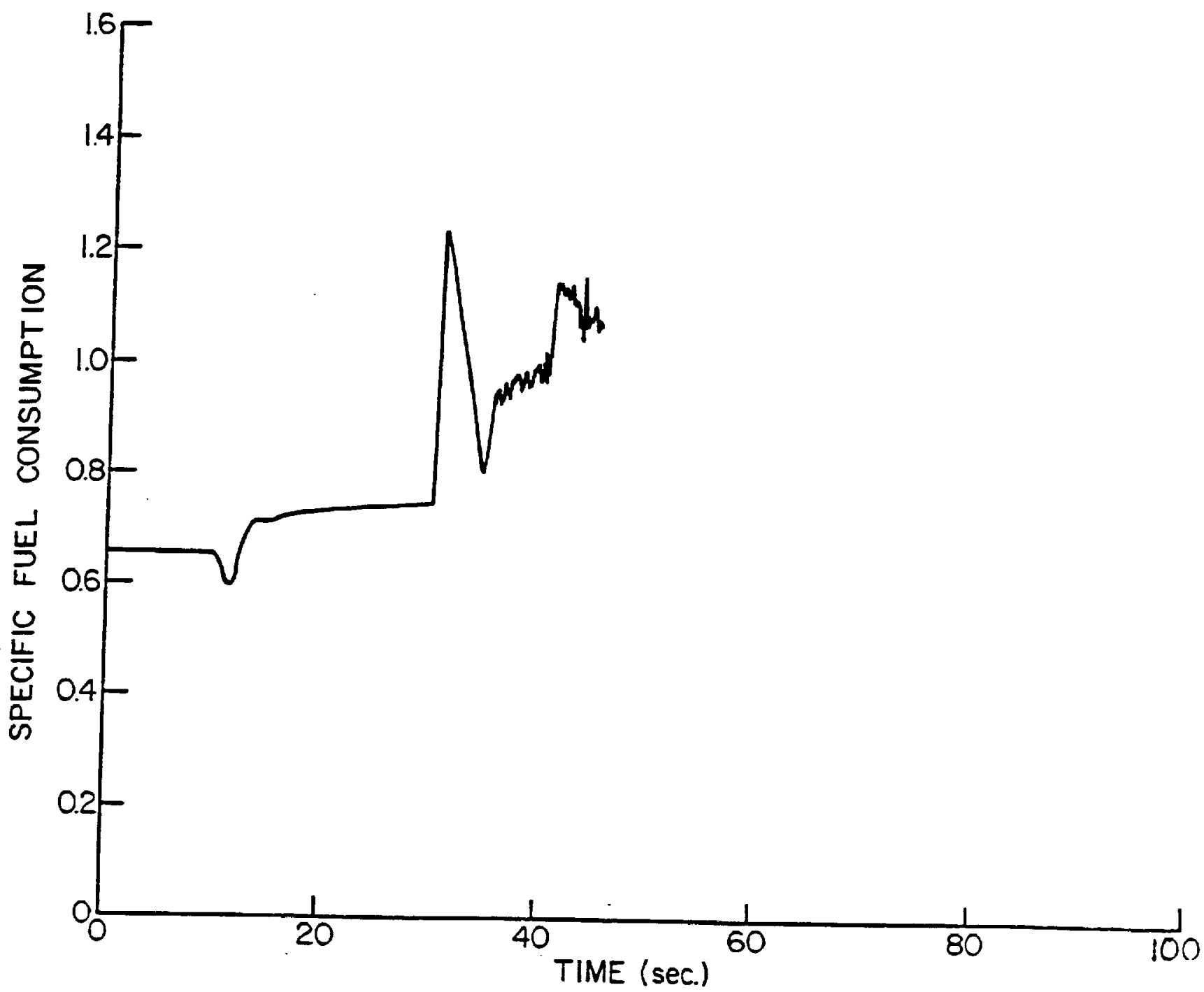

Figure 4.9.(iv)

Figure 4.9. Transient Engine Performance: (i), (ii), (iii), and (iv). Engine power setting constant at flight idle power setting for $0-30$ secs; then changed to maximum power setting in 10 secs. Mass fraction of water ingested changed from zero to 4.0 per cent in 10 secs., and then from 4.0 to 8.0 secs. in 50 secs. 


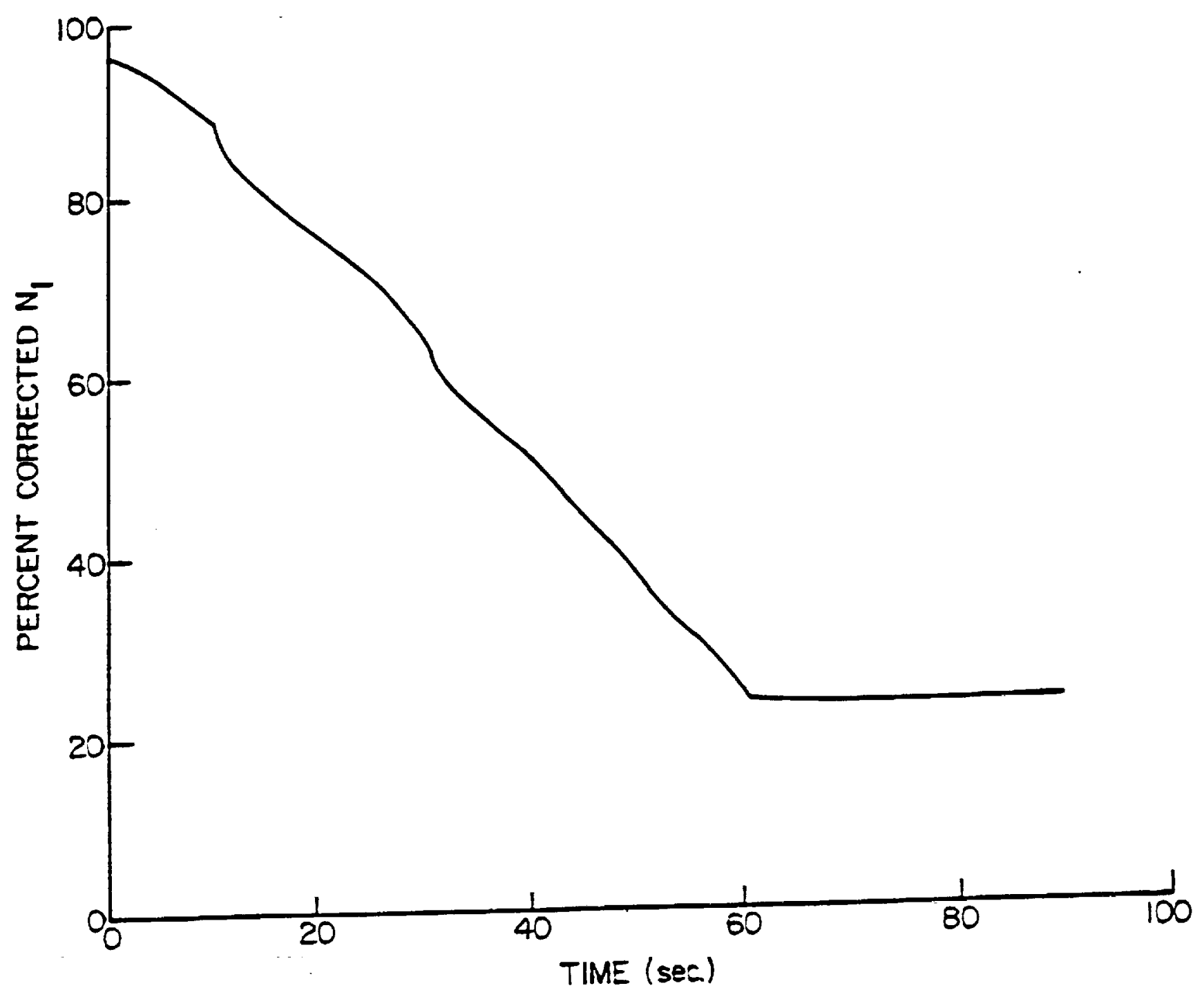

Figure 4.10.(i)

Caption on Figure 4.10.(iv) 


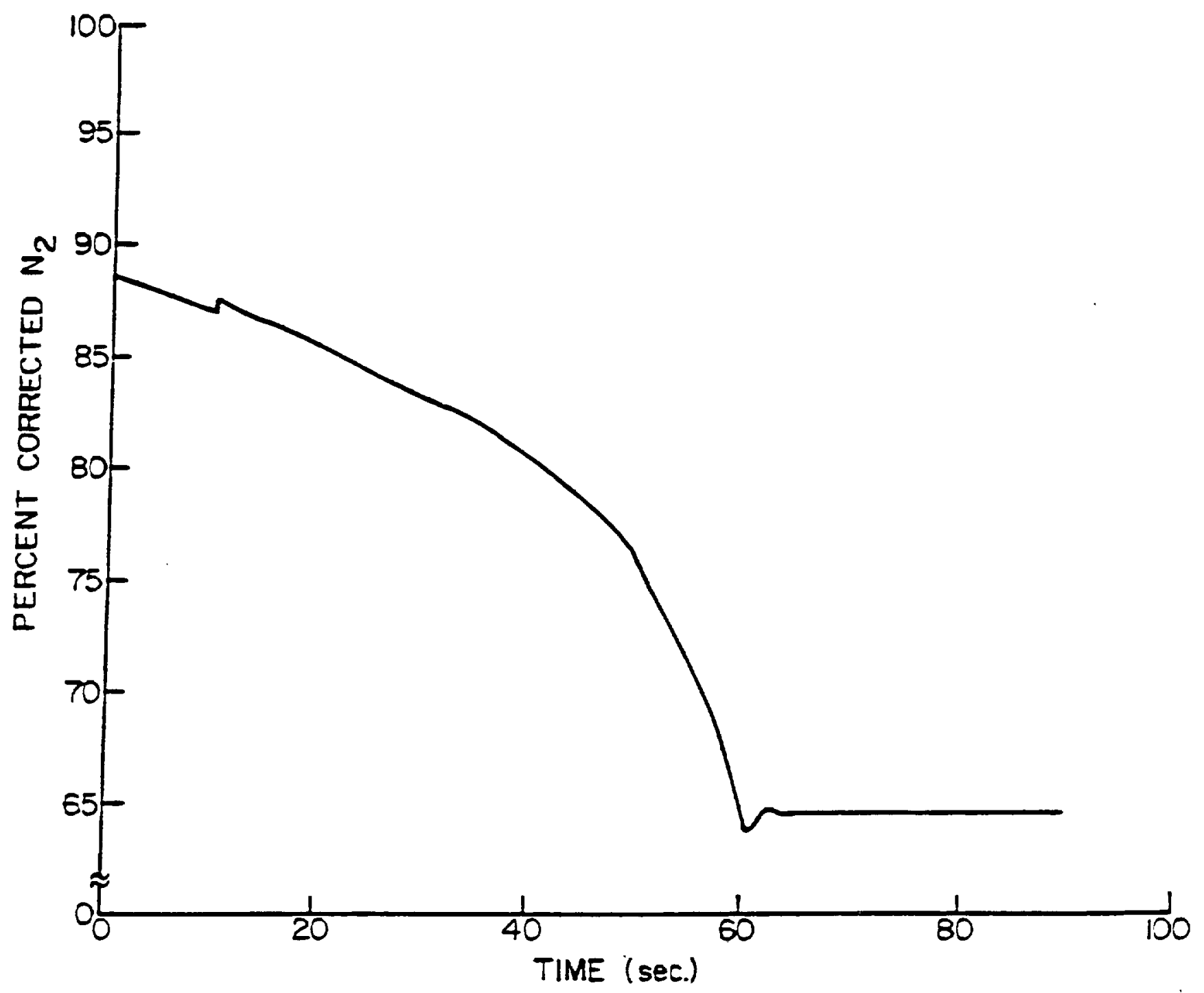

Figure 4.10.(ii)

Caption on Figure 4.10.(iv) 


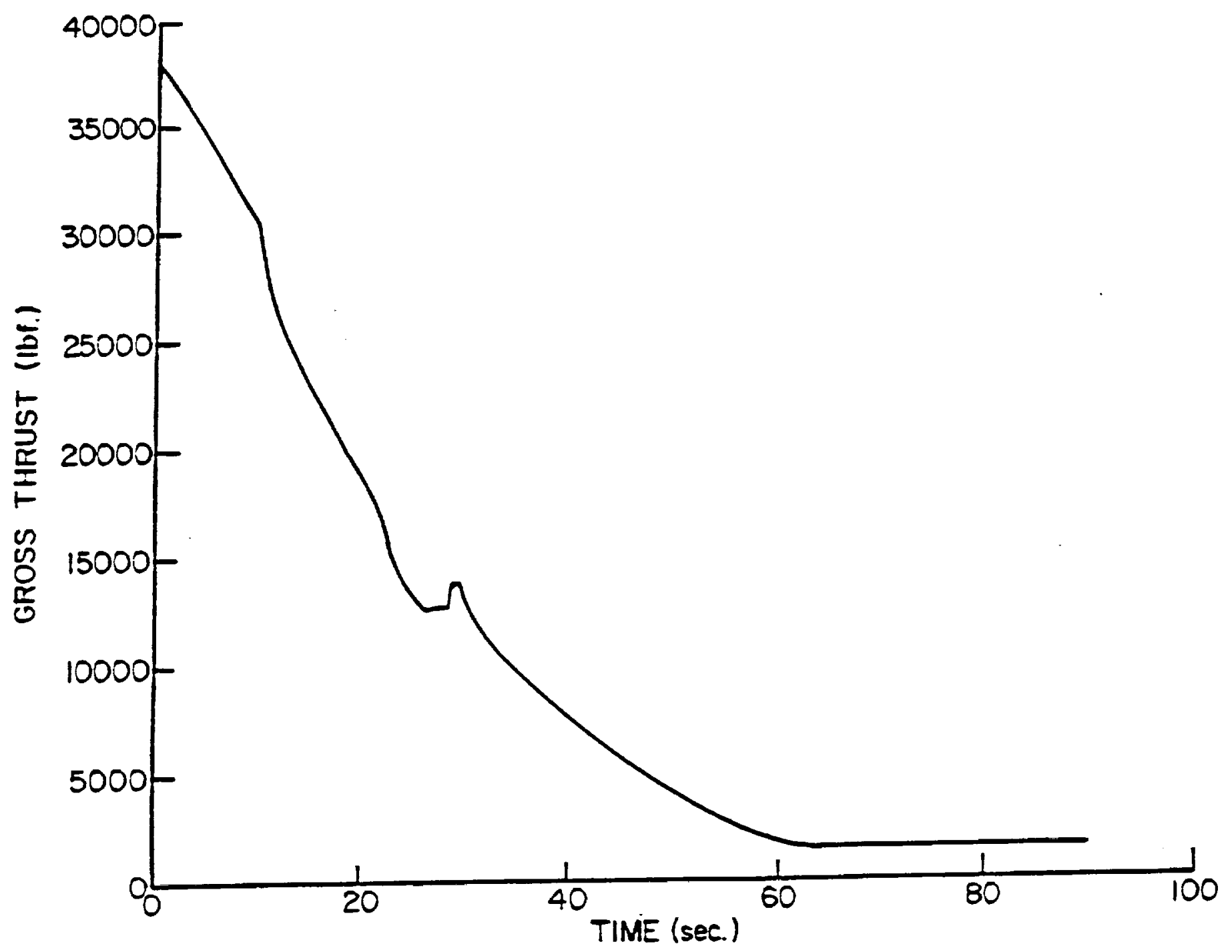

Figure 4.10.(iii)

Caption on Figure 4.10.(iv) 


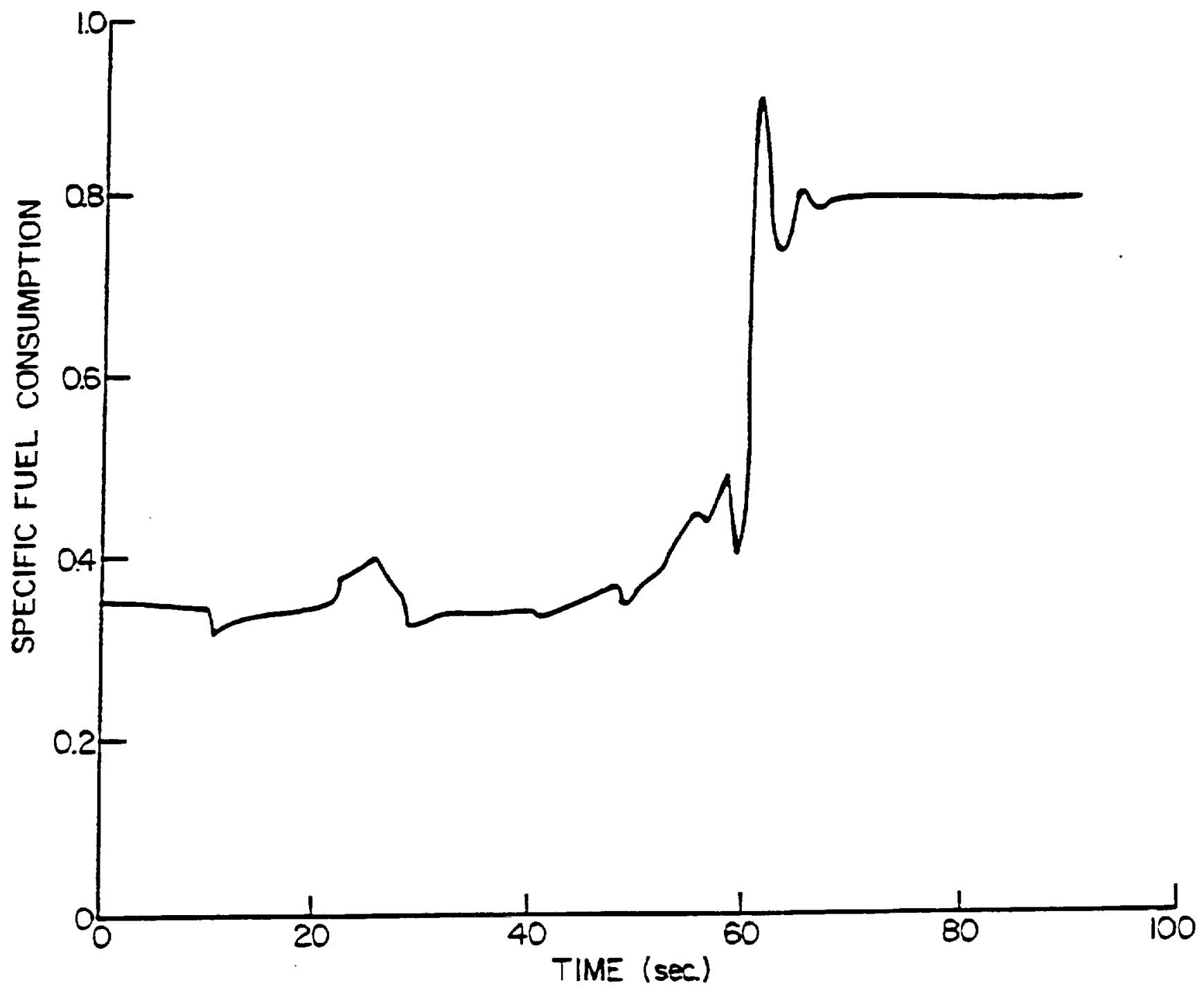

Figure 4.10.(iv)

Figure 4.10. Transient Engine Performance: (i), (ii), (iii), and (iv). Engine power setting changed from maximum power to cruise power in 10 secs, and then to flight idle in 60 secs. Mass fraction of water ingested constant at zero value from 0 to 10 secs. and then constant at 4.0 per cent. 


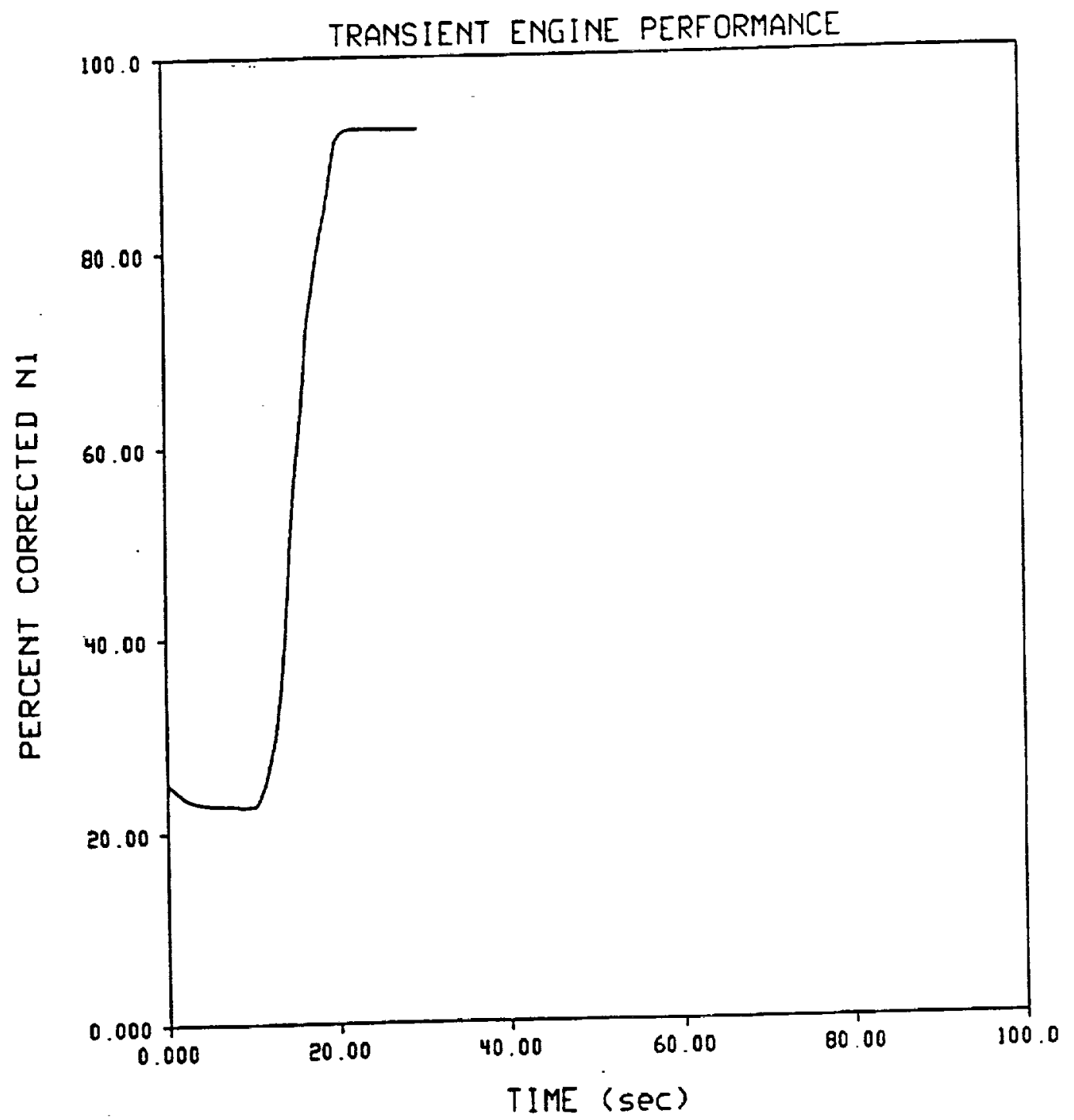

Figure 4.11.(i)

Caption on Figure 4.11.(iv) 


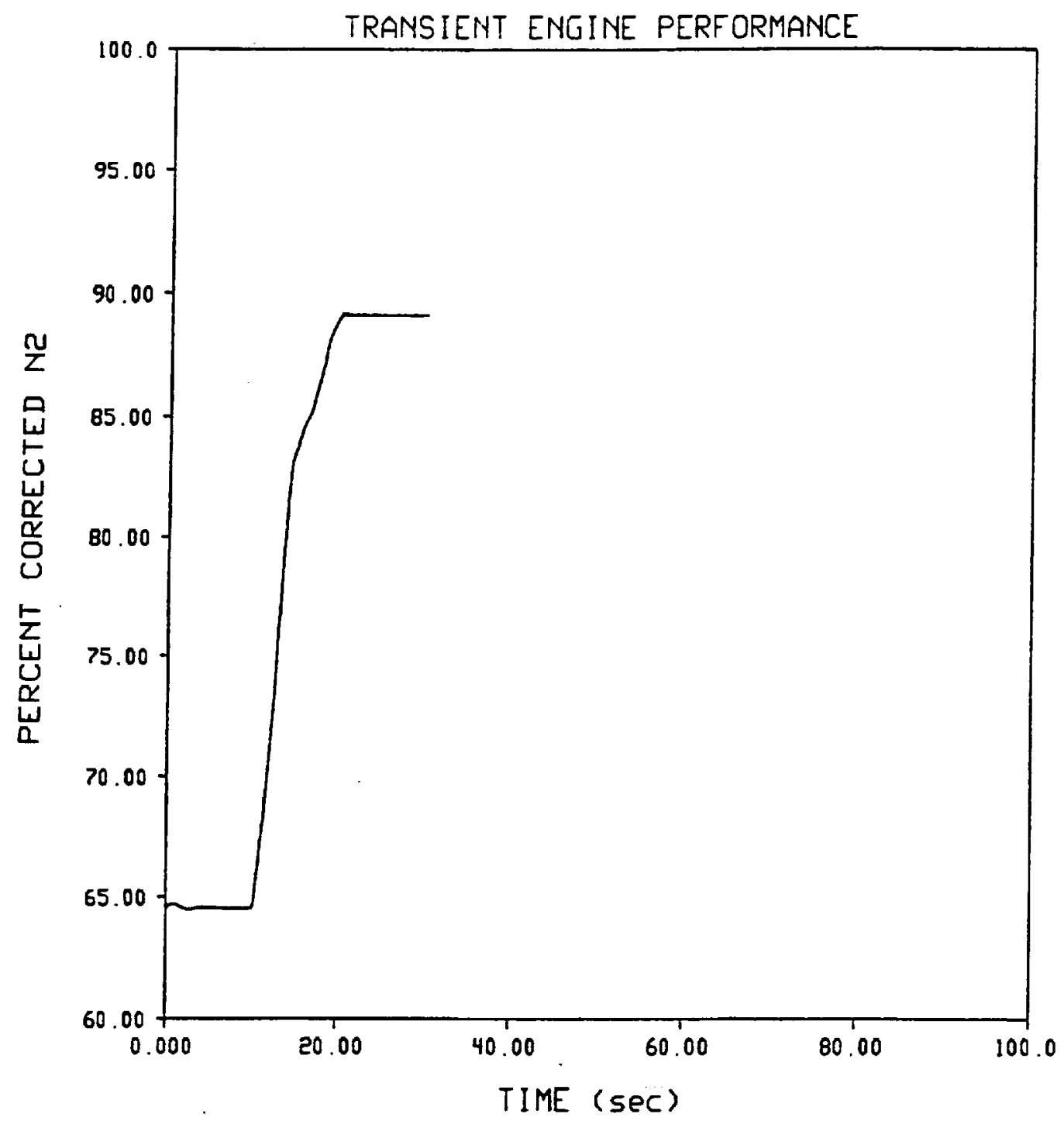

Figure 4.11.(ii)

Caption on Figure 4.11.(iv) 


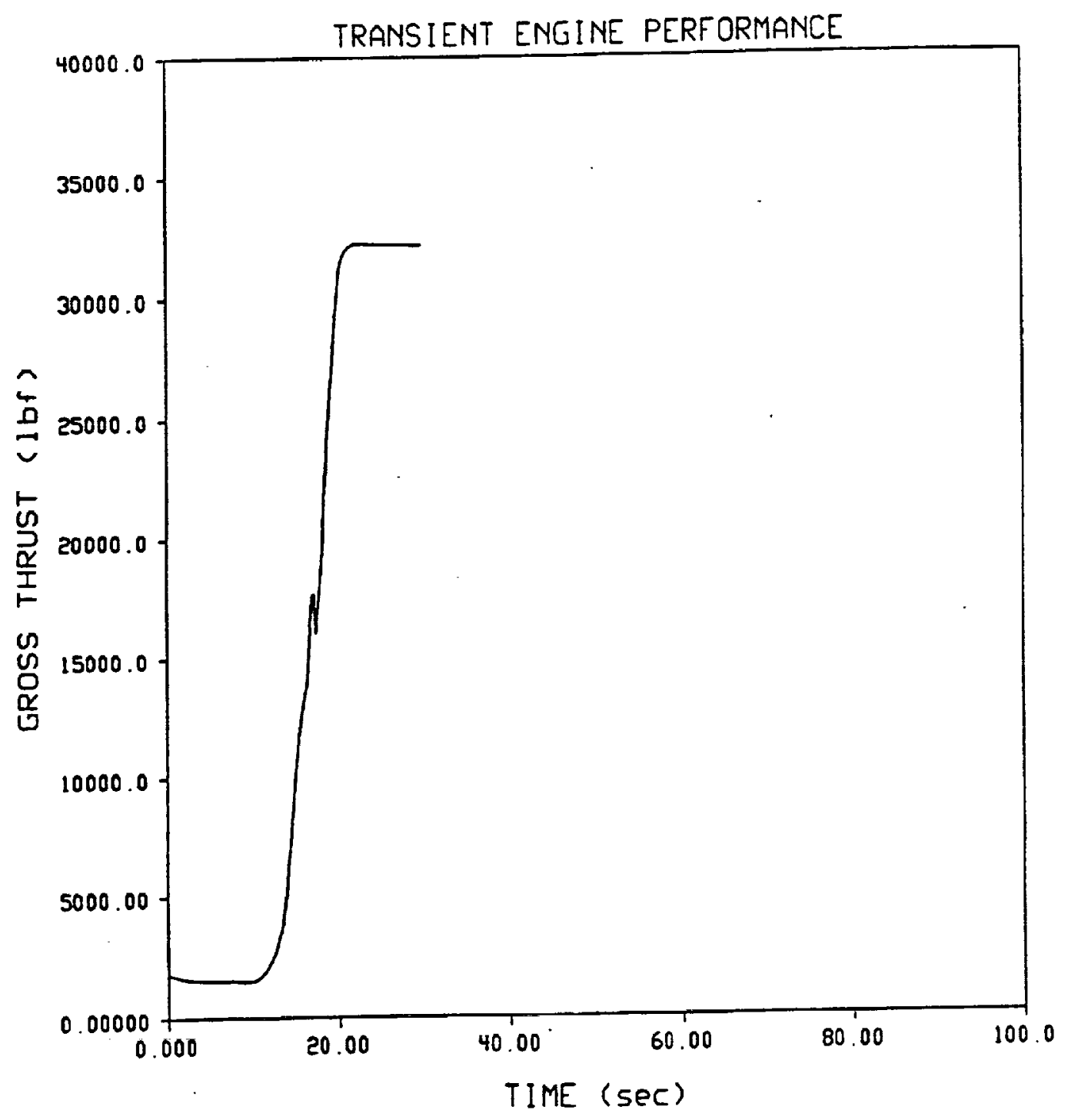

Figure 4.11.(iii)

Caption on Figure 4.11.(iv) 


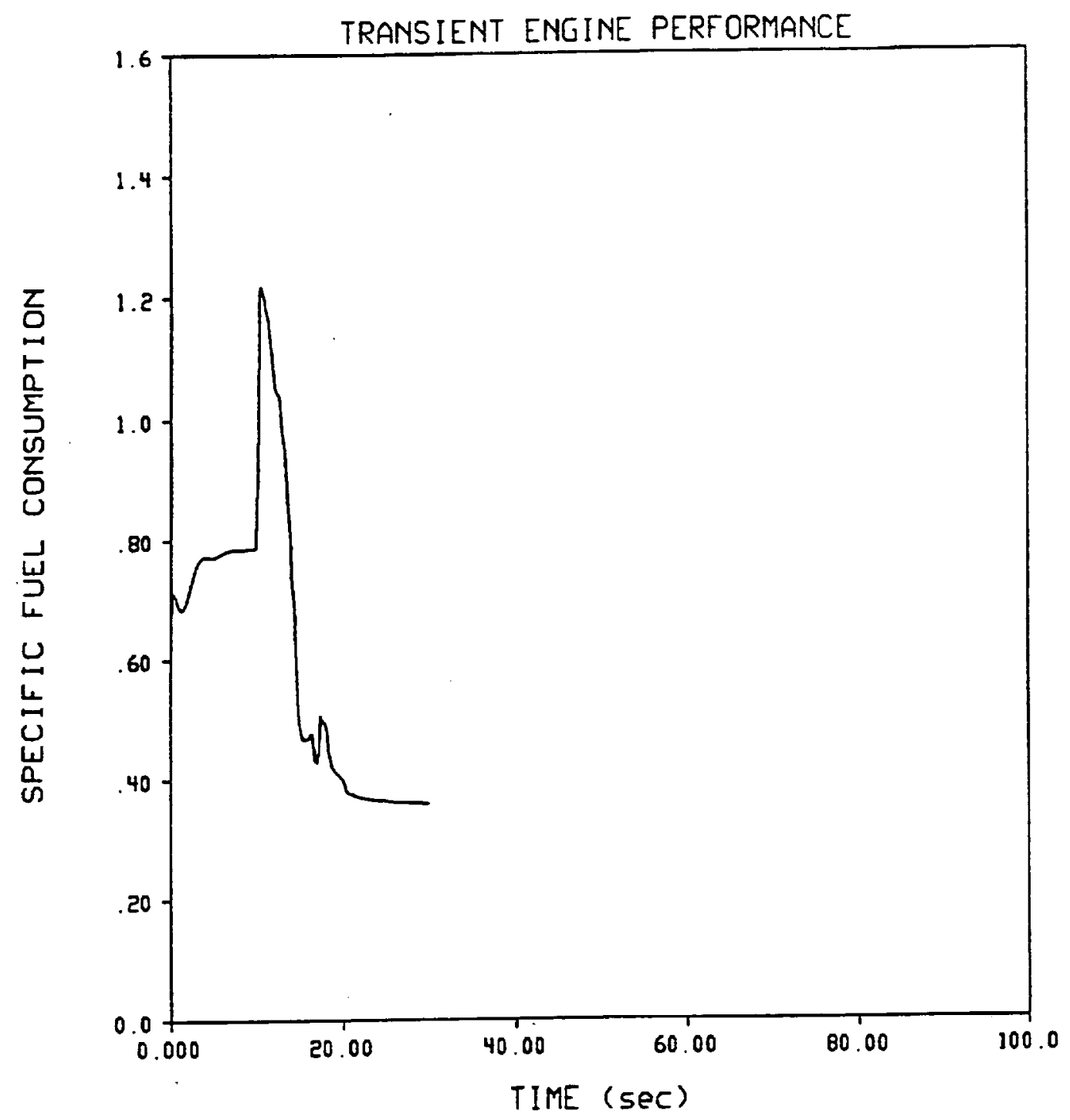

Figure 4.11.(iv)

Figure 4.11. Transient Engine Performance: (i), (ii), (iii), and (iv). Engine power setting fixed at flight idle 0 to 10 secs., then changed to maximum power in 10 secs, then held constant for 30 secs., and then changed to flight idle in 30 secs. Mass fraction of water ingested changed from 0 to 8.0 per cent in $0.1 \mathrm{sec}$., then constant for 30 secs., and then changed to 4.0 per cent. 


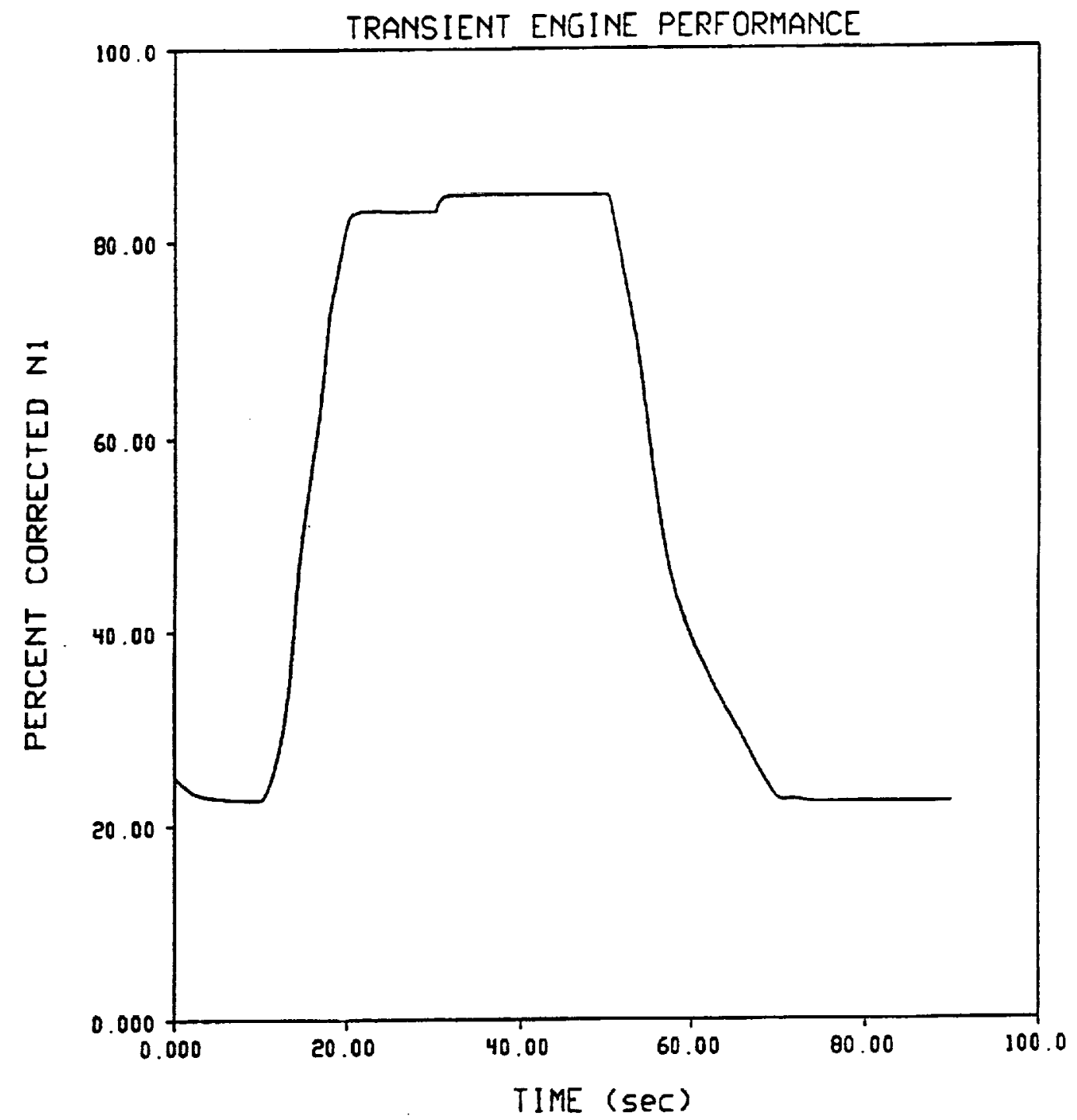

Figure 4.12.(i)

Caption on Figure 4.12.(iv) 


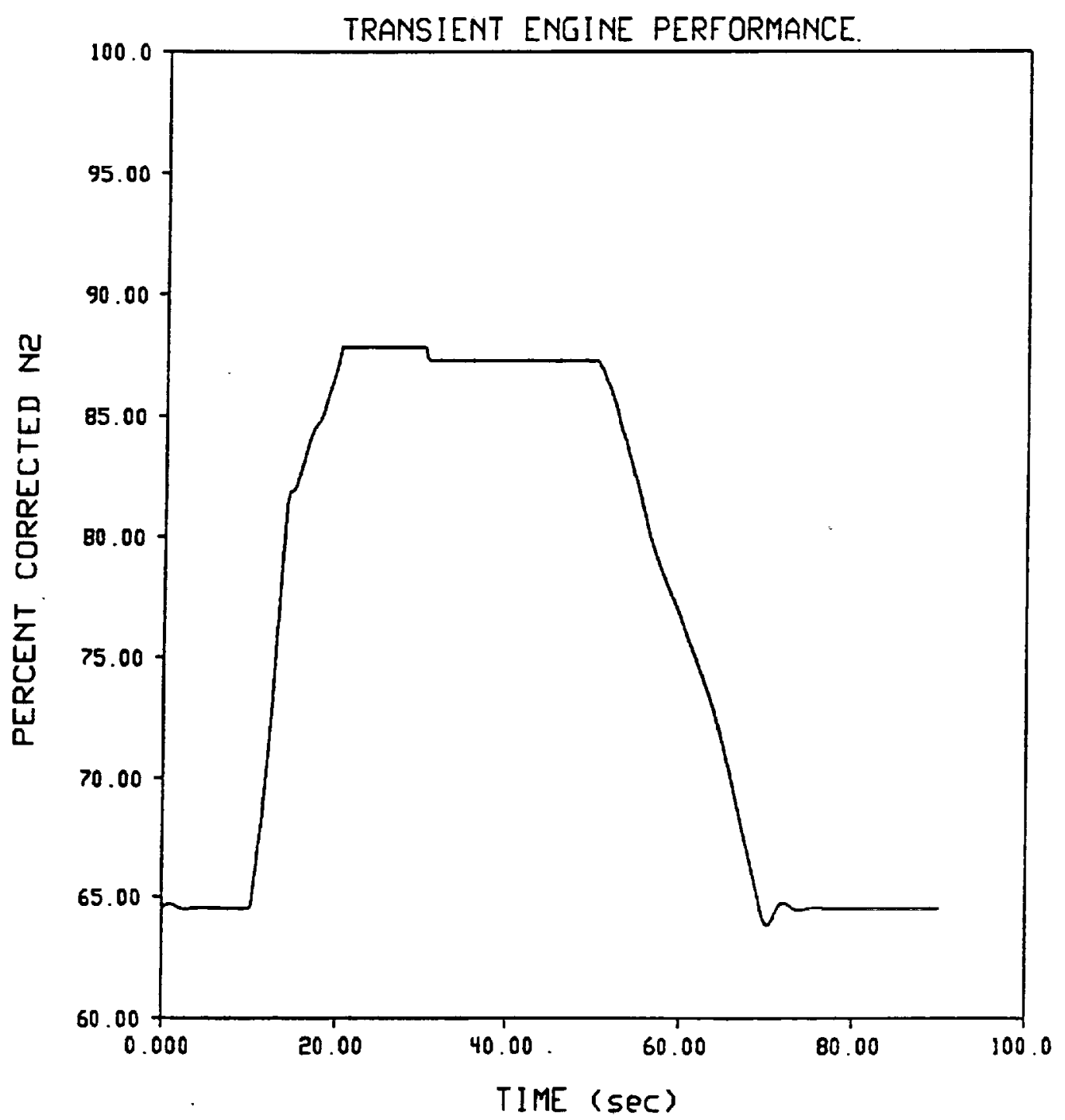

Figure 4.12.(ii)

Caption on Figure 4.12.(iv) 


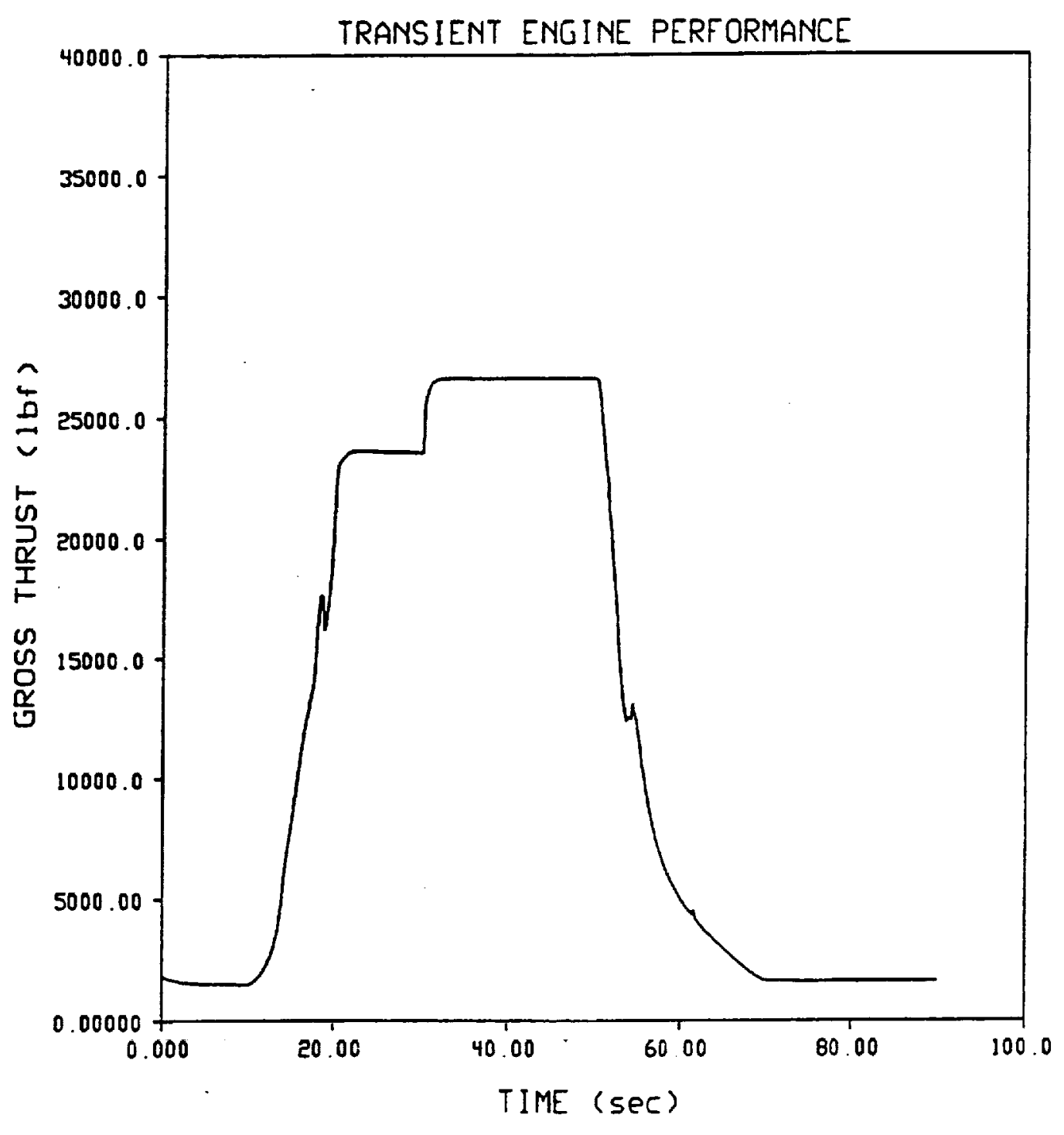

Figure 4.12.(iii)

Caption on Figure 4.12.(iv) 


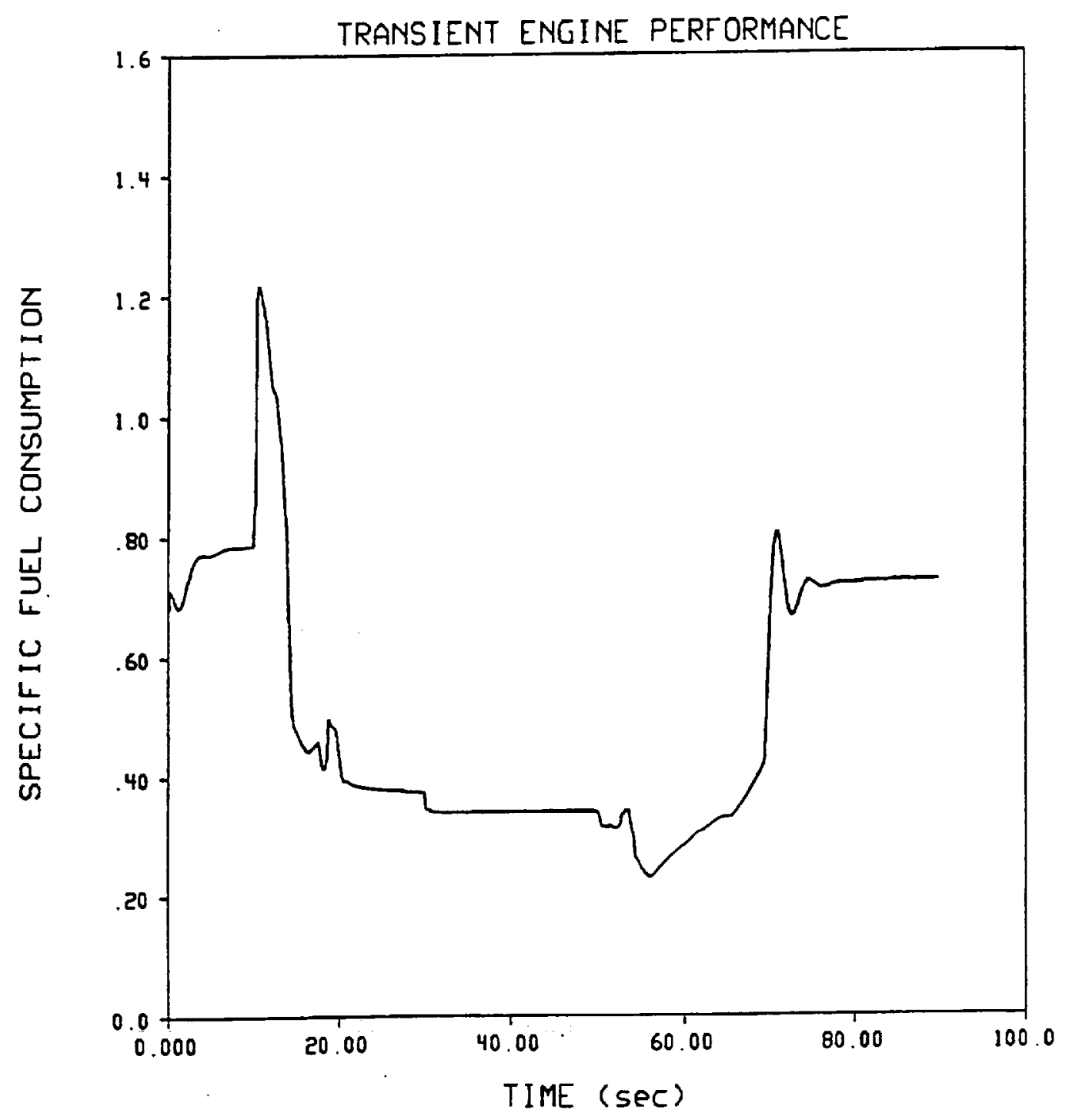

Figure 4.12.(iv)

Figure 4.12. Transient Engine Performance: (i), (ii), (iii), and (iv). Engine power setting at flight idle 0 to 10 secs., then changed to cruise power setting in 10 secs., then constant for 30 secs., and then changed to flight idle conditions in 10 secs. Mass fraction of water ingested changed from 0 to 8.0 per cent in $0.1 \mathrm{sec}$., constant up to 30 secs., and then changed to 4.0 per cent. 


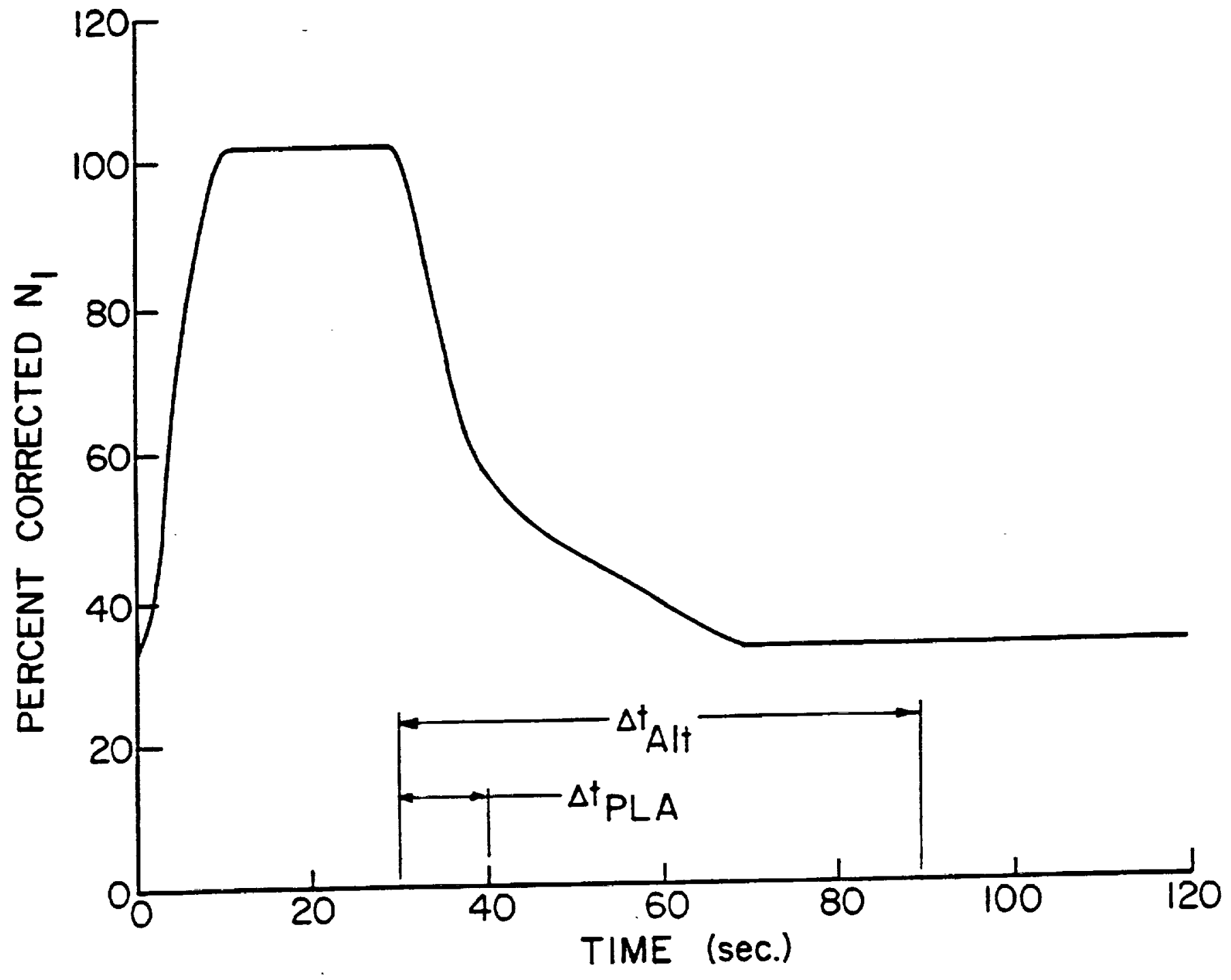

Figure 4.13.(i)

Caption on Figure 4.13.(iv) 


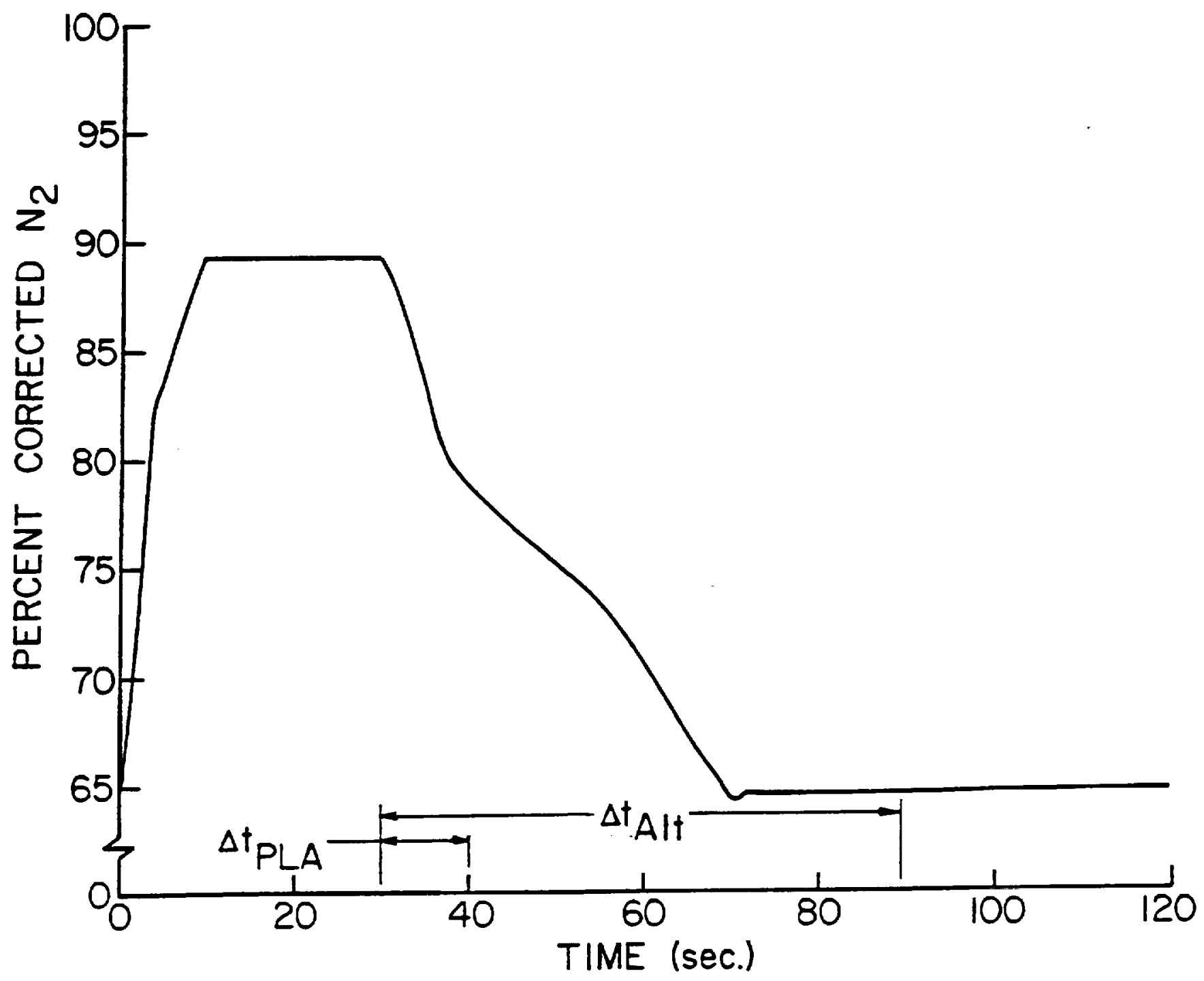

Figure 4.13.(ii)

Caption on Figure 4.13.(iv) 


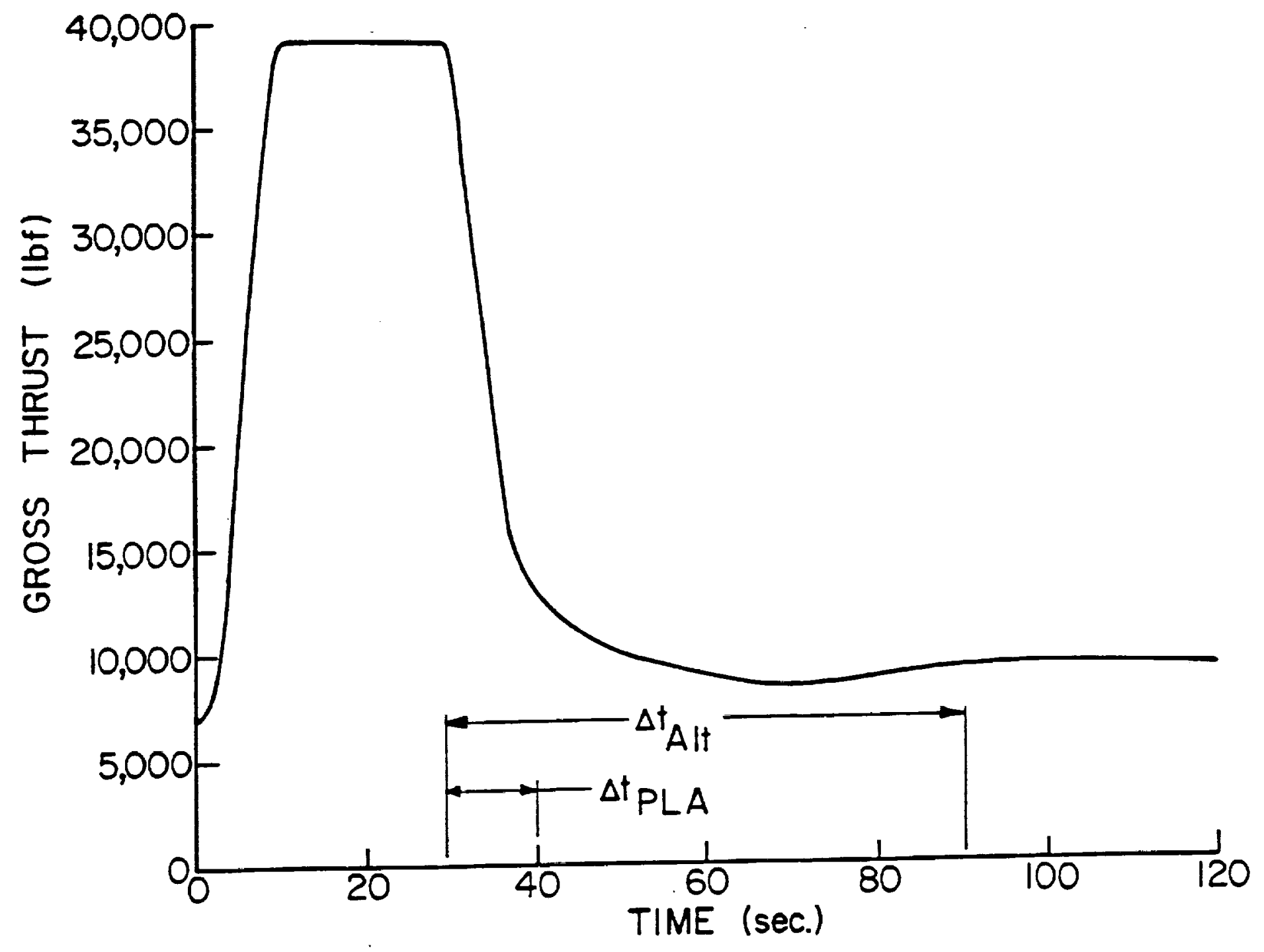

Figure 4.13.(iii)

Caption on Figure 4.13.(iv) 


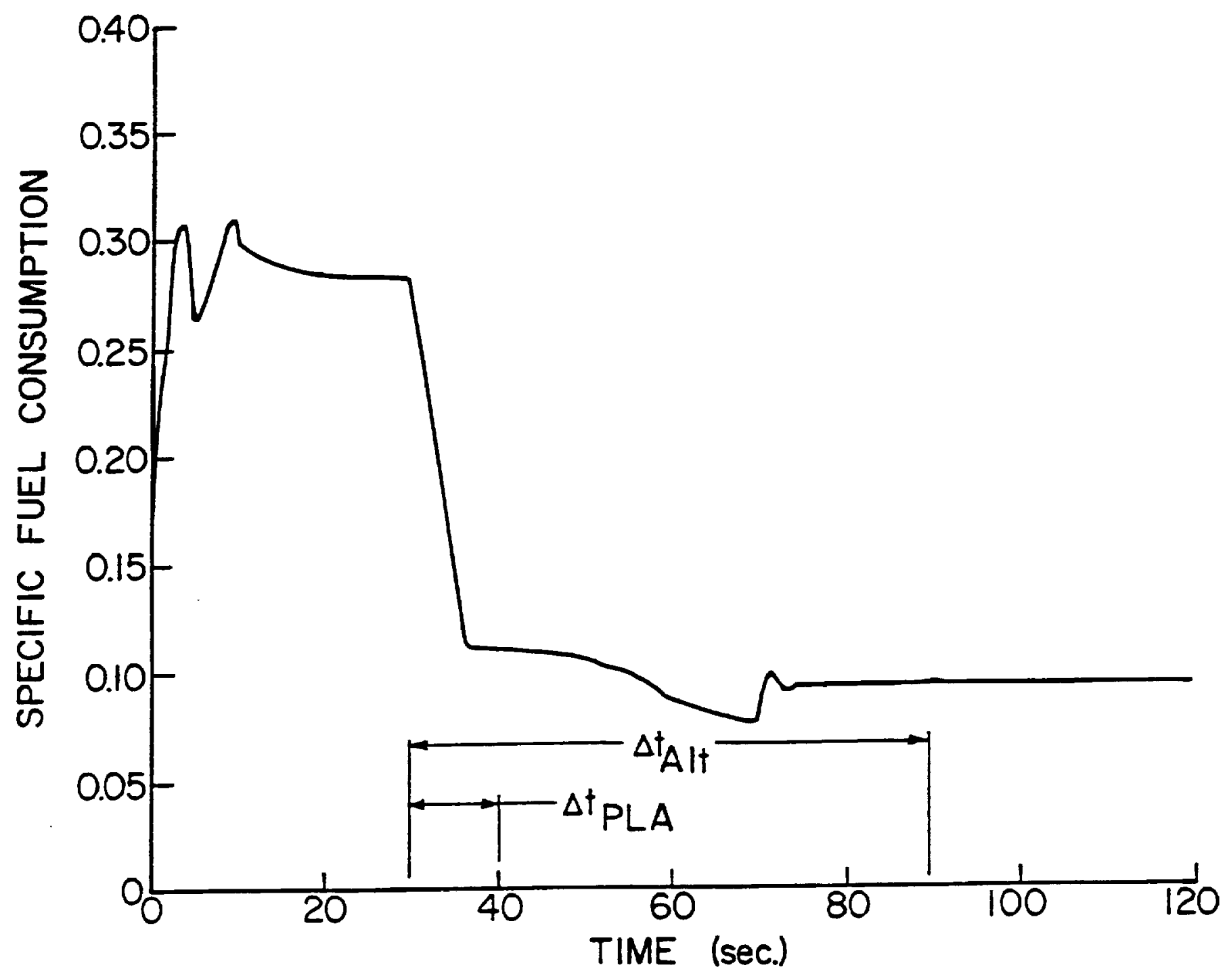

Figure 4.13.(iv)

Figure 4.13. Transient Engine Performance under varying Ambient Conditions: (i), (ii), (iii) and (iv). Case 012 of Group I in Table III. 


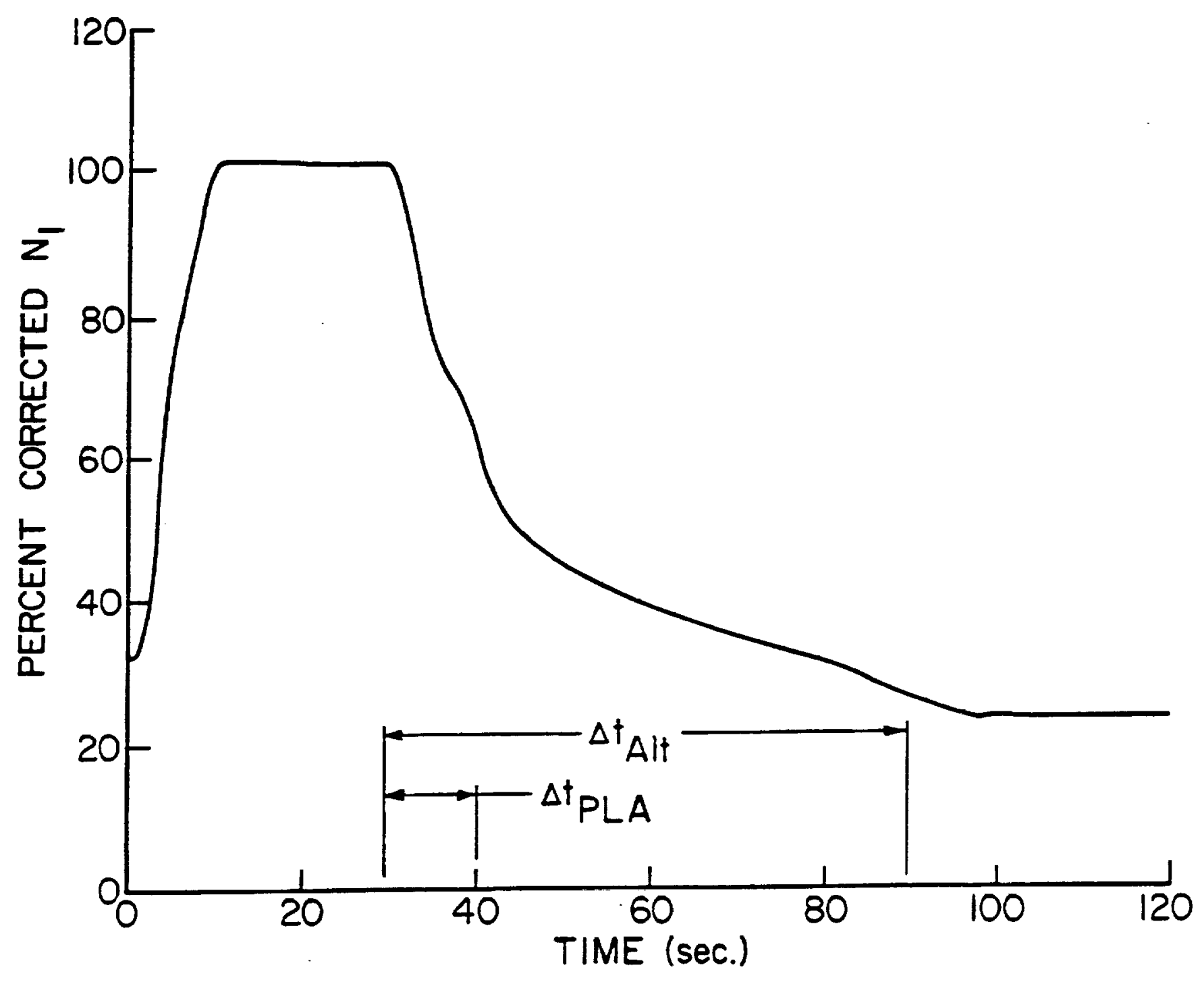

Figure 4.14.(i)

Caption on Figure 4.14.(iv) 


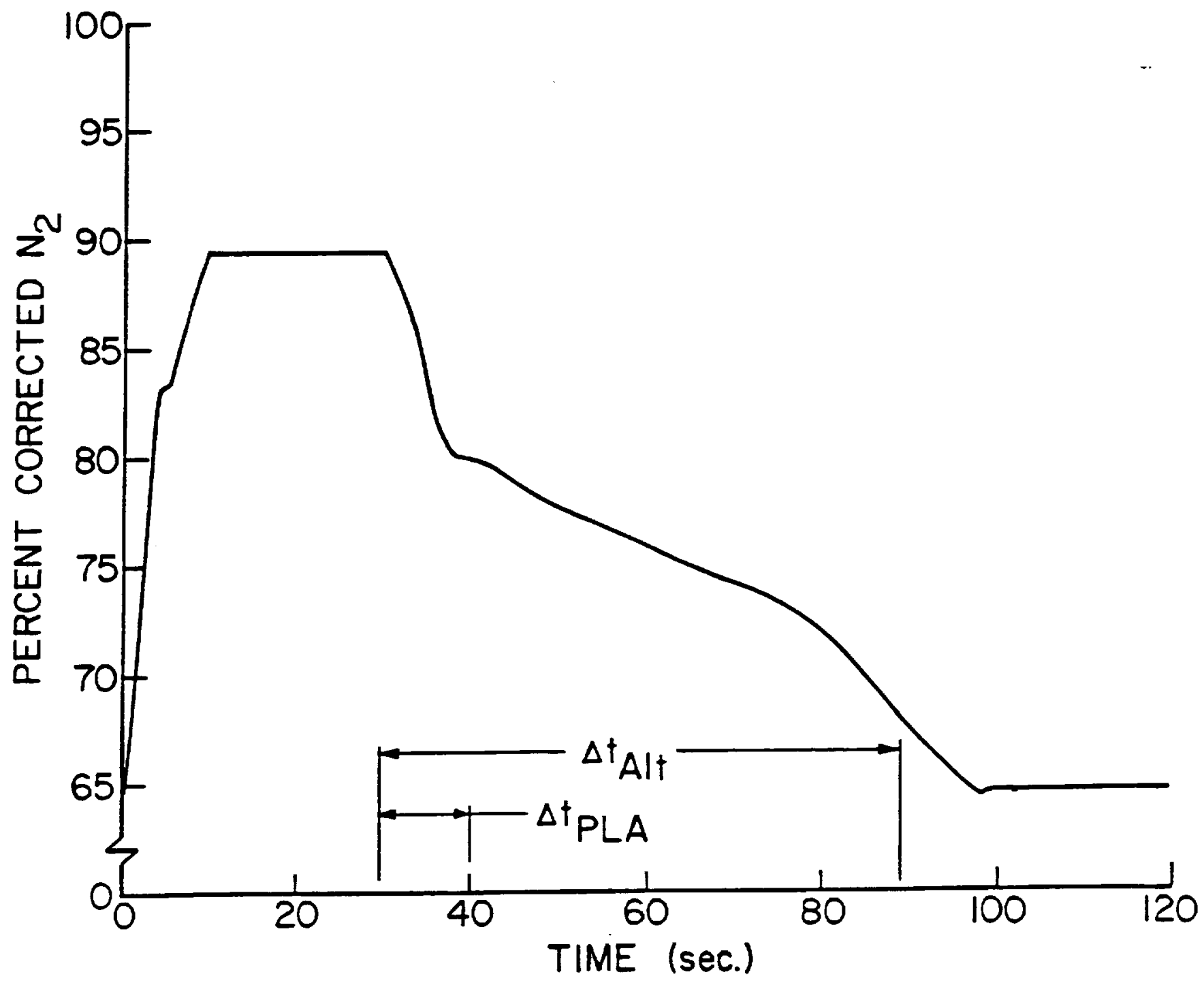

Figure 4.14.(ii)

Caption on Figure 4.14.(iv) 


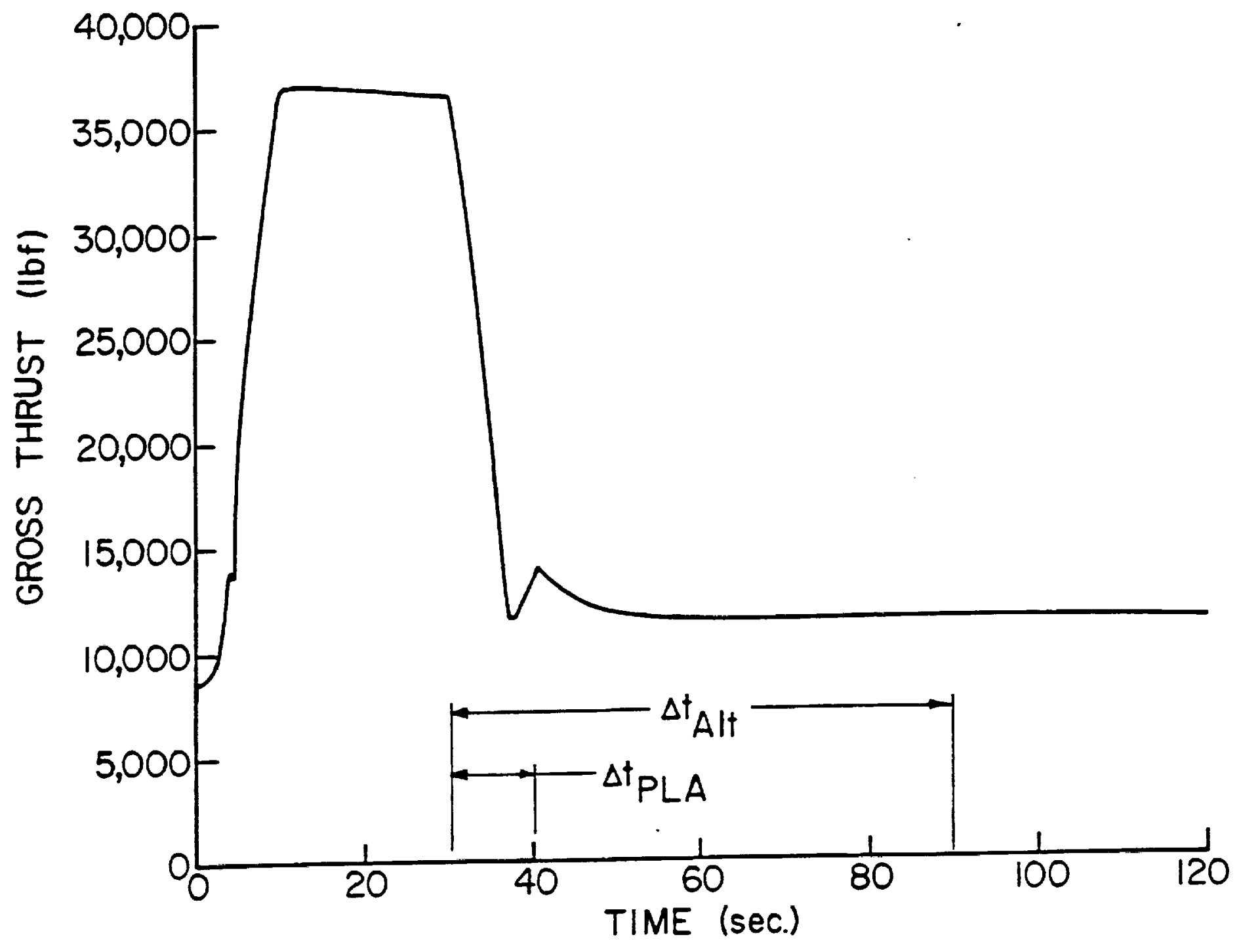

Figure 4.14.(iii)

Caption on Figure 4.14.(iv) 


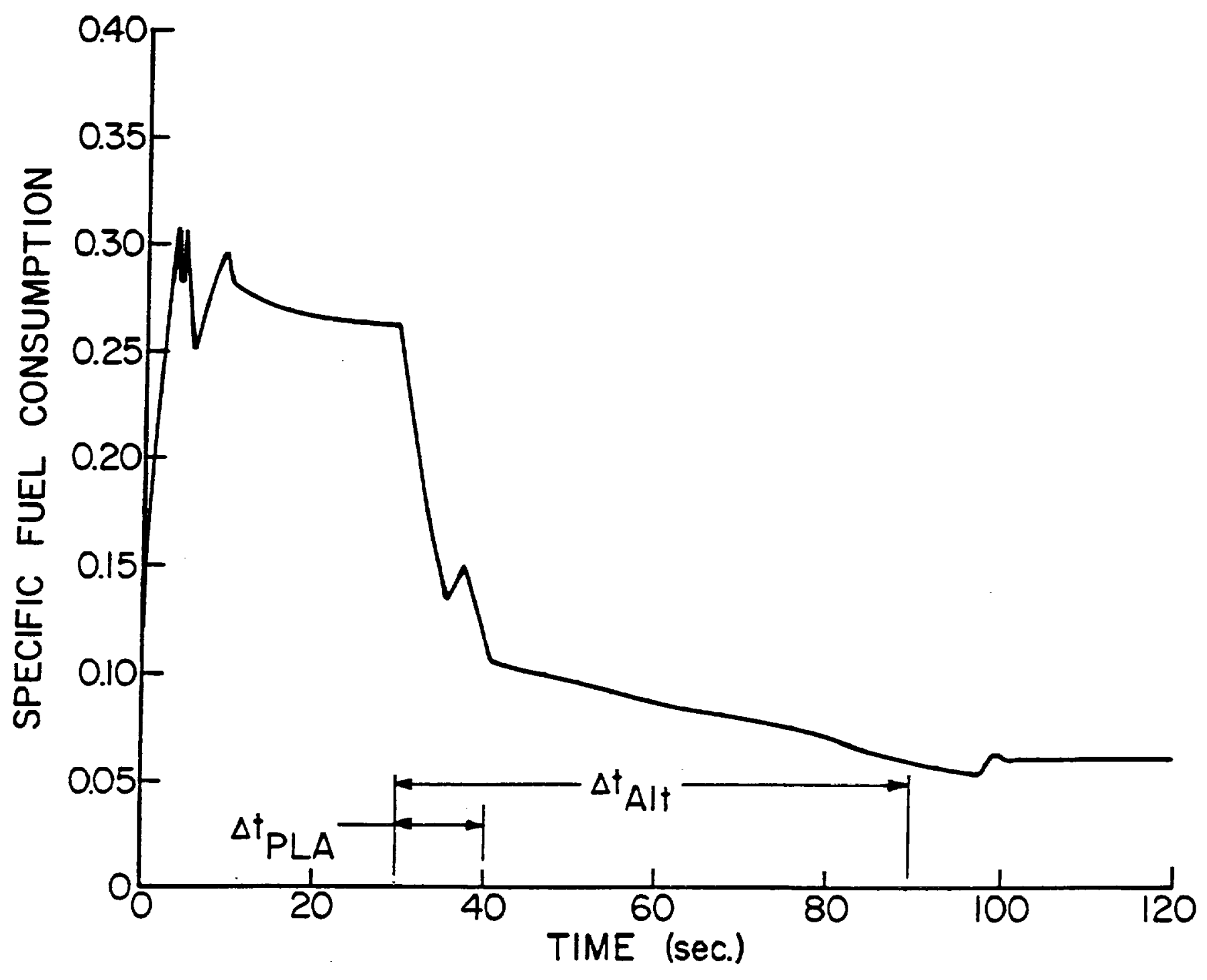

Figure 4.14.(iv)

Figure 4.14. Transient Engine Performance under Varying Ambient Conditions: (i), (ii), (iii), and (iv). Case 212 of Group I in Table III. 


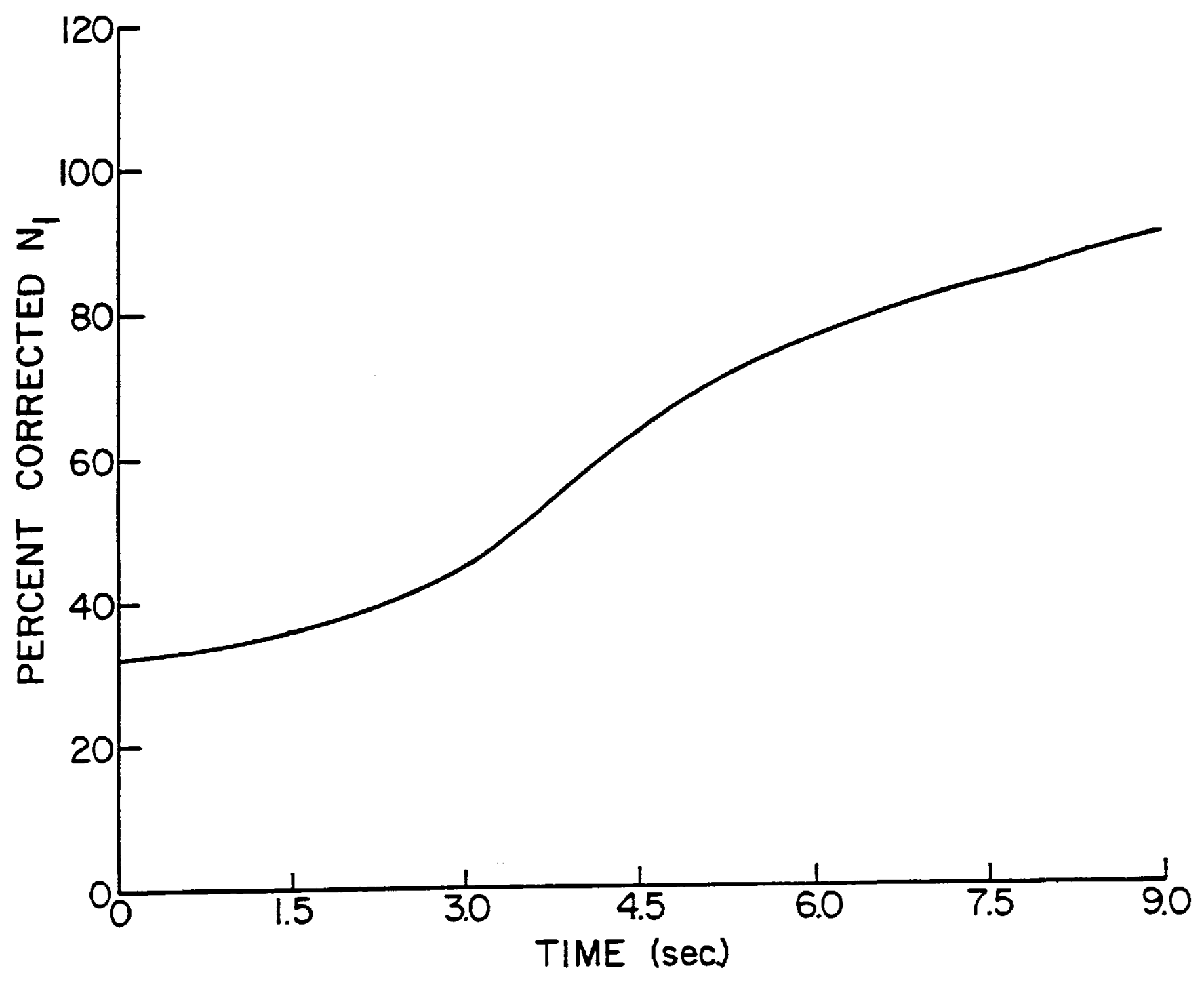

Figure 4.15.(i)

Caption on Figure 4.15.(iv)

194 


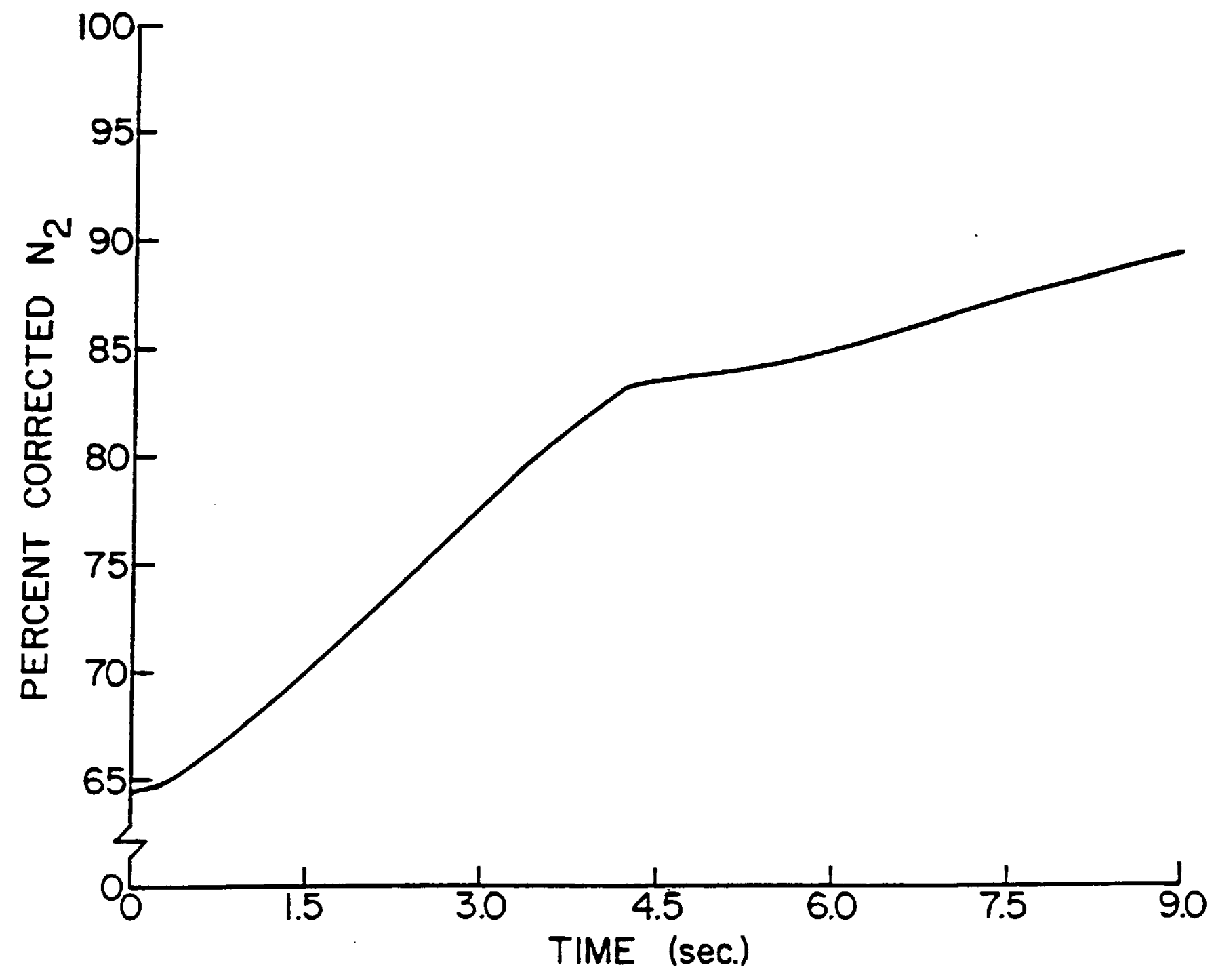

Figure 4.15.(ii)

Caption on Figure 4.15.(iv) 


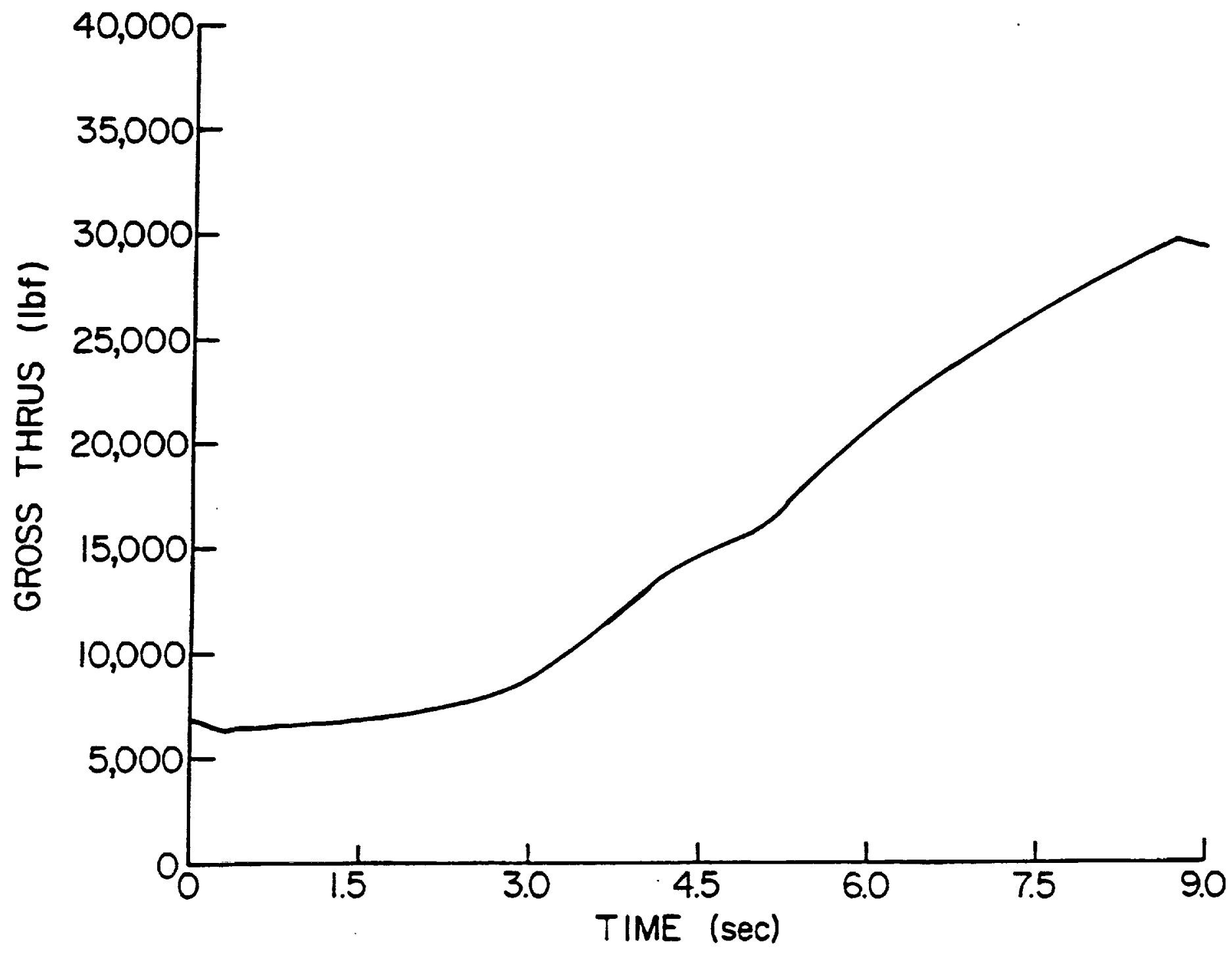

Figure 4.15.(iii)

Caption on Figure 4.15.(iv) 


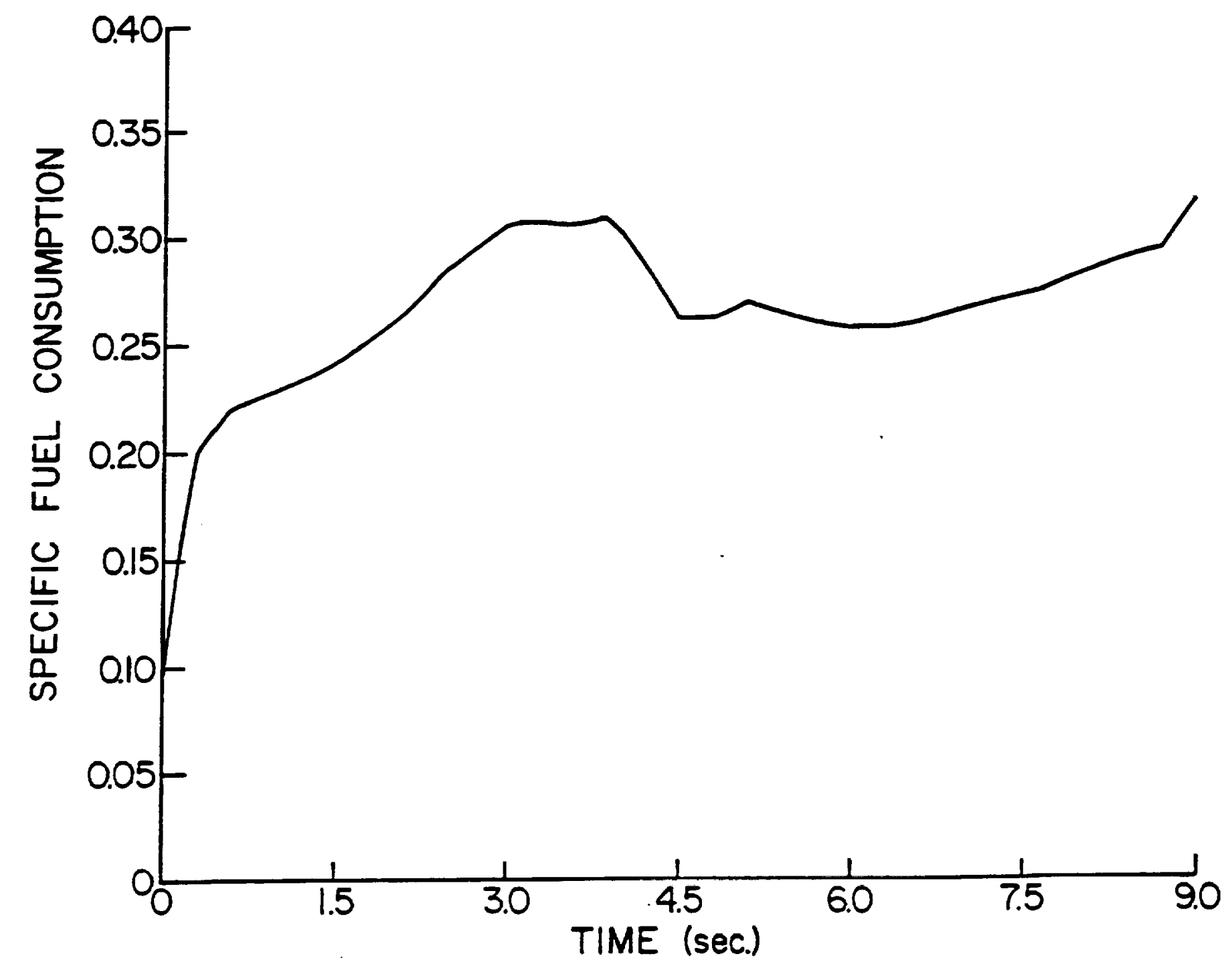

Figure 4.15.(iv)

Figure 4.15. Transient Engine Performance under Varying Ambient Conditions: (i), (ii), (iii), and (iv). Case 412 of Group I in Table III. 


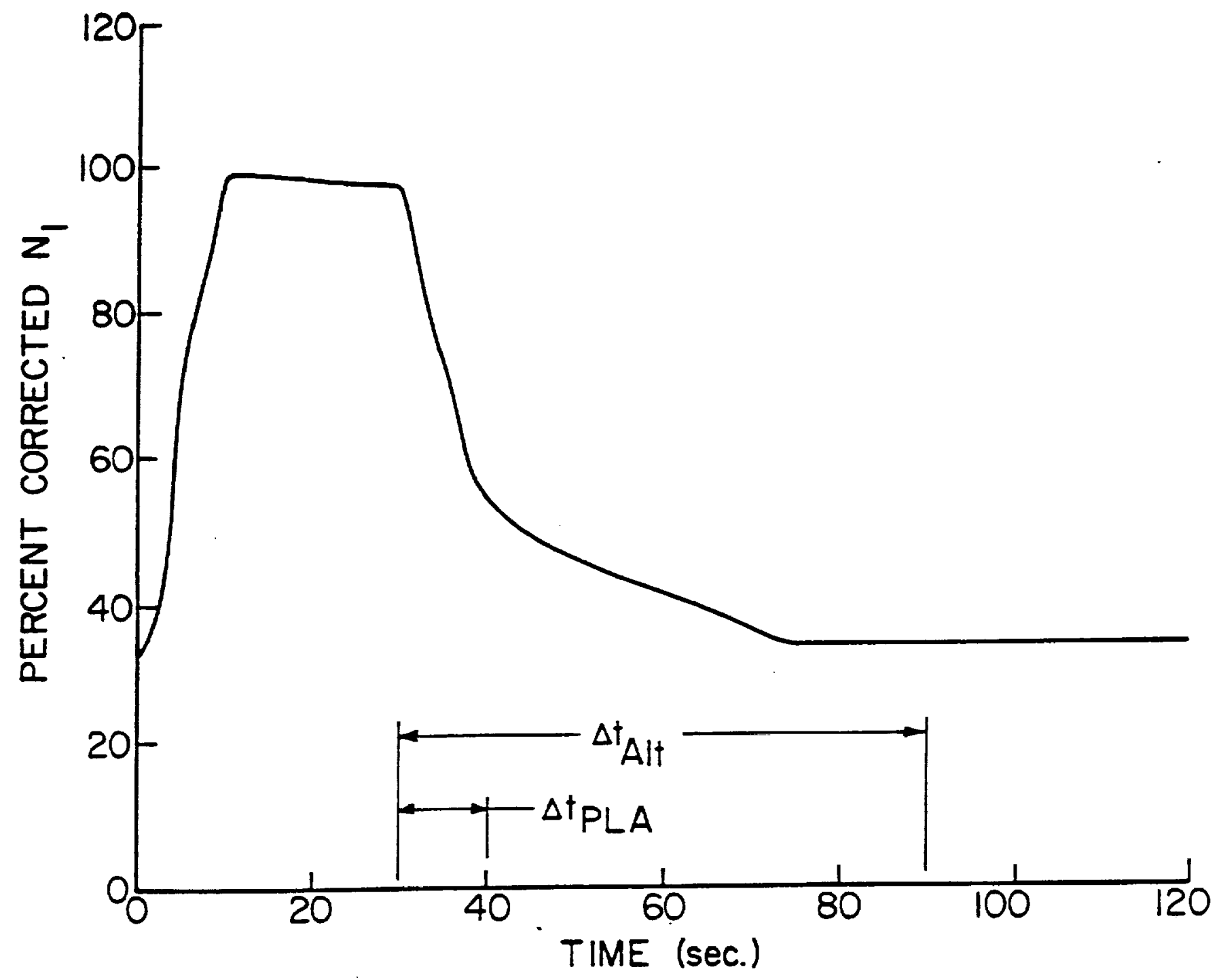

Figure 4.16.(i)

Caption on Figure 4.16.(iv) 


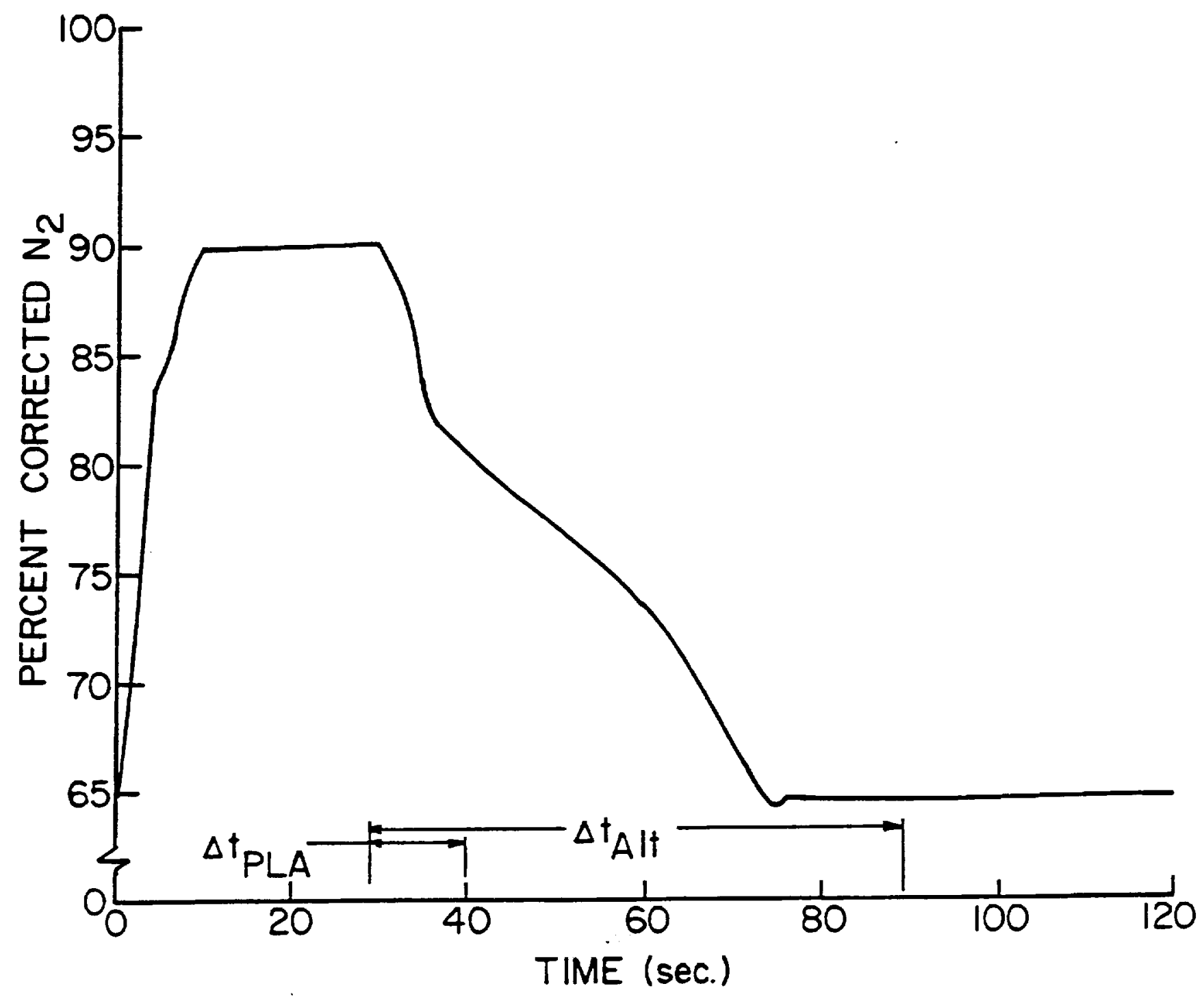

Figure 4.16.(ii)

Caption on Figure 4.16.(iv) 


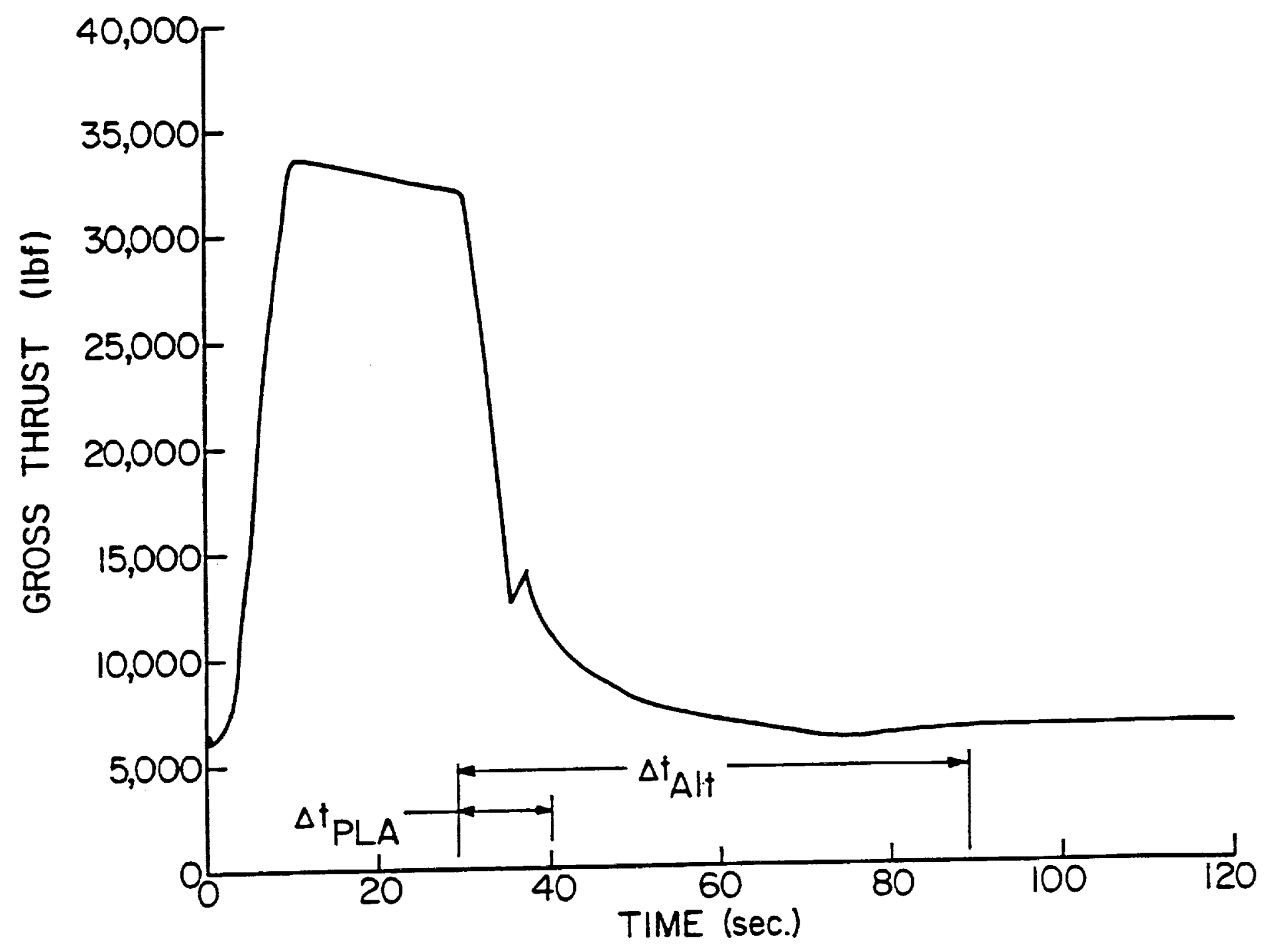

Figure 4.16.(iii)

Caption on Figure 4.16.(iv) 


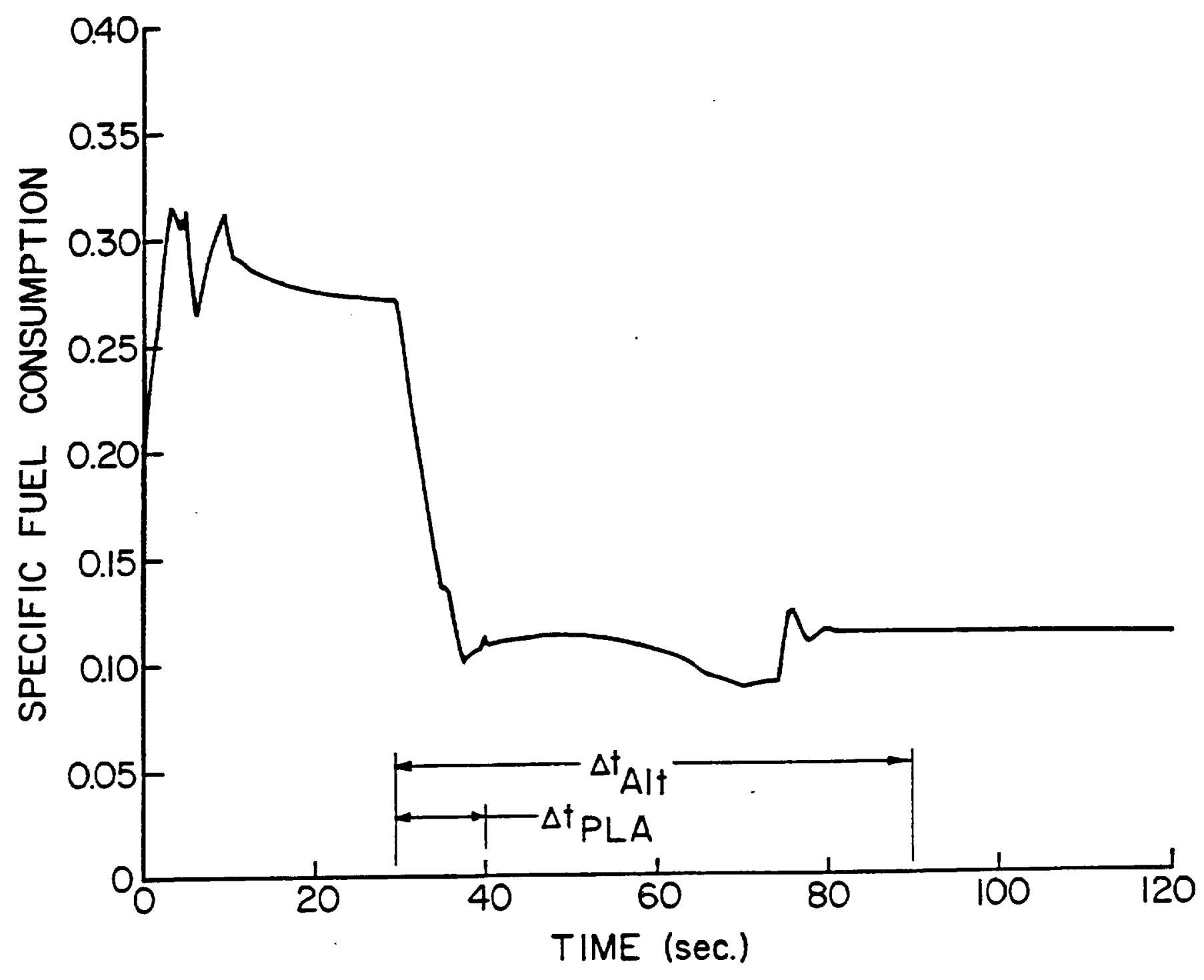

Figure 4.16.(iv)

Figure 4.16. Transient Engine Performance under Varying Ambient Conditions: (i), (ii), (iii), and (iv). Case 812 of Group I in Table III. 


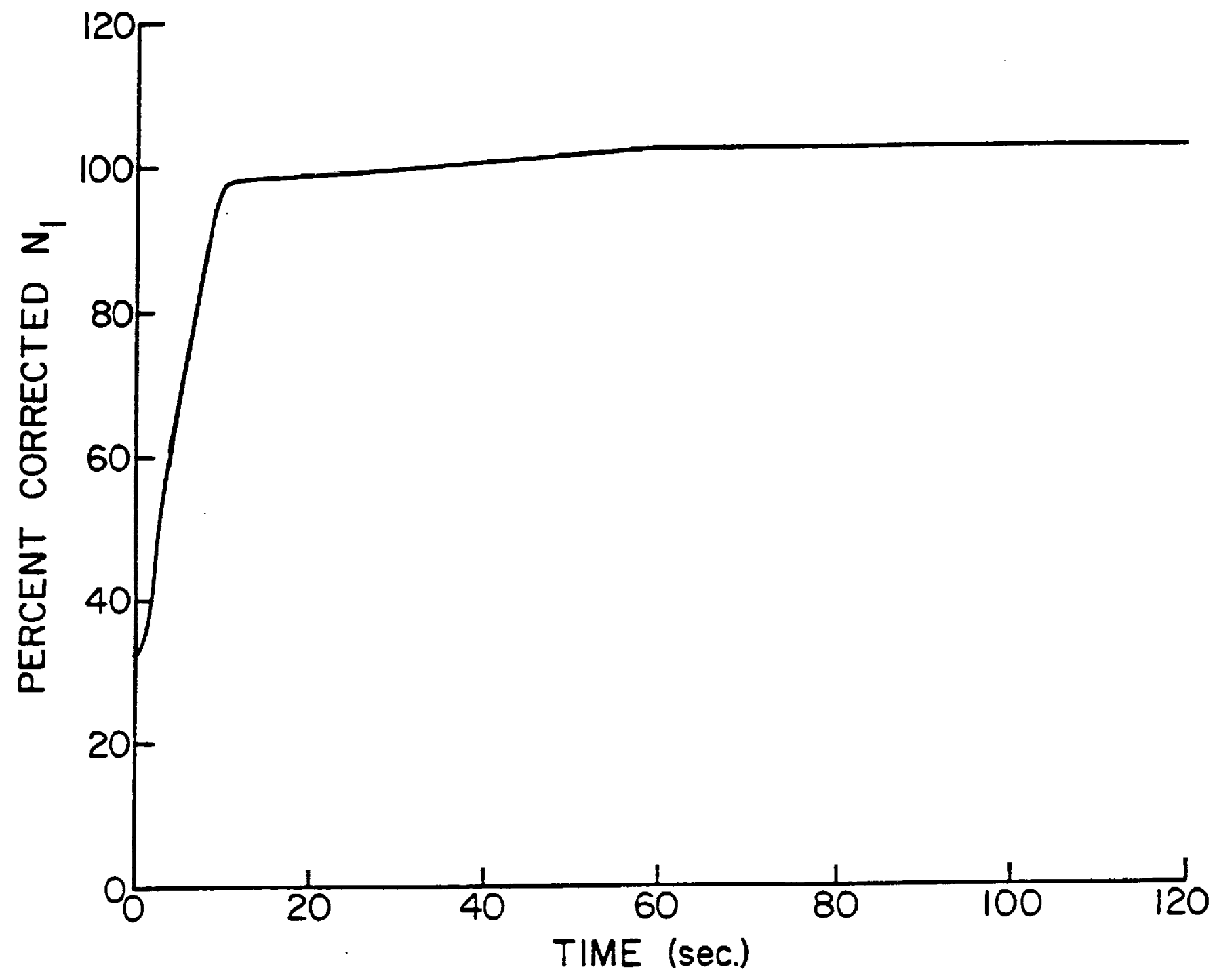

Figure 4.17.(i)

Caption on Figure 4.17.(iv) 


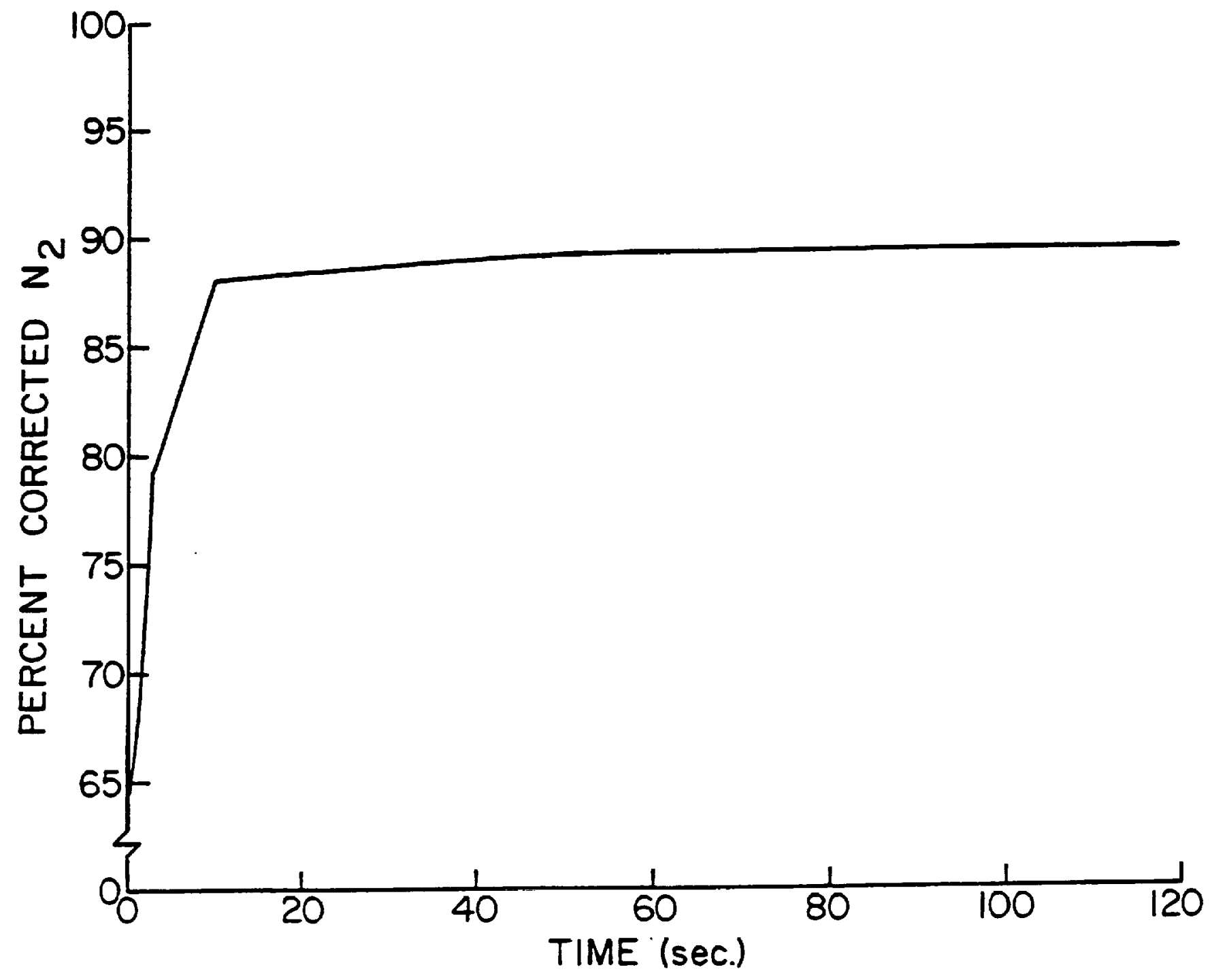

Figure 4.17.(ii)

Caption on Figure 4.17.(iv) 


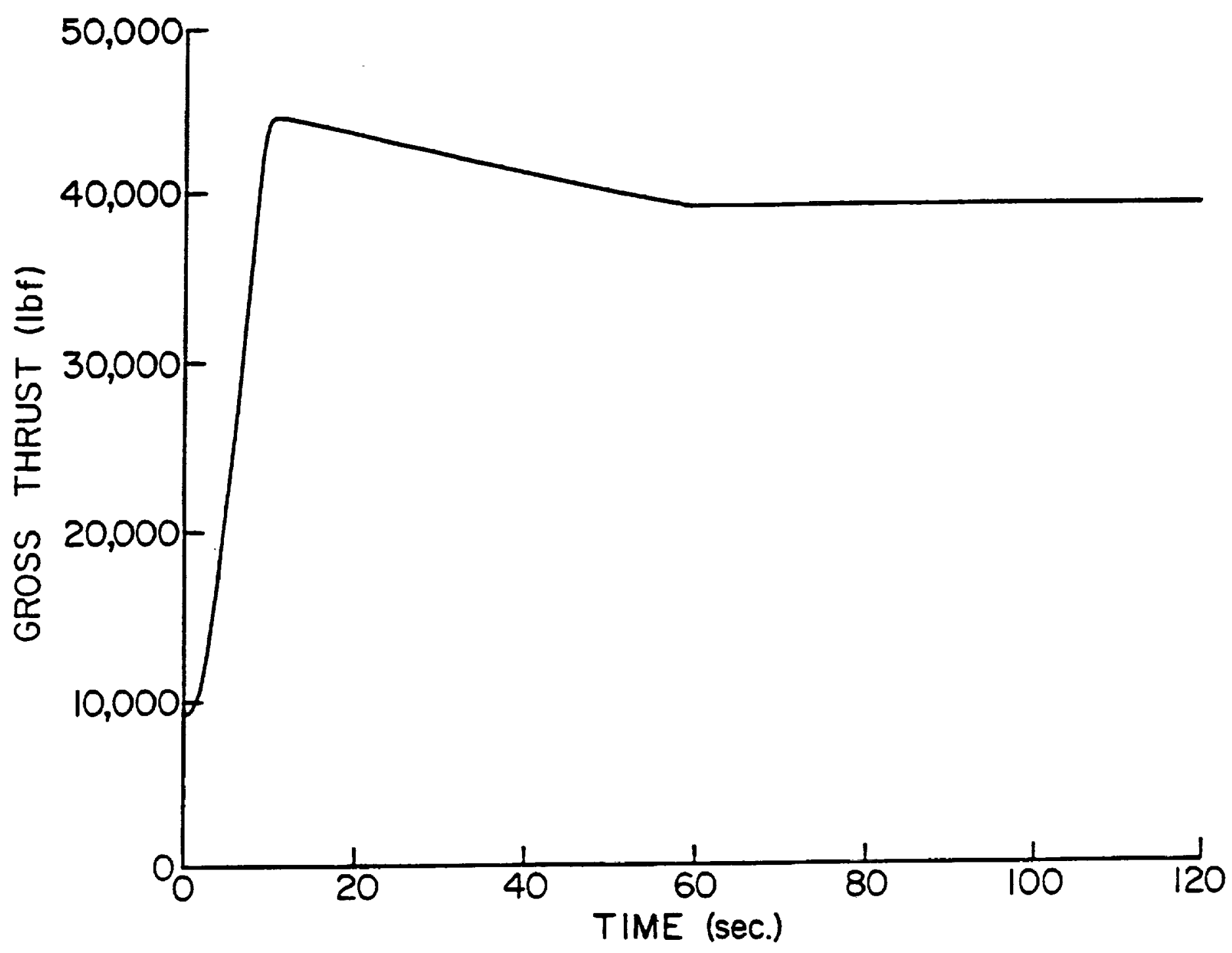

Figure 4.17.(iii)

Caption on Figure 4.17.(iv) 


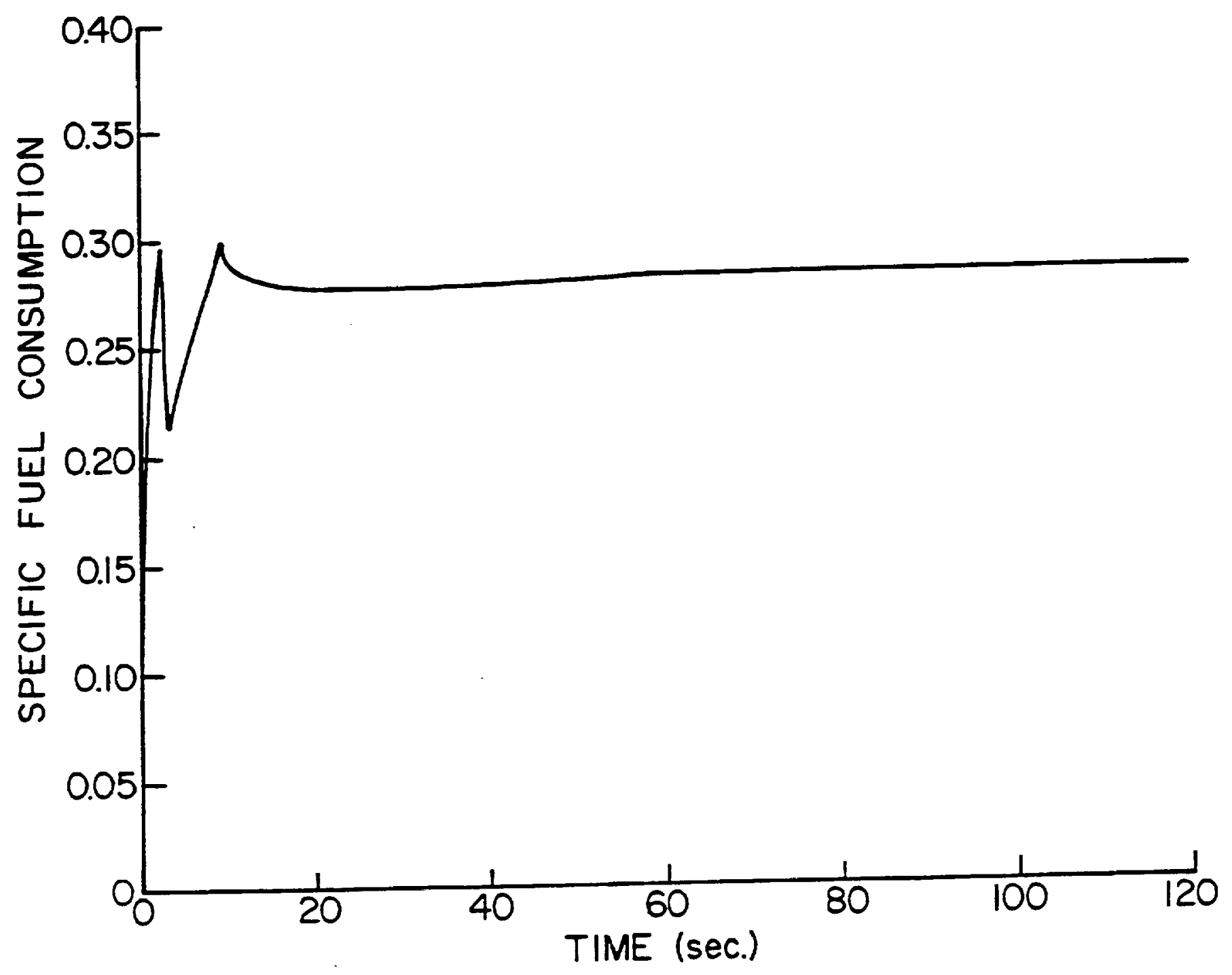

Figure 4.17.(iv)

Figure 4.17. Transient Engine Performance under Varying Ambient Conditions: (i), (ii), (iii), and (iv). Case 021 of Group II in Table III. 


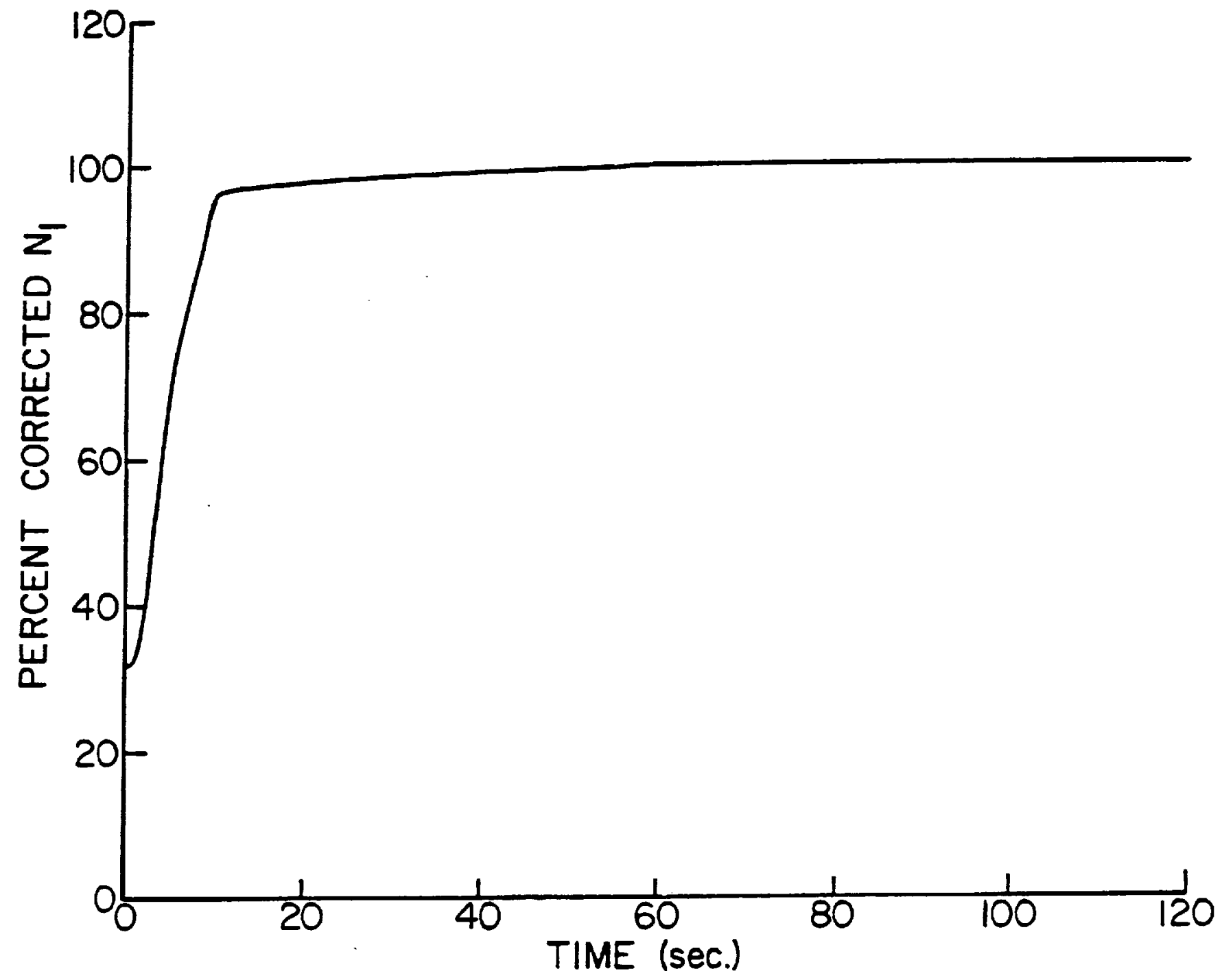

Figure 4.18.(i)

Caption on Figure 4.18.(iv) 


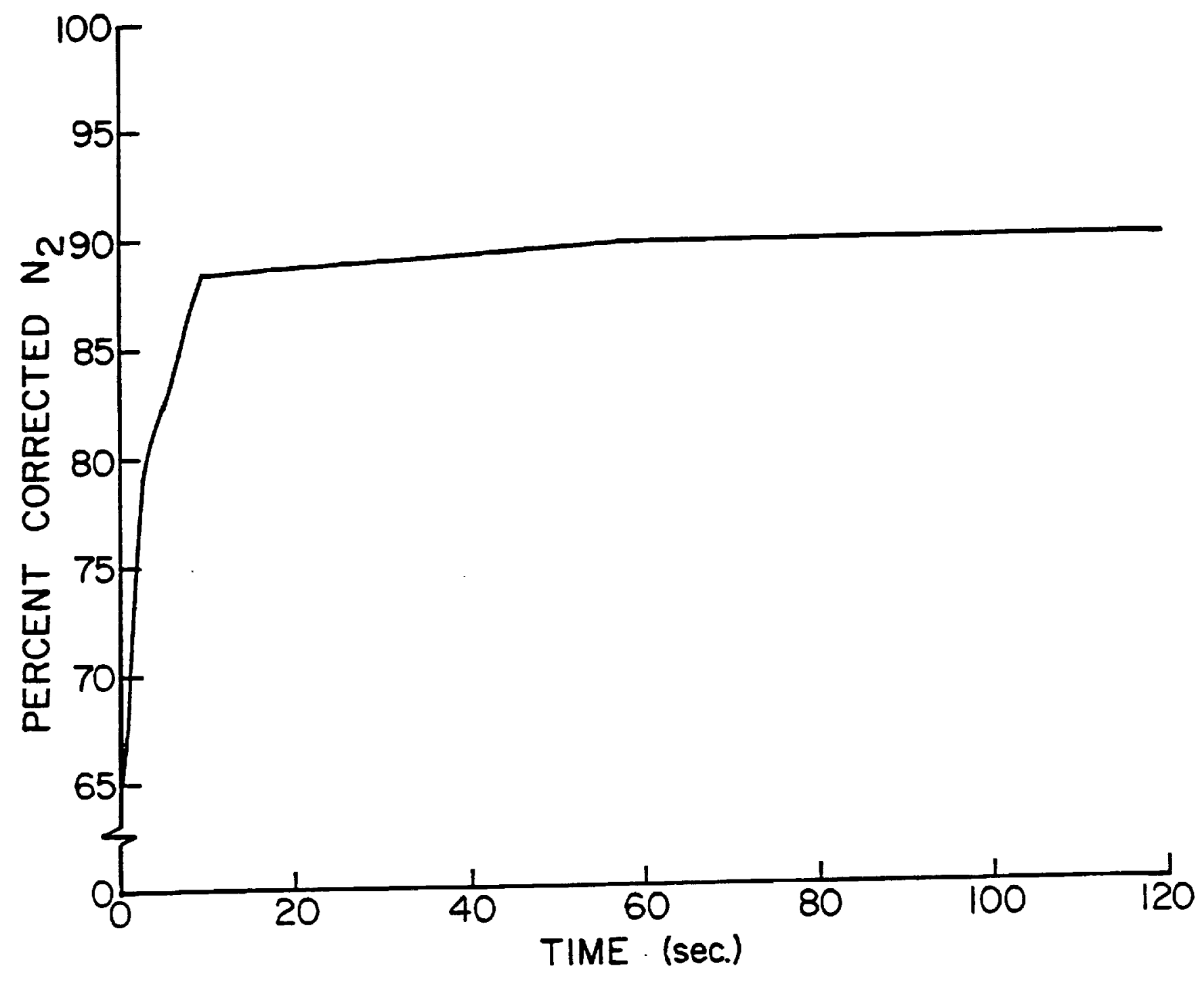

Figure 4.18.(ii)

Caption on Figure 4.18.(iv) 


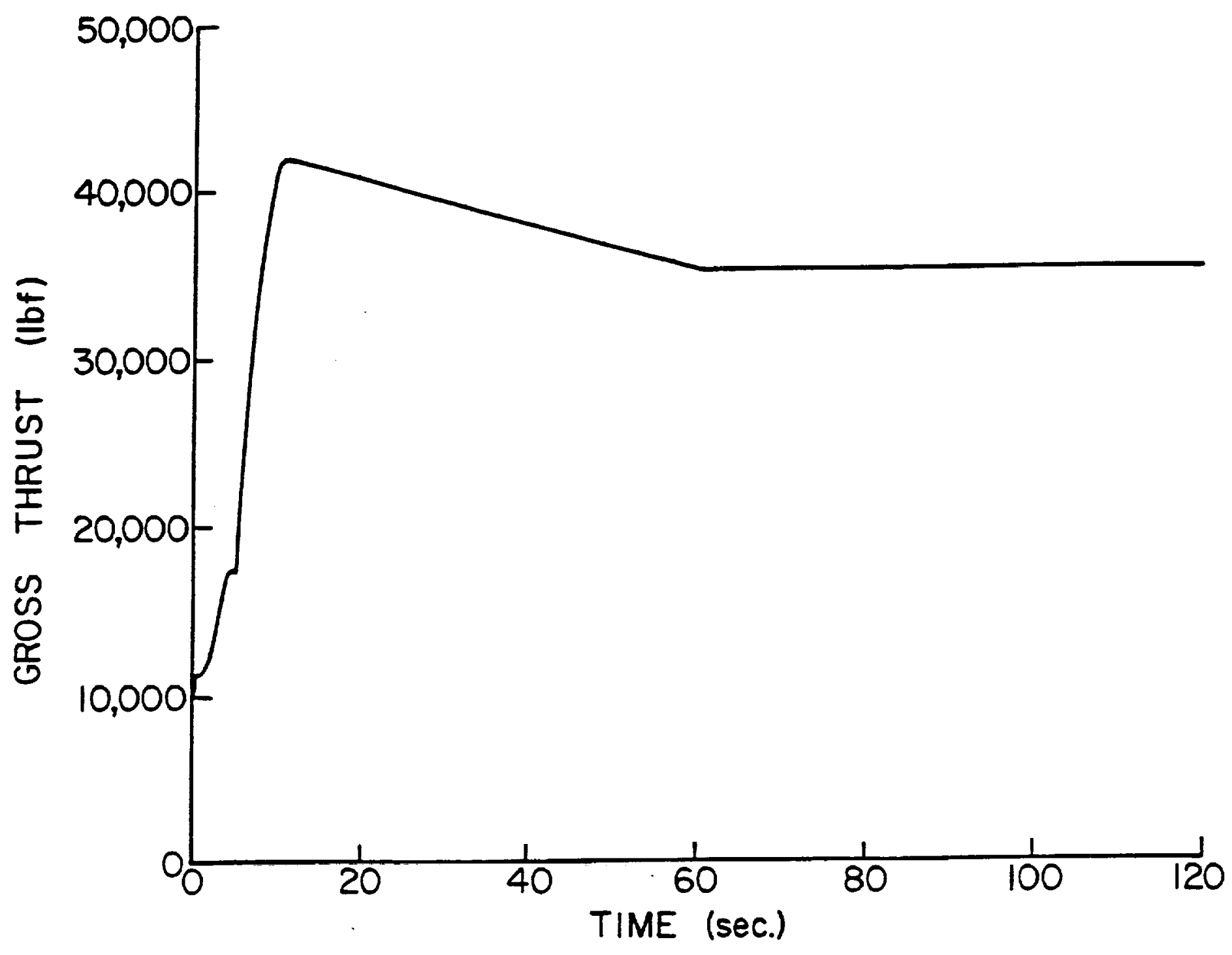

Figure 4.18.(iii)

Caption on Figure 4.18.(iv) 


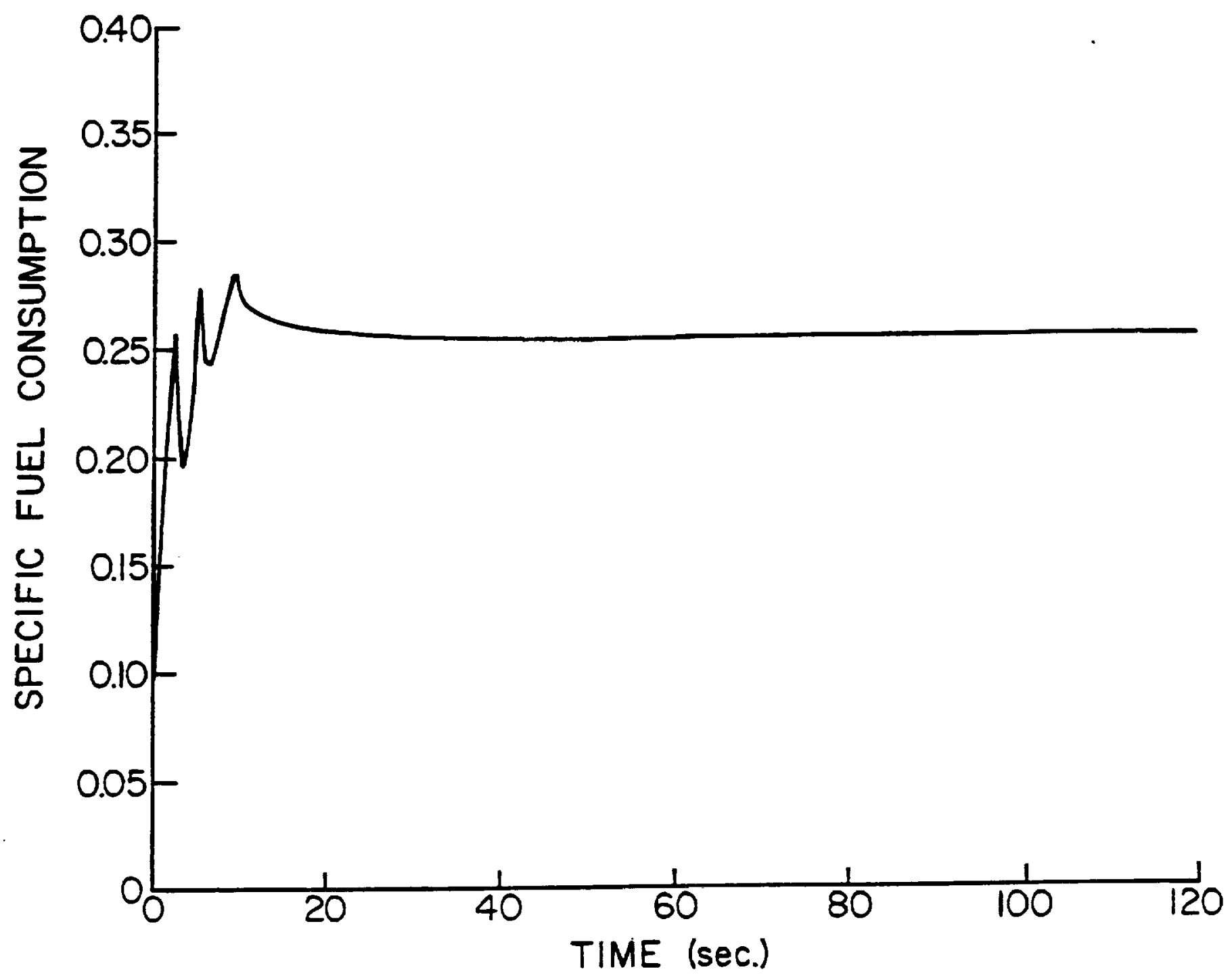

Figure 4.18.(iv)

Figure 4.18. Transient Engine Performance under Varying Ambient Conditions: (i), (ii), (iii), and (iv). Case 221 of Group II in Table III. 


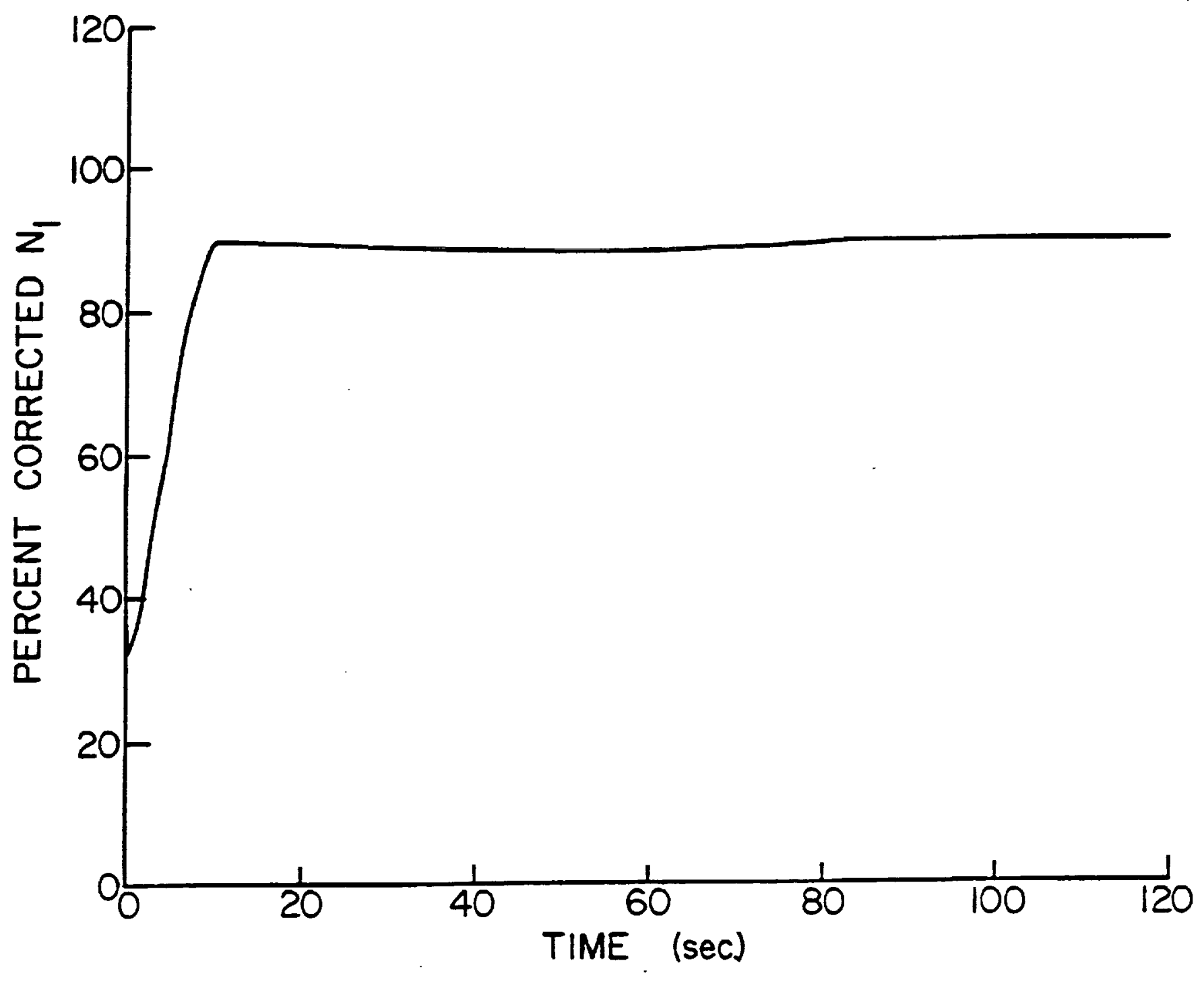

Figure 4.19.(i)

Caption on Figure 4.19.(iv) 


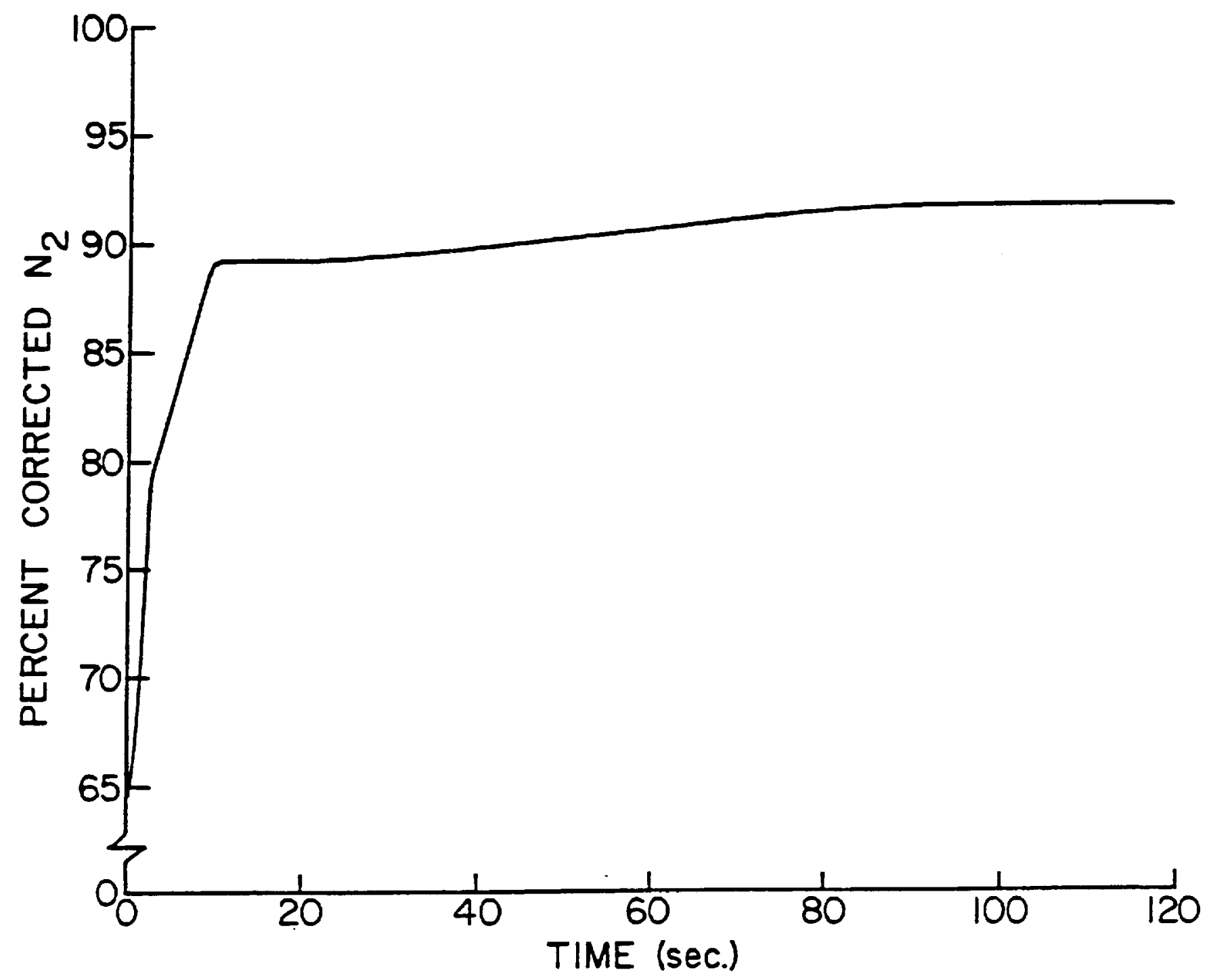

Figure 4.19.(ii)

Caption on Figure 4.19.(iv) 


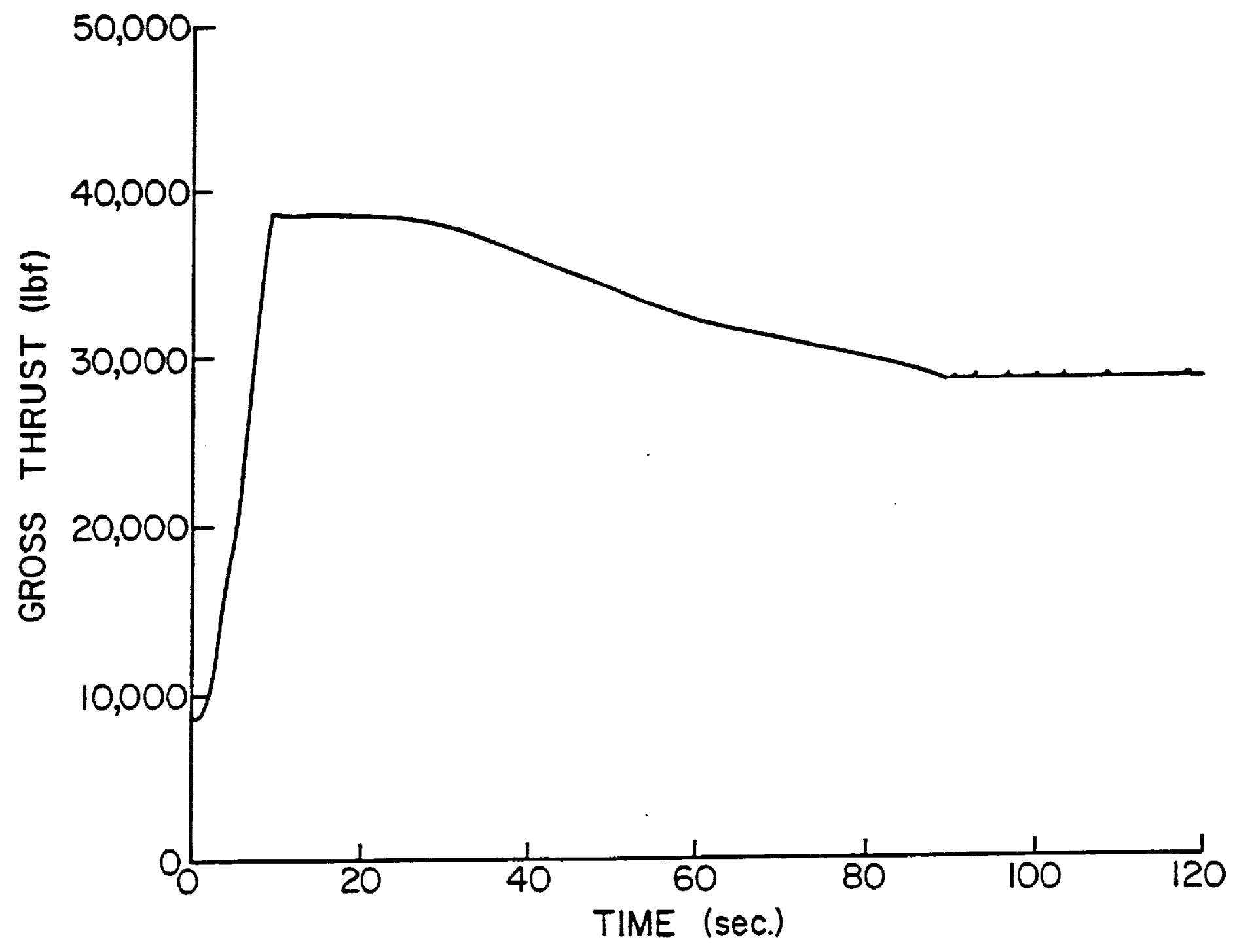

Figure 4.19.(iii)

Caption on Figure 4.19.(iv) 


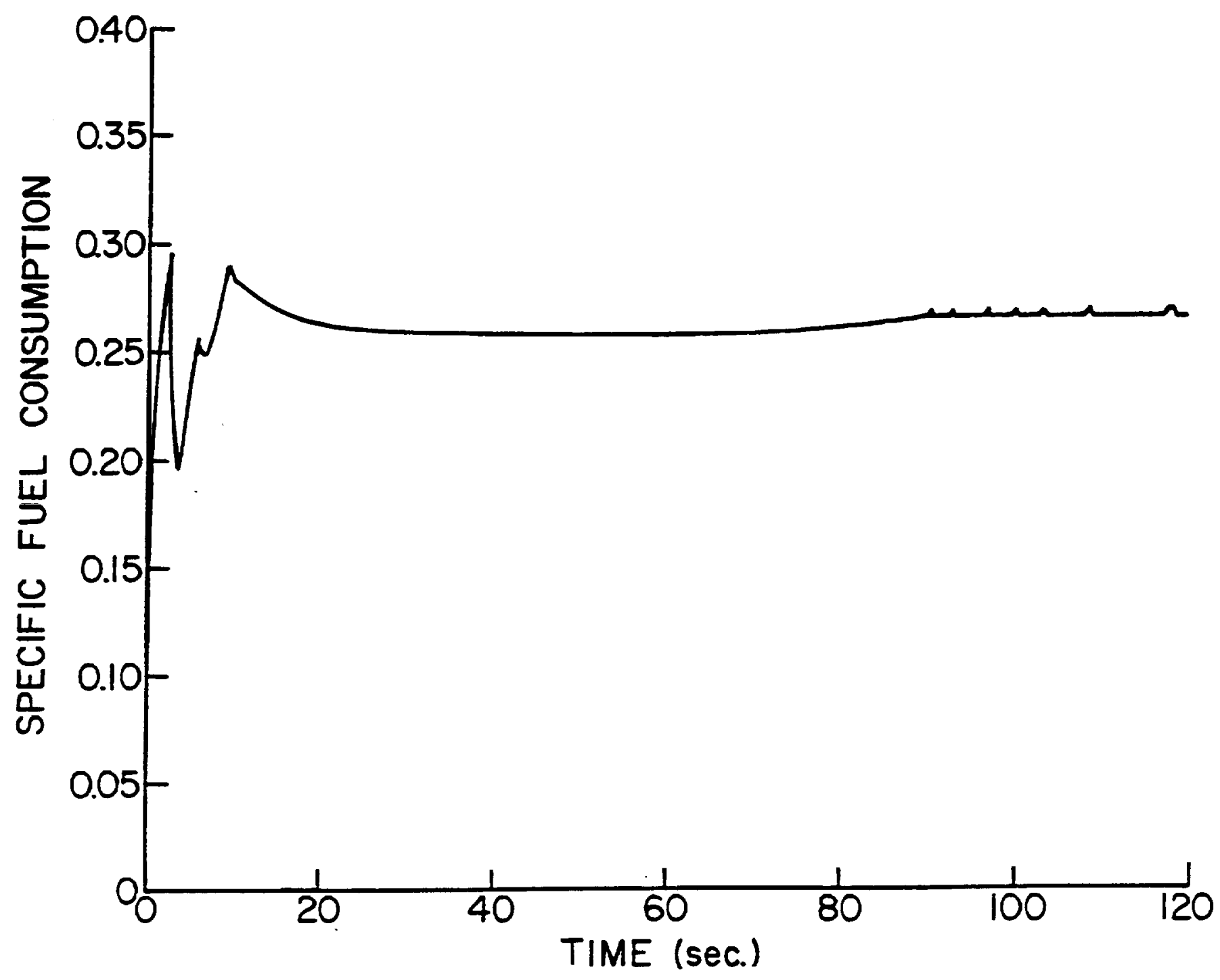

Figure 4.19.(iv)

Figure 4.19. Transient Engine Performance under Varying Ambient Conditions: (i), (ii), (iii), and (iv). Case 421 of Group II in Table III. 


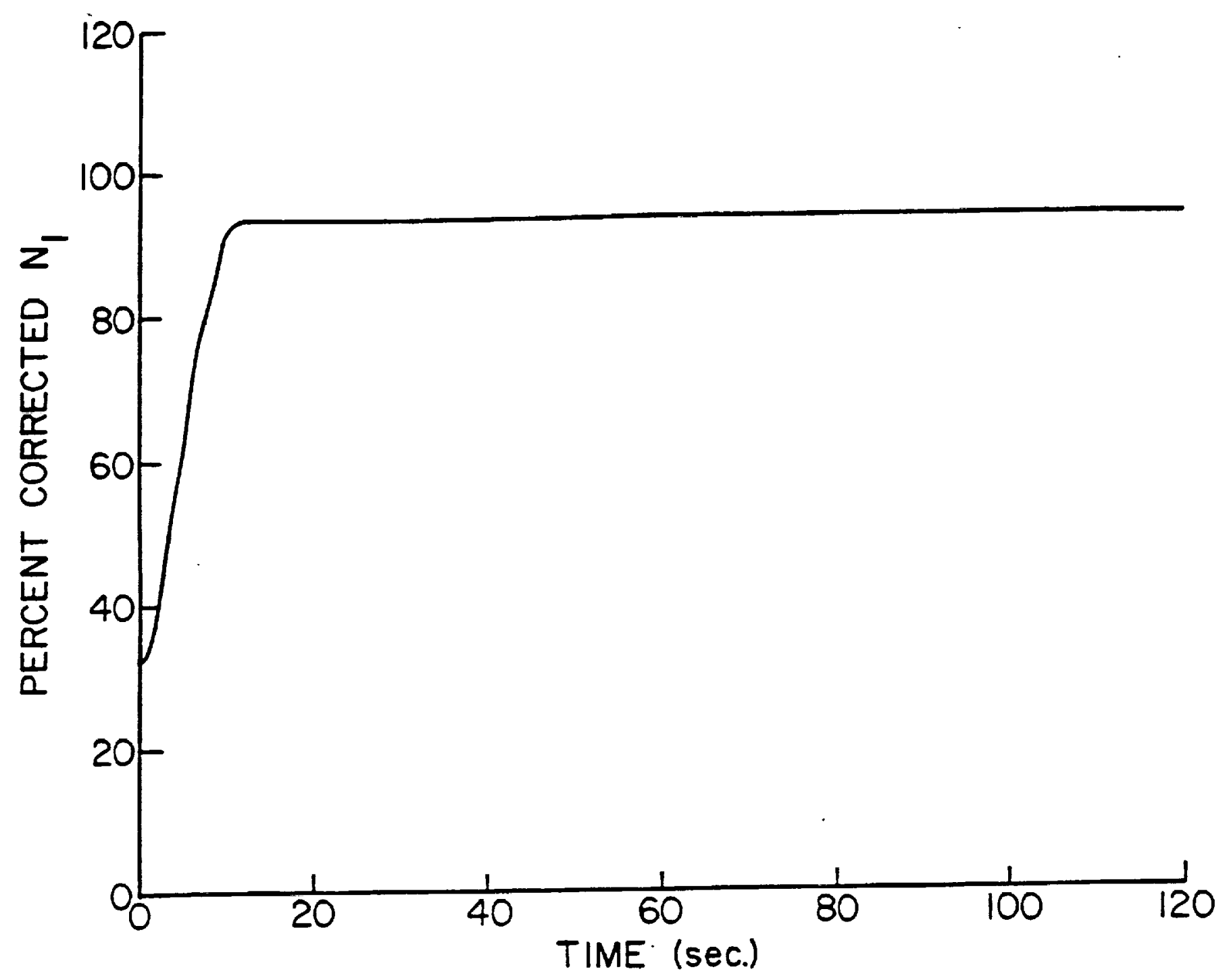

Figure 4.20.(i)

Caption on Figure 4.20.(iv) 


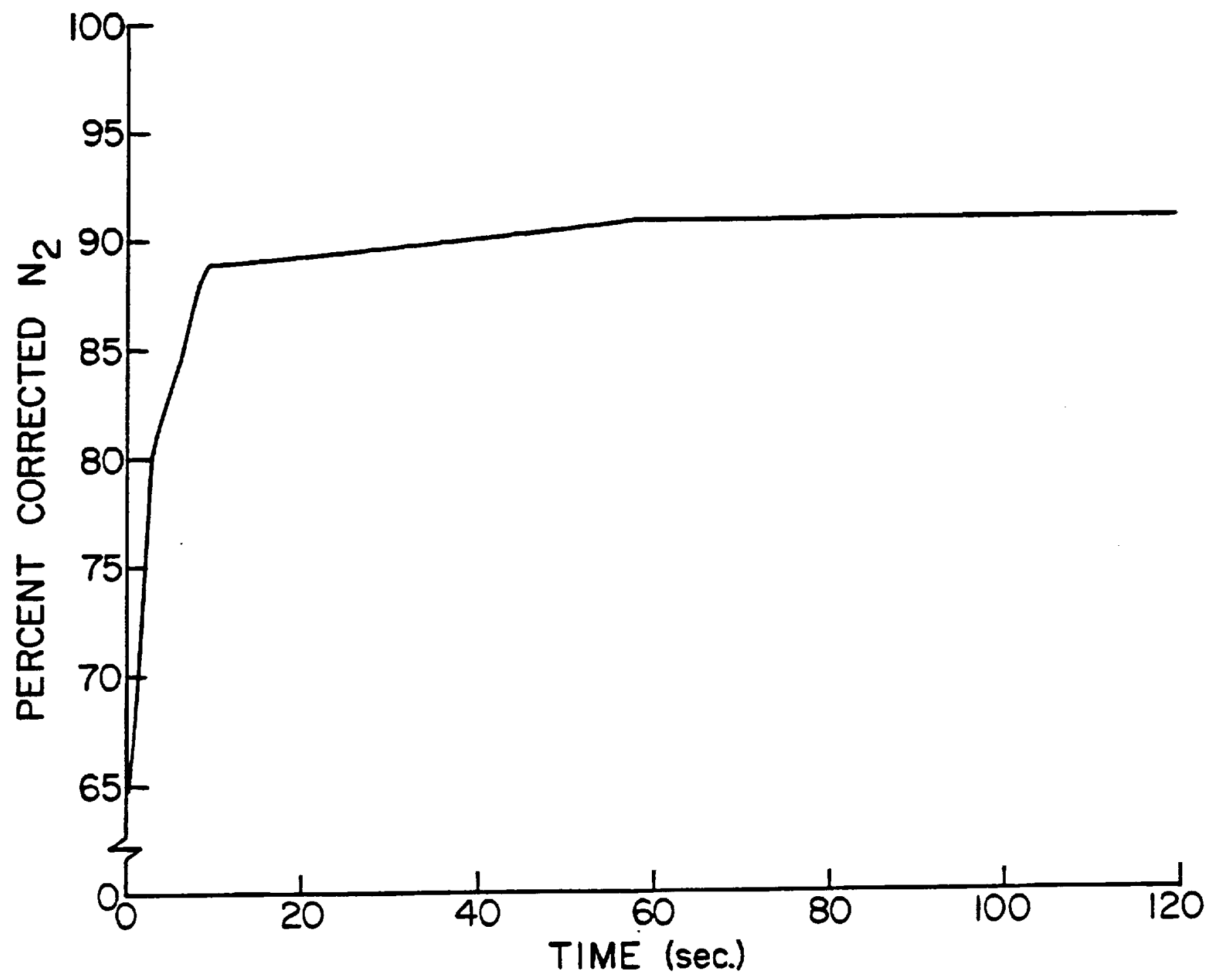

Figure 4.20.(ii)

Caption on Figure 4.20.(iv) 


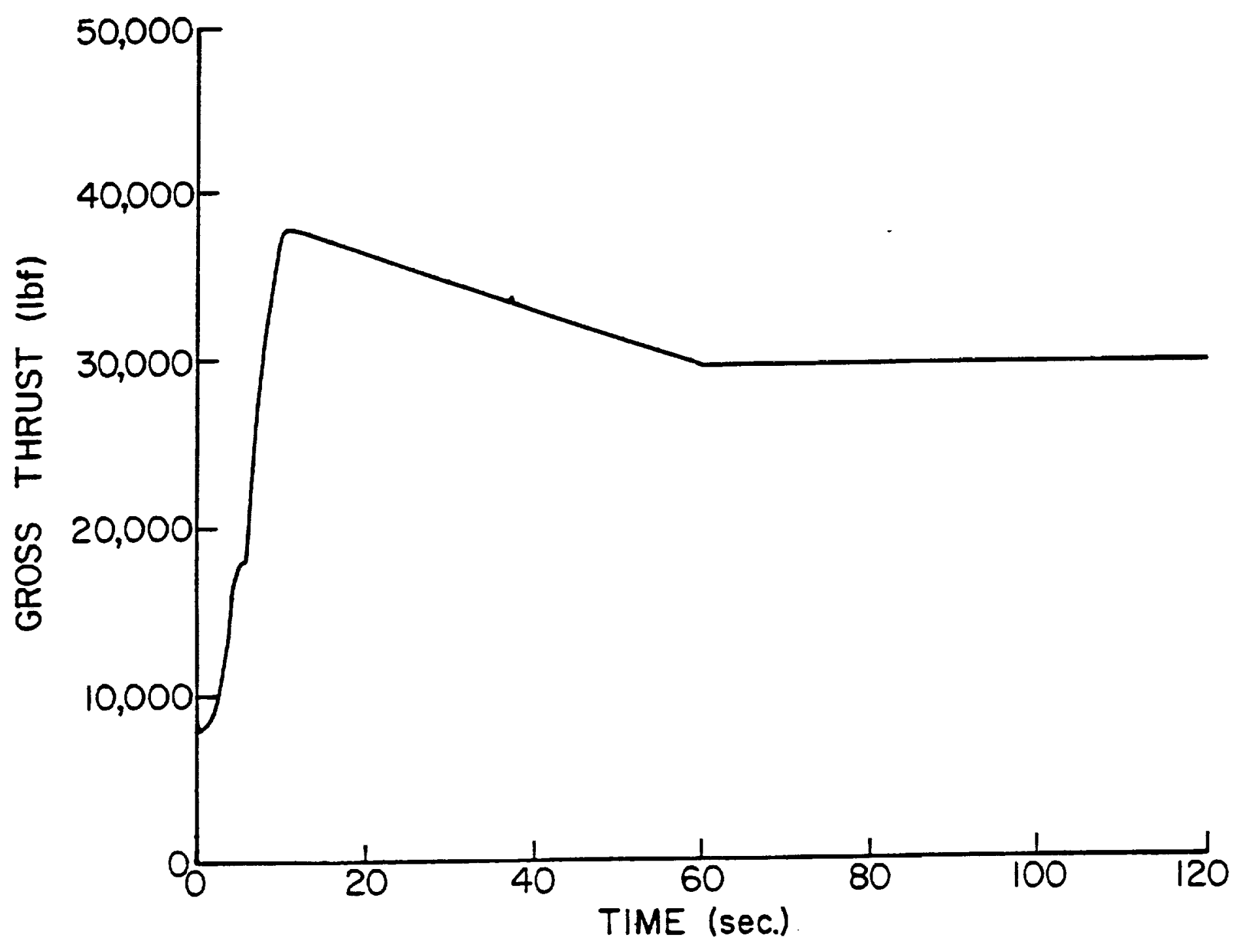

Figure 4.20.(iii)

Caption on Figure 4.20.(iv) 


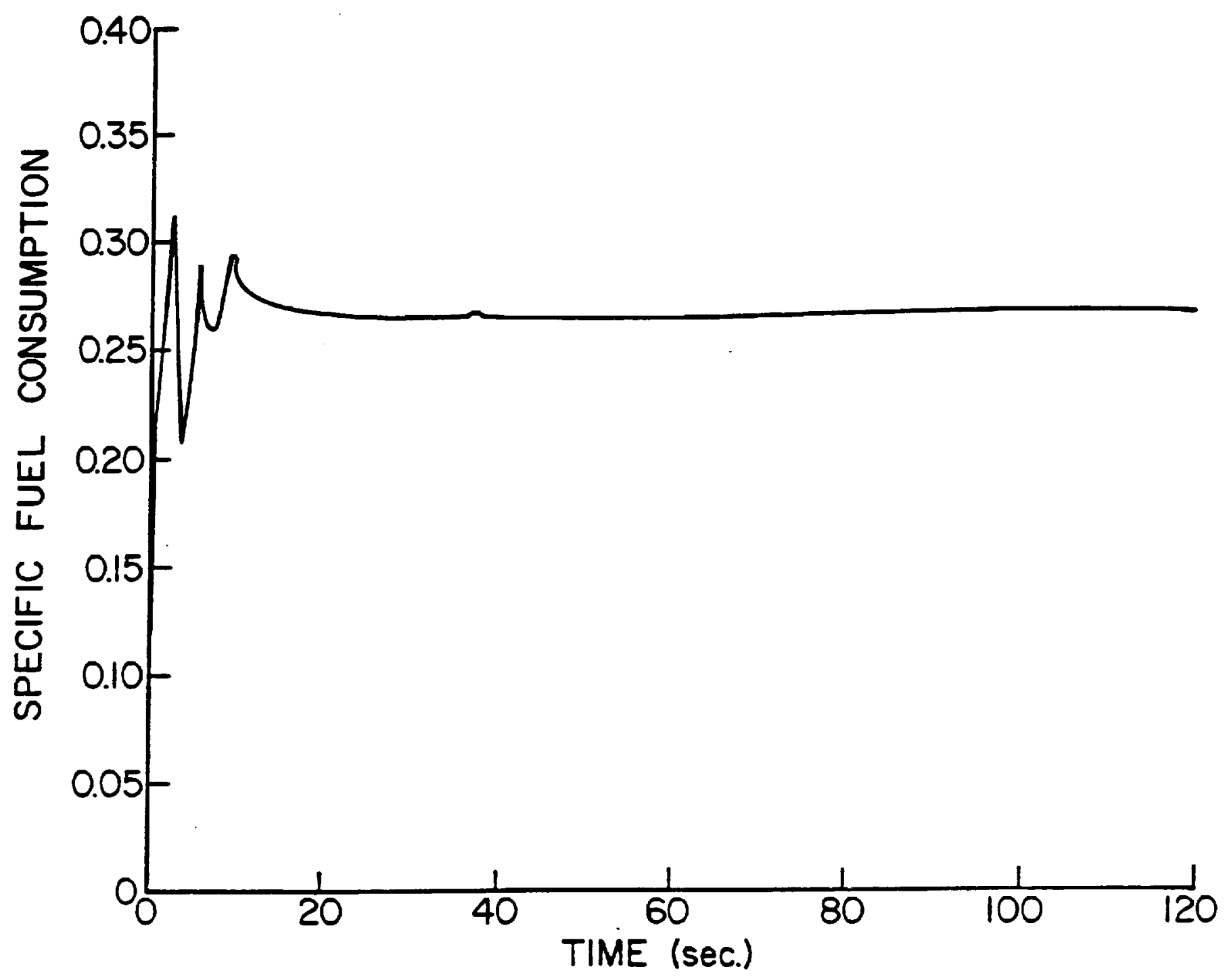

Figure 4.20.(iv)

Figure 4.20 Transient Engine Performance under Varying Ambient Conditions: (i), (ii), (iii), and (iv). Case 821 of Group II in Table III. 


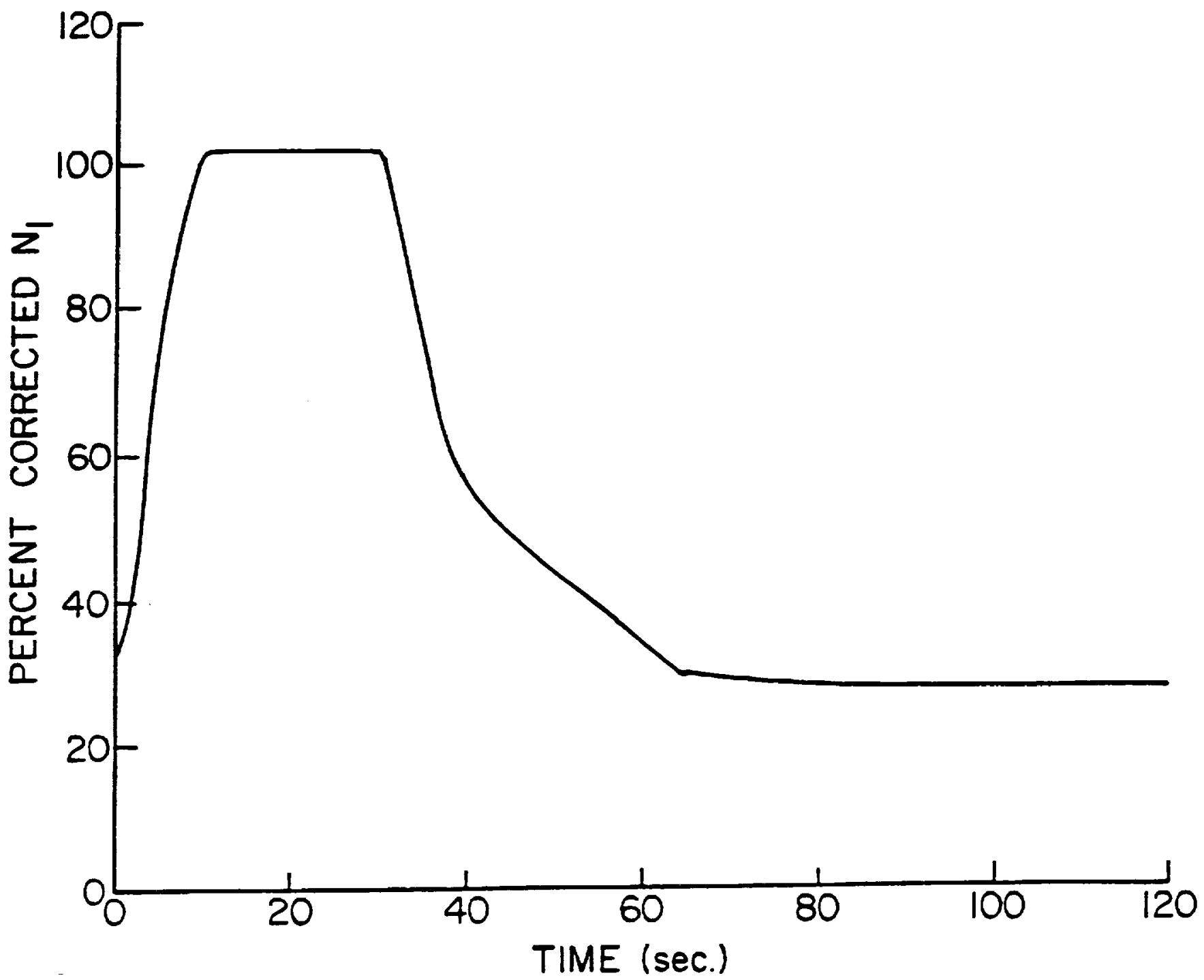

Figure 4.21.(i)

Caption on Figure 4.21.(iv) 


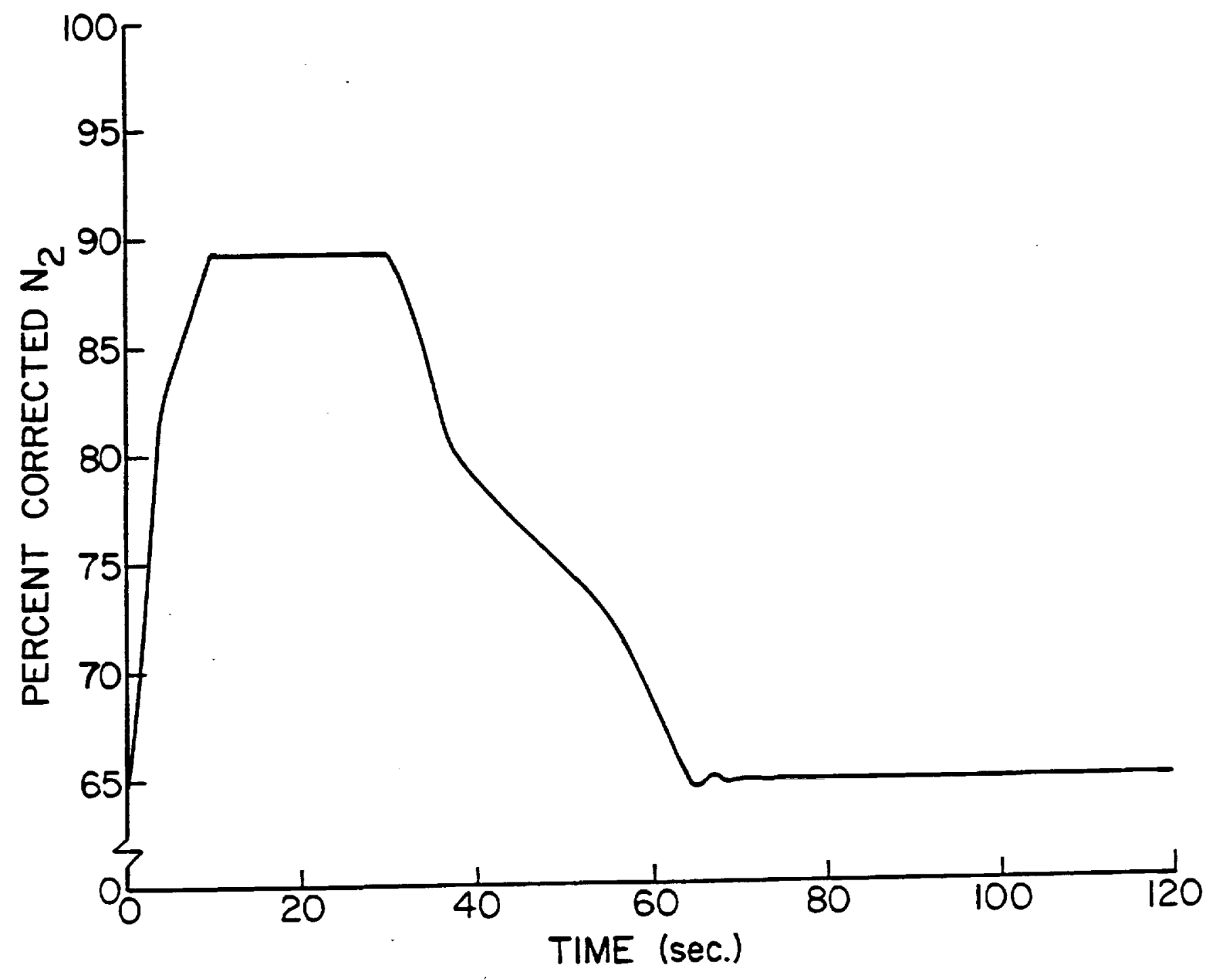

Figure 4.21.(ii)

Caption on Figure 4.21.(iv) 


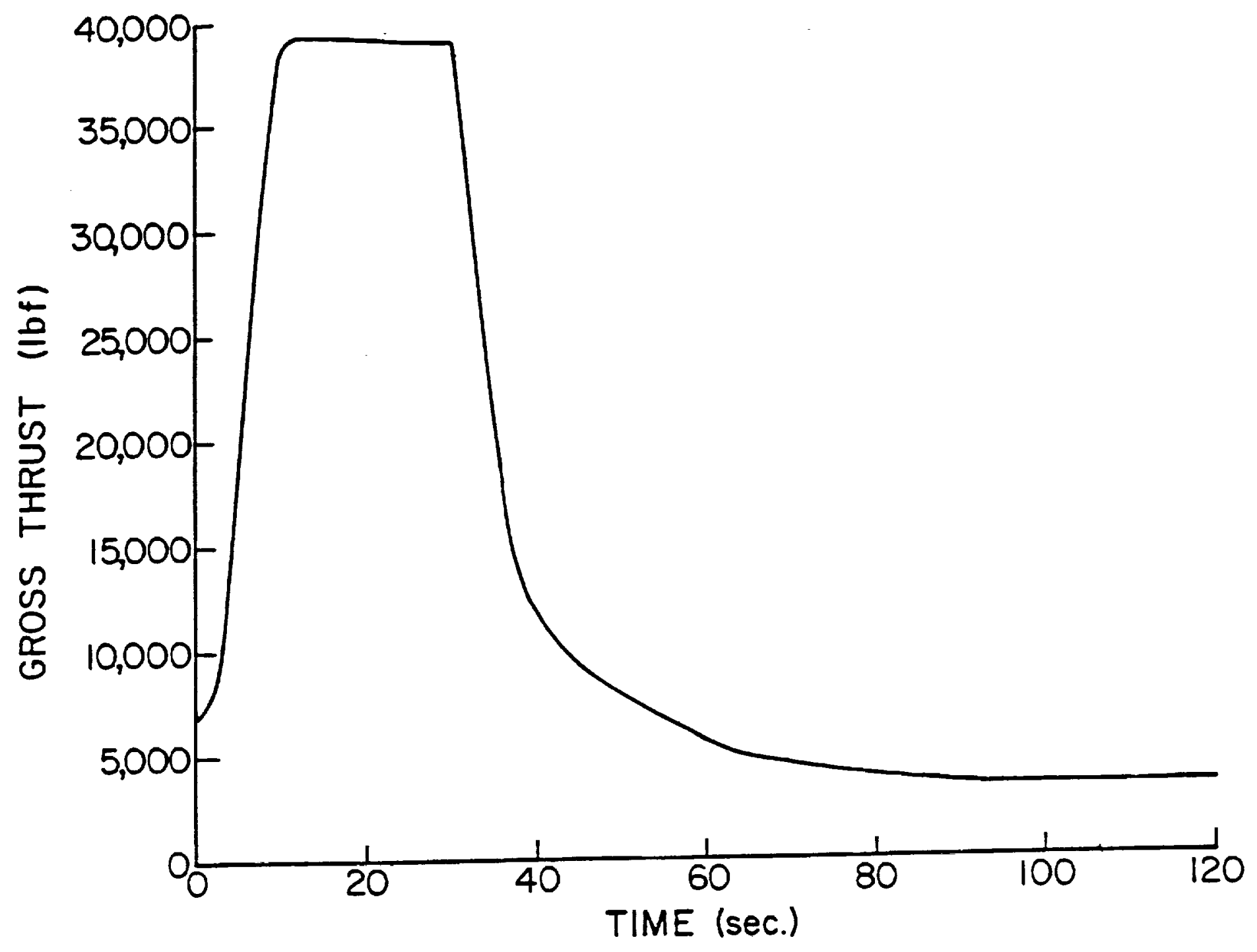

Figure 4.21.(iii)

Caption on Figure 4.21.(iv) 


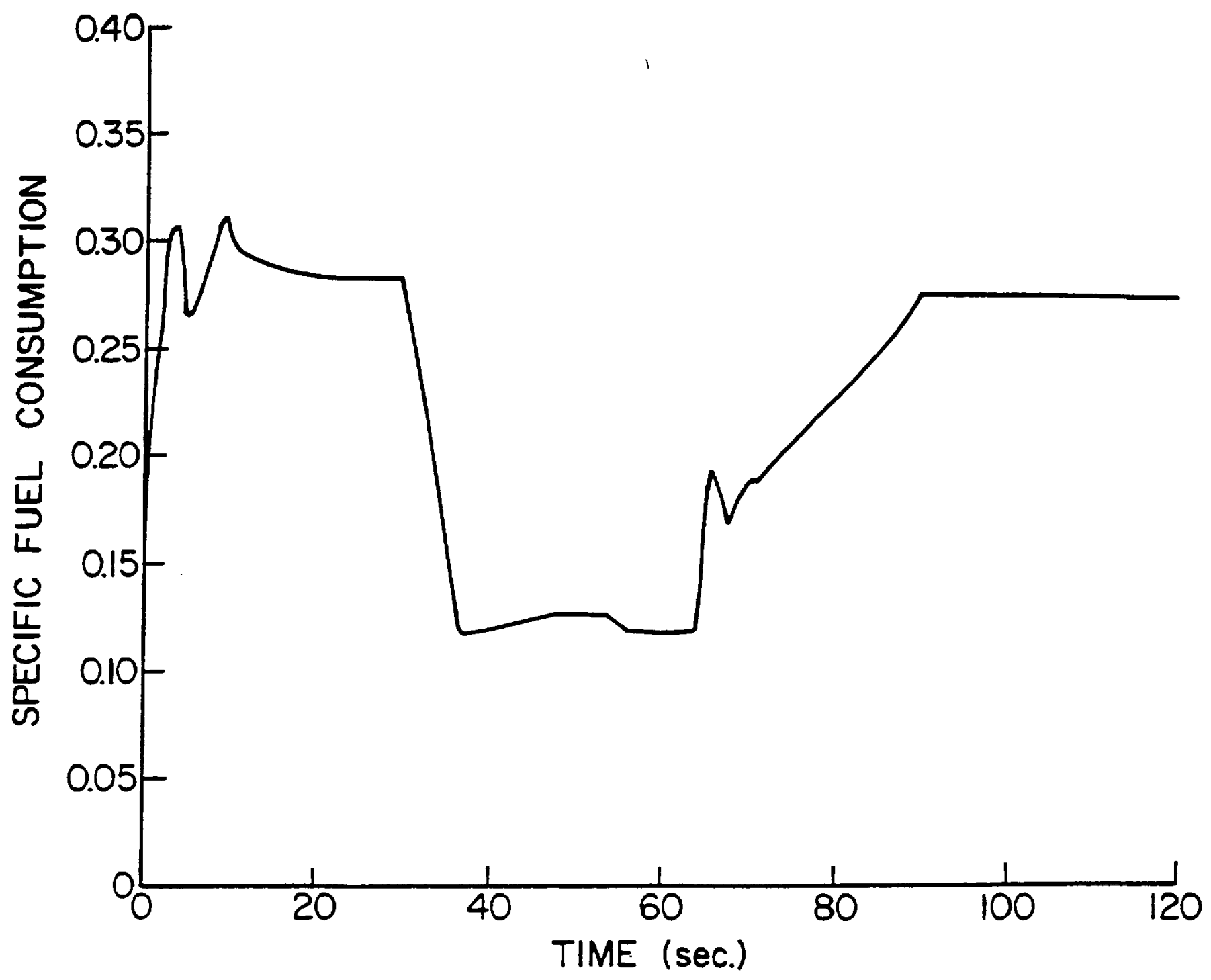

Figure 4.21.(iv)

Figure 4.21. Transient Engine Performance under Varying Ambient Conditions: (i), (ii), (iii), and (iv). Case 013 of Group III in Table III. 


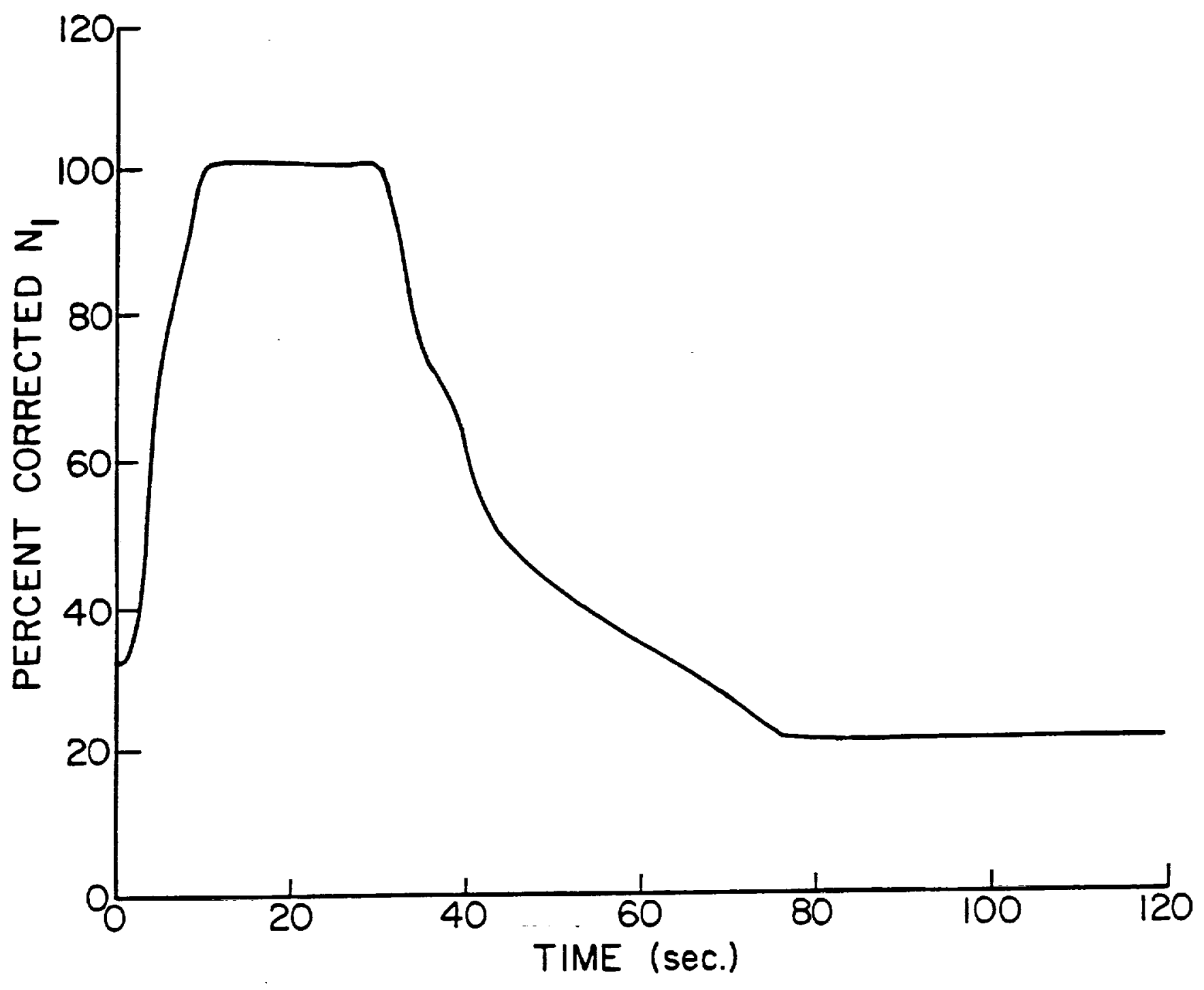

Figure 4.22.(i)

Caption on Figure 4.22.(iv) 


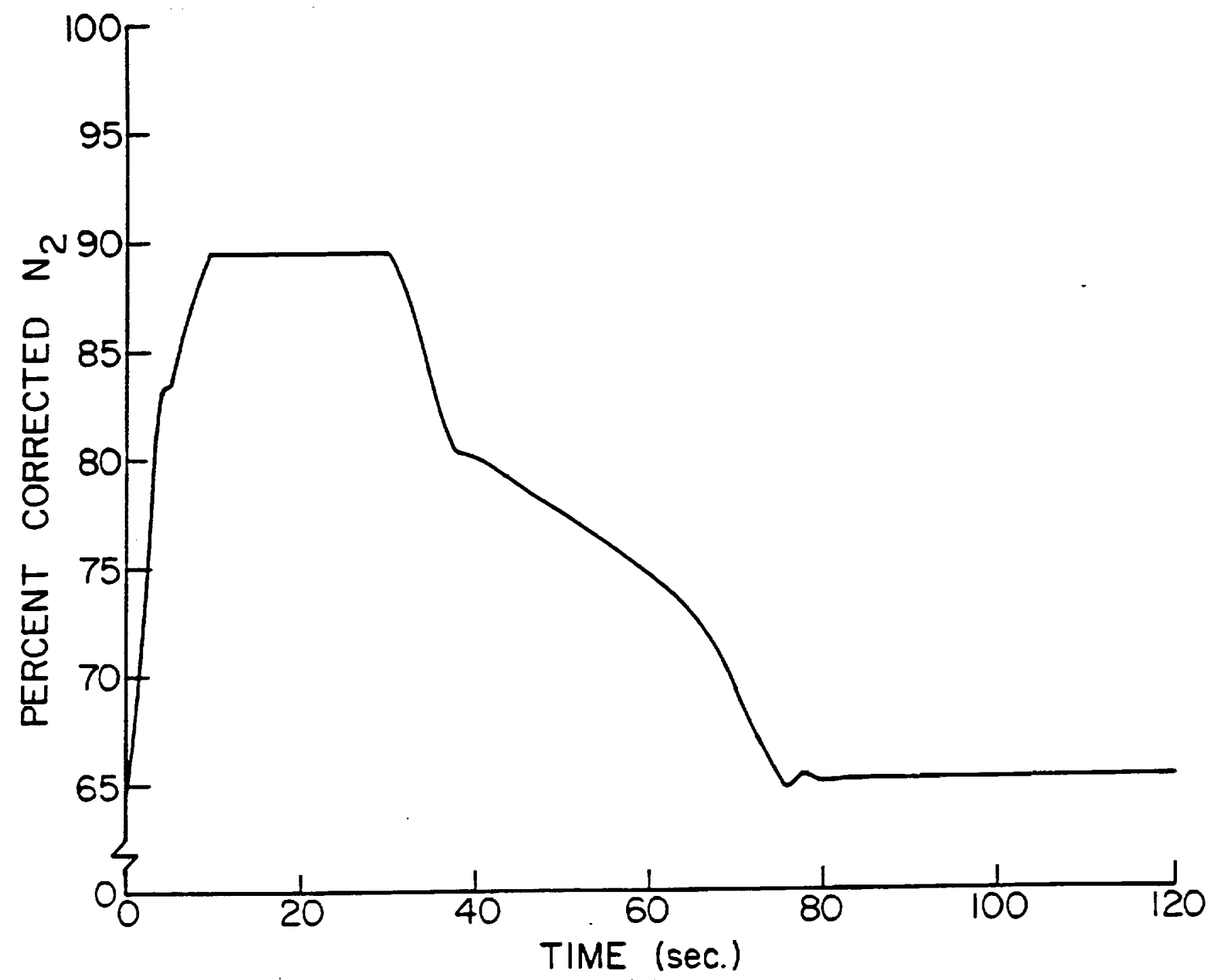

Figure 4.22.(ii)

Caption on Figure 4.22.(iv)

223 


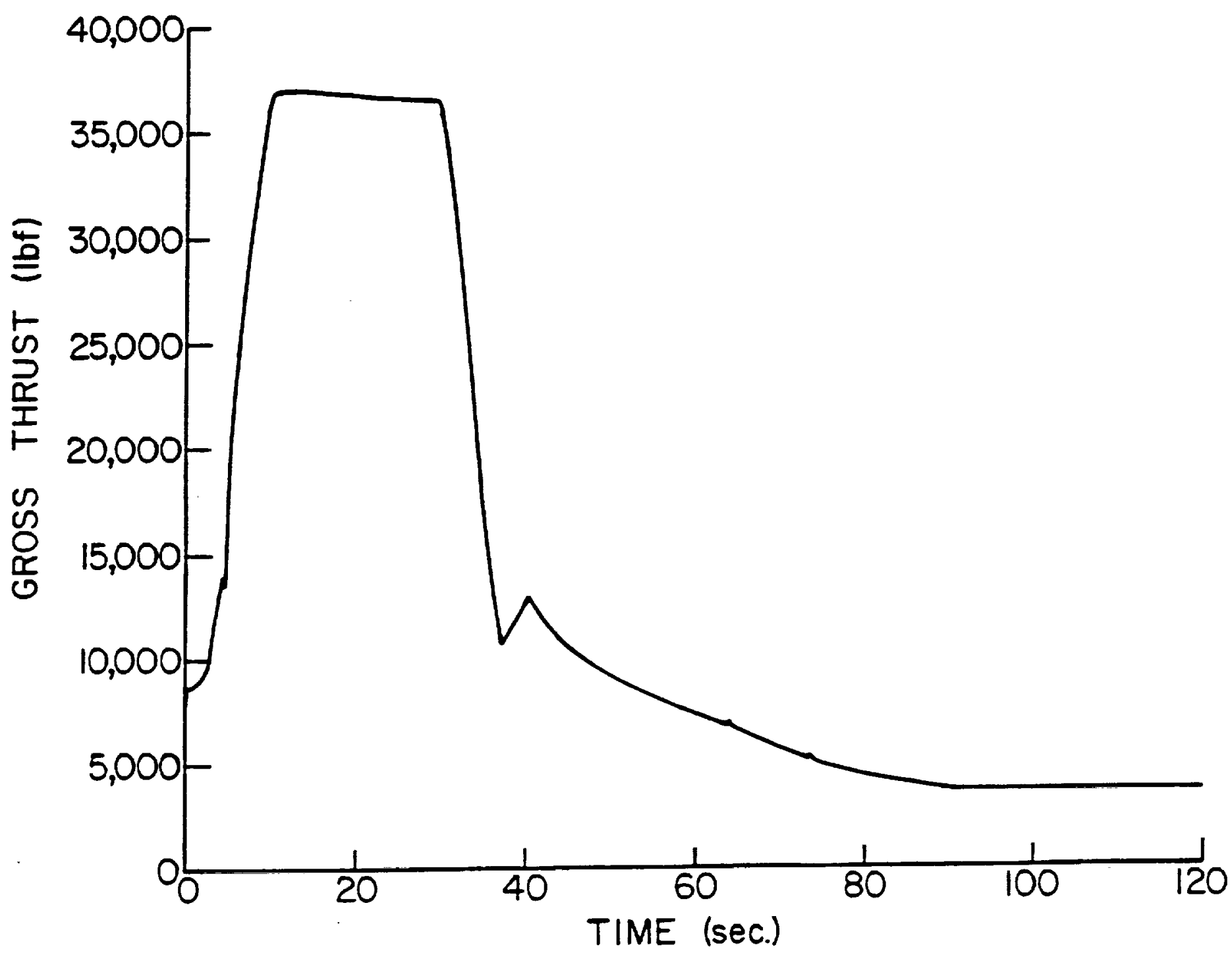

Figure 4.22.(iii)

Caption on Figure 4.22.(iv) 


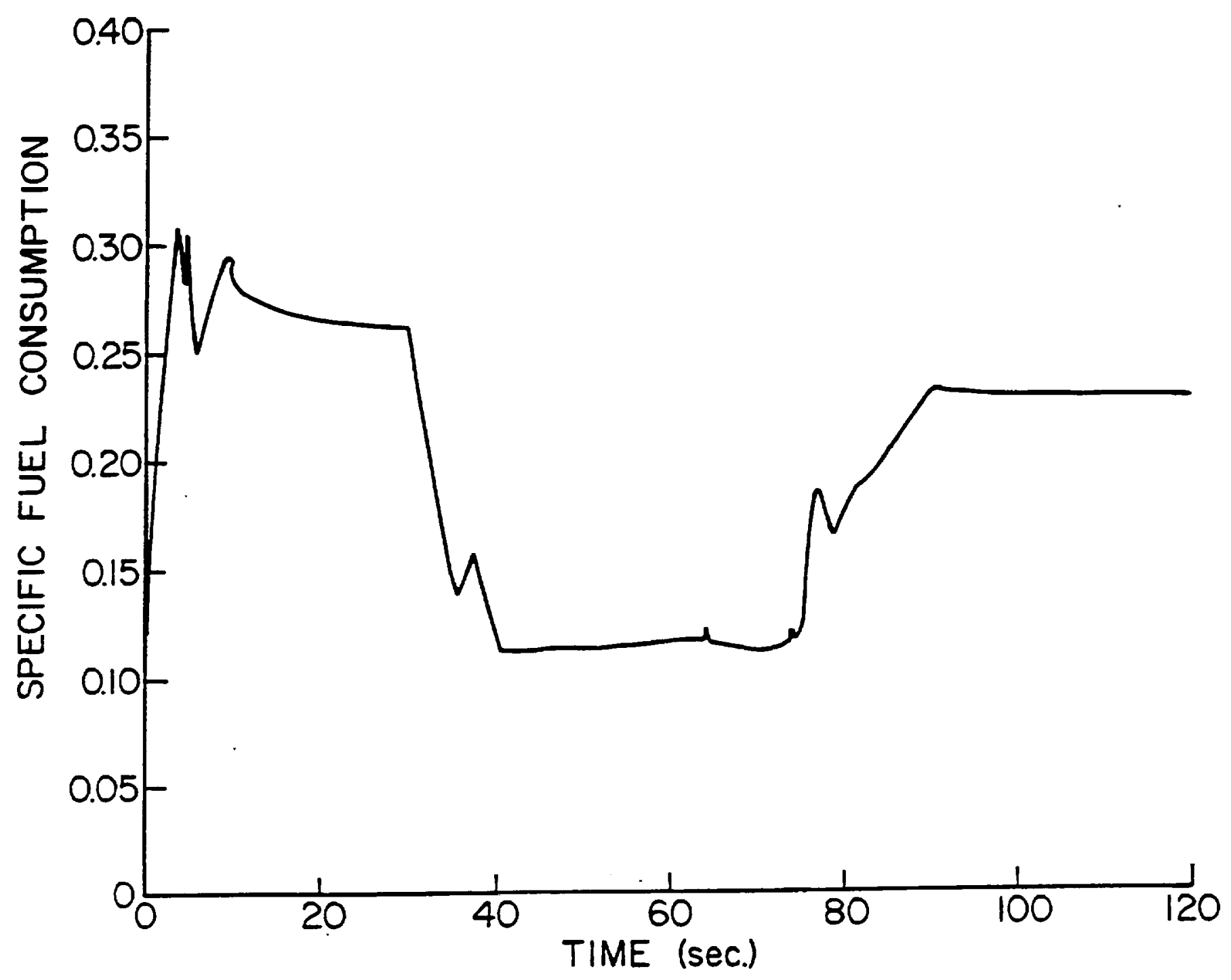

Figure 4.22.(iv)

Figure 4.22. Transient Engine Performance under Varying Ambient Conditions: (i), (ii), (iii). and (iv). Case 213 of Group III in Table III. 


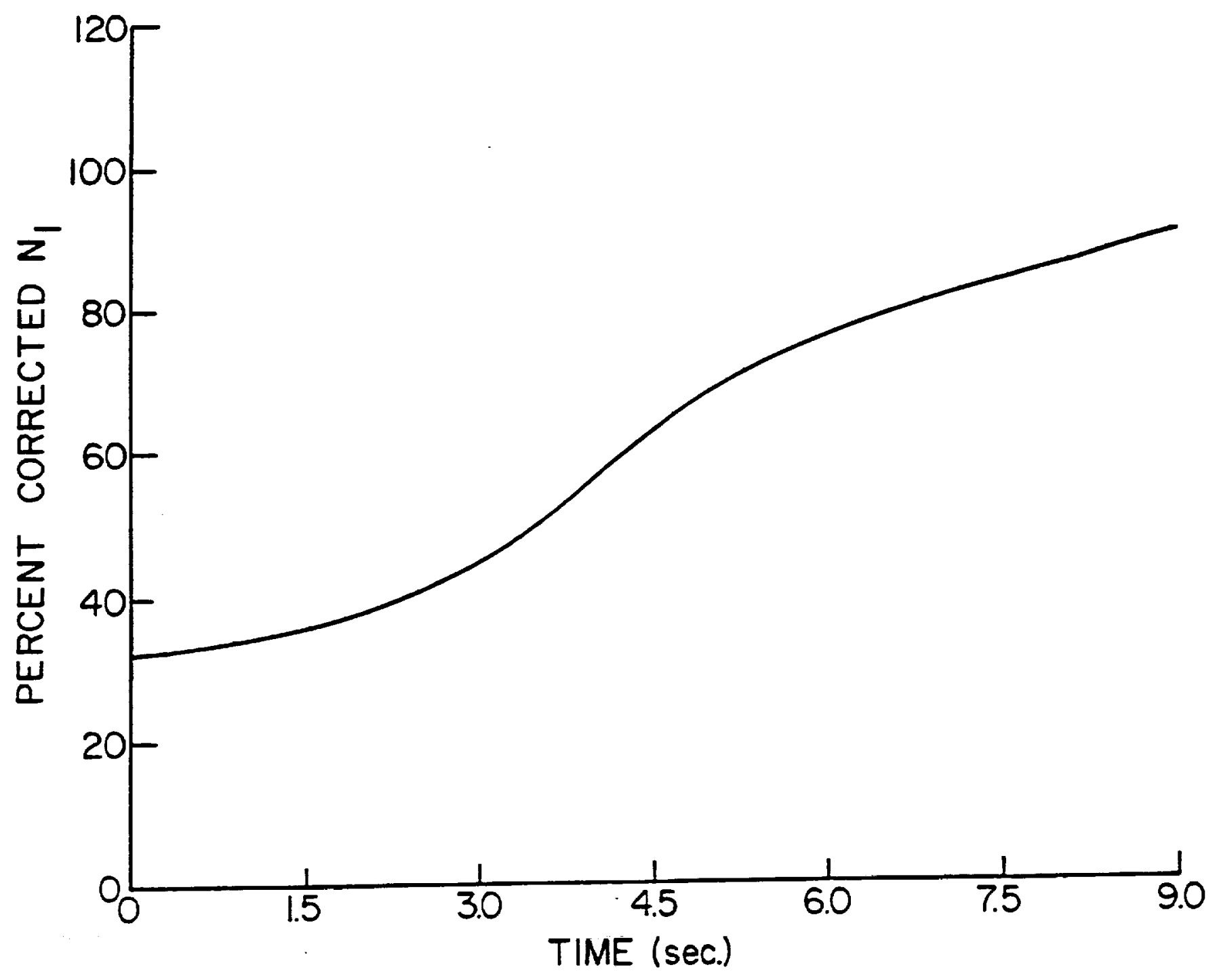

Figure 4.23.(i)

Caption on Figure 4.23.(iv) 


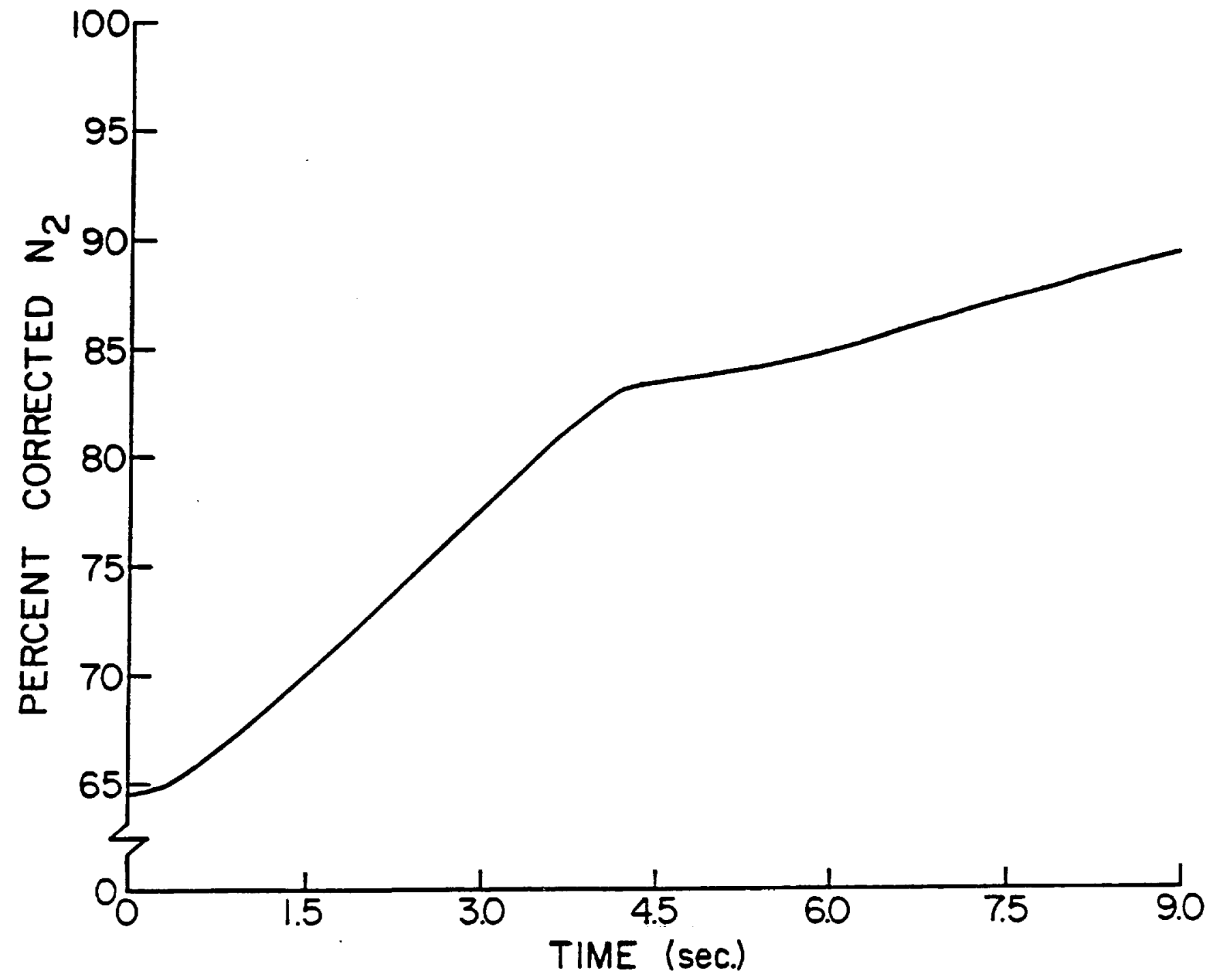

Figure 4.23.(ii)

Caption on Figure 4.23.(iv) 


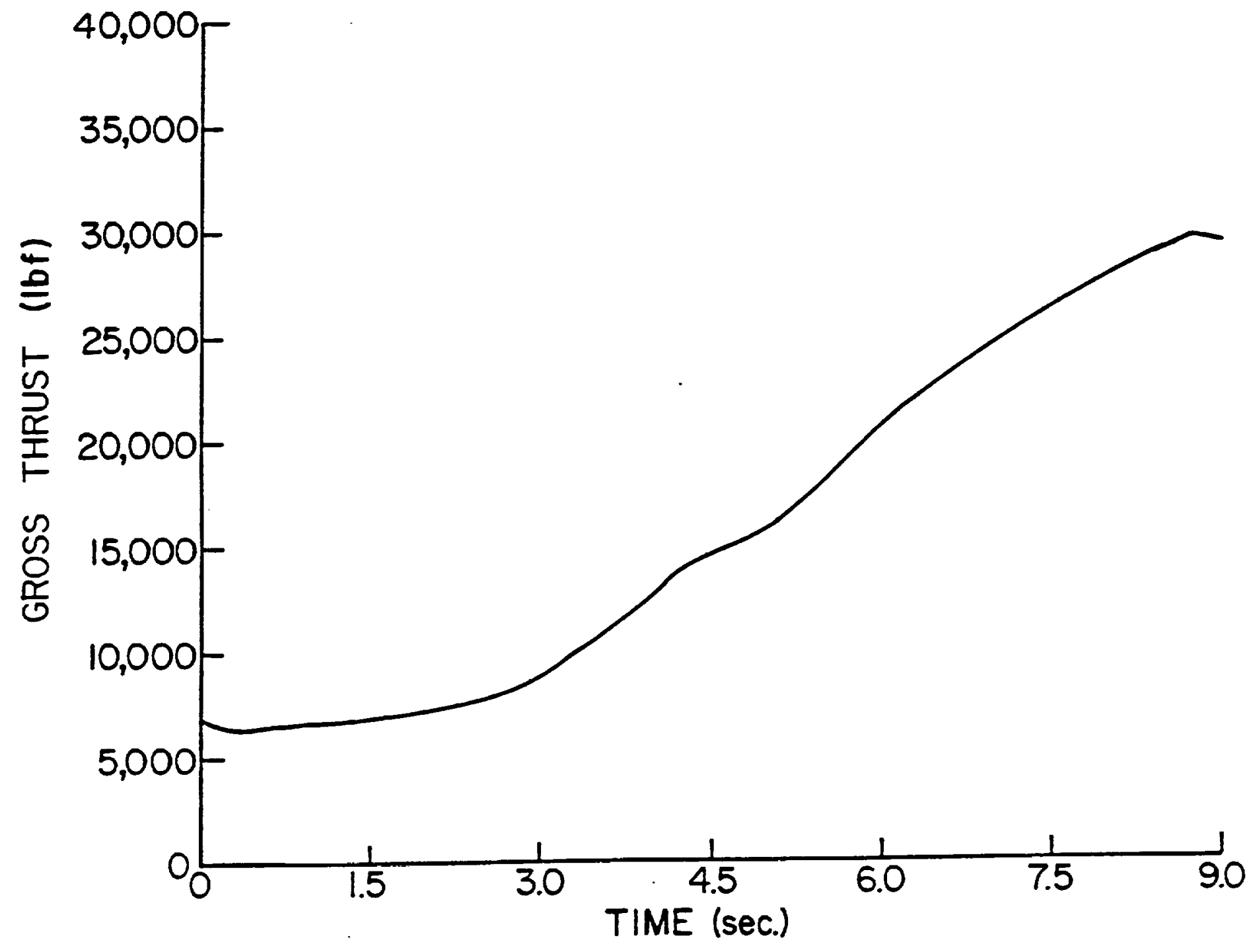

Figure 4.23.(iii)

Caption on Figure 4.23.(iv) 


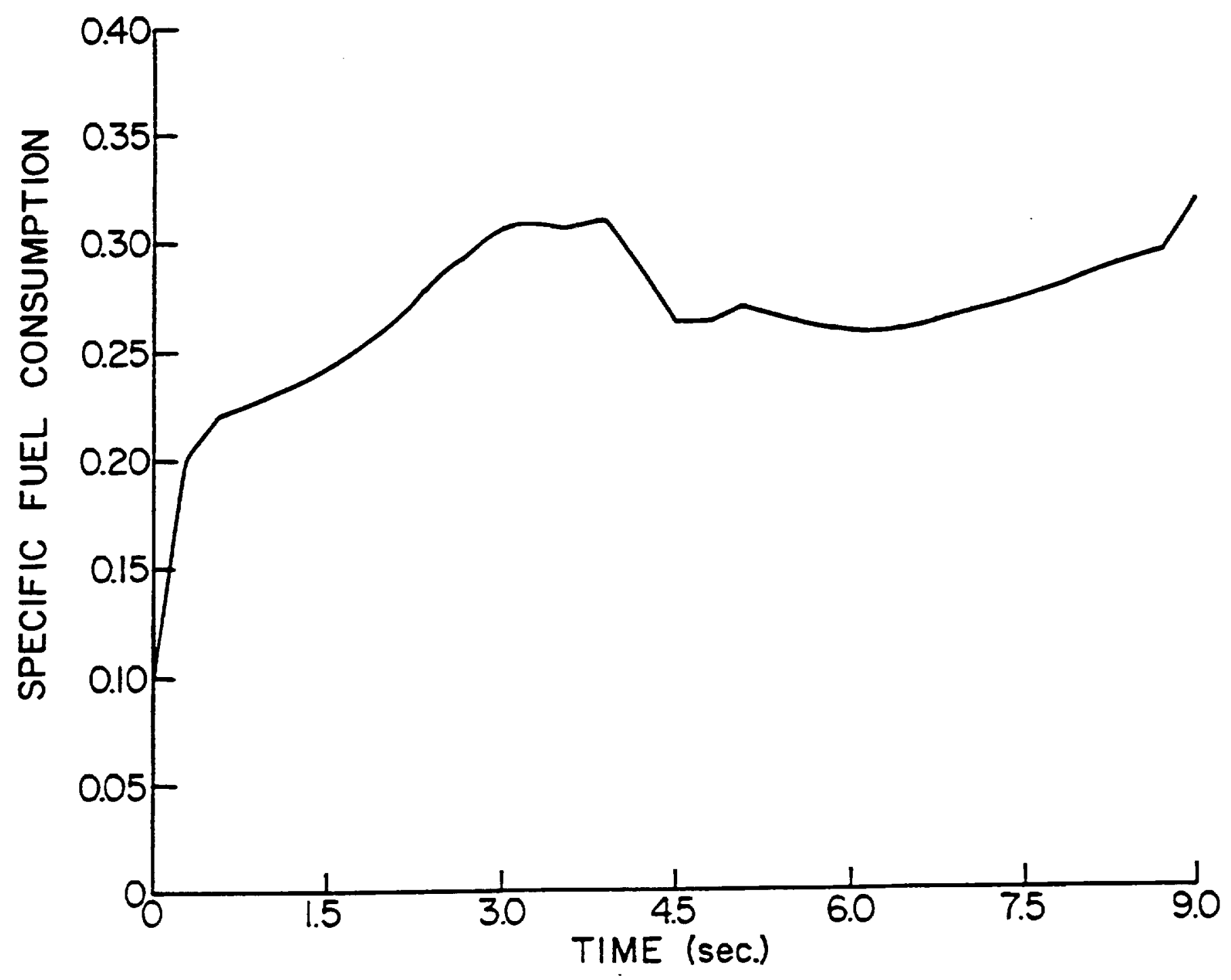

Figure 4.23.(iv)

Figure 4.23. Transient Engine Performance under Varying Ambient Conditions: (i), (ii), (iii), and (iv). Case 413 of Group III of Table III. 


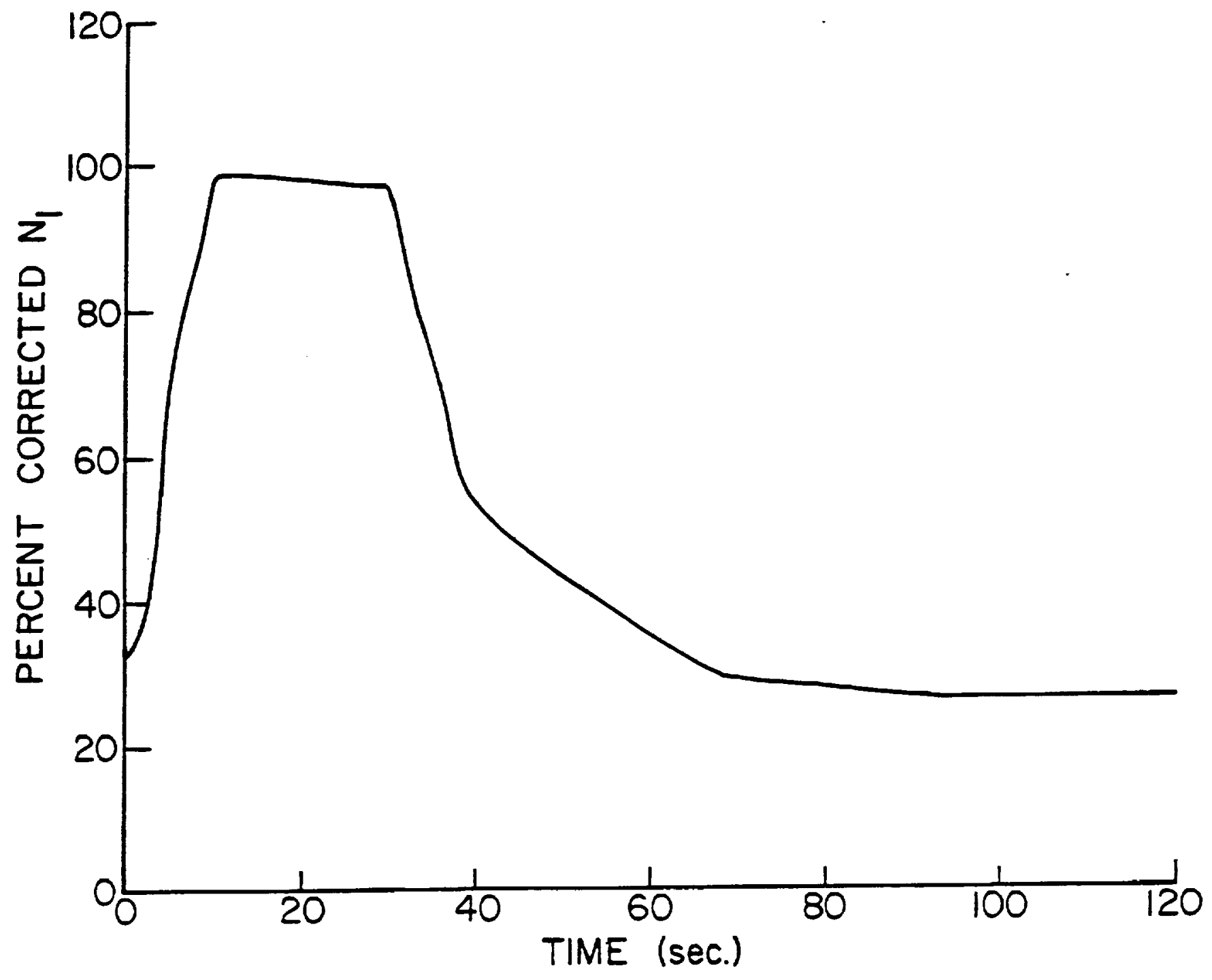

Figure 4.24.(i)

Caption on Figure 4.24.(iv) 


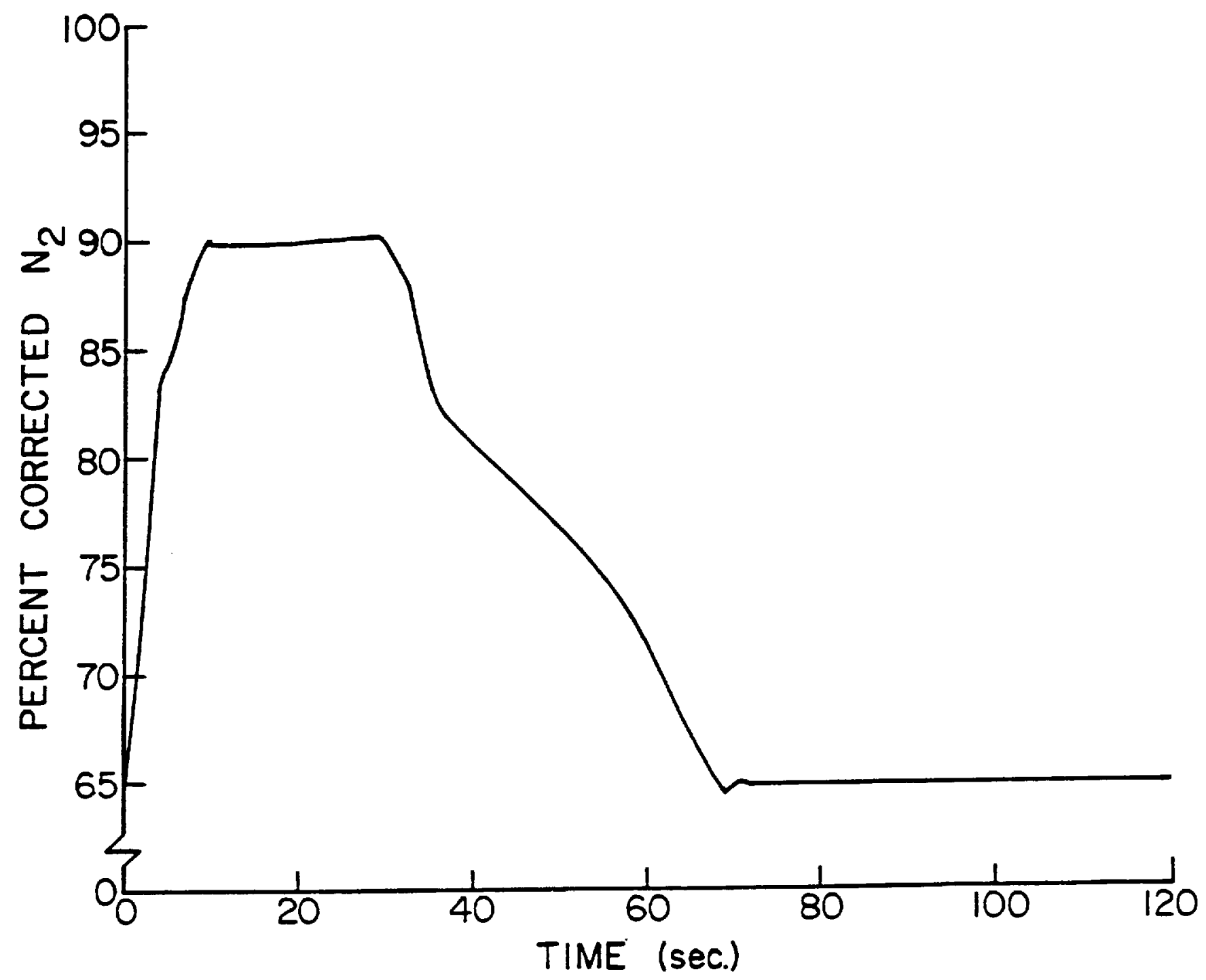

Figure 4.24.(ii)

Caption on Figure 4.24.(iv) 


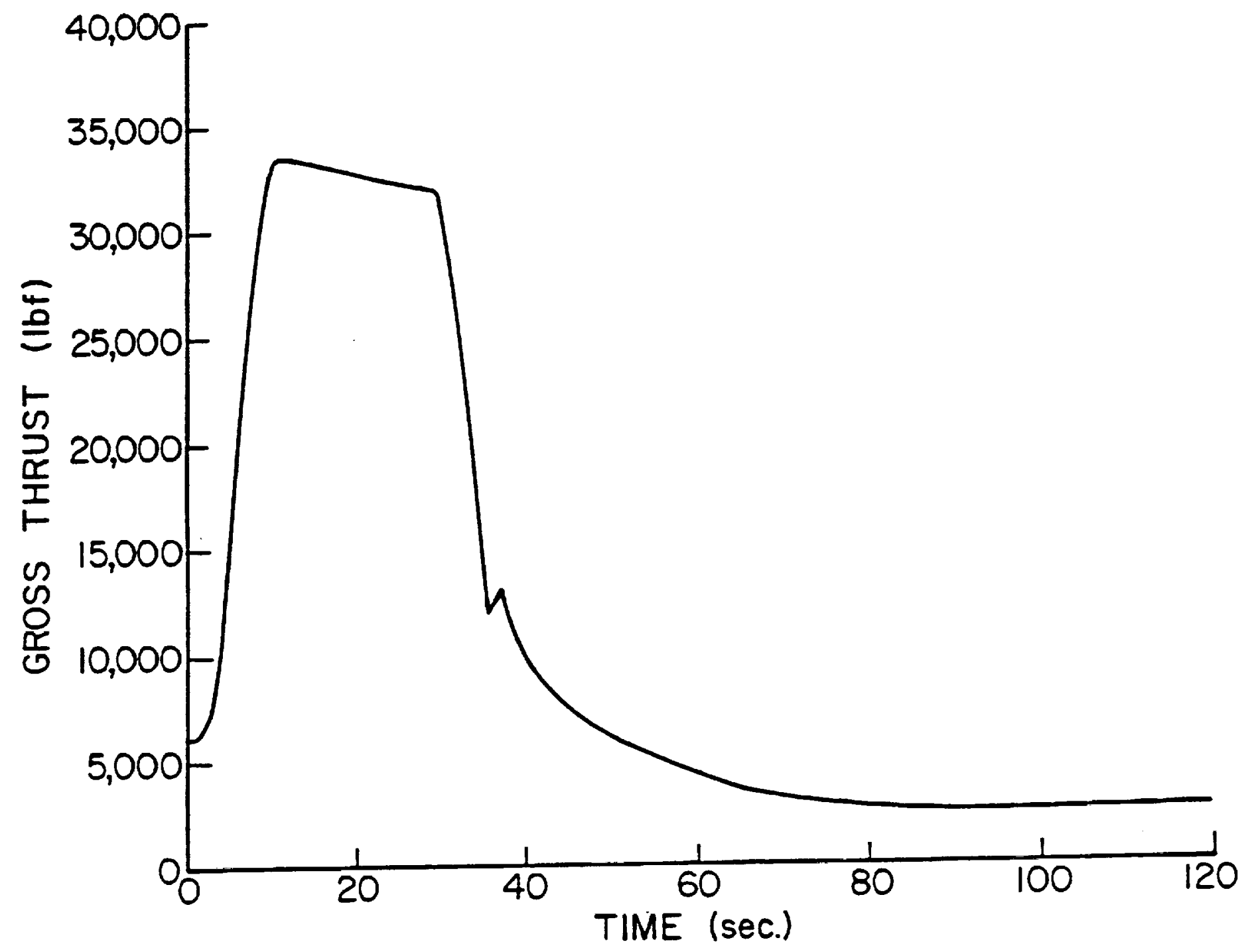

Figure 4.24.(iii)

Caption on Figure 4.24.(iv) 


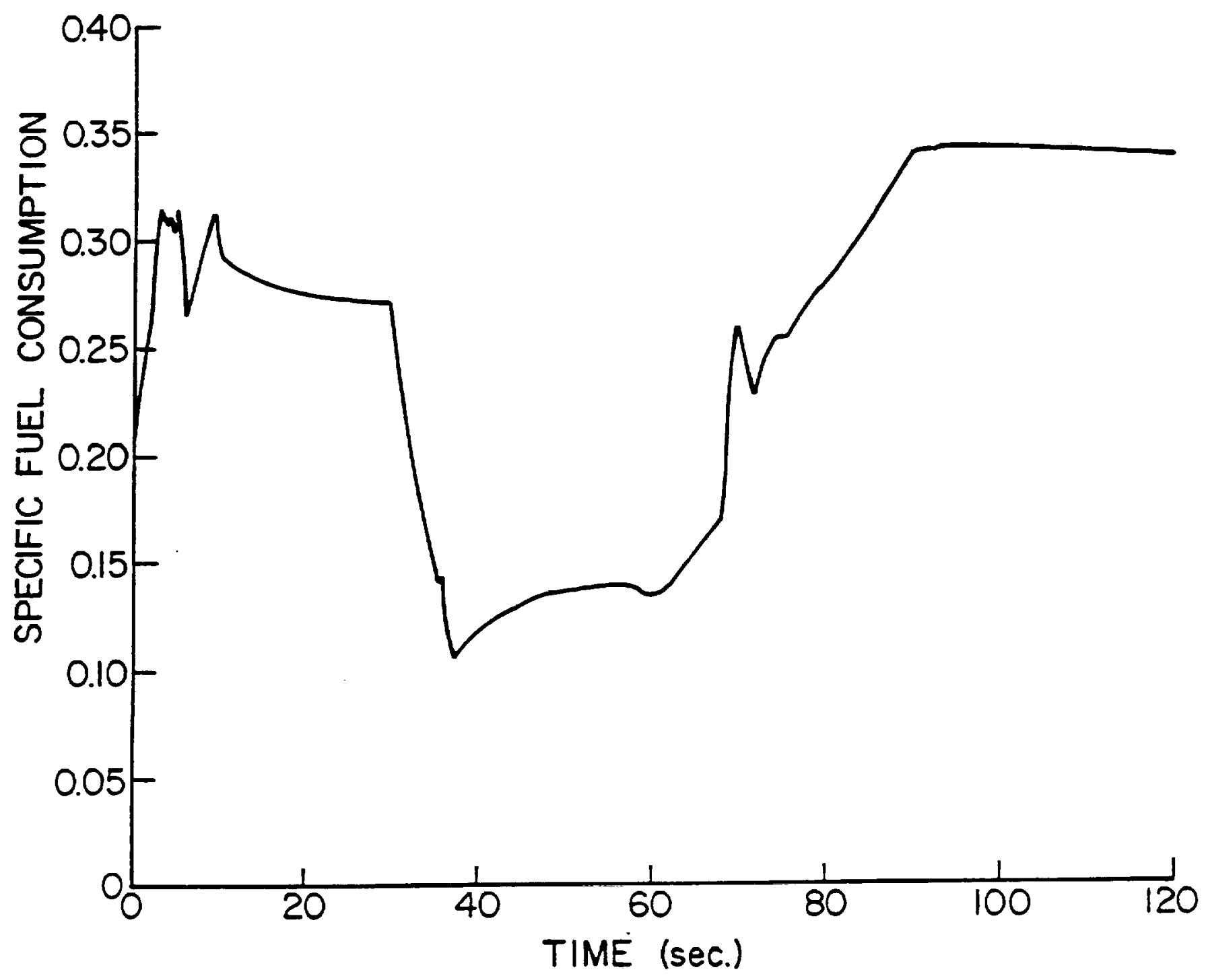

Figure 4.24.(iv)

Figure 4.24. Transient Engine Performance under Varying Ambient Conditions: (i), (ii), (iii), and (iv). Case 813 of Group III in Table III. 


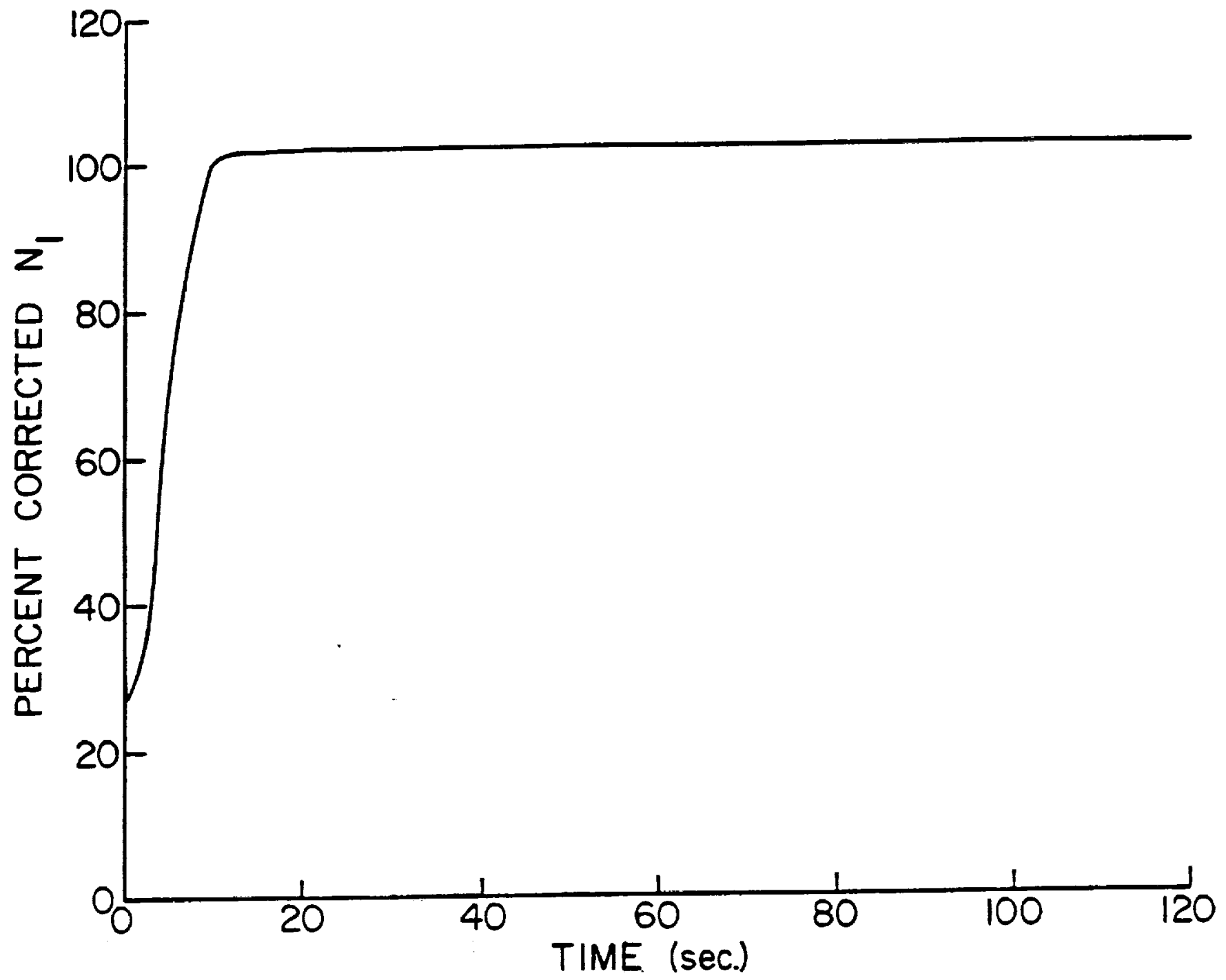

Figure 4.25.(i)

Caption on Figure 4.25.(iv) 


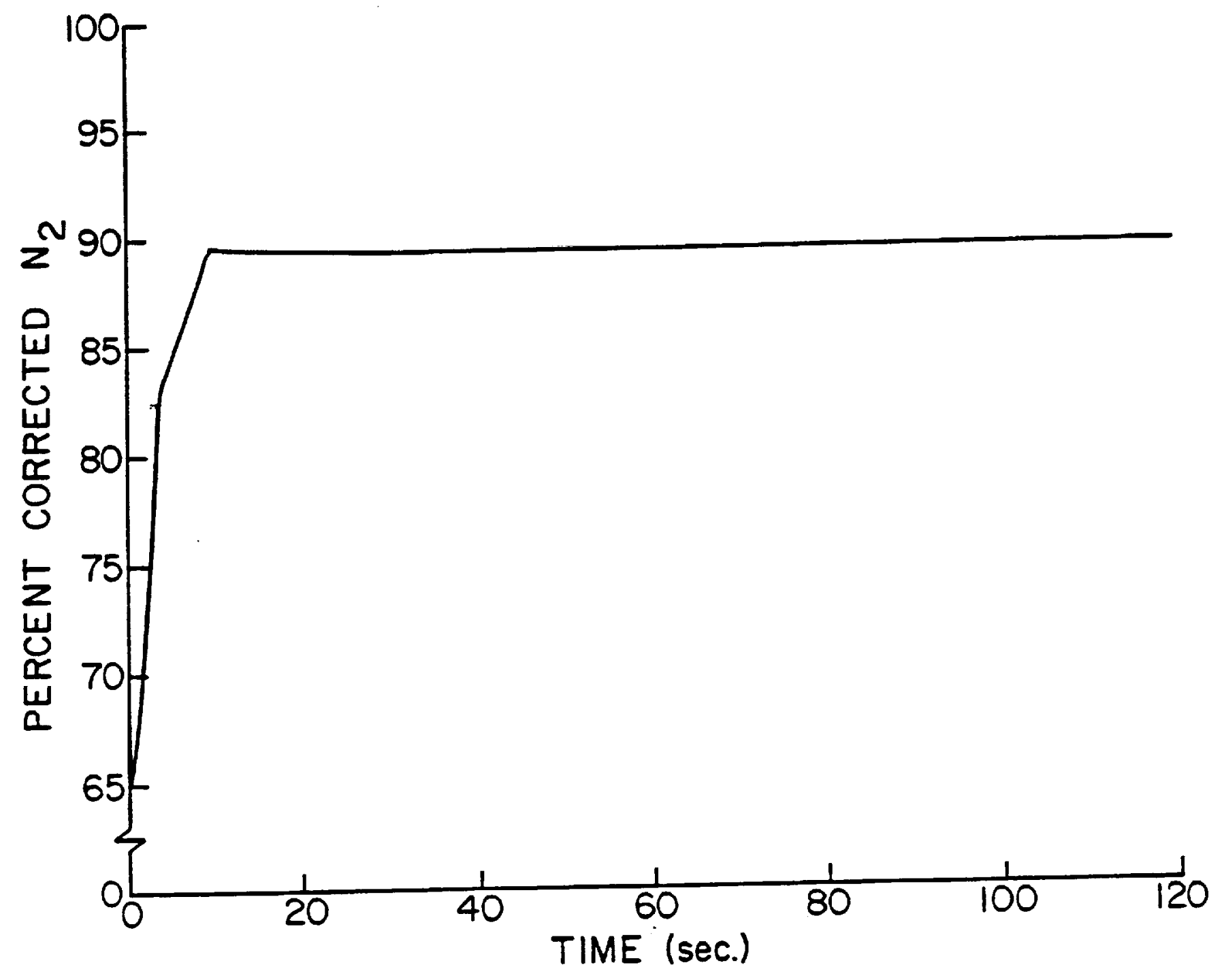

Figure 4.25.(ii)

Caption on Figure 4.25.(iv) 


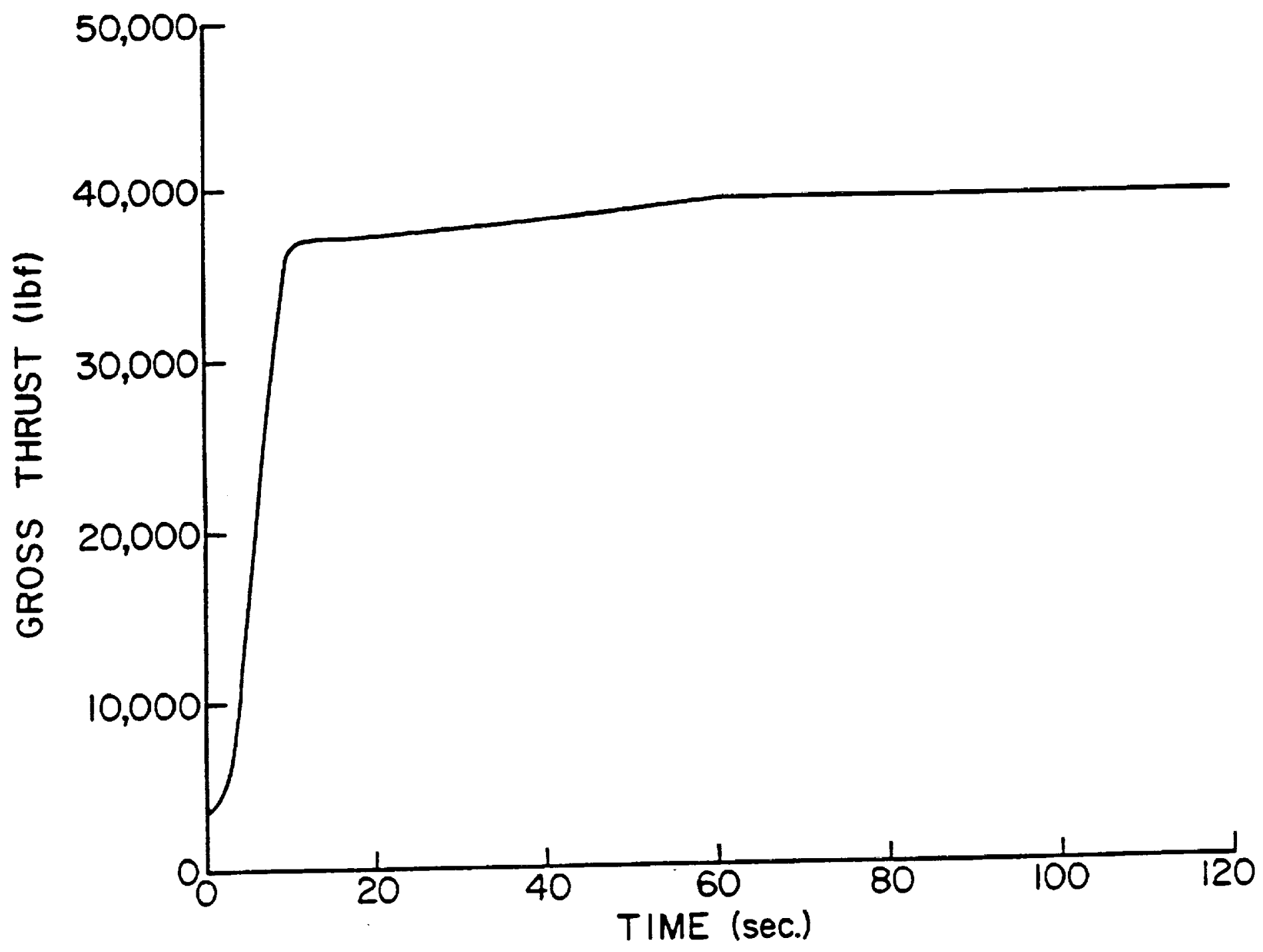

Figure 4.25.(iii)

Caption on Figure 4.25.(iv) 


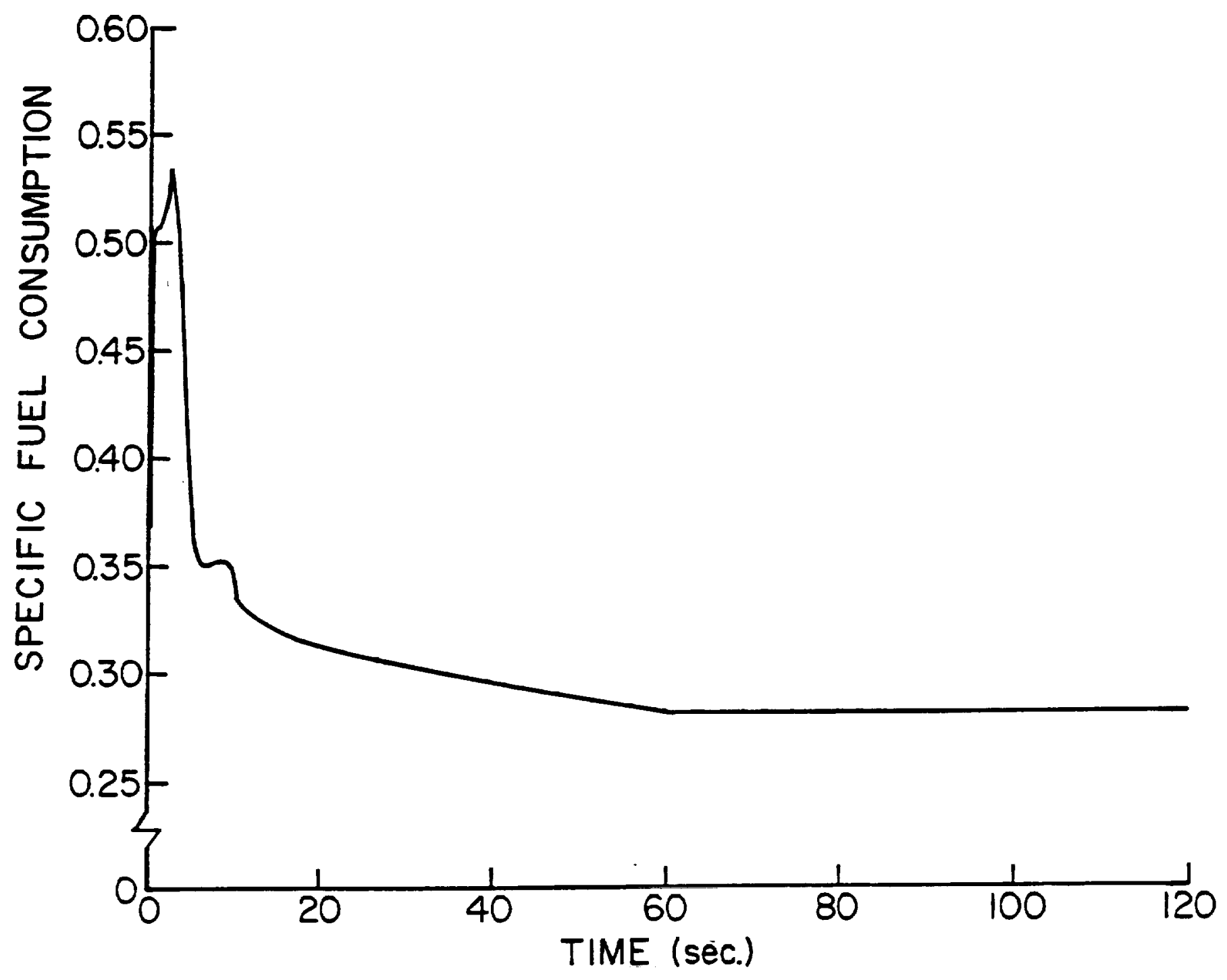

Figure 4.25.(iv)

Figure 4.25. Transient Engine Performance under Varying Ambient Conditions: (i), (ii), (iii), and (iv). Case 031 of Group IV of Table III. 


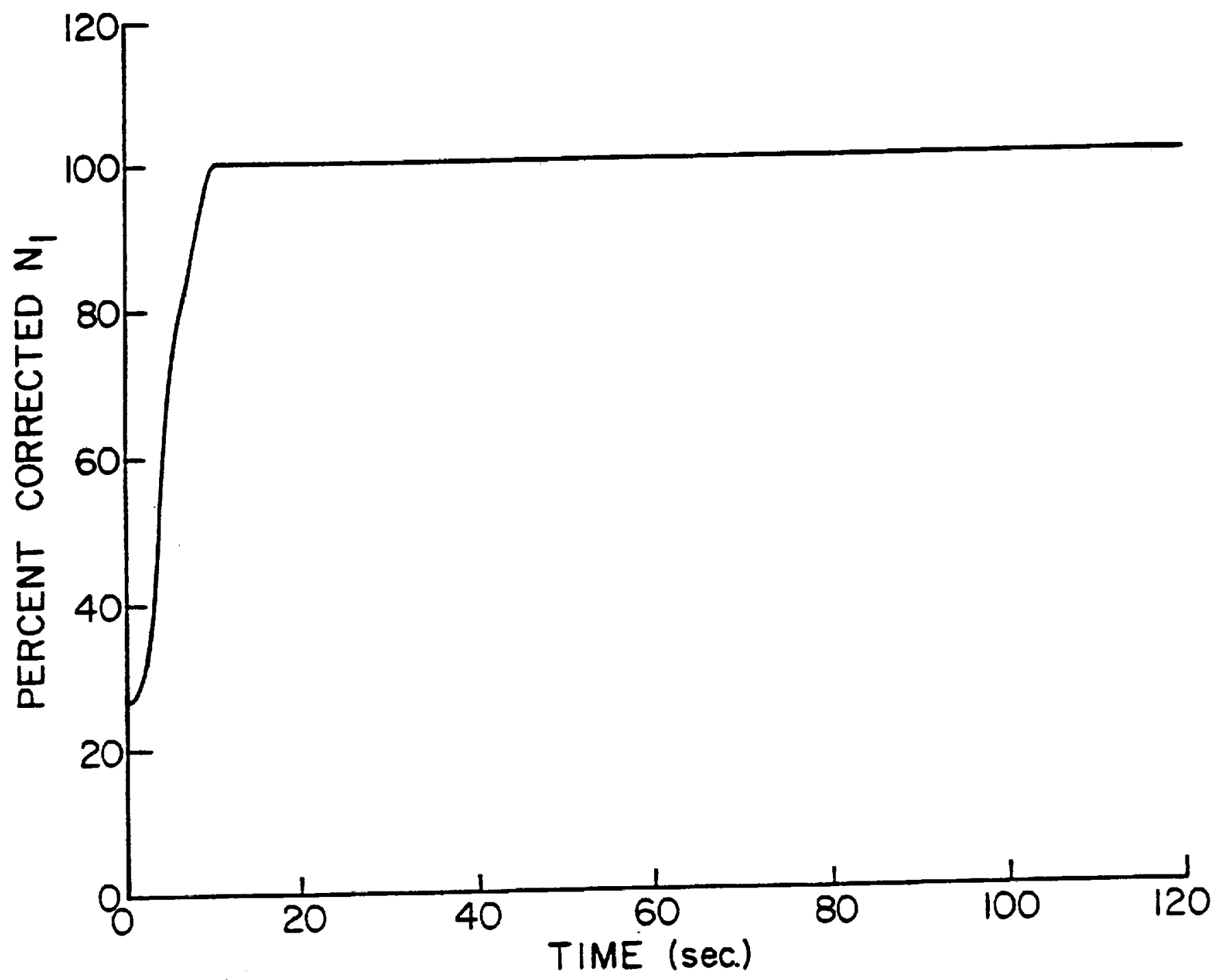

Figure 4.26.(i)

Caption on Figure 4.26.(iv) 


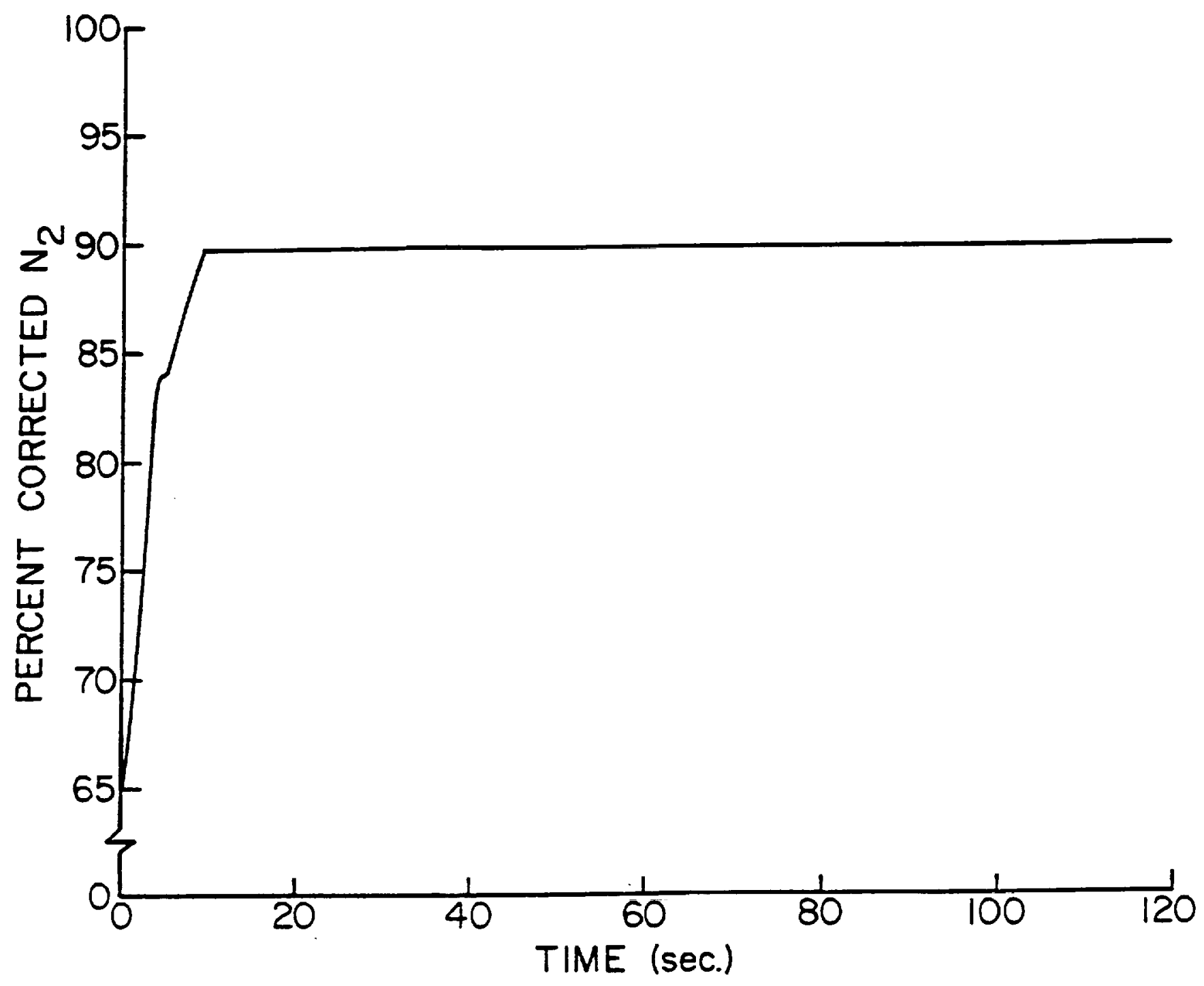

Figure 4.26.(ii)

Caption on Figure 4.26.(iv) 


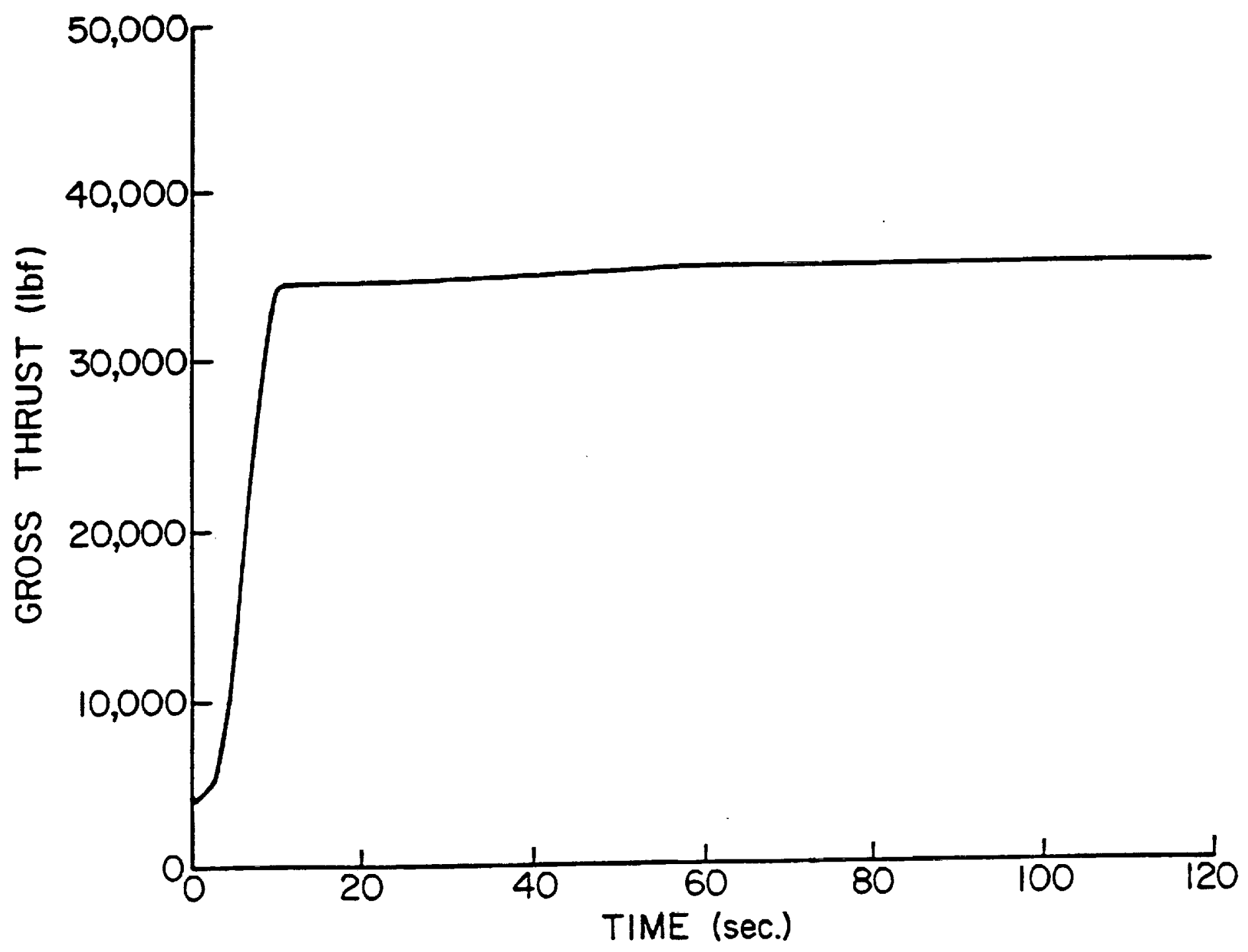

Figure 4.26.(iii)

Caption on Figure 4.26.(iv) 


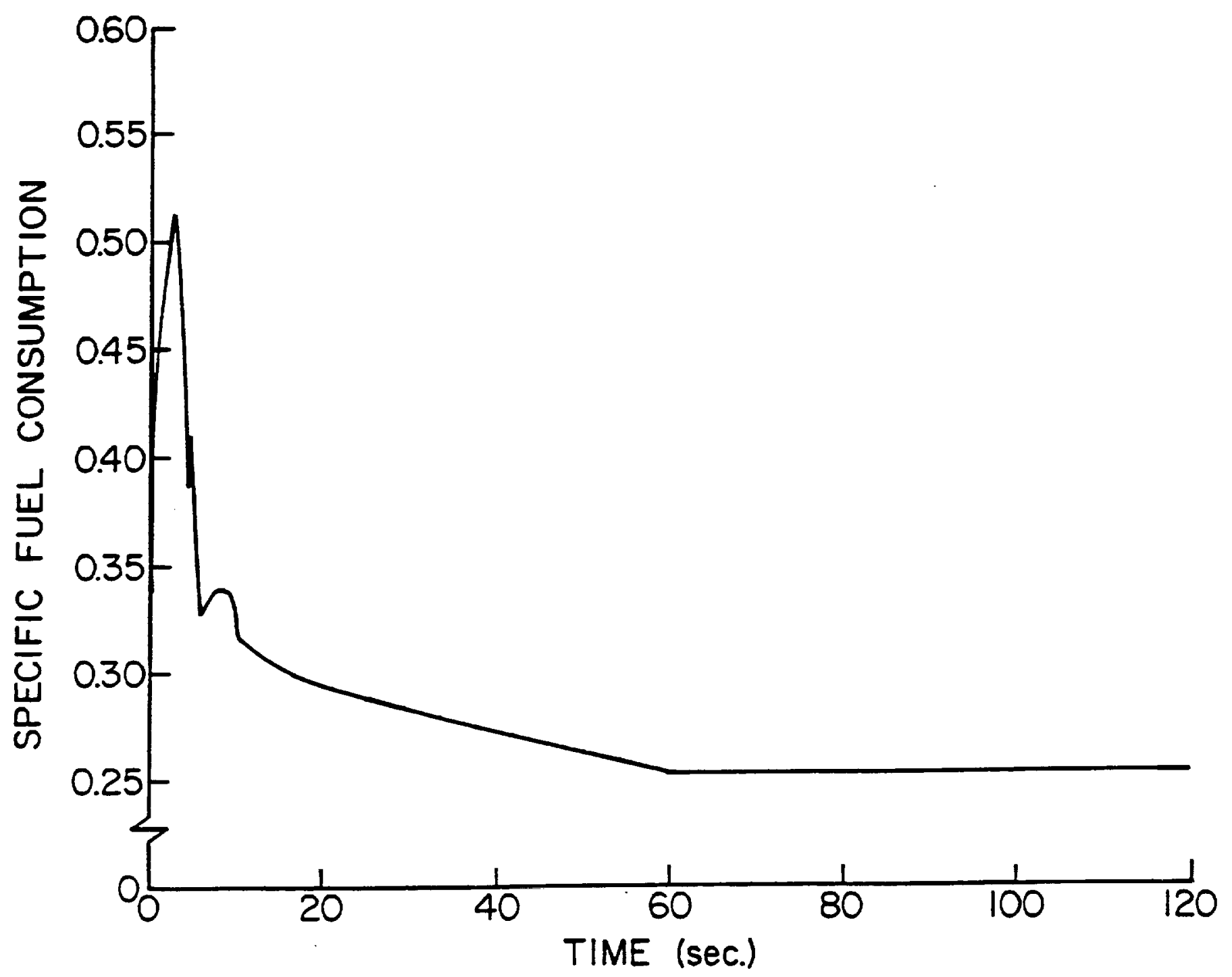

Figure 4.26.(iv)

Figure 4.26. Transient Engine Performance under Varying Ambient Conditions: (i), (ii), (iii), and (iv). Case 231 of Group IV of Task III. 


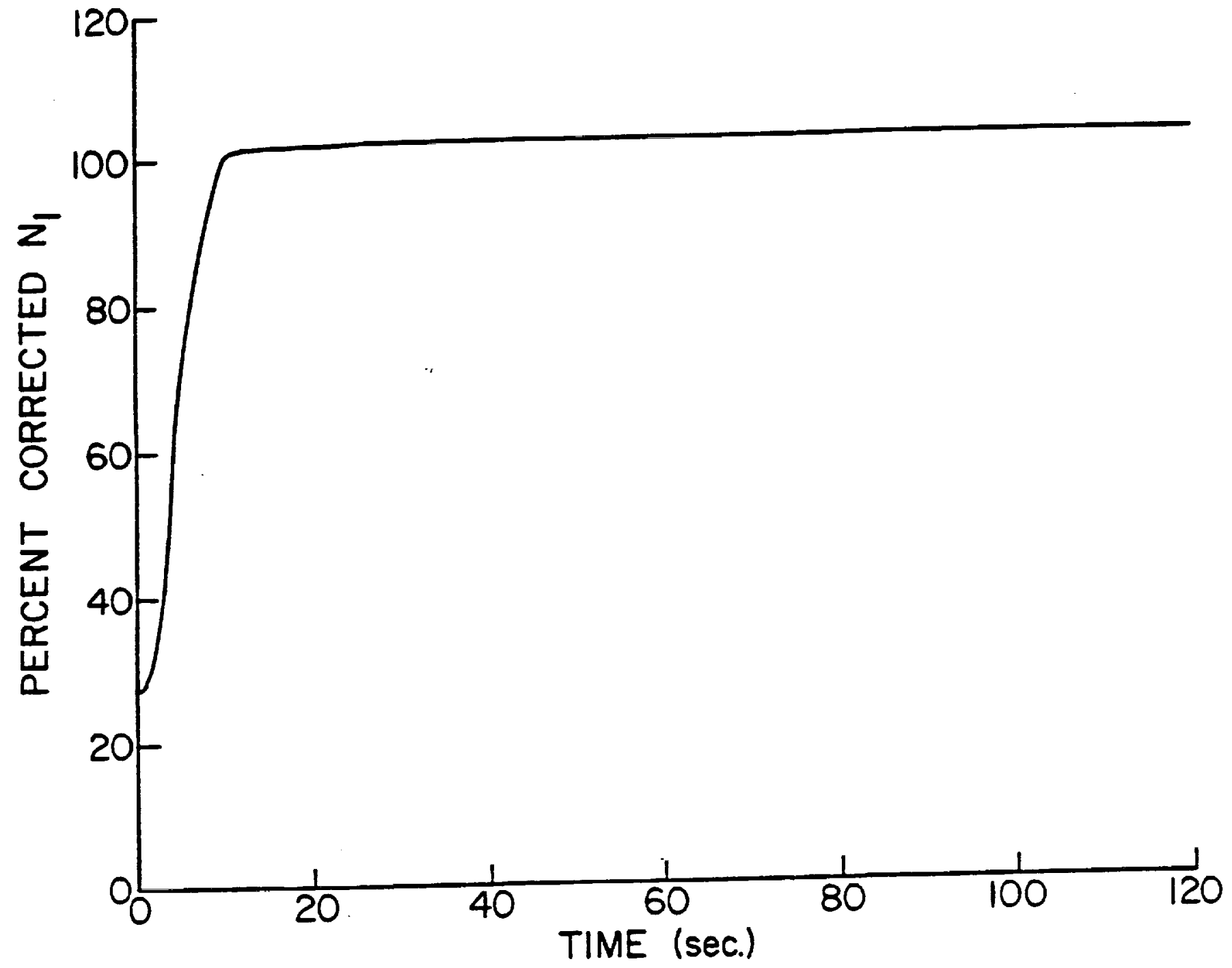

Figure 4.27.(i)

Caption on Figure 4.27.(iv) 


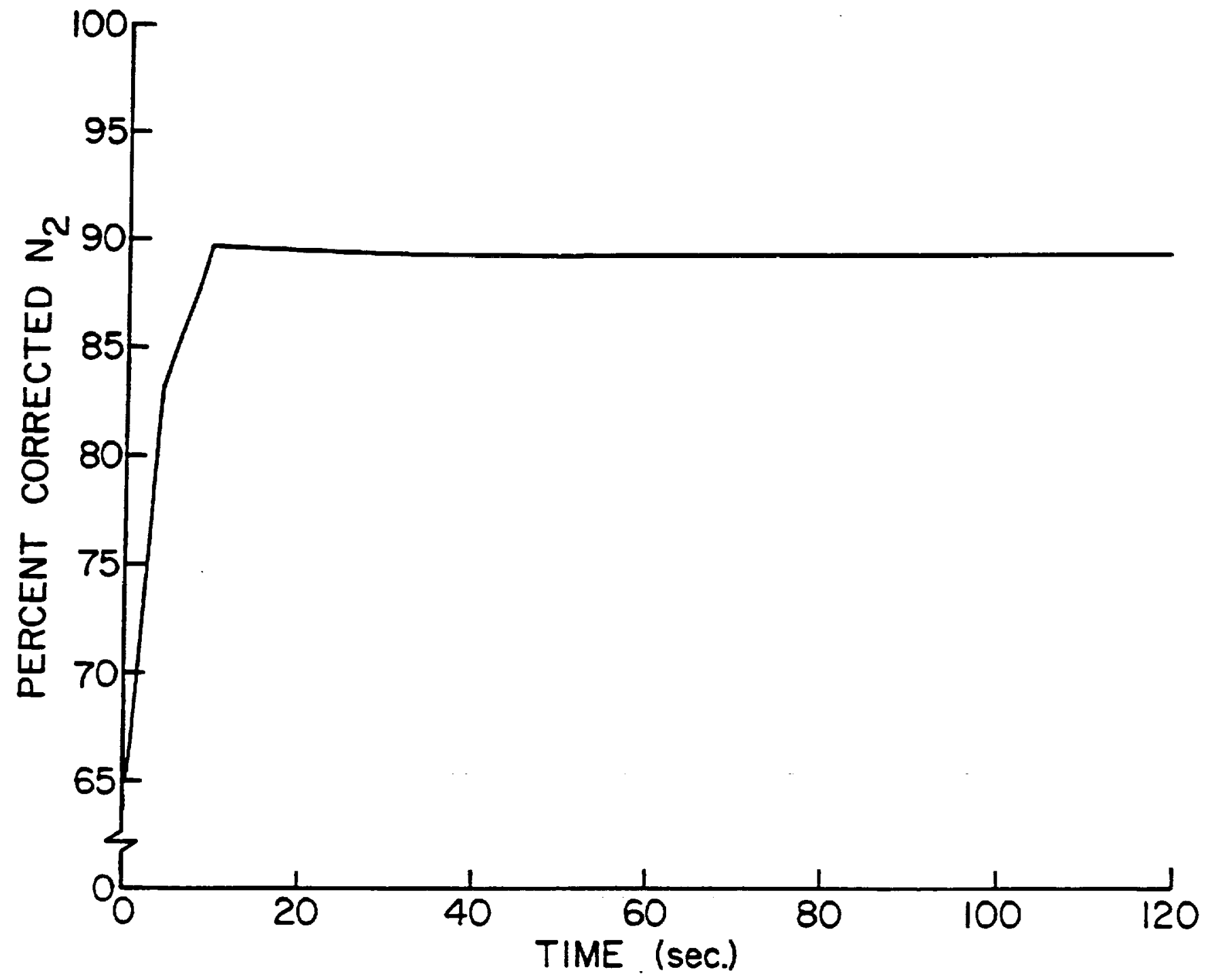

Figure 4.27.(ii)

Caption on Figure 4.27.(iv) 


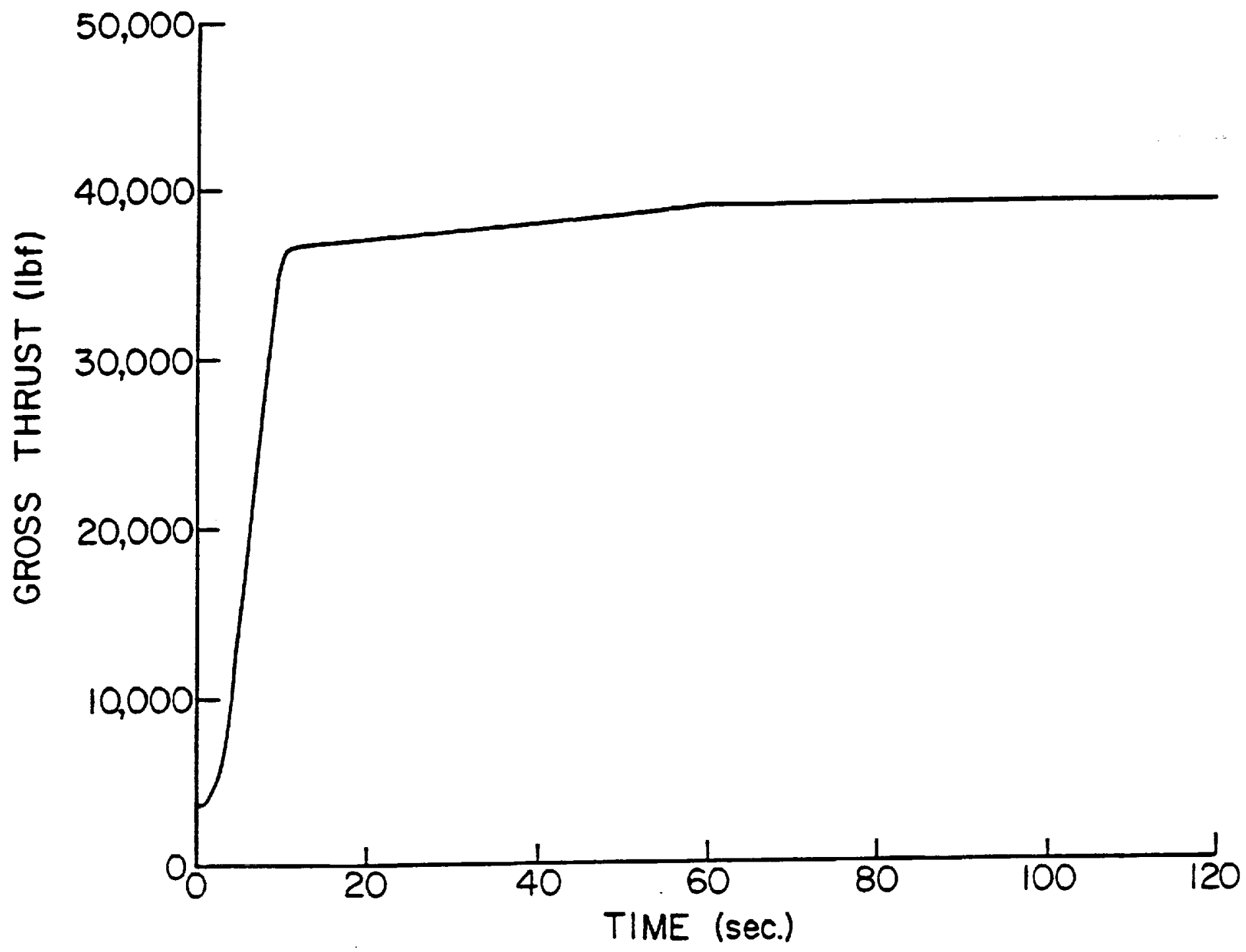

Figure 4.27.(iii)

Caption on Figure 4.27.(iv) 


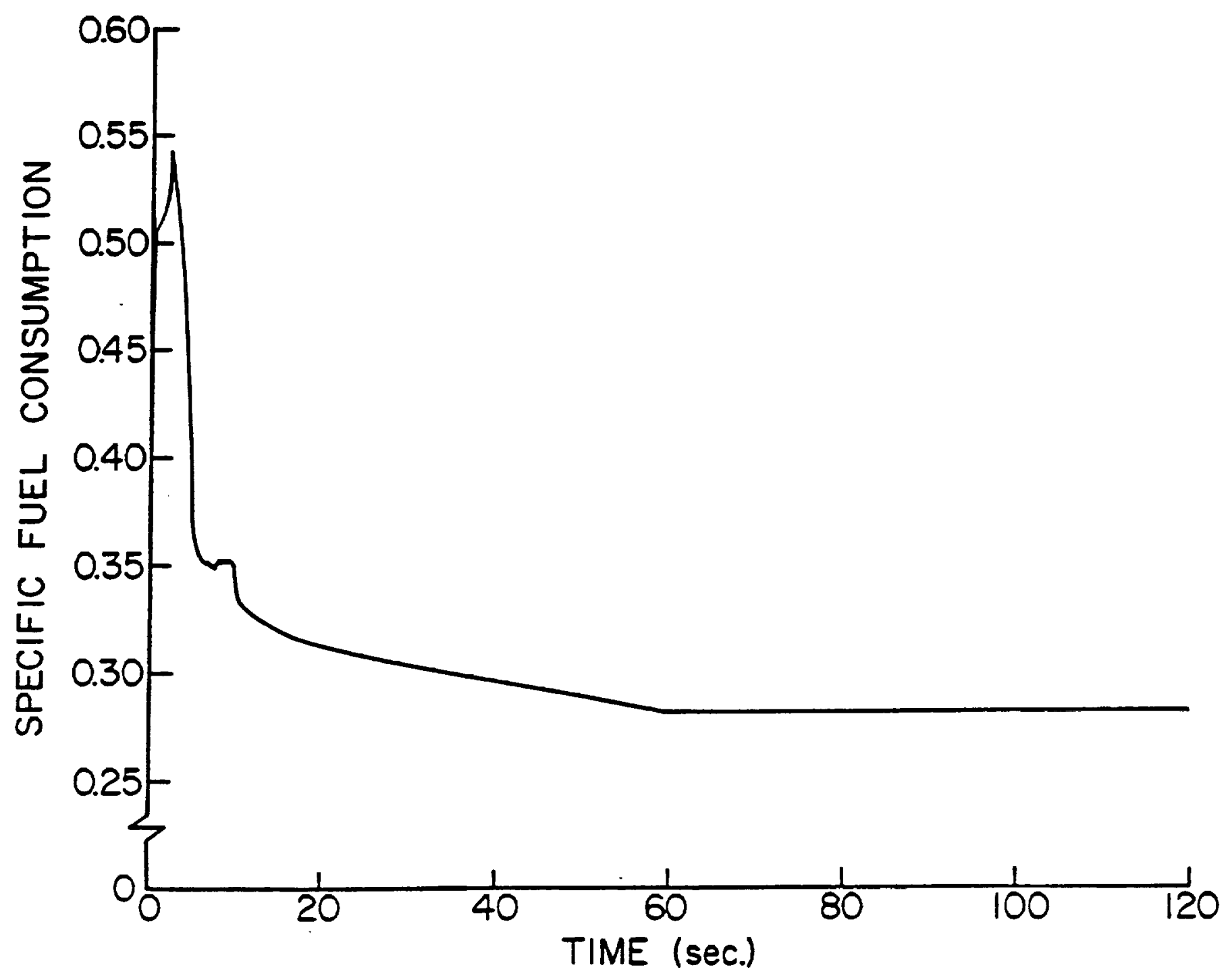

Figure 4.27.(iv)

Figure 4.27. Transient Engine Performance under Varying Ambient Conditions: (i), (ii), (iii), and (iv). Case 431 of Group IV of Table III. 


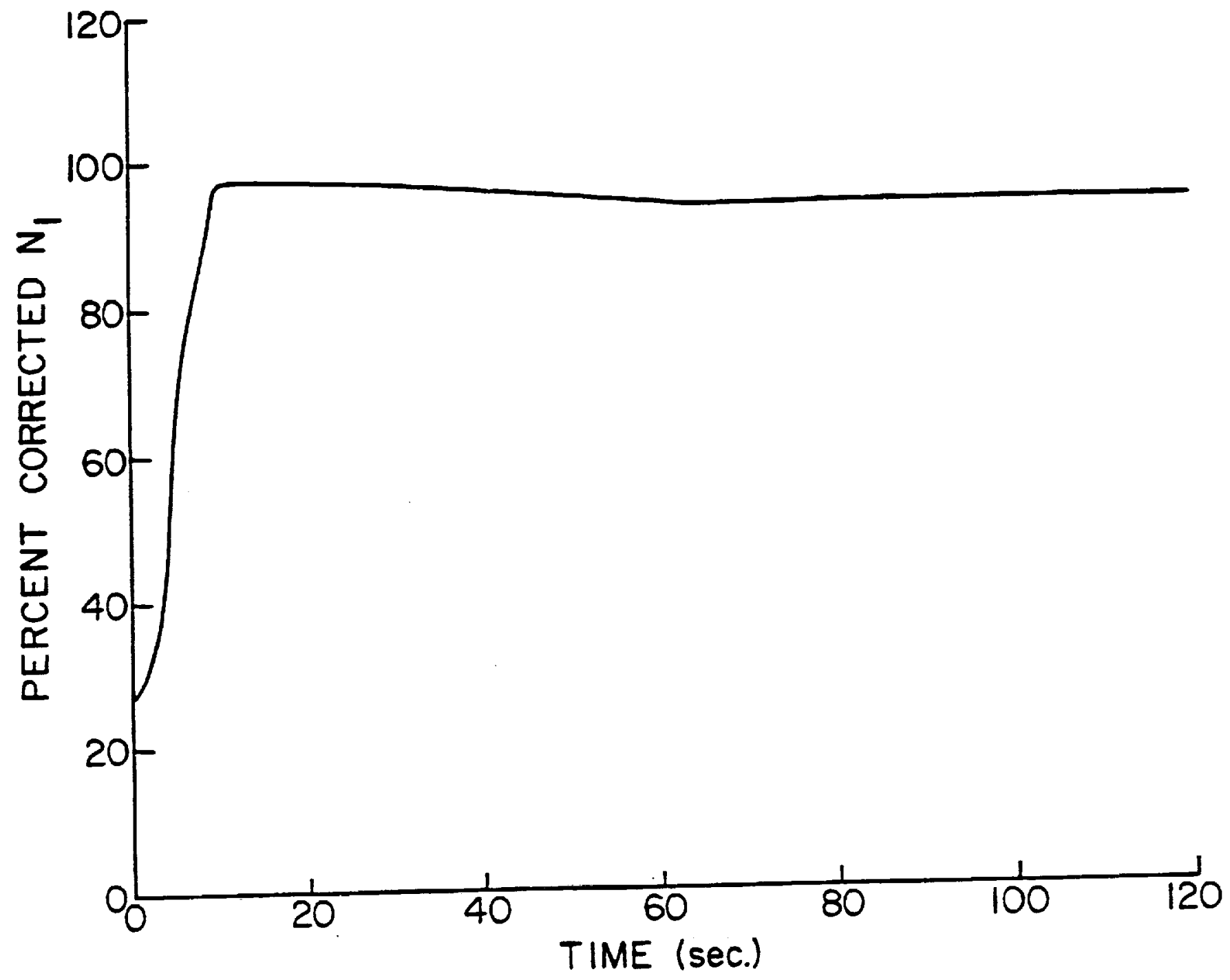

Figure 4.28.(i)

Caption on Figure 4.28.(iv) 


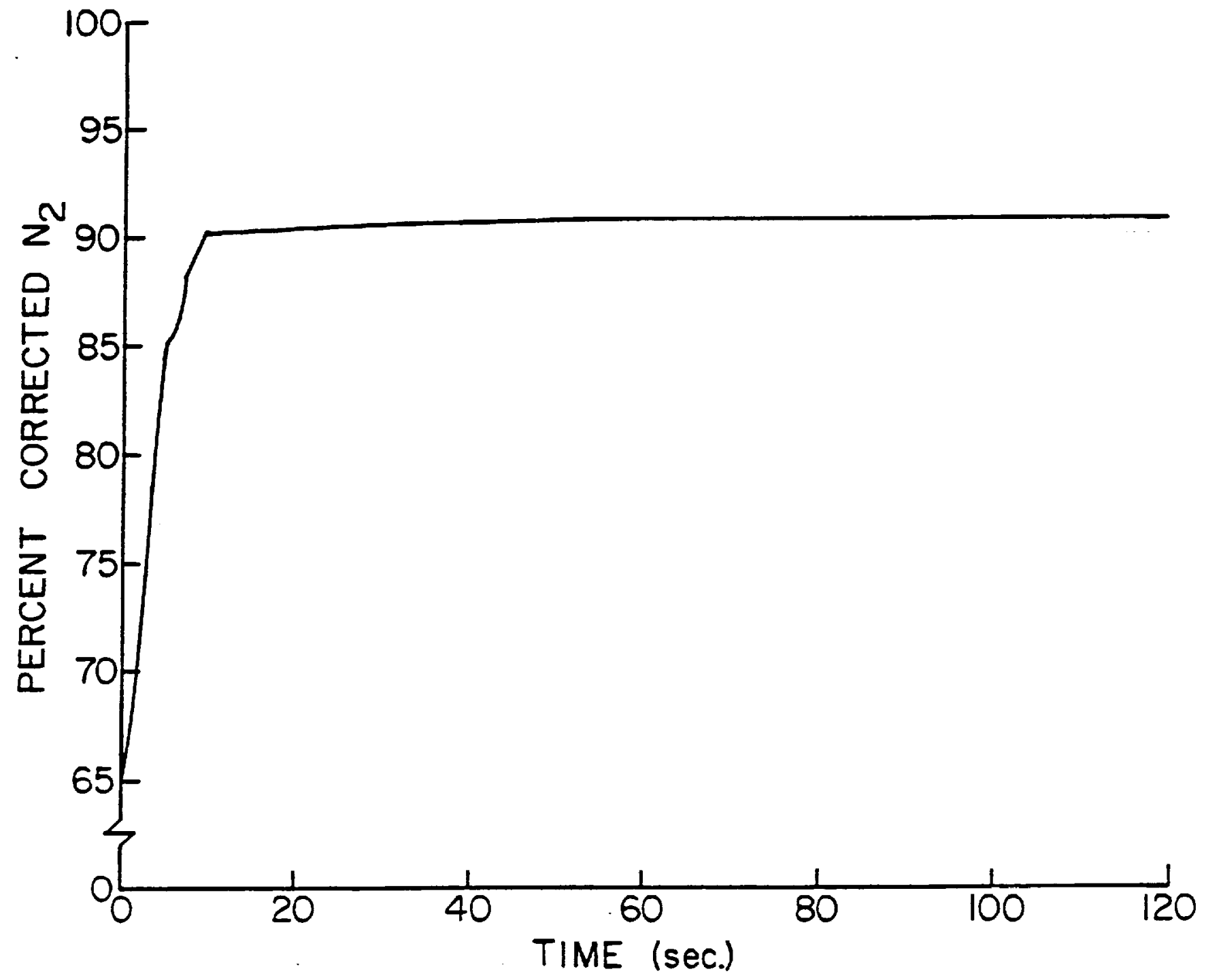

Figure 4.28.(ii)

Caption on Figure 4.28.(iv) 


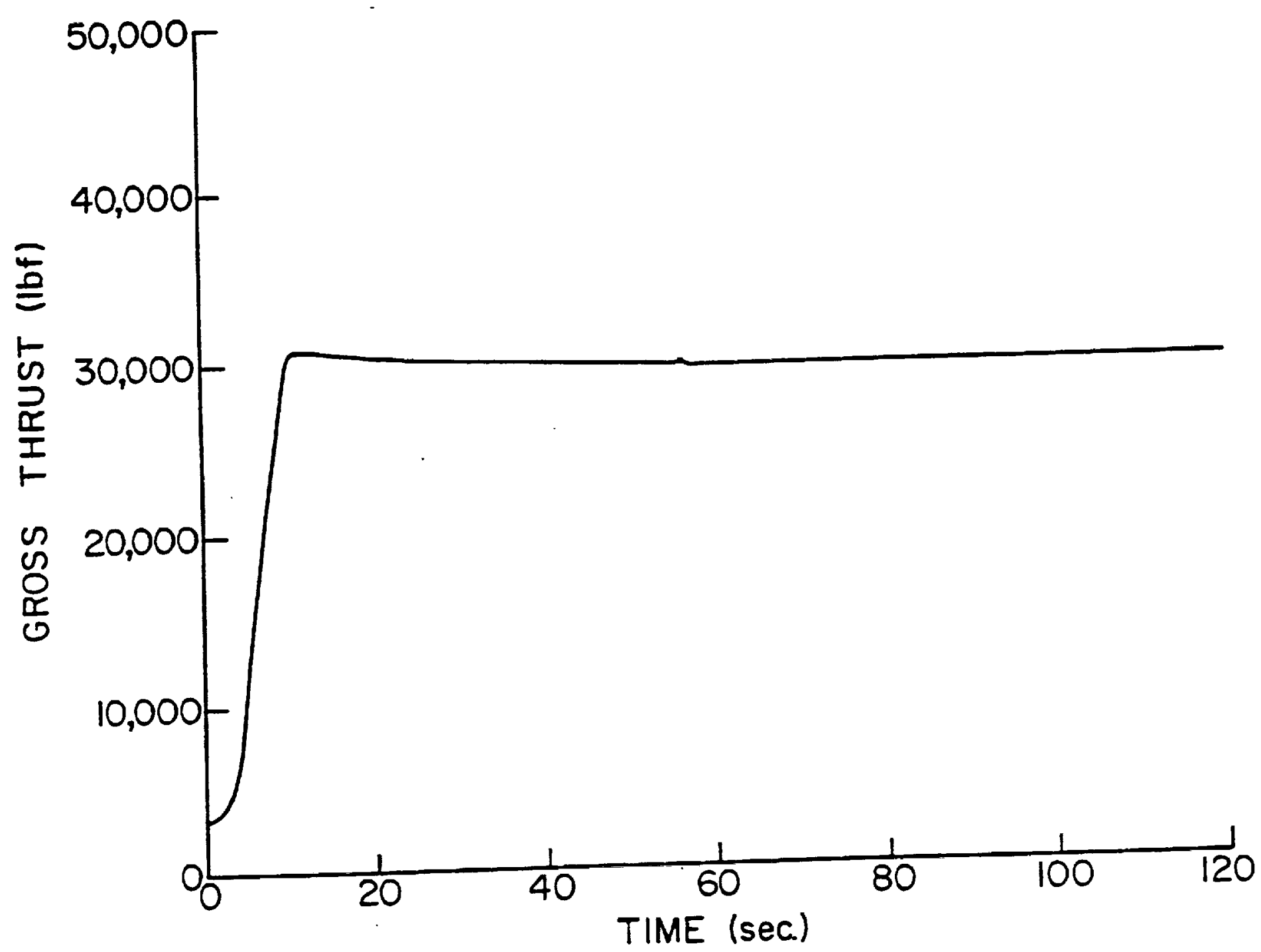

Figure 4.28.(iii)

Caption on Figure 4.28.(iv) 


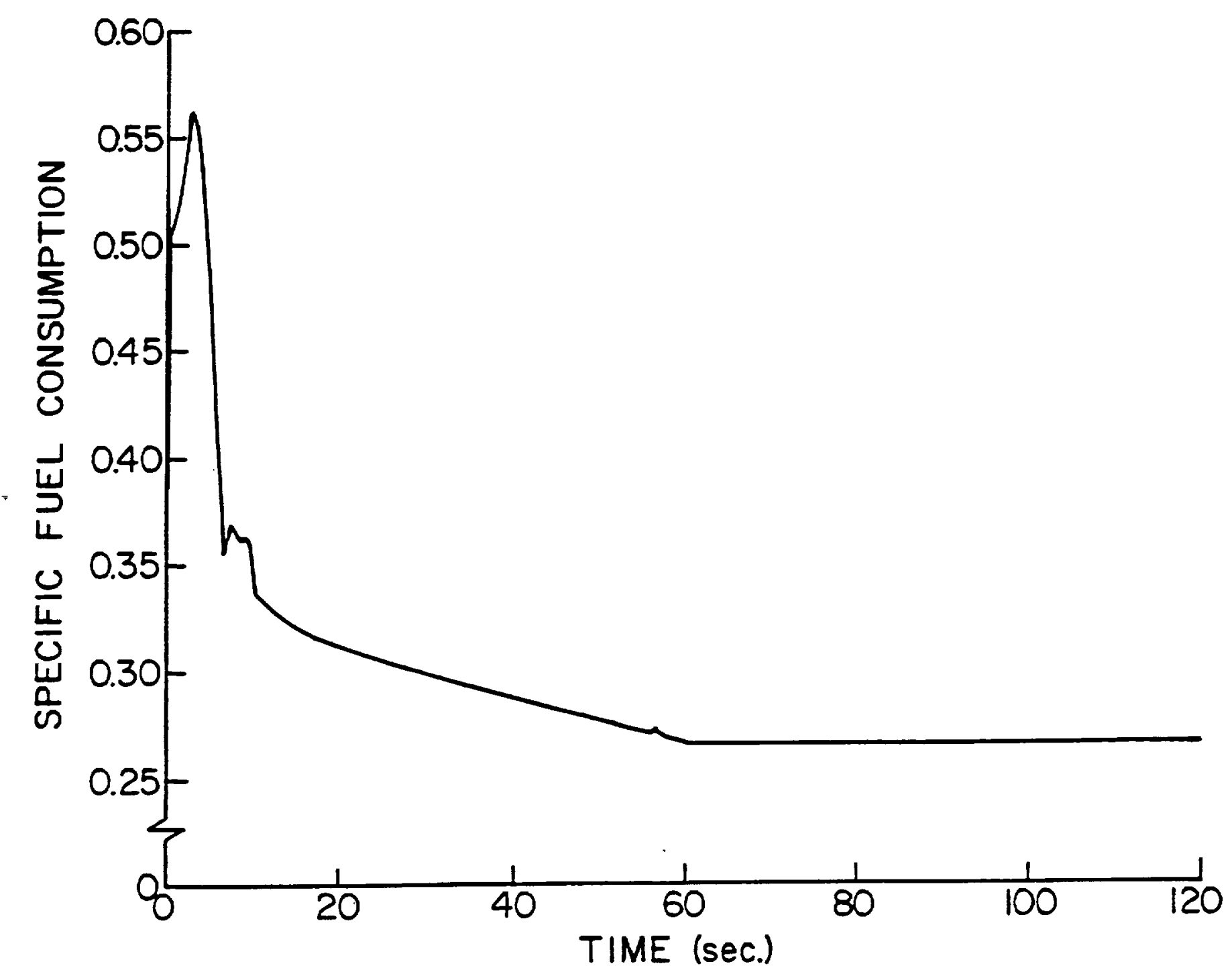

Figure 4.28.(iv)

Figure 4.28. Transient Engine Performance under Varying Ambient Conditions: (i), (ii), (iii), and (iv). Case 831 of Group IV of Table III. 
Public reporting burden for this collection of information is estimated to average 1 hour per response, including the time for reviewing instructions, searching existing data sources, gathering and maintaining the data needed, and completing and reviewing the collection of information. Send comments regarding this burden estimate or any other aspect of this Gliog Davis Highway, Suite 1204, Arlington, VA 22202-4302, and to the Office of Management and Budget, Paperwork Reduction Project (0704-0188). Washington, DC 20503.

\begin{tabular}{|l|c|c|}
\hline 1. AGENCY USE ONLY (Leave blank) & $\begin{array}{r}\text { 2. REPOAT DATE } \\
\text { April } 1993\end{array}$ & $\begin{array}{r}\text { 3. REPORT TYPE AND DATES COVERED } \\
\text { Interim Contractor Report }\end{array}$ \\
\hline
\end{tabular}

\section{TTLE AND SUBTTLE}

Transient Performance of Fan Engine With Water Ingestion 5. FUNDING NUMBERS

6. AUTHOR(S)

WU-505-62-21

G-NAG3-481

S.N.B. Murthy and A. Mullican

\section{PERFORMING ORGANIZATION NAME(S) AND ADDRESS(ES)}

Purdue University

School of Mechanical Engineering

West Lafayette, Indiana 47907
8. PERFoRMING ORGANIzATION REPORT NUMBER

E-7709
9. SPONSORINGMONTORING AGENCY NAMES(S) AND ADDRESS(ES)

National Aeronautics and Space Administration

Lewis Research Center

Cleveland, Ohio 44135-3191
10. SPONSORING/MONITORING AGENCY REPORT NUMBER

NASA CR-190778

DOT/FAA/CT-TN 92/11

\section{SUPPLEMENTARY NOTES}

Project Manager, Ronald J. Steinke, Intemal Fluid Mechanics Division, (216) 433-5854. Work partially funded by the U.S. Department of Transportation, FAA Technical Center, Atlantic City International Airport, New Jersey, under Interagency Agreement DTFA-03-83-A-00328. FAA Technical Monitor, Howard Banilower, FAA Technical Center.

12a. DISTRIBUTION/AVAILABILTY STATEMENT

12b. DISTRIBUTION CODE

Unclassified - Unlimited

Subject Category 01

\section{ABSTRACT (Maximum 200 words)}

In a continuing investigation on developing and applying codes for prediction of performance of a turbine jet engine and its components with water ingestion during flight operation, including power settings, and flight altitudes and speed changes, an attempt has been made to establish the effects of water ingestion through simulation of a generic high bypass ratio engine with a generic control. In view of the large effects arising in the air compression system and the prediffusercombustor unit during water ingestion, attention has been focused on those effects and the resulting changes in engine performance. Under all conditions of operation, whether ingestion is steady or not, it has become evident that water ingestion causes a fan-compressor unit to operate in a time-dependent fashion with periodic features, particularly with respect to the state of water in the span and the film in the casing clearance space, at the exit of the machine. On the other hand, the aerodynamic performance of the unit may be considered as quasi-steady once the distribution of water has attained an equilibrium state with respect to its distribution and motion. For purposes of engine simulation, the performance maps for the generic fan-compressor unit have been generated based on the attainment of a quasi-steady state (meaning steady except for long-period variations in performance) during ingestion and operation over a wide enough range of rotational speeds.

\begin{tabular}{|c|c|c|c|}
\hline $\begin{array}{c}\text { 14. SUBJECT TERMS } \\
\text { Turbomachinery; Water ingestion; Computational }\end{array}$ & $\begin{array}{c}\text { 15. NUMBER OF PAGES } \\
250\end{array}$ & $\begin{array}{c}\text { 16. PRICE CODE } \\
\text { A11 }\end{array}$ \\
\hline $\begin{array}{c}\text { 17. SECURIY CLASSIFICATION } \\
\text { OF REPORT } \\
\text { Unclassified }\end{array}$ & $\begin{array}{c}\text { 18. SECURIT CLASSIFICATION } \\
\text { OF THIS PAGE } \\
\text { Unclassified }\end{array}$ & $\begin{array}{c}\text { 19. SECURIY CLASSIFICATION } \\
\text { OF ABSTRACT } \\
\text { Unclassified }\end{array}$ & 20. LIMITATION OF ABSTRACT \\
\hline NSN 7540-01-280-5500 & & $\begin{array}{c}\text { Standard Form 298 (Rev. 2-89) } \\
\text { Prescribed by ANSI Sid. Z39-18 } \\
298-102\end{array}$
\end{tabular}

